\title{
RESEARCHES ON FUNGI
}

A. H. REGINALD BUULER 


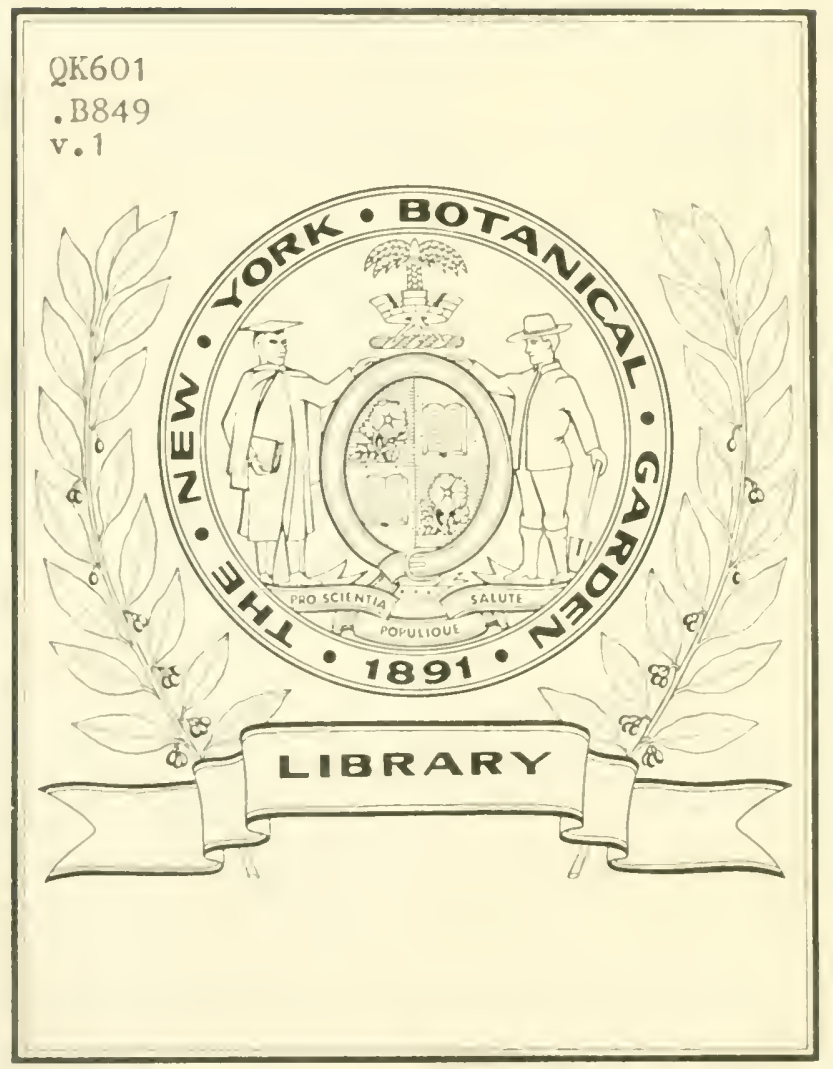




RESEARCHES ON FUNGI 



\section{R E S E A R G H E S O N F U N I}

AN ACCOUN'T OF 'THE PIRODUC'TION, LIBERA'TION, AND DISPERSION OF THE SPORES OF HYMENOMYCETES TREATED BOTANICALLY AND PHYSICALLY

ALSO SOME OBSERVATIONS UPON THE DISCHARGE AND DISPERSION OF THE SPORES OF ASCONYCETES AND OF PILOBOLUS

BY

A. H. REGINALD BULLER B.Sc. (Lond.); D.Sc. (Brru.); Ph.D. (LeIr.) PROFESSOR OF BOTANY AT THE UNIVERITY OF MANITOBA

WITH FIVE PLATES AND EIGHTY-THREE FIGURES IN THE TEXT

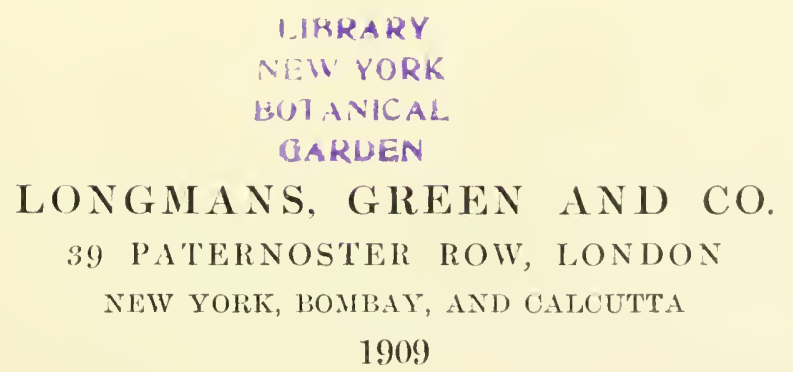

All rights reserved 

TO

\section{WILHELM PFEFFER}

UNDER WHOSE STIMULATING GUIDANCE

THE AUTHOR ONCE HAD THE

PRIVILEGE OF STUDYING 



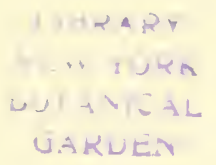

\section{PREFACE}

UARUEV

THEse pages contain a contribution to the physiologr. morphologr, and physics of reproduction in the Hrmenompotes, and also a record of some obsertations upon the discharge of spores of Ascompcetes and of Pilobolus. Naturally many problems have been left unsolred. but I hope that the new data obtained will give an added interest to some of our commanest plants. The delicare adaptations of structure to tunction. an revealed by a

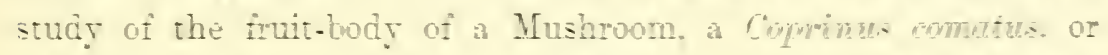
a Polyporus hare prorided me with no small cause for monderment and delight and ther seem well worthy of the artention of all those who desire to undersand more full the vegetable world by which ther are surrounded. The ralue of the more purely phrsical work must be left to phrsicists to decide. Howerer, as showing how closely the rarious branches of science may be knit together. it is not without interest that the fret direct iesi of Siokes Law for the fall of mierosopio spheres in air has been carried out with the help of a lowly Croptogam.

The research. which has occupied fire rears was preceded ind suggested by a systematic study of fungus spectes in the field. in

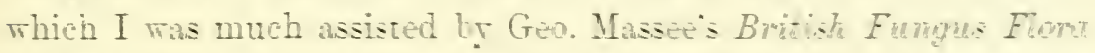
and M. C. Cooke's Illutuntion of Britin Fungh. During the winters the experimental work was cartied on in my own laboratery at the University of Manitoba and during the summers in the Phrsics and Botanieal laboratories at the Unirersity of Birmingham. I hare much pleasure in expressing my best thanks io Profiessors Pornting and Hilholise for the facilities acerced me. I also wish to acknowledge my indebtedness to Dr. Guy Barlow 
for valuable help and eriticism in the more purely physical and mathematieal parts of the research. Of the photographs here published ten were kindly made for me by Mr. J. E. Titley of Four Oaks, Warwickshire, three ench by Mr. J. H. Pickard and Mr. P. Grafton of Birmingham, and two by Mr. C. W. Lowe of Winnipeg. They are all acknowledged in the text. In the final revision of the proofs, Mr. Wr. B. Grove has been good enough to give me the benefit of his wide mycological knowledge and experience. Lastly, my gratitude is due to the Birmingham Natural History and Philosophical Society for defraying the cost of three of the Plates.

A. H. REGISALH BULLER.

Wixilieg, July 1909. 


\section{TABLE OF CON'TEN'TS}

PAGE

Preface

\section{PART I}

Ax Account of the Production, Liberatiox, and I)ispersion of the

Spores of Hrmenomycetes treated Botaxically and

РhYSICALLY

INTRODUCTION

\section{CHAPTER 1}

The Hymenium-Basidia and Paraphyses-Nuclear phenomena-The Colour of Spores-Cwo-spored Basidia in Cultivated Varieties of Psalliota campestris-Occasional Sterility of Coprinus Fruit-bodies-Cystidia-Fungus Guats, Springtails, and Mites-Position of the Hymenium--Comparison of the Basidium with the Ascus-The Effect of Sunlight upon Spores .

\section{CHAPTER II}

The Extent of the Hymenium-Principles underlying the Arrangement of Gills and Hymenial Tubes-The Margin of Safety-The grenus Fomes.

\section{CHAPTER III}

The Functions of the Stipe and Flesh of the Pilens-The Gill-chamber

\section{CHAPTER IV}

Adjustments of Fruit-bodies in the Interests of Spore-liberation-Lentinus lepideus, Psulliotu cumpestrix, Polyporus squamosus, Coprinus plicutilis, C'oprinus niveus, and Coprinus plicatiloides-Reactions of Fruit-bodies to Light and Gravity-The Problem of Pileus Eccentricity-Gsotropic Swinging-Rudimentary Fruit-bodies

\section{CHAPTER V}

Spore-deposits--The Number of Spores .

\section{CHAPTER VI}

Macroscopic Observations on tha Fall of Spores of Polyporus squumosus. 
CHAPTER VIH

The Demonstration of the Fall of Spores by means of a lieam of Lichlit

(IHAP'TER VIII

The Spore-fall P'riod

\section{CHAPTER IX}

Desication of Fruit-borlies--A Xerophytic Fungus Flora-The genns sehizophyllum .

\section{CHAPTER N}

External Conditions and Spone-discharre-The Effect of Light-The Effect of Gravity The Effeet of the Hygroseopic Condition of the Air-The Effect of Heat - The Effect of Alteration in the Gaseons Euviromment -The Etfect of Anestheties . . . . . . . . . 120

\section{CHAPTER XI}

The Violent Projection of Spores from the Hymenimm--Muthods 1., II., HI., $\mathrm{IV}$, and $\mathrm{V}$.

\section{CHAPTER XII}

The Mechanism of spore-discharge

\section{(HAPTER XII}

'The Specitic Gravity of Spores

\section{CHAP'TEI: XIS}

The size of Spores--Poynting's Plate Mierometer .

\section{CHAPTER XV}

'I'be Riate of Fill of spores and stokes' Law-Appendix

\section{('HAPTER XVI}

'The Eltiet of Humidity on the Rate of Fall of spores

\section{CIIAPTER XYII}

The l'ath of the Sipores between the (iills, dic. - The Sporabola-Appendix on the Motion of a sphere in is Viscons Medium, by 1)r. Guy Parlow . Int 
CHAPTER XVIII

The Electric Charges on the Spores

\section{CHAPTER XIX}

The Coprinus Tyle of Fruit-body.

\section{CHAPTER NT}

The Dispersion of the Spores after Liberation from the Fruit-bodies-

Falck's Theory . . . . . . . . . . . . 216

\section{CHAPTER XXI}

The Dispersion of Spores by Animals-Coprophilons HymenomycetesSlugs and Hymenomyceter

\section{P.R'T II}

Some Observations upox the Disoharge axd Dispersiox of the Spores of Ascumycetes axd of Piloboles

\section{CHAPTER I}

The Dispersion of Spores by the Wind in Asconycetes--Puffing-The Physics of the Ascus Jet in Peziza-The Fixation of the Spores in the Ascus of Pezizt repundu-Comparison of the Sizes of Wind-borne Spores in Ascomycetes and Hymenomycetes-The Helvellacere. . . . .

\section{CHAPTER II}

The Dispersal of the Spores of Ascomycetes by Herbivorous Animals illustrated by an Account of Ascobolus iminersus-Pilobolus, Empusc muscaLycoperdon-The Sound produced by the Discharge of Spores with special reference to Pilobolus . . . . . . . . . 251

\section{Gexeral Sumari-}

Part I.

Paut II.

Plates I.-T. . . . . . . T'o follow p. 274 



\section{PAR'T I}

AN ACCOUNT OF THE PRODUCTION, LIBERATION, AND DISPERSION OF THE SPORES OF HYMENOMYCETES TREATED BOTANICALLY AND PHYSICALLY 



\section{INTRODUC'TION}

THE researches recorded in Part I, were undertaken with the object of throwing light upon the production, liberation, and dispersion of the spores of Hymenomyeetes. More especially, an eftort has been made to find out how the spores manage to escape from the hymenial surfaces where they have been produced, and how they find their way between gills, down tubes, \&e., to the exterior of the fruit-bodies. By using appropriate optical methods, it has been attempted to follow the spores individually from the moment they leave the basidia, to determine their paths through the air, and to measure by accurate means their rate of fall. This part of the research has led me to the border-land where botany passes into pure physies. Hitherto, it appears that physicists have never yet determined directly by experiment the rate of fall of individual mieroscopic spheres with a diameter of $3-10 \mu$ through air. ${ }^{1}$ Therefore, by means of observations on the fill of spores, I have endeavoured to test the well-known and often assumed Stokes' Law.

In studying the effect of external conditions upon the liberation of spores, and in determining the length of the spore-fall period, the work has been much simplified by two diseoveries. The first is that spore-clouds, and even individual spores, can be seen falling beneath a fruit-body without magnification when illuminated with a concentrited beam of light. Whether or not spores are falling from a fruit-body can thus be ascertained in a few seconds. The second discovery is that practically all the leathery or corky fruitbodies to be found on logs, i.e. those belonging to the genera Lenzites, Polystictus, Diedilea, Stereum, \&e., retain their vitality on desiecation for months or years, and that, when they are subsequently placed under moist conditions, the liberation of spores begins once

1 Cf. the Appendix to Chap. XV. 
more within a few hours, and continnes for dilys or weeks. It was therefore possible for me to collect a stock of these fruit-bodies in atutumn, to revive them at will, and thus to study the liberation of spores thronghont winter and spring.

There seems to be but little literature dealing with the liberation of spores of Hynenomyeetes. Some observations of Brefeld, ${ }^{1}$ given in a footnote in his deseription of the life-history of Coprinus stricorcerius, will be mentioned and criticised later on. Riehard Falck lias published a patper on the scattering of spores of Basidionycetes, in which he has given an aceount of the gradual accumnlation of spore-deposits on upper surfaces in elosed chambers. He diel not suceed in actually seeing the spores in the air, but his experiments showed that they are earried with remarkible ease by the slightest air-eurrents. This faet ean be verified direetly and very simply by neans of my beam-of-light nethod, and rendered capable of mathematical treatment by an exact determination of the rates of fall of the spores in still air.

A visible spore-discharge from a fruit-body las been oecasionally observed as a very rare phenomenon hy a few botanists. 'To the records of Hoffman, H. von Sehrenk, and Hammer ${ }^{3}$ will be added ny own upon the visible discharge of spores from fruit-bodies of l'olyforues styumosus.

In his translation of Pfeffer's Ply grindegy of P'lents, Ewart ${ }^{4}$ added a brief statement of some of my then mpublished conclusions concerning the liberation and fill of spores. The evidence in support of these conclusions is brought forward for the first time in this book.

In an account of the biology of l'olyporess squamosus, I recorded a number of obscrvations rupon the fall of spores in that species, and gave an illustration showing the paths taken by the spores in falling down the hymenial tubes.5 A subsequent calculation, however,

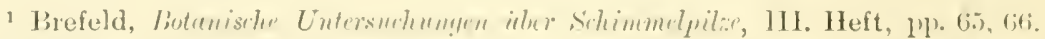

2 R. Falck, "Die sporenverbreitung bei den Basidionyceten," Beitriigr :ur

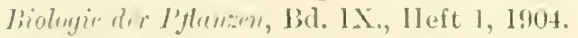

${ }^{3}$ For refurences, ride infin, ('lau. V'l.

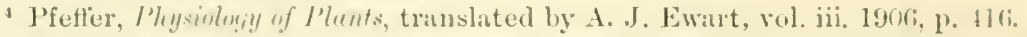

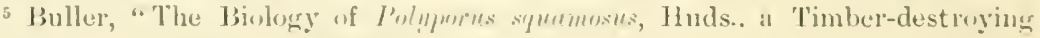

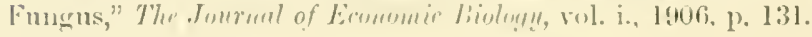


has taught me that the curves which we shall refer to later on as sporabolas, should have been made to turn more sharply from the horizontal to the vertical direction. This eorrection is given in Fig. 66 (p. 189).

The material for the present investigation has ineluded more than fifty speeies, chiefly belonging to the Agaricine:e and Polyporea. Speeies of Thelephorex and of Hydnea have been used less often. The research has not been extender to the Clavariex, but there seems to be no reason to expect that the mechanism for sporedischarge in this group is different from that in those already named. To what extent my generalisations upon the liberation of spores into the air are applicable to the gelatinous fungi, only further investigations can decide. Spore-discharge was found to take place in the normal manner in Himeole auriculu-juda, but the mode of spore-dispersion is not clear to me in gyrose Tremellinest. In the light of my observations upon other fruit-bodies, it seems diffieult to understand how spores produced on a hymenium which looks upwards ean eseape into the air. Possibly only those spores are thus set free which are developed on that part of the hymenium which is situated in a vertical or downwardly looking position. Possibly the wind is not the only agent in the dispersion of the spores. This matter certainly requires further elucidation. Unfortunately, gyrose Tremellinere so far have not been at my disposal.

The reneral result of the observations recorded in this book seems to be that of laying emphasis on the fact that the fruit-bodies of Hymenomycetes are highly efficient organs for the production and liberation of spores. In the ease of the Coprini, I believe that the old puzzle as to the significance of "deliquescence" has at last been solved. It can be shown, eg. in Coprinus comutus, that autodigestion takes place for the purpose of permitting the spores to be liberated into the air, and is correlated with several other structural and developmental features in the fruit-bodies in question. It has become elear to me that, included in the Agaricinea, there are two distinet fruit-body types for the production and liberation of spores -the Nushroom, or Psalliota type, and the Coprimus comutus type. The latter appears to have been evolved from the former, and to be, in some respects at least, superior to it in point of efficiency. 


\section{CHAP'TER I}

THE HYMEXILM-BASIDLA AND PARAPHYSES-NLCLEAR PHENOMENA-THE COLOUR OF SPORE-TWO-SPORED BASIDLA IN CULTIYATED VARIETIES OF JSALIIOTA CAMPLSTLIS-OUCASIONAL STERILITY OF COPRINCS FRUIT-BODIES-CYSTIDIAFUNGTS GXATS, SPRINGTALS, AND MITES-POSITION OF THE HYMENIUM-COMPARINON OF 'THE BASIDICM WITH THE ASUC' -THE EFFECT OF SUNLIGHT UPON SPORES

T'He hymenium of most Hymenomycetes is made up of sporehearing hasidia and of sterile paraphyses. In a great many species, it consists solely of these two kinds of elements: but in a number of others, cystidia and other specialised cells enter into its structure.

Basidia and Paraphyses. - It is a general rule, with comparatively few exceptions, that each basidium produces four sterigmata. Each sterigma tapers conically, and bears at its apex a single spore which, although sometimes spherical, in most eases is oval in shape (Fig. 55, p. 162). The spore-wall in some species bears spines, but usually is quite smooth. A sterigma, at the point of attachment to its spore, las an extrenely small dianeter which in many instances measures only $0.5 \mu$ (Plate I., Fig. 34: Plate IlI., Fig. 16). This narrow neck is of great importance, for, when a spore is set free, the neck breaks across and the spore is projected with considerable violence straight outwards from the basidium.1 It must be at the neek that the propelling force eomes to be exerted.

The spores of all Hymenomycetes are very adhesive, and on contact readily adhere to one another or to any object upon which they settle. As if to prevent them touching one another during development and discharge, the four spores on a basilinm are borne laterally on the sterigmata in such a mamer that they are situated as far apart as possible (Plate I., Fig. 3, ": Plate III., Fig. 16).

1 Vide infre, Chap. $\mathrm{X} 1$. 
In the Coprini, the hymenium, when seen in face view, presents to the eye a remarkably regular pattern (Plate IIL, Fig. 15). The basidia, bearing black spores, are evenly spaced between the paraphyses. Adjacent basidia, in a zone procceding from below upwards on each gill, ripen their spores simultaneously. Hence, on any small portion of a gill, all the basidia are practically in the same stage of derelopment. It appears to be the chief function of the paraphyses to act as spaeing agents, so that by their presence they prevent the spores bolonging to adjacent basidia from coming into contact. The large, unicellular cystidia which are so prominent on the swollen edges of the gills in many species, eg. Coprimus comutus, seem to be significant in that they form suitable surfaces of contact where the gills touch one another and the stipe. The swollen gill-margins serve to keep the gills sufficiently separated from one another, during the development of the basidia and spores (Plate I., Fig. 5; Plate III., Fig. 14). If the gills were not kept apart, the spores of opposing gills would touch one another, and, owing to their great adhesiveness, would stick together. The proper spacing of the gills during derelopment, therefore, is essential in securing the efficiency of a fruitbody as a spore-produeing organ.

Excluding the highly specialised Coprini, we find that in the Agaricinea generally, as well as in the other groups of Hymenomycetes, the basidia do not all ripen on any part of the hymenium simultaneously. Adjacent basidia on the gill of a Mushroom, in the hymenial tube of Polyporus squmosus, \&c., we at any one time in the most diverse stages of development (Plate I., Fig. 3). A basidium, learing ripe spores, may thus have adjacent to it one basidium which has shed its spores some hours or days previonsly: a serond which has spores in the most rudimentary condition: and, possibly, yet a third upon which not even the sterigmata have appeared. Neighbouring basidia with ripe spores are often very closely situated, but nerer near enough to touch one another. To what extent this spacing is brought about by the paraphyses, or by other basidia, is difficult to determine. Possibly, the fact that, in a Mushroom, adjacent basidia ripen and shed their spores successively, instead of simultaneously, 
permits of the hymenimu being constructed with less space devoted

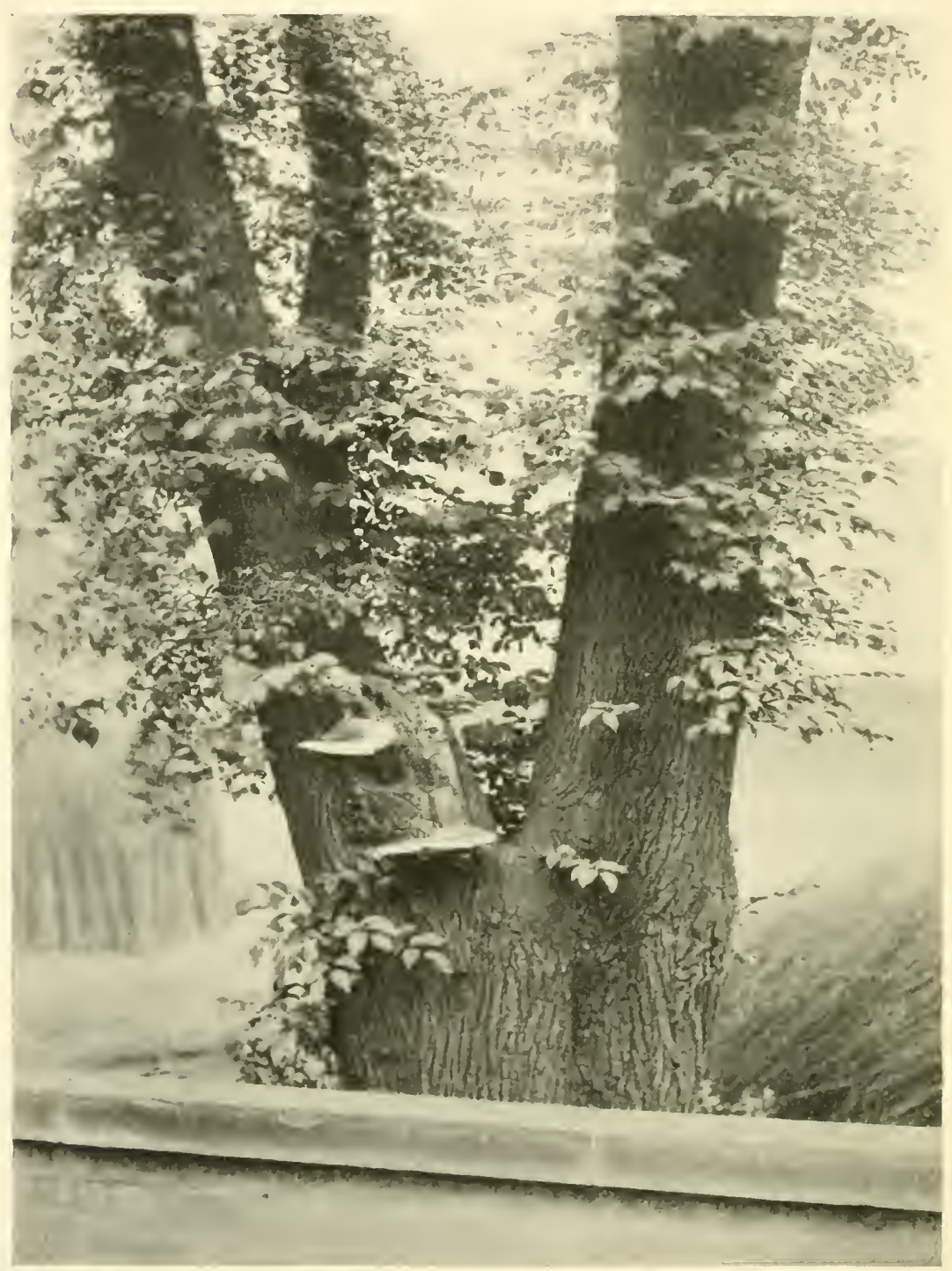

Fig. 1. - $\lambda$ n Elm (ITmus montunu) with five fruit-botics of Polyporus squemosus growing out from a large wounl surface where a great branch hald been broken off. The uppermost fruit-huly lats a vertical rentral stipe in the middle of the pileus. P'botorraphed hy R H. l'ickard at the lBlind Asylum, Birminglam. About $q^{\prime}$ natural size.

to sterile paraphyses in that species than is required for a Coprinus. 
The spacial arrangements of the basidia and their successive development certainly require a more detailed study in the Mushroom and fruit-bodies of the same type. ${ }^{1}$

Nuclear Phenomena.-The nuclear ehanges occurring in the basidia and paraphyses during development have now been investigated by modern inethods, and it has been found that each hymenial cell, when first formed, contains two nuclei." In cells destined to become basidia, the nuclei fuse to form a single nucleus. By means of two successive bipartitions the fusion nucleus then divides into four nuclei, whereupon the sterigmata and spores begin their development. When the spores have attained a certain size, the four nuclei severally and simultaneously approach the four sterigmata, ereep through them, and pass into the spores, each of which thus becomes provided with a single nucleus. Whilst making their way into the spores, it is necessary for the nuclei to squeeze throngh the very narrow sterigmatic necks, which feat is accomplished by their becoming compressed into slender filaments. The extent to which the nuclei suffer constriction affords striking evidence of protoplasmic plasticity, and may be regarded as indicating that cytoplasm may move with considerable ease from cell to cell through pits in cell-walls. It seems to be highly probable that a ripening spore becomes eut oft from its sterigma by a cell-wall, which eventually becomes double. If this were not the case, one might expect that spore-diseharge would be accompanied by the collapse of both spores and basidia: but this I have observed does not occur. ${ }^{3}$ However, anatomical evidence of the existence of the double wall just before sporedischarge has not as yet been obtained.

As the spores are ripening, the basidium is devoid of nuclei. However, its cytoplasm remains living, and is useful in main-

1 The gills of Punzolus phatanurum and of some allied species become finely mottled at maturity. Numerous ripe spores are to be found on the darker areas, whilst those on the lighter areas are still mncolonred.

2 I have not made any original investigations upon the cytology of the developing hymenium. The facts here given in this connection are taken from the paper by W. Ruhland, "Zur Kenntniss der intracellularen Karyogamie bei den Basidiomyceten," Bot. Zeit., 1901, Abt. I., Pp. 187-204.

3 Vide infiu, Chap. XII. 
taining the turgidity of the cell. The gill of a Coprimes. comentus was laid on a crliss slitte. On looking at one of the hymenial surfaces from above with a microscope, I observed that, as the gill began to lose water, the four sterigmata of each basidium bent together so that the spores came into contact and athered to one another. The turgidity of the basidium is important therefore in that it serves to keep the spores in their proper positions in space. In dry weather, spores - which have a relatively high ratio of transpiring surface to volume-lose water rapidly, and a constant stream nust flow to them through the sterigmata in order to prevent them from collapsing. ${ }^{1}$

In hymenial cells destined to remain sterile, i.e., to become paraphyses, the two original nuelei with which each is provided, do not unite with one another, but renain small and show no signs of special activity. It is eoneeivable that at first all the hymenial cells have equal possibilities of development, but that for some reason the hymenium becomes divided up physiologieally into small areas, in each of which only a single cell ean develop into a basidium. We might suppose that each basidium has a sphere of influenee and by its own development causes the eells adjacent to it to remain sterile. The problem of the spacial arrangement of basidia upon a hymenimm seems to be essentially of the same nature as that of the arrangement of gills, hymenial tubes, or spines on pilei, or as that of the arrangement of leaves upon stems.

The nature of the nuclear fusion in basidia is a matter which is still under diseussion. Dangeard ${ }^{2}$ regards it as morphologically and physiologically equivalent to a sexual aet, and this view has been accepted by Brefelt. ${ }^{3}$ The union of the two nuclei-ealled karyogramy-must lead to a donbling of the number of ehromosomes. The reduetion of the latter to one half-the number which we may suppose eharacterises the nuclei of the mycelium and of the non-basidial cells of the hymenophore-is in all

1 ef. Chap. XVI.

${ }^{2}$ Dangeard, "La sexualiti" che\% lus Champignons," lierme sirentifupe, 5e série, T. IV., 1905. Alsstract in Jint. Centrell., Bd. C11., 1906, p. 378.

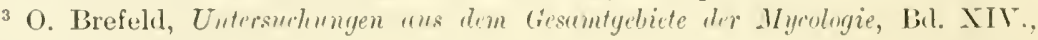
1908, pp. 246;-256;. 
probability brought about in the basidium itself during the two successive bipartitions of the fusion nucleus. The two original nuclei in each hasidium are not sisters but are very remotely related to one another. Investigation seems to show that they are derived by a long series of successive conjugate divisions from a pair of nuclei, the two nembers of which come to lie side by side prior to the development of the fruit-body. The nucleus which wanders into a spore soon divides into two after its entry so that each spore becomes binucleate. ${ }^{1}$ As soon as the spore germinates, these two nuclei enter the germ-tube, where they divide at different rates and not in a conjugate manner. ${ }^{2}$ By further nuclear divisions the germ-tube comes to contain more than eight nuclei in Hypholoma perplexum, and up to thirty in a species of Coprinus. ${ }^{3}$ However, so far it has not been found possible to determine exactly where the first pair or first pairs of nuclei come into existence. ${ }^{4}$ In one group of Basidiomycetes-the UredineieBlackman ${ }^{5}$ and others ${ }^{6}$ have observed that each pair of nuclei which undergo fusion in the teleutospore, is derived by a long series of successive conjugate divisions from a pair of nuelei brought into existence by the conjugation of neighbouring mycelial cells. The wall between the two cells becomes perforated and the nucleus of one cell wanders into the other cell. It yet remains to be decided whether or not anything of a similar nature occurs in the Hymenomycetes. In this connection some interesting discoveries may be in store for us. In species of Coprinus, \&c., where it has been found possible to obtain fruit-bodies from the mycelium produced from a single spore, doubtless cross-fertilisation between two individual mycelia either does not oceur or is not necessary for the completion of the life-cycle. Whether or not cross-

1 Miss S. P. Nichols, "The Nature and Origin of the Binucleated Cells in some Basidiomycetes," Trans. of the Wisconsin Arted. of Srienes, Arts, and Letters, rol. xv., 1904, pp. 30-70. Abstract in Brit. Keit., Abt. II., Bd. LXIV., 1906, p. 266.

\footnotetext{
2 Ibil.

${ }^{3}$ Ilinel.

4 Ibid.
}

${ }^{5}$ V. H. Blackman, "On the Fertilisation, Alternation of Generations, and General Cytology of the Uredinere," Aim. of Bot., vol. xviii., 1904.

${ }^{6}$ A. H. Christman, "Sexual Reprodnetion in the Rusts," lot. Gü, vol. xxxix., 1905 ; also E. W. Olive, "Sexual Cell Fusions and Vegetative Nuclear Divisions in the Rusts," Ann. of Bot., vol. xxii., 1908. 
fertilisation ever occurs in any species of Hymenomycetes can only be decided by extended observations. At present no Hymenomycetes seem to be known which suggest that they are hybrids produced from two individuals of distinct speeies. However, it would be interesting to plant the spawn of several distinet varieties of the cultivated Mushroom (Pralliota cempestric) side by sille in beds of manure, and to observe whether or not under these conditions any intermediate fruit-bodies wonld be produced.

It seems probable that the original sexual organs of Hymenomycetes-those corresponding to oogonia and antheridia in Ascomycetes-have disappeared, and that a new form of sexuality has arisen by the fusion in the basidia of the descendants of what were originally merely vegetative nuclei. ${ }^{1}$ This view is supported by the discovery of Miss Fraser, ${ }^{2}$ that in Humuin rutilans, one of the Ascomycetes, normal fertilisation by means of sexual organs is replaced by the fusion of vegetative nuclei in pairs-a process analogous to that which takes place in psendapogamous fern prothallia and also in the Uredineit.

The Colour of Spores.-The colour of spores has long attracted attention, owing to the fact that it has provided a useful means of subdividing the Agaricinese. It must be admitted, however, that the classification of this great group according to spore colour is a purely artificial arrangement, although it fulfils its primary olject of enabling the student the more readily to find the name of a particular species. There is no good reason for believing that the Melanospora, the Porphyrospore, the Ochrospore, the Rhodosporat, and the Leucospore are separate and distinct offshoots from a common stock, and this has heen fully recognised by Hemnings in his treatment of the Agari-

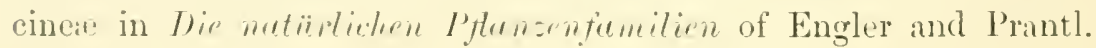

1 The vegetative origin of the fusion muclei in Hymenomycetes seems to be generally accepted. Cf. X. lieruard, "Phenomines reproducteurs chez les Cham-

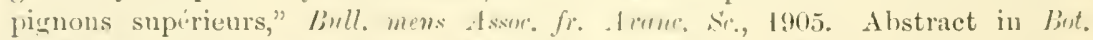
Centrell., 13d. CI., 1906, 1). 394; Miss H. C. 1. Fraser, "Nuclear Fusions and

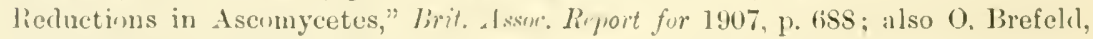
1908, ler. rit., p. 256.

2 Miss H. C. I. Friser, "Contrilutions to the Cytology of Humeria rutilems," Aun. of Bit., vol. xxii., 1908, p. 42. 
In a classification purely on the colour basis, we are obliged to place together such diverse black-spored genera as Coprinus, Anthracophyllum, and Gomphidius. Coprinus is a highly specialised genus, the fruit-bodies of which are fragile and often "deliquescent." On the other hand, the fruit-bodies of Anthracophyllum are tough and possess leathery or horny gills. ${ }^{1}$ This genus is evidently much more closely related to the white-spored Xerotus, Lentinus, and Marasmius than to Coprinus. Gomphidius, with its fleshy fruit-bodies and thick, fleshy, non-deliquescent gills, seems to be more closely related to the white-spored Hygrophorus than to either Coprimus or Anthracophyllum. This example will serve to show that spore colour by itself is not a safe guide in deciding generic relationships.

During the evolution of the Hymenomycetes there must have been an evolution of spore colour, and it would certainly be very interesting if some law of progressive colouration could be discovered. It seems to me that a fairly good case has been made out for the view that, in flowers in general, yellow is a more primitive colour than red, and red more primitive than blue; "2 but no attempt to work out the phylogeny of the colour of spores has yet been made. Massee came to the conclusion that the genus Coprinus is the remmant of a primitive group from which have descended the entire group of the Agaricineve, ${ }^{3}$ and he then made the deduction that since Coprinus spores are black, blackness in spore colour is a primitive feature. According to this view, the species of Agaricinee with yellow, red, brown, purple, and white spores have descended from black-spored ancestors. In Chapter XIX. I shall bring forward what I believe to be strong reasons for dissenting from Massee's view as to the ancestral position of the Coprini. If, as I hold, the genus Coprinus has been derived from fungi having radially symmetrieal, stiped, non-deliquescent fruitbodies, with the Mushroom type of spore-liberation, then Massee's

1 P. Hennings in Engler u. Prantl, Die mut. Pflanzenfunitien, 'Teil I., Abt. 1**, p. 222.

2 (irant Allen, The Colorers of Florers (Macmillan \& Co.), 1891, pp. 17-60.

${ }^{3}$ G. Massee, "A Revision of the Genus Coprinus," Amn. of Jiot., vol, x., 1906, p. 129 . 
theory of the primitiveness of blickness as at spore colour loses its chicf support.

On general gromnds, I am inclined to regard colourlessness as the most printive condition in spores. We maty well helieve that at first the conidia were as colourless as the basidia off which they became constricted. It seems to me probable that the various pigments were only gradually developed, possibly hy a series of mutations. Many so-called black spores are not truly black: thus in Gomphidius the spores are smoky-olive, and in Copnimus atormentarius the spore powder has a brownish tinge. Intermediate gradations of this kind seem to suggest that blackness in spores was not acquired all at once but step by step. This view is further supported hy ontogeny. Thus in cominus amutas the spores when very young are colomrless: they then lecome pinkish, and thereby tum the grills pink: they then gradually become blatck. In many species of Coprints the spores whilst ripening become brown, and the lrown colour then gradually deepens into black. As further support for the view that rolourlessness in spores is a primitive feature in Hymenomycetes, may be mentioned the fact that five out of the six generat of Hypochnacea, ${ }^{1}$ as well as such a primitive enems of Thelephoreas as Corticimm, have unpigmented spores.

No suggestion has yet been male as to the signiticance of the colours of spores. It is certain that sume colouring matters, ry. those of heart-rood, of selerenchymatums strands in the rhizomes of ferns, of carmot roots, and of the rhizomorphat subterrancal of Armillmein meller, cimnot be of ecological value, since they are dereloped in organs not normally exposed to the light. Possibly, too, the colomring matters of spores are useless so fatr as their colour properties are concerned: they may he merely bye-products of certain metabolic processes. However, it will shortly be shown that smolight is injurious to the spores of certain Hymenomyectes. It therefore seems possible that the varions colouring matters deposited in spore walls maly he of value in that they serve to absorb injurious rays of light, thus preventing them from reathing the livines proteplasm. If coloured spore walls are useful in tiltering 1 P. Henniness, lor, rit., 1'. 11 t. 
sunlight, future experiments should show that the black spores of Coprini and other Melanospore suffer less from prolonged exposure to the sun than the colourless spores of the Leucosporie.

Two-spored Basidia in Cultivated Varieties of Psalliota campestris.-Atkinson ${ }^{1}$ has observed that the basidia of the cultivated forms of Psulliota cumpestris (the varieties Columbia, Aliska, Bohemia, and others) are two-spored, whereas those of the wild field form are four-spored. However, he found a two-spored variety of Psalliotu campestris in the open-once on a lawn, and once on the hillside of a wooded ravine on the campus of Cornell University. My own experience is similar to that of Atkinson. I have noticed that the basidia of the wild form of Psallinte campestris obtained from fields near Birmingham, England, are four-spored, and that those of a cultivated variety on sale in Winnipeg are two-spored. I have also observed a two-spored form occurring on manured ground included within the campus of the University of Manitoba. The campus Mushrooms differed considerably from the wild field Mushrooms of England in that they were more scaly, browner, and possessed relatively very shallow gills. Whether or not normal two-spored forms of Psolliote cumpestris oceur in nature as constant types still seems to be a matter of doubt. Atkinson thinks it probable that the cultivated varieties of Psalliota campestris originated as mutations either from Psulliote cumpestris, or from some other species which has been confounded with it; and with this view I an inclined to agree. Of two equally well developed Mushrooms, one of which possessed four-spored and the other two-spored basidia, the former would doubtless produce the greater number of spores, and therefore be the more efficient reproductive organ. If this be granted, the two-spored varieties of Psalliota compestris may be regarded as degenerate mutations derived from four-spored ancestors.

Occasional Sterility of Coprinus Fruit-bodies.-One of the most curious phenomena which has cone to my notice in studying the Hymenomycetes, is the oucasional sterility of Coprinus fruit-bodies. Strange indeed is the reproductive organ which otherwise undergoes normal development but fails in its

${ }^{1}$ G. F. Atkinson, "The Development of Aturirus campestris." The liotunical Gurette, vol. xlii., 1906, pp. $260-261$. 
essential function of producing spores. Instances of sterility of this kind have been noticed in two different speeies. A board was found in a cellar infected with Coprinus fimeturius, var. cinreres, and a small piece of it, bearing a young fruit-body, was sawn off, brought to the laboratory, and placed in a damp-chamber. After further development the fruit-body attained average size and form, but exhibited the peculiarity of being yellowish-white in colour instead of ashy grey. Upon examining the pileus with the microscope, I found that it was ahmost completely sterile. Only a few basidia had produced spores, whilst the great majority had remained in a rudimentary condition. The normal basidia were found chiefly at the pileus margin, but a very few were sparsely scattered over the general surfaces of the gills. Two other fruit-bodies subsequently appenred on the piece of board, lut in these the spores were developed in the usual manner. Coprinus plicutiloides ${ }^{1}$ was grown on sterilised horse-dung, from the surface of which its fruit-bodies were produced in large numbers, several each day for more than a month. At snccessive intervals about six fruit-bodies came up, which seemed to be quite normal in size and form, but which were conspicuous among their companions by being whitish-yellow instear of grey. The microscope revealed the fact that the gills had failed to produce any spores. The basidia, surrounded by large paraphyses, had remained quite small; they did not protrude beyond the greneral surface of the hymenium and, so far as I could obselve, they had not even given rise to sterigmata.

The cause of the occasional sterility of Coprinus fruit-bodies scems to be somewhat obscure. Sinee, however, the sterile fruit-bodies of Coprinus plicatiloides grew in company with, and closely adjacent to, other fruit-bodies which were completely fertile, it seems safe to infer that the sterility was not conditioned by temperature, light, heat, moisture, or atmospherie gases. Perhaps the phenomenon is due to some accident hippening to the mycelium at the time when its contents are being poured into the young fruit-boty. It is conceivable that, if the mycelimm attached to the fruit-body were reduced in quantity, the fruit-body might suffer from starvation during its further derelopment, and yet, in consequence of the

\footnotetext{
${ }^{1}$ For unnenclature of this species, rite infm, Chap. IV.
} 
continued absorption of water, still be able to stretch its stipe and expand its pileus. The diminution in the supply of food materials might lead to the non-development of the basidia. I have attempted to induce sterility in Coprinus plicatiloides by mechanically disturbing the substratum of young fruit-bodies, and have partially succeeded. In one experiment a large fruit-body became pale yellowish-grey at maturity, and it was found that the number of basidia which had developed in the neighbourhood of the stipe was very much below the normal. However, it must not be supposed that sterile fruit-bodies are produced only after artificial disturbance of the substratum, for in one instance, in a culture left undisturbed for some weeks, two fruit-bodies of equal size came up side by side with the bases of the stipes in contact, yet one of them was perfectly fertile and the other quite sterile.

Cystidia.-The significance of cystidia, once thought by Corda, Hoffman, ${ }^{1}$ Worthington Smith, ${ }^{2}$ and others, to be male organs, still seems not to have been elucidated with any certainty. According to Cooke, "The usual interpretation of the function of cystidia is, that they are simply mechanical contrivances projecting from the hymenium and thus keeping the gills or lamelle apart." Possibly this view may be correct for certain species of Coprinus, e.g. C. micaceus, where large cystidia are found on the gill surfaces; but where cystidia coat the swollen gill edges, as in C. comatus, we may regard them as packing cells. They form cushions where the gills are in contact with each other and the stipe, and they probably facilitate the separation of these structures on the expansion of the pileus. Stress has already been laid on the necessity for the provision of spaces between adjacent gills during development, owing to the adhesiveness of the spores; but these spaces can be brought into existence, e.g. in $C$. comatus, by other means than by the production of cystidia (vide infra, Chap. XIX.: Plate I. Fig. 5; Plate III. Fig. 14). In the genus Peniophora, the

${ }^{1}$ H. Hoffman, "Die Pollinarien und Spermatien von Agarieus," Jot. Zeit., xiv., 1856, pp. 137-48, 153-63.

2 Worthington Smith, "Reproduction in Coprinus radiutus," Grerillea, vol. iv., 1875-6, pp. 53-65.

3 M. C. Cooke, Introduction to the Stuly of Fungi, London, 1895, p. 41. 
eystidia (metuloids), which are very numerous, prominent, and encrusted with calcium oxalate, eould not possibly act as spacing agents: for here the hymonimm is smmoth. Possibly, in this genus, they serve to protect the fruit-hodies from shoss or other hammful animal parasites. The same interpetation might apply to the rigid coloured setar of Hymenochate, but does not secm smitable for those of some species of the woody gemus Fomes, e.g. F. migricums and $F$. salicimus.

De Bary's investigation led him to the conclusion that in Lacterius delirioses the cystidia arise from ordinary hyphe of the trama, but according to Massee ${ }^{2}$ the cystidia of Russula and Lactarins are direet teminations of the laticiferous system. Massec's view is supported by the work of Biffen, ${ }^{3}$ who found that in Collylia erlutipes the cystidia form the hymenial endings of the conducting hyphe. In these cases, doubtless, the cell contents are of importance, although exactly in what way still remains to be cxplained. In Russula, at least, they do not seem to render the gills unpalatable to slugs, since these animals are particularly fond of the members of this genus, and often devastate the fruitborlies in a wood to such an extent that scarcely a single specimen is left molamaged.

Earlier writers, Corda and others, stated that the cystidia of the fleshy fungi discharge their contents through their apices in the form of drops, lut de Bary ${ }^{+}$and Brefeld could nerer satisfy themselves that this is done spontaneously. However, Massee and Worthington Sunith have both upheld the older view. Aceording to Massee, ${ }^{5}$ eystidia, when matue, contain glycogen which is emitted throngh the nipple-like openings at their apices, and poured over the surrounding hymonim, where it serves as food for the developing

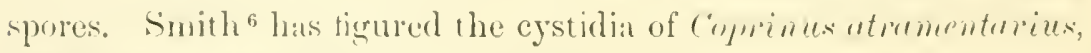

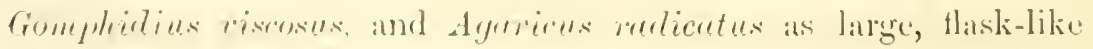

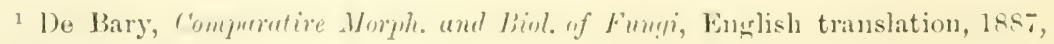
p. 304.

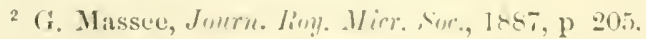

3 li. H. Biffen, Jumru, I.imn. kice, vol. 34, 1898, 1. 14 .

1 De birry, lor rit. 5 G. Massee, lene cit.

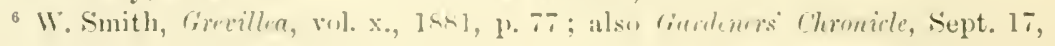
1SRI, ]. 367. 
structures with narrow necks each provided with a tiny operculum. He states that the opercula drop off when the cystidia are mature, and thus permit the cell-contents to escape. According to both Smith and Nassee, the cystidia in many cases drop out of the hymenium after they have discharged their contents. A detailed confirmation or refutation of these various statements seems to me to be desirable.

In a recent paper Massee ${ }^{1}$ has described two forms of cystidia as occurring on the surface of the gills in the genus Inoeybe-the ventricose and the fusoid. He states that the tip of each cystidium becomes crowned with mucilage, which escapes from the interior after the deliquescence of the thin portion of the wall at its apex.

From the morphological point of view, we may follow de Bary in placing cystidia in the category of hair formations. Since the hymenial hairs are of several distinct types, it scems fairly certain from analogy with the Phanerogams that they have different functious varying with their structure. In some species they may be only functional during the early development of the gills, whilst in others they may be of importance afterwards.

From the point of view of spore-emission, cystidia have a limit set to the distance they may project beyond the basidia. Where a hymenial surface is in a vertical plane, they only project so far that they do not interfere with the falling spores. These are shot out horizontally from the basidia to a distance of about (0.1 $\mathrm{mm}$. They then make a sharp turn and fall down vertically (cf. Fig. 64, p. 185, and Plate I., Fig. 4). Since the cystidia do not project so far horizontally as the spores ean be shot outwards, they do not restrict the freedom of the latter whilst escaping from the fruit-body.

Fungus Gnats, Springtails, and Mites.-Possibly in some instances cystidia may have become evolved in relationship with insects or other small animals. Over one hundred and fifty species of Mycetophilidie or "Fungus Gnats" have been deseribed." and most of them appear to live on fungi only." 'The whole groul'

1 G. Massee, "A Monograph of the (ienus Inocybe,' Ann. of Bot, vol, xviii., 1904, p. 462.

${ }^{2}$ Fred. V. Theobald, An Account of British Flies (I)ipter c), vol. i., 189:- p. 93.

${ }^{3}$ Ibid., p. 96. 
is geologically of considerable antiquity, and specimens have often been preserved very perfertly in amber. ${ }^{1}$ At the present day, in the grenus Mycetophila, a female "lays her eggrs generally on the under surface of the pilens, walling about over the surface first to find a suitalle place, then depositing the ova singly." 2 The eggs of the Mreetophilide, after being laid, quickly hateh and derelop into the well-known maggots. These feed on the stipe, the pileus flesh, or even the gills; and they often cause the infested parts to become rapidly and prematurely putrescent.

The gills of expanded fruit-bodies are frequently visited, not only by Fungus Gnats, but also hy Springtails (Collembolia) and Mites (Arachnida). As an instance, it may be mentioned that on the under side of an musually perfect fruit-body of Parillus. immolutus, which had just opened, I observed members of all these three groups present in some numbers. So far as my experience goes, it seems to be rather the rule than the exception, that at least some small animals are to be found on all large fruit-bodies. When a pilens is disturbed, the Springtails and Mites run rapidly over the gill surfaces, but the Ginats usually Hy away. Some fruit-bodies of Polyporus squmosus, which were growing on a $\log$ and had not yet become fully expanded, were infested with small black Collembola. There were as many as fifty to the square inch, and each one ocenpied a hymenial tube which was just wide enough to hold it. The springtails (genus Achorutes), infesting the gills of stroplection semiglubete and some other species of Agaricinear, were found to contain spores in the mid-gut. They are therefore parasites. It yet remains to be investigated whether the hymenimu, by means of its hairs, is adapted in any way to suit its needs when visited by tiny animals; or whether, on the contrary, Mites and sipringtails, dic., are simply to be regarded as fungus theas which have had no effect on the phylogeny of their hosts.

1 Fossils have been found in the Liper Oolite beds in the Sunth of Englancl, and also in the solenhofen Slates. More than 280 species have been obtained from the T'ertiary in widely separated areas. Mlost of them were discovered in the ambers of Emope and Amerien, the rock specimens being few in comparison (ilinil., P. 93).

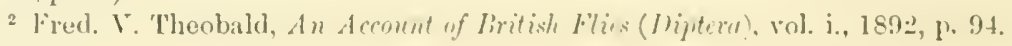


Position of the Hymenium.-Excepting a few gelatinous species which require further investigation, it is a general rule that in Hymenomycetes the hymenium is situated on the underside of the fruit-bodies. Enerusting forms, developing on $\operatorname{logs}$ and twigs, usually produce their hymenium on the under or lateral surfaces of the substratum. ${ }^{1}$ That the hymenium should not be developed on a surface looking upwards is of great importance for spore-liberation. It was found with the beam-of-light method that, if a fruit-body of a Polyporus, Polystictus, Lenzites, Psalliota, Stereum, \&c., is turned on its back, it is unable to liberate its spores into the air. It has been determined that, if the hymenium on the gill of a Mushroom, \&e., is made to look directly upwards, the spores can be shot upwards about $0.1 \mathrm{~mm}$. above the basidia. ${ }^{2}$ This does not seem to be high enough to permit of the spores, which fall at the rate of $1-5 \mathrm{~mm}$. per second, being carried off by moderate aircurrents. Hence, when a hymenial surface looks upwards, the spores shot upwards from it fall back again inmediately on to the hymenium and adhere there. Even when a fruit-body is set in its natural position onee more, such spores never regain their freedom.

In the great groups of the Agaricinex and the Polyporex, the fruit-bodies are characterised by having the greater part of the hymenial surfaces disposed in almost vertical planes. In the Agaricinere the hymenium is situated on the surfaces of wedgeshaped gills (Figs. 2 and 3 ; also Plate I., Fig. 4): and in the Polypores it lines the inner sides of eylindrical or slightly conical, vertically-placed tubes (Fig. 7, p. 33, and Fig. 66, p. 189). From observations on the paths and rates of fall of individual spores, as well as by direct beam-of-light studies of spore-clouds produced from fruit-bodies when tilted at various angles, I have come to the conclusion that it is only when the hymenium is vertical or looking downwards at a greater or less angle that suceessful spore-liberation

1 I have noticed the fruit-bodies of Irpex obliques growing on the npper side of an inclined tree, but the hymenium appeared to be irregular. Falck (loc. cit.) grew abnormal fruit-bodies of P'oria raporeriu and Merulius lucrimans on the upper surfaces of wooden blocks in the laboratory.

2 Vide infre, Chap. XI. 
can take place in these groups. The mechanism for liberating spores is of such a mature as to limit the possible forms of the fruitbodies in question.

Comparison of the Basidium with the Ascus. - The rertical or downwarly-looking position of the hymenial surfaces of Hymenomy-

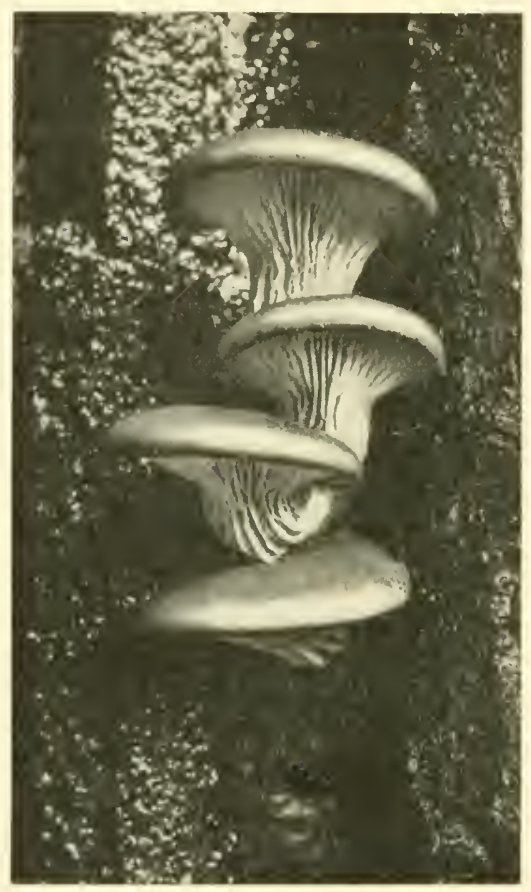

Fic. 2.-Gromp of young fruit-borlies of I lourotues ostrutus (the Oyster Fingus growing from a wound on the trink of at lexech. The gills are developing in vertical planes in resuonse to a creotropic stimulus. Photographed at sutton Park, Warwickshire, l, J. E. 'Titley. Abont $\frac{3}{4}$ natural size. cetes may be contrasted with the upwarlly-looking hymenial surfaces of Discomycetes. From the physiological point of view, the ascus in this great gromp of fungi is significant in that it is an apparatus by which spores may be liberated suc:cessfully, when it looks upwards. It is an explosive mechanism of considerable efficiency. In many instances it shoots out its spores en masse to a distance of one or several centimetres, and thus causes them to become effectively separated from the ascocalp. It seems to be the derelopment of the explosive aseus which has permitted of the fruit - bodies of Discomyectes taking on their sancer- Or cup-like shapes. Here anain, as in the Hymenomycetes, spore-liberating meehanism and fruit-body strueture go hand in hand.

There appears to be just as strict a correlation between the general structure of an Agaricus or Polyporus and its basidia as between the greneral structure of a Periza and its asci. If the basidia and asci in these types were interehanged. each fruit-body wonld lose its efticiency. The spores condd not be liberated, but

$$
1 \text { Tile infia, Pirt II. }
$$




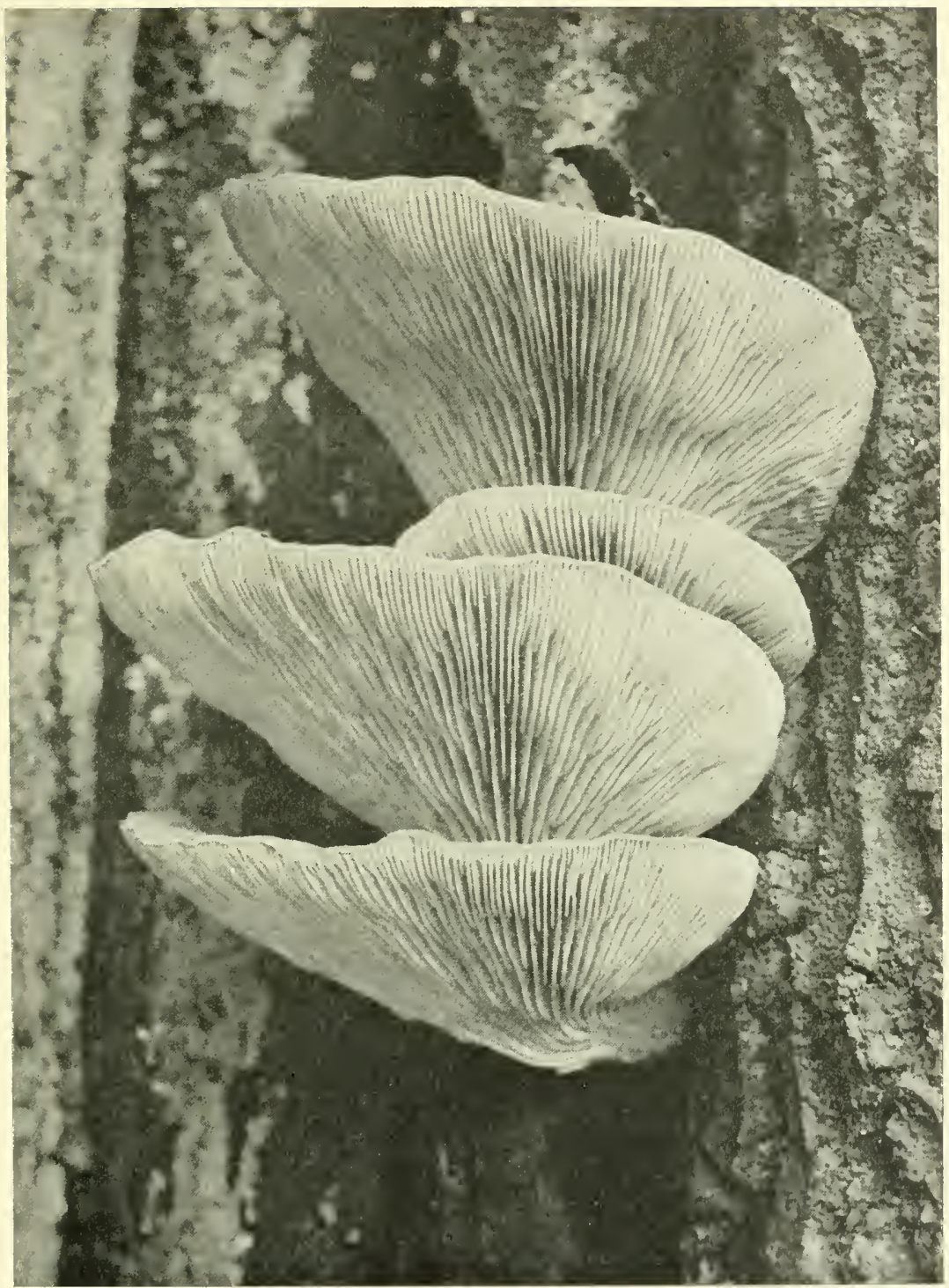

FiG. 3.--Same group of fruit-bodies of Plcurotus ostratus as shown in Fig. 2, photographed ten days later at maturity. The tops of the pilei have now become flattener. The thin gills, separated by interlamellar spaces, have developed along vertical planes, and are of various lengths, so as to be very compactly arranged. The gills on the stipe of the lowest fruit-hody have been damaged by a slug. Photographed at Sutton l'ark, Warwickshire, by J. E. 'Titley. About 
would be entirely wasted. Not a single basidinspore would be shot up far enough to surceed in escapiner from a Peziza cup: whilst in a Mushrom or Polyporus the ascospores, when discharged, would strike and adhere to the opposite hymenial surfaces. An upwardlylonkiner. Periza-like, enp-shaped Hymenomyecte, provided with yppical basidia and liberating its spores into the air, is just as impossilile as a Mrushroom- or Polyporus-shapped Ascomyecte with its hymenimm composed of typical explosive asci. Where, in the Hymenomyectes, as in the genus Cyphetla, the fruit-body has the form of a samer, a culp, or a filter fummel, with the hymenimu inside, its month looks not upwards but downwads, so that it resembles an inverted Periza. It is true that the conical wineglass-shaped fruit-hodies of the species of the hymenomyectous Eenus Craterellus stand erect. Here, however, in contradistinction to Cyphellat, the hymenimu is horne on the exterior of the fruitbodies, whilst the interior is barren. 'The position of the hasidia of a Craterellus is exactly the reverse of that of the asci in the rect wine-grlass-shaped fruit-bodies of certain Ascomyeetes. These remarks may serve to emphasise the close correlation between the mechanism for spore-liheration and fruit-body structure.

The Effect of Sunlight upon Spores.-Some years ago, Massee ${ }^{1}$ expresed the view that the hymenimu of the Hymenomycetes, during progressive phylogenetic development, had cone to be phiced on the lower sides of the pilej, instend of on the upper, for the prrpose of concealing it from the light. On the other hatnd, my own researches seen to show that the position of the hymenimm has leen primarily deeided ly the necessity of the basidia being so placed that they can readily liberate theil spores into the air. Other, but subsiliary, alvantages aterming to the hymenium from its position on the lower side of a pileus, rather than the upper, are: protection from rain, falling leaves, de. and molue transpiration in dry weather.

The raret effert of direct smolight, upon the spores of Hymenoinyeetes still remains to be worked out. In the Clavariear, many species live in fields. dec., where their hymenial surfaces are freely

2 (i. Massee, "A Momograph of b.itish Gastronycetes," Ann. of liot., vol. iv. IAxi, p. =-2. 
exposed to the sun. During their transportation by the wind, spores must often be exposed to sunlight for several hours together: by analogy, therefore, one might expect them to be fairly resistant to its influence. However, an experiment by Miss Ferguson ${ }^{1}$ tends to show that light has an inhibitory effect on the germination of the spores Psalliota campestris.

In order to test the effect of sunlight upon the vitality of the spores of Schizoplyyllum commune, which are colourless, I proceeded as follows. A fruit-body was revived in the manner to be described in Chapter IX., and, when shedding spores, it was set in a closed chamber (cf. Fig. 37, p. 97), at the bottom of which were two glass slides lying side by side. In the course of a night the slides became thinly and evenly coated with a spore-deposit, and next morning they were removed from the chamber. One of them was then supported by a clamp-stand so that it was freely exposed to the direct action of the sunlight streaming through a window in the laboratory, and the other was kept in the dark. The temperature of the laboratory was about $19^{\circ} \mathrm{C}$. Tests for germination were made by placing the spores in hanging drops of a neutralised nutrient medium consisting of 1 per cent. glucose, 1 per cent. peptone, 0.3 per cent. meat extract, 0.5 per cent. sodium chloride, and 10 per cent. gelatine. The ring chambers containing the drops were partially filled with distilled water, and were kept in the dark. Comparative tests made during the month of April showed that spores which had been exposed to sunlight for eight hours germinated more slowly than spores which had been exposed to sunlight for two hours, and these more slowly than those which had been kept in the dark. Spores kept in the dark germinated about twenty hours sooner than those which had been exposed to sumlight for seven or eight hours. After three days the mycelia produced from spores which had been kept in the dark were much more advanced than those which had been produced from spores which had been exposed to sunlight for periods of one, two, thrce, six, seven, and eight hours respectively. It was also found that exposure of the

1 Miss M. C. Ferguson, "A Preliminary Study of the Germination of the Spores of Agurims cumpestris and other Basidiomycetous Fungi," U.s. Dep. of Agric., Bureau of Plant Industry, Bull. No. 16, 1902, p. 21. 
spore-deposits to sunlight resulted in a marked diminution in the proportion of germinating spores. This series of experiments, together with three others, has led me to the conchision that, when dried spores of Schisoply yllum commune are exposed to direct sumlight for a few homrs, a certain proportion of them are remlered incapable of germination, whilst those which germinate do so more slowly than dried spores kept in darkness. Subsequent experiments showerl that the spores of bartulea unicolor are affected by sunlight in the sanne manner as those of Schizophyllum comemume. From the point of view of spore-dispersion, the experiments seem to indicate that the spores of these fungi, when drifting about in the air, may survive exposure to smolight for a whole day, and that they may subsequently germinate, although with diminished vitality. ${ }^{1}$

1 The injurions effect of sumlight upon the development of pathogenic bacteria is now well known. In the pase of fungi, Elving has shown that the spores of Aspergillus glaurus, and Lanrent that those of Ustilago carto, are killed by long exposure to smulight. Pfeffer's I'hysioloy!n of I'louts, English translation, vol, ii. 1. $24 i$.

Note- Since this chapter was set up, W. B. Grove has called my attention

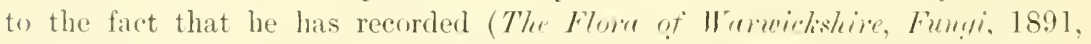
1. 419) the oecurrence of a fruit-body of stroplenine semiylolute with the gills white owing to the non-development of the spores, but otherwise perfect. 


\section{CHAP'TER II}

THE EXTENT OF THE HYMENIUM-PRINCIPLES CNDERLYIXG THE ARRANGEMENT OF GILLS AND HYMENIAL TUBES-THE MARGIN OF SAFETY - THE GENTS FOMES

'THe Hymenomycetes are classitied in subdirisions corresponding in the main with the manner in which the pileus is arranged in relation to the hymenial surfaces. Only in the Thelephoreae, some Tremelline:e, and the Exobasidineat is the hymenium smooth and Hat, whilst in the Agaricinee it is arranger upon gills, in the Polyporea in tubes, in the Hydnee upon spinous prolongations, and in the Clavariete upon the exterior of more or less numerous branches of the fruit-body.

The various forms of fruit-bodies may be explained in their erolutionary aspect on the supposition that a chief factor in their survival has been the advantage arising from the production of a relatively large number of spores with a relatively small expenditure of fruit-body material and energy. The gills, spines, tubes, ke., all have the same significance, namely, that of increasing the extent of the hymenium which a fruit-body may bear. The same end has been attained by different means. One can easily imagine how, beginning with the Thelephorea with smooth and flat hymenial surfaces, the more highly complex fruit-bodies of the Agaricine:e, the Polyporea, the Hydnei", and the Clavariese have been evolved. The principle of folding to increase surface is well illustrated in these four groups. Perhaps every possible means of economically increasing hymenial surface, consistent with the liberation of the spores, has been exhausted by them.

In order to obtain more precise information with regard to the advantage obtained by the production of gills, spines, tubes, \&c., a number of calculations have been made.

Let $\mathrm{A}$ be the area of the flat surface on the underside of a 
fruit-body, when grills, tubes, or spines have been removed. Let

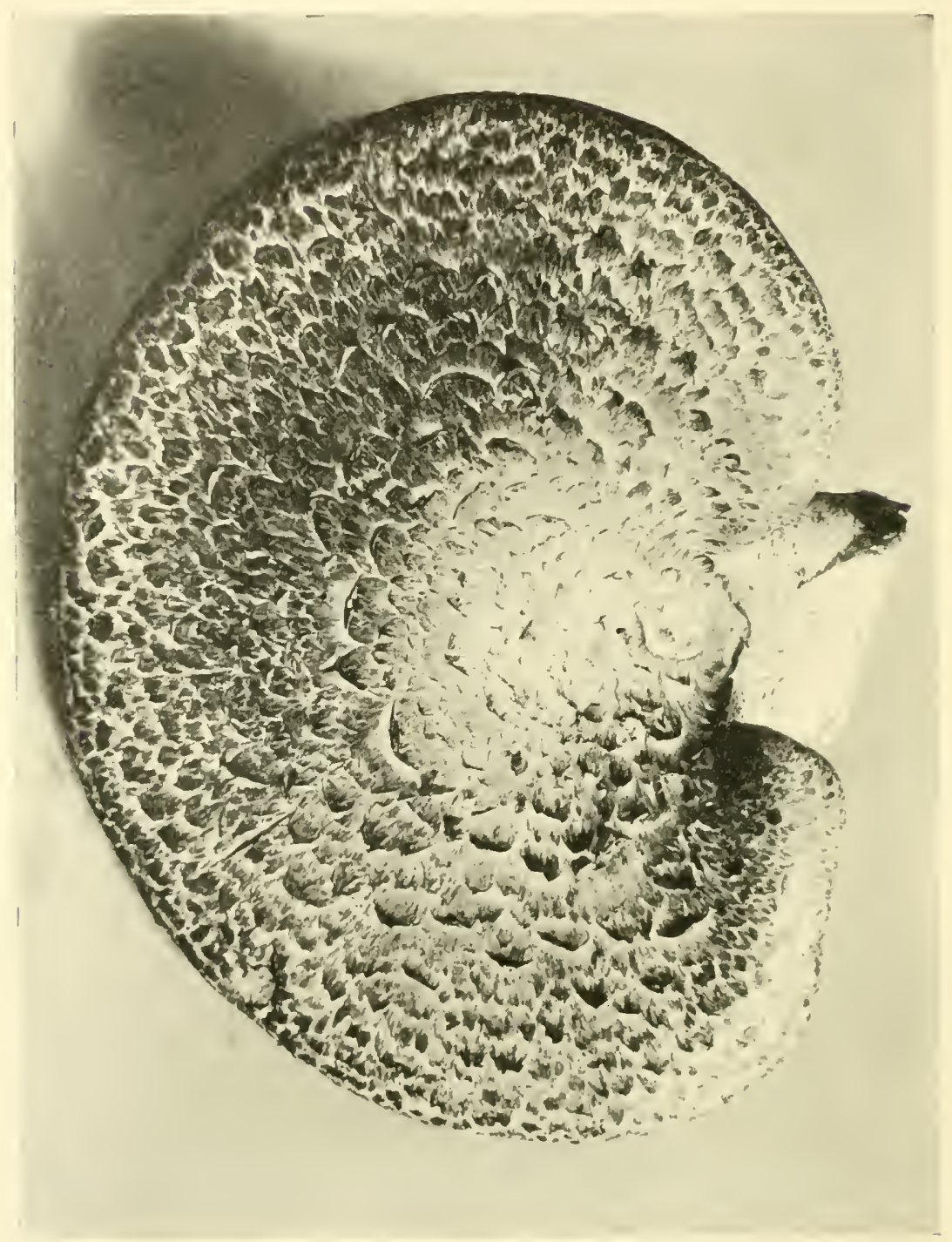

Fig. 4.- Fruit-tody of l'olyporus squumosus nearly full-grown; upper surface covered with brown seales. The full length of the stipe is photographed. Photographed by R. H. Pickari. $\frac{1}{3}$ natural size.

$H$ be the area of the hymenium upon the gills, tubes, or spines. Then the ratio $\frac{H}{A}$ gives the increase of surface of the hymenimm 
for which the gills, tubes, or spines are responsible. Let the

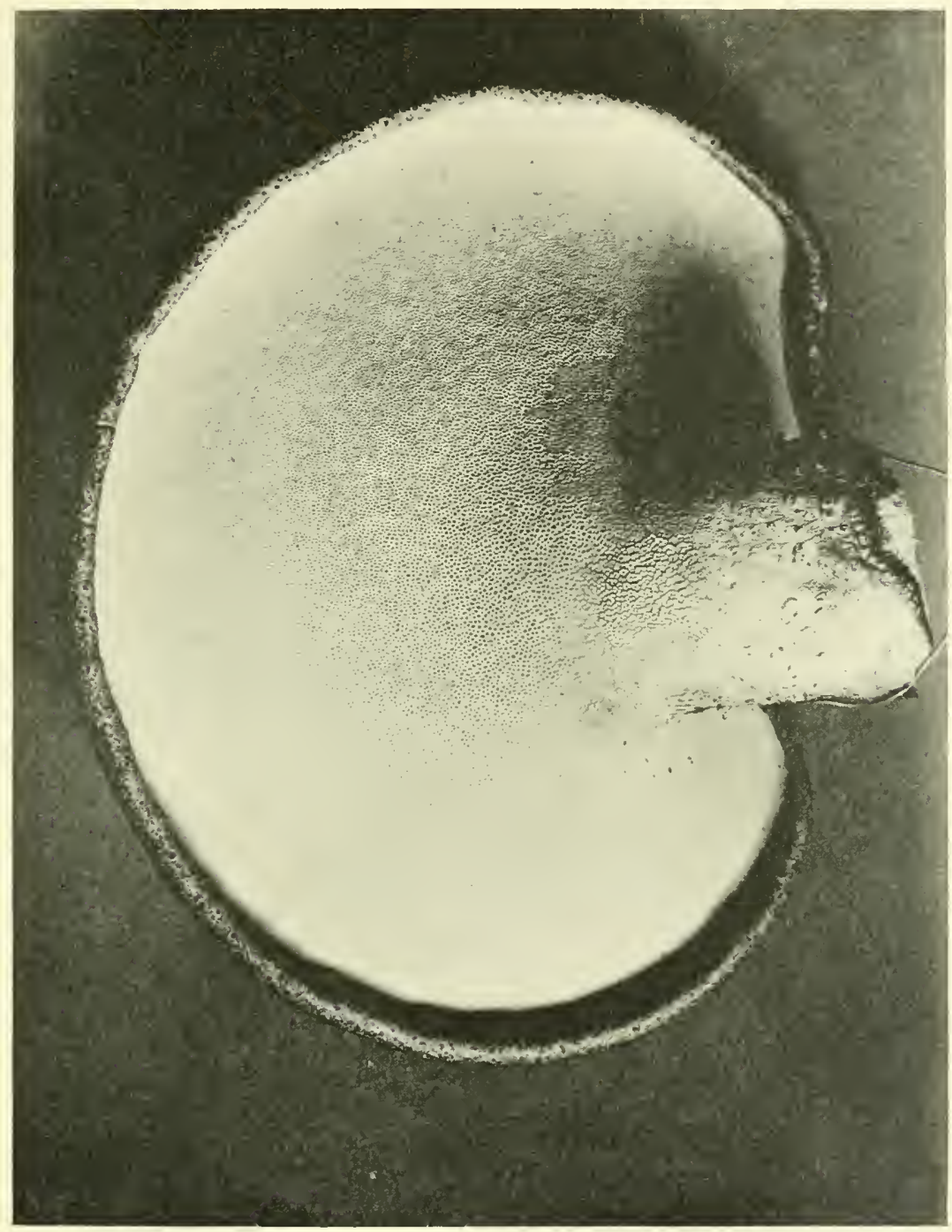

FIG. 5.- Under surface of fruit-body of Polyporus squamosus nearly full-grown, showing the pores of the hymenial tubes and the reticulations on the stipe. The fruit-body was photographed immediately after it was cut : the involution of the edge of the pileus is quite natural. Photographer by R. H. Pickard. $\frac{1}{3}$ natural size.

specitic increase of hymenial surface, due to the presence of gills, 
tubes, or spines in any fruit-body, be represented by the contraction sp. Inc.

Then

$$
\text { sp. Inc. }=\frac{H}{A} .
$$

The value of the specifie increase has been measured in a few instances.

For species of Agarieinea the number of gills was counted and the gill-systems studied. The number of gills of each size was determined. A fow gills of each size were dissected off the fruitbody, placed on paper, and drawn. The paper drawings were then cut out with seissors, and their area determined by weighing them against squares of paper marked out in square millimetres. The fact that each gill has two sides was taken into account. With the data thus obtained the total area of the gills could be calculated. The value of $A$ was calculated from measurements of the diameters of the pileus and of the stipe.

Full-grown specimens yielded the following results:-

\begin{tabular}{|c|c|c|}
\hline species. & $\begin{array}{l}\text { Minmeter of } \\
\text { l'ilen- in } \\
\text { Millinetres. }\end{array}$ & 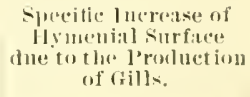 \\
\hline Russula citrina. & (ii) & $7 \cdot 0$ \\
\hline Amanita rubescens & 50 & $10 \cdot()$ \\
\hline & 76 & $12 \cdot 2$ \\
\hline Armillaria mellea . & $i 6$ & $1: 2 \cdot 8$ \\
\hline Tricholoma personatum & 127 & $16 \cdot 0$ \\
\hline Hypholoma sublateritimn & $i f$ & $17 \div 5$ \\
\hline Psalliota campestris . & 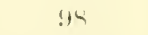 & $20 \cdot 14$ \\
\hline
\end{tabular}

As an illustration of the method of calculating specific increase, details for the specimen of Tricholome personutum will be given.

Diameter of pilens $=127 \mathrm{~mm}$.

Diameter of stipe $=24$,

Hence, the area of the umderside of the pileus, with the gills removed, exchsive of the part oceupied by the stipe, $=120 ;-2 \cdot 8$ $-\$ 16 \mathrm{~mm} .^{2}$, or $\mathrm{A}=1 \stackrel{2}{0} \cdot 1 \mathrm{~cm} .^{2}$.

$$
\begin{aligned}
& \text { Ninmber of primary gills }=101 \\
& \text {, , secundary , }, \quad \text { - I01 } \\
& \text {., ., tertiary }, \quad=202 \\
& \text {, "quaternary, },=104 \text { approximately. }
\end{aligned}
$$


By the weighing method already described, the area of the gills, including both sides, i.e. $\mathrm{H}$, was determined to be $1942 \mathrm{~cm}^{2}$ approximately.

$$
\text { Hence, Sp. Inc. }=\frac{1942}{120 \cdot 1}=16 \text { approximately, }
$$

i.e. the fruit-body had sixteen times more hymenial surface than it would have had if the underside of the pileus had not been produced into gills.

In the case of the Mushroom, the gills on one quarter of the pileus were isolated one by one, and their outlines marked out on paper. The figures were then cut out and weighed against paper ruled into square millimetres. The area so determined was multiplied by four, and thus the whole surface area of the gills obtained.

From the above table it will be seen that the common field Mushroom has the highest specitic increase, namely 20. This is not surprising, for field Mushroous have deep grills closely packed together (cf. Plate IV., Fig. 25). Russulu citrinu, on the other hand, has much shallower gills of one length only, which are placed at some distance apart. The specific increase in this species is consequently very small: it is only 7 , i.e. one-third of that of the Mushroom. Again, it is clear that with pilei of equal diameters, Hyplodome subluteritium has considerably more gill-surface than either Amanitu mbescens or Ameillumir mellea. If we take the specific increase of gill-surface as a test, it seems fair to conelude that of the fungi investigated, the greatest morphological advancement is exhibited by Psalliota campestris and Hypholoma subluteritium, and the least by Russula citrinu.

In the Polypores the formation of hymenial tubes often leads to a considerable inerease in the spore-bearing area. The amount of increase depends upon the length and breadth of the tubes. In three species the specitic increase has been measured.

Polyporus squamosus (Figs. 1 and 4 -7). - In the speeimen examined it was found that in the middle of the pileus there were 2.) tubes to each square centimetre. Each tube on the average 
Was $9 \mathrm{~mm}$. long, and possessect a perimeter at its base of $6 \mathrm{~mm}$. Hence, the area of hymenium for each square centimetre $=9 \times 6 \times 2.2$ $=1188 \mathrm{~mm}{ }^{2}$ approximately. Therefore, for $1 \mathrm{~cm}^{2},=100 \mathrm{~mm} .^{2}$, we find that the specitic increase $=\frac{1188}{100}=11 \cdot 8$ approximately.

In most sprecinens of the fungus the tubes do not attain a length of !) mm. The specitic increase is therefore usually less than 11.8 . By comparison with the results in the table griven above, it may be coneluded that many $\Lambda$ garieinea have a larger specific increase than Polypores squamosus. Howerer, this species has unusually wide tubes. When the tubes are very narrow, as in the eases of Fomes regeters and $F$. igmierien, now to be discussed, it is found that

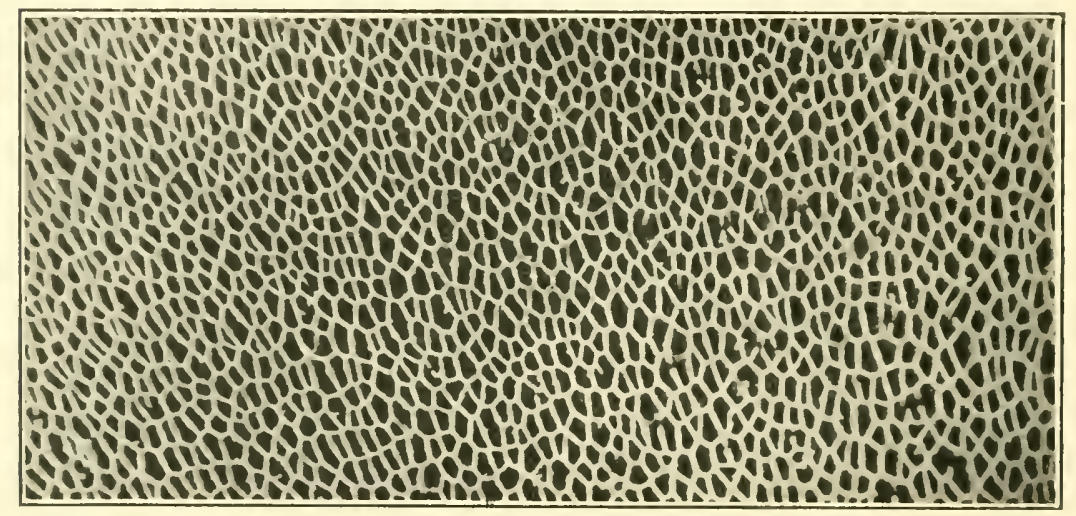

Fis: 6.-Tiew of part of the underside of a mature fruit-hody of Inolyporns squamosus which was $2 \mathrm{ft}$. $2 \mathrm{in}$ across. The openings of the hymenial tubes are polygonal. Natural size.

the specific increase may be much greater than that in any of the grilled fungi.

Fomes vegetus.-The fruit-bodies are perennial and produce a layer of tules amually (Fig. 11). In the specimen examined it was found that for one year there were 2080 tubes to 1 square ent. The length of each tube on the average was 12 mm. and the dianeter $0.17 \mathrm{~mm}$. Hence, the area of the hymenimm for each square centimetre $=12\left(\frac{22}{7} \times 0.17\right) \times 2080=148.00 .4$ mm. ${ }^{2}$ approx. Therefore, for $1 \mathrm{~cm}^{2}{ }^{2},=100 \mathrm{~mm}^{2}$, we find that the specific increase $=\frac{14830^{\circ} 4}{100}=148$ approximately. In the specimen examined three 
layers of tubes had been produced, and these possessed a total vertical length of $40 \mathrm{~mm}$. Hence, taking the three years together, the total specific increase amounted to 493.

Fomes igniarius.-In this species also, the fruit-bodies are perennial and produce successive layers of tubes. In a large specimen it was found for one layer that in $1 \mathrm{sq}$. cm. the number of tubes was 2000. The breadth of each tube on the average was $0.15 \mathrm{~mm}$. and the length $4 \mathrm{~mm}$. Hence, the area of hymenium for each square centimetre $=4\left(\frac{22}{7} \times 0 \cdot 15\right) \times 2000=3800 \mathrm{~mm}^{2}{ }^{2}$ approxinately. Therefore, for $1 \mathrm{~cm} .^{2},=100 \mathrm{~mm}^{2}{ }^{2}$, the specific increase $=\frac{3800}{100}=38$ approximately. In the specimen examined there were twenty-five

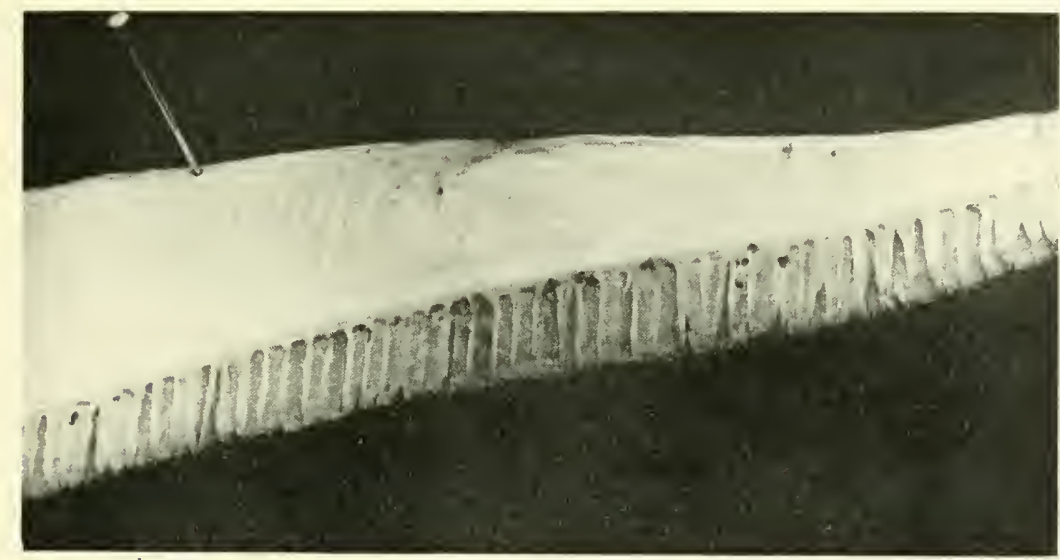

FIG. 7.- View of part of a transverse section throngh the middle of a mature fruit-body of Polyporus squamosus. The hymenial tubes are directed down. wards. Natural size.

layers of tubes, having a total thickness of $100 \mathrm{~mm}$. For the total period of growth, therefore, the specific increase amounted to the high value of 942 .

From the figures just given, which show that in one year's growth the specific increase for a specimen of Fomes ignarius was approximately 38 , and for one of $F$. vegetus approximately 148 , it is clear that the perennial Polyporea with narrow tubes produce much more hymenial surface for a given area of pileus than any of the Agaricinee. The specific increase for Psculliota campestris, which was the highest in the Agaricinee investigated, was only 20.04. 
We have seen that in the Agaricinese the extent of the hymenium has been increased by the production of radial wedgeshaped gills with vertical median planes, so that the fruit-bodies are characterised by an admirable compactness. However, certain principles underlying the spacing of the gills in reference to one another still require an elucidation. The gills are usually erowded together on the underside of a pileus. Two adjacent gills, however, must be a certain distance apart in order to permit of the liberation of the spores. It will subsequently be slown ${ }^{1}$ that for Psulliotu compestris, \&c., the spores are actually shot horizontally for about $0.1 \mathrm{~mm}$. into the interlamellar spaces before their paths of movement become vertical. 'Two adjacent gills, where they are closest to one another, i.e. near the pileus flesh, must therefore be separated from one another by a distance which at least just exceeds $0.1 \mathrm{~mm}$. In the Mushroom the minimum space between the gills was actually found to be about 0.2 mm. (Plate I., Fig. 1). Probably nearly 50 per cent. of this should be regarded as a margin of safety. When a mature pileus is tilted slightly, so that the plane of the flesh is no longer horizontal, the grills, displaced from their vertical planes, react to the stimulus of gravity by growth in such a manner that they quickly come to take up rertical positions onee more. ${ }^{2}$ This, however, entails a reduction in the margin of safety, for the spaces between the gills become narrowed. If the pileus is tilted beyond a certain amount, it necessarily follows that, when the gills have arjusted themselves, the margin of safety must have disappeared altogether. This must lead to a diminution in the number of spores escaping from the pileus.

In the Mushroom, judging from a study of gill-dimensions as embodied in Plate I., Fig. 4, the margin of safety would not be used up milil the pileus had been tilted to an angle of about $30^{\circ}$. In this instance, and probably quite generally for Agaricinea, provided only that the rills have taken up vertical planes, just as many spores ean he liberated from a slightly tilted as from an

1 Tirle infru, Chatp. XI.

2 rf. A. H. R. Buller, "The Reactions of the Fruit-bodies of Lentimus lepridme, Fr., to External Stimuli," Amn of liot., vol. xix., 1905, p. 432. Also vile infru, ('hap. IV'. 
untilted pileus. This arrangement must be of some value, for in woods and fields slightly tilted pilei with vertical gills are quite commonly met with.

It is now elear that two adjacent gills must be at least a certain minimum distance apart to permit of the successful liberation of the spores. It is equally clear, however, that when the space between two gills exceeds a certain maximum their arrangement is a wasteful one, for the underside of the pileus is then not being used up to the best advantage. The gills of Agaricinee are disposed radially, so that in passing from the stipe to the edge of the pileus they necessarily diverge. Near the stipe two adjacent gills may be economically spaced. Further from the stipe, however, owing to divergence, their spacing becomes wasteful. There is much more room left between them than is necessary for the liberation of the spores, and for the provision of an adequate margin of safety. This defect is obviated almost entirely in most Agaricinese by the introduction of shorter gills between the longer ones, in suceession, proceeding from the stipe to the pileus periphery (Fig. 8). In some specimens of Marusmius oreades it was found that the gills were of three different lengths, and that in a specimen of Tricholomu personutum they were of four different lengths. The complexity of the gill-system is usually greatest in pilei with large diameters. Good examples of the economical arrangement of gills, so that the space between any adjacent two shall never exceed a certain maximum width,

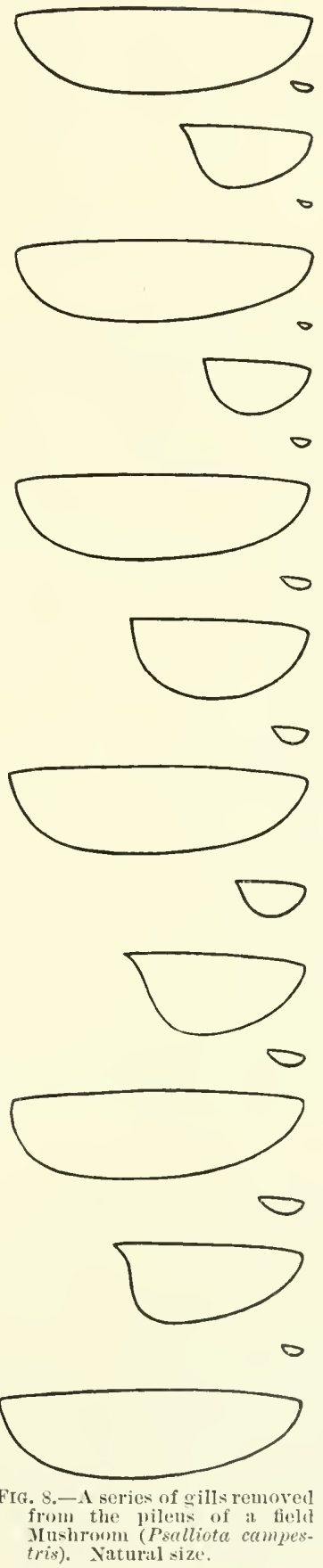


and yet never be less than a certain minimum width, are seen in the Oyster Fungus (Peurotus ostroutus, Figs. 2 and 3) and in the Mushroom (Fig. 9 and Plate IV., Fig. 25). Certain speeies of Russula have gills which are all of one length, with the exeeption of very occasional shorter ones (Fig. 10). Since the gills in the fully-expanded fruit-bodies diverge considerably in

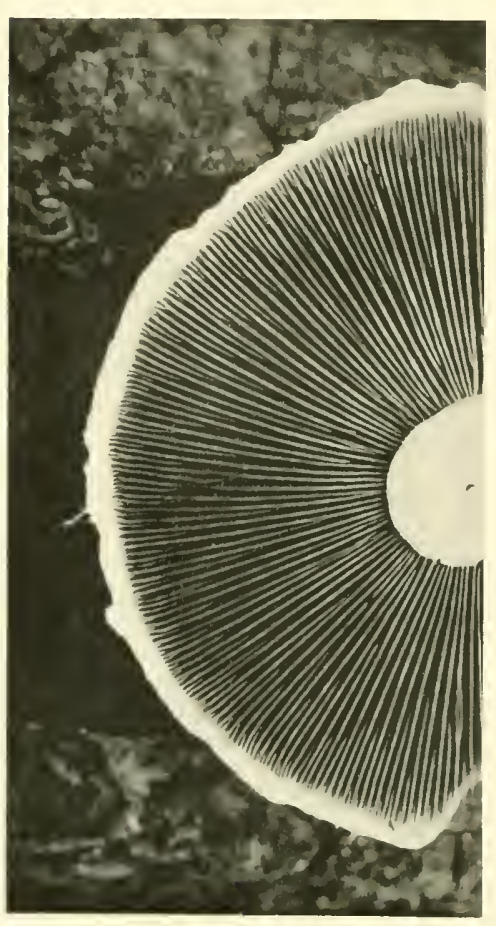

FIc. 4.-Psalliota campestris. Jart of a pileus plotographed from below. showing that the gills are accurately arljusterl so that they look directly downwarls. Naturil size.

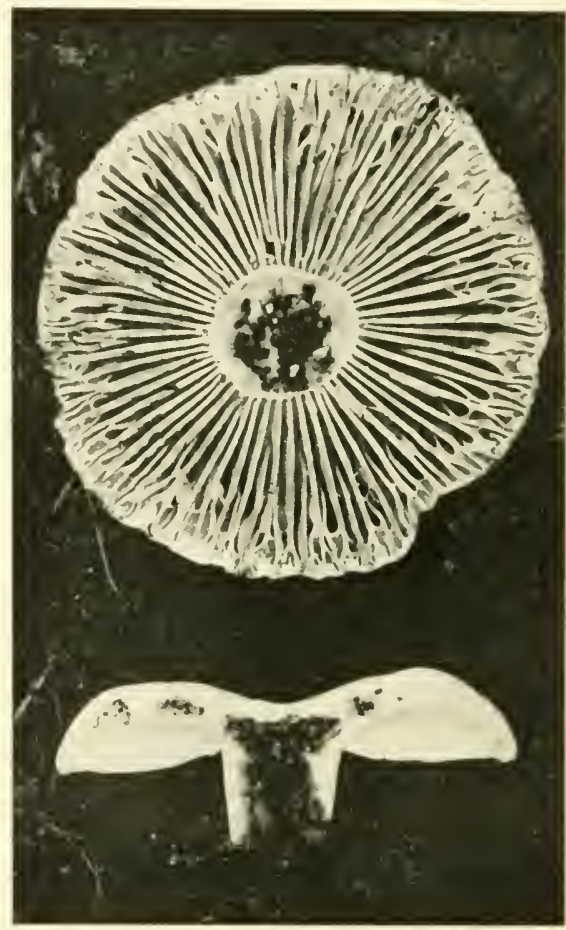

FIG, 10, The pileus of Russula nigriransan Agaric in which the gills are very erarsely spaced. The stije is maggoteaten. Reduced to $\frac{1}{2}$ natural size.

passing from the stipe to the margin of the pileus, their arrangement appears to be relatively imperfect.

The principles molerlying the arrangement of the gills of the Agaricince doubtless also apply to the arrangement of the hymenial tubes beneath the pilei of species of Polyporeic. Other things being equal, the greatest econony is affected when the tubes are 
as numerous as possible, for this entails a corresponding increase of hymenial surface. The diameter of the tubes, however, must always be sufficiently wide to permit of the liberation of the spores. Since these are shot outwards horizontally into the tubes for a distance of about $0.1 \mathrm{~mm} .{ }^{1}$ the tubes can never be less than this in diameter. In species of Polystictus and Fomes, where the width of the tubes is about $0.0-0.25 \mathrm{~mm}$., the ultimate reduction consistent with safety seems to have been attained.

The genus Fomes, from the point of view of efficiency in the production and liberation of spores, may be looked upon as having fruit-bodies of a highly specialised kind. In the first place the fruitbodies are perennial. This is economical, for the old flesh is used

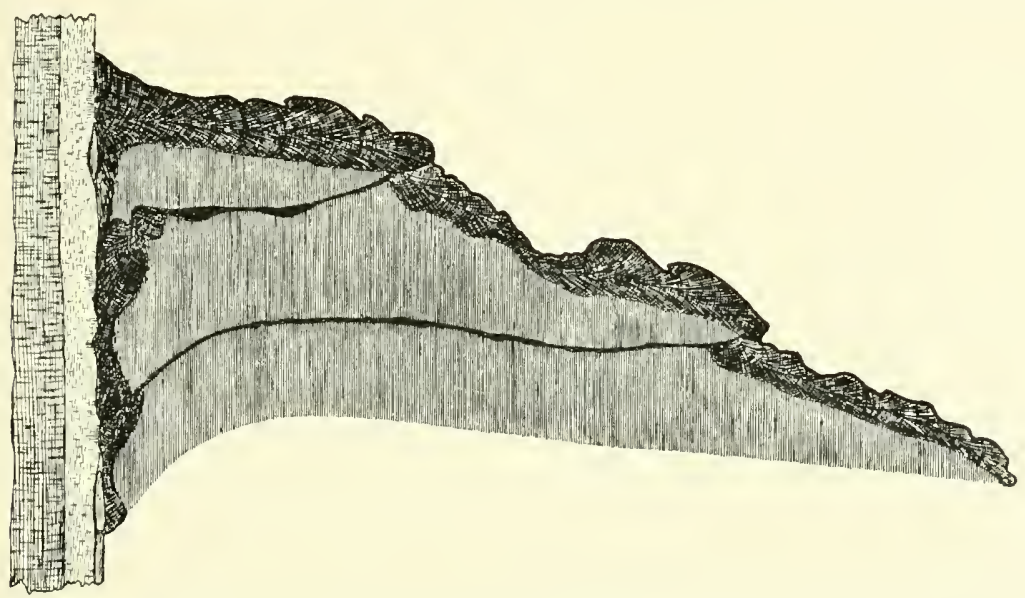

FIG. 11.-Fones applanatus $(=F$. vegctus). Vertical section through a fruit-body three years old. A new layer of hymenial tubes was produced each year. Reduced to $\frac{1}{2}$ natural size.

each year to support new hymenial tubes, and does not function only once, as in the case of such annual fruit-bodies as Polyporus squemosus, or those of the Agariciner, the Hydnex, the Clavariex, or the Tremellinese. Again, most of the Fomes fruit-bodies are very hard and "woody," possess no stipes, and are attached by a broad surface to the wood on which they are produced (Fig. 11). This gives them extreme rigidity, so that even in the course of years accidents are little likely to injure them. The extreme rigidity also

${ }^{1}$ Vide infru, Chap. XI. 
ensures that the very narrow hymenial tubes shall be kept exactly in the vertical position. The importance of this is obvious when it is realised that even a very slight tilt of the tubes would prevent the spores from escaping from them.' Further, the fruit-bodies ean withstand uninjured the severest frosts of winter, and, judging from some experiments nade with Fomes igmiurius, ean reeover after prolonged desiceation. ${ }^{2}$ Lastly, they have extremely narrow hymenial tubes. This, as we have seen, involves a great increase of sporebearing surface. Taking into account the manner in which the spores are discharged from the basidia in Polyporese (Fig. 66, p. 189), it would seem that for $F$. vegetus and $F$. igniurius the width of the tubes is so small that, after allowing for a small margin of safety, it has almost, if not quite, reached its limit.

The more liable a polyporaceous fruit-body is to become slightly tilted, owing to developmental changes, transpiration, the accumulation of rain-water on its upper surface, the visits of birds, ce., the greater is the advantage of wide hymenial tubes over narrow ones in liberating the spores. Perhaps it is for this reason that the tubes in the soft and wide-spreading brackets of Polyporus squemosus are of considerable width, so that they stand in marked contrast with those of the more compact and extremely rigid fruit-bodies of fomes igniurium, \&e. The dimensions of the tubes in these and other species seem to me, at least to a certain degree, to be correlated with the nature of the pileus flesh.

1 With the beam-of-light method (ride infro, Chap. VII.) it was observed that when the tubes of Polystictue hirsutues were tilted to an angle of $15^{\circ}$ from the vertical, there was a marked diminution in the number of spores liberated, and that with a tilt of $30^{\circ}$ spore-liberation almost entirely ceased.

2 Specimens which had been gathered and kept dry for six months began to grow on their undersides when they were placed in a damp-chamber. 


\section{CHAP'IER III}

THE FUNCTIONS OF THE STIPE AND OF THE PILEUS FLESHTHE GILL-CHAMBER

T'He mechanics of the stipes of the more complex Hymenomyeetes might well form the subject of an interesting and a detailed investigation. A few remarks may here be made in this connection upon the stipes which are eentrally situated beneath radiate pilei in the most highly developed fruit-bodies. The stipe can support the pileus with far less strain in a centric than in an eccentric position, and it seems probable that this mechanical prineiple has been one of the chief factors in bringing about the evolution of the umbrella form of Agaric. In different species stipes vary much in length, thickness, and in the nature and disposition of the materials of which they are composed; but no doubt there is always a eorrelation, and often a close one, between their structure and the work which they have to do in supporting the pileus at a distance from the ground, and in keeping the gills in exactly vertical planes.

When one realises how very important it is, from the point of view of spore-liberation, that the planes of gills, the axes of hymenial tubes, \&c., should be kept quite motionless in a vertical position, one cannot be surprised to find that the mechanical structure of the stipe and pileus flesh is such as to give the whole fruit-body a remarkable amount of stability. Were the gills of Agaricinee, or the hymenial tubes of Polyporeie, subjected to even slight continuous tilting movements, it is certain that a great proportion of the spores could never be liberated-for after discharge from their basidia, vast numbers of them would strike and adhere to the hymenium. In the Mushroom, for example, it has been found ${ }^{1}$ that in still air the paths of fall of the spores in the interlamellar spaces are as shown in Fig. 12, A. When the planes of the gills are tilted $1^{\circ} 30^{\prime}$, the spores

1 Vide infra, Chap. XVII. 
can readily escape (B). If the tilt be inereased to ' $2^{\circ} 30^{\prime}$, the critical congle is reached (C): all the spores can still make their way out between the gills, but with any increase in the tilt some of them fall upon the hymenimm and alhere there. With a tilt of $5^{\circ}$ half the spores are lost (1), and with a tilt of $9^{\circ} 30^{\prime}$ four-fifths of them (E). The gills of a IIushroom are radially disposed, and it is therefore evident that, if a Ilushroom is tilted, those gills with their planes

A

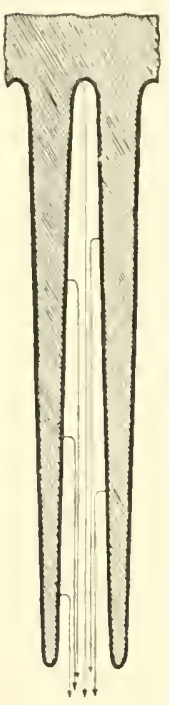

B

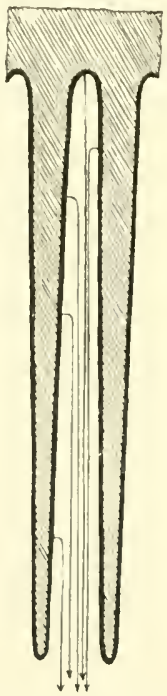

C

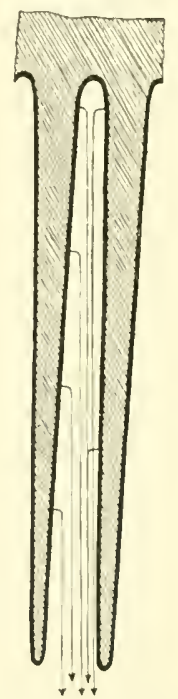

D

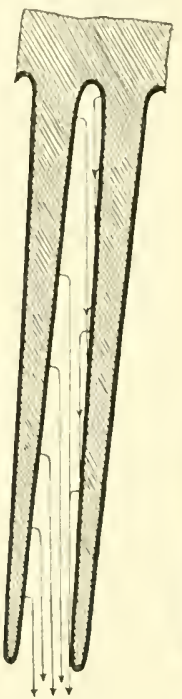

$E$

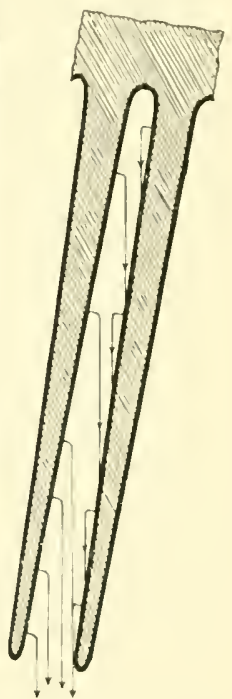

FIG. 12. - The effect of tilting the gills of Psulliotu campestris. Two grills are shown in eross section. 'The arrows in the interlamellar space indicate the paths of the spores discharged in still air. $A$, gills in the normal position. In $B$ the gills are tilted $1^{\circ} 30^{\prime}$ from the vertical, in $\mathrm{C}^{\circ} 30^{\prime}$, in $\mathrm{I} 5^{\circ}$, and in $\mathrm{E}, 3^{\circ} 30^{\prime}$.

most nearly perpendicular to the plane of tilt will suffer most, whilst those with their planes most nearly parallel to the plane of tilt will suffer least. The exact proportion of spores lost by a whole Mushroom with a tilt of a given angle would be somewhat diffieult to calculate, and no attempt will be made here to solve this problem. It is sufficiently clear, however, that when the pileus of one of the Agaricinex is tilted only a few degrees from its normal position, its spore-liberating efficiency is greatly reduced. In this connection, it is a distinetly significant fact that all hymenomycetous fruit-bodies 
are so constructed that in ordinary weather they remain quite motionless. Those with the longest stipes, e.g. Coprinus comatus, scarcely sway on very windy days, whilst most fruit-bodies remain practically unstirred even during gales. In a field, the stability of a Mushroom may be contrasted with the instability of a neighbouring grass stem; but we must recognise that the peculiar nechanical properties of both Cryptogam and Phanerogam are equally fraught with a beautiful significance. Each plant reacts to the motion of the breeze in a manner most suited to its own special needs.

Centric stipes are usually cylindrical. In some species, e.g. Russula, \&c., the cylinder is quite solid, although, as a rule, it is firmest toward the exterior; in others, it has a narrow central core, stuffed with soft, loosely interlacing hyphe, or left quite unfilled as in Amanita plualloides (Fig. 13) or the Mushroom; whilst in yet others, of which Coprinus comutus is a good example, it assumes the form of a perfect hollow cylinder with a comparatively thin wall (Plate I., Fig. 1). The hollow cylinder has the same significance in Fungi, in Flowering Plants, and in structures built by engineers. Where it is employed, advantage is taken of the fact that with a given length and a given amount of material, a hollow cylinder is more rigid and offers more resistance to bending than a solid one.

Where the pileus is large, as in many Russule and Boleti, the stipe is usually thick, solid, and so rigid or tough that it is not easily displaced; it appears to be constructed as if to resist more particularly any downward pressure from above, arising from obstacles met with in pushing up the broad pileus, or which might come to rest on the fruit-body after its development. On the other hand, there are many species with small pilei placed on long stipes. Here the pileus is usually conical or dome-shaped, and the stipe forms a perfectly hollow cylinder or one with a thin firm wall and a very soft core. The whole fruit-body, whilst being fairly rigid, is much more elastic than the larger ones to which we have referred, and scems adapted for pushing its way up between surrounding grass stems, \&c., for throwing off rain-water, and for resisting lateral pressure. Illustrations of long, hollow stipes may be found in the genera: Mycena, Galera, Stropharia, Coprinus, \&c. Thin-stiped fruit- 
bodies, r.y. those of dlycence epipterygu, have a distinct advantage over thick-stiped, such as those of Russula emetica, in that, if the fruit-borly should be even considerably displaced by any aceident, it can quickly be set once more with the gills in vertical plines by means of a suitable geotropic curvature of the stipe. With hussulie, Psallioter, \&c., owing to the thickness of the stipes, this is impossible when the pilei have become outstretched. In these cases, the gills themselves react to the stimulus of gravity, and after a slight clisplacement of the fruit-body, quickly readjust themselves so at to come to lie in vertical planes once more; lut when the displacenent is considerable, this remedy becomes of very little avail. In species of Caler: Mycena, \&c., the structure of the stipe is such as to remind one of the hollow peduncle which supports the capitulum of at Dandelion or the pith-filled one of a Chrysanthemum. It is clear that for the stipes of Agarience we have a series of rariations in the cylindrical form comparable with that found in the stems of Phanerogams and bearing a sinilar interpretation.

A certain amount of rigidity is given to many stipes, not merely by their eylindrical form, but also by longitudinal tensions set up in the layers of hyphe of which they are composed. The existence of these tensions can easily be proved liy partially bisecting or quadrisecting the stipes concerned, e.g. those of coprinus comutur, Mycence, de., in a longitudinal direction from below upwards, with a knife. The halves or quarters so produced bend outwards and resist attempts to replace them in their original positions (Fig. 13). It is well known that similar tensions ocenr in the young stems of the Higher Plants.

The foregoing remarks tend to show that stipes in general are well adapted to give the basidia the hest possible chance of discharging their spores, so that they may freely escape from the fruit-body. There can be no doubt that the pileus flesh is adapted to the same end. Its function is not merely to support the weight of the gills or hymenial tubes, but to hold them fixed in one particular position. As one might expect from a very simple mechanical consideration, the pileus flesh is always thickest toward the centre and thins ont rapilly in the peripheral direction. Its exact form and the materials of which it is composed vary much 
in different species, so that its peculiar mechanical needs are doubtless met in slightly different ways.

In certain species of Polyporus which have central stipesP. pisochapani, P. rugosus, P. lepideus, and P. floccopus-there is present, according to Massee, ${ }^{1}$ a highly developed mechanical sheath to both pileus and stipe. The occurrence of this strueture points to an unusually marked division of labour between the nutritive and supporting parts of the fruit-bodies.

In Coprinus comatus (Plate I., Fig. 1) the pileus has the form of a bell, and its centre of gravity is situated at some distance below its place of attachment to the stipe. It is thus in a state of stable equilibrium, and doubtless, in correlation with this mechanical fact, it happens that the pileus and stipe are very loosely attached together. If one slightly tilts the stipe of a fruit-body which has just opened, the pileus refuses to become
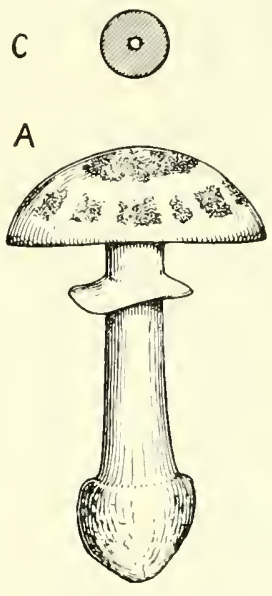

FIG. 13.-1menite phalloides (volva removed). A, young fruit-body. B, mature fruit-body. The stipe has been quadrisected and the tensions in it have caused the four parts to separate. C, cross-section of a stipe. All $\frac{2}{3}$ natural size.

tilted too, but instead remains in its optimum position. High winds sometimes cause the pileus to swing slightly about the fixed stipe. However, few or possibly none of the spores would thereby be prevented from escaping from the fruit-body, owing to the peculiar manner in which they are liberated.2

Among the most beantiful Agaries in nature are the so-called Parasol or Umbrella Fungi-Lepiota procere and L. rachodes-

${ }^{1}$ G. Massee, "On the Differentiation of Tissues in Fungi," Journ. Riun. Micr. Sor., 1887, p. 205.

2 Tide infra, Chap. XIX. 
which, owing to their large size and striking form, attract general attention as they come up in open woods (Figr. 14). The pilei consist of broad plates which are often as much as 20 (1m. in diameter and raised $25 \mathrm{~cm}$. above the ground. The place of attachment of the stipe to the pileus flesh is very high, so that it is evident that it must be situated $1-2 \mathrm{~cm}$. above the centre

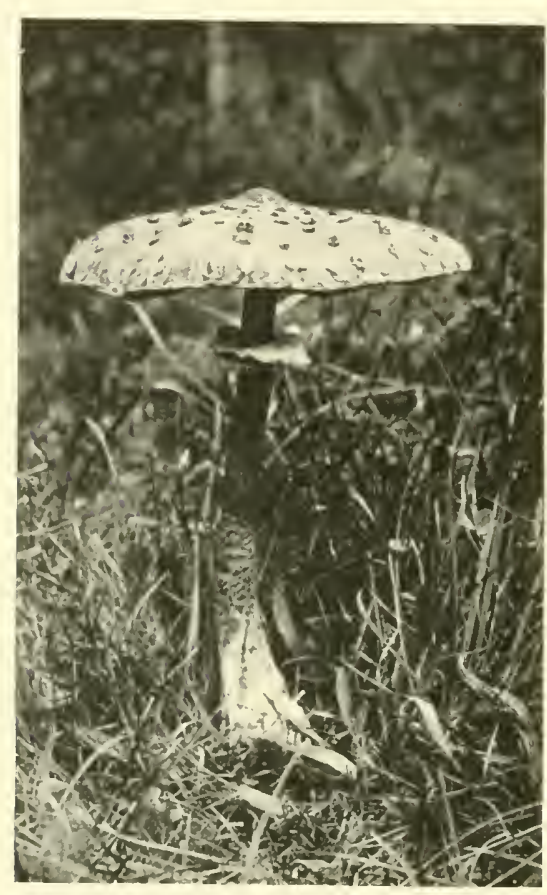

Fici, 14. - Le piota procera - the Parasol Fun. gus. Fruit-body growing among grass. Pbotographed at Sutton Park, Warwick-hire, by J. E. 'Titles. $\frac{1}{6}$ natural size. of gravity of the whole pileus in large fruit-bodies (Fig. 15). The stipe can easily be pulled ont from the pileus, and after its removal one may observe that it has a flattened top. The free pileus can again be set on the upright stipe. If, when this has been done, one tilts the pileus by pressing down one side of it with the finger and then lets it gro, it swings back into its original horizontal position. This could not happen if the centre of gravity of the pileus were in any other situation than that of stable equilibrium. Whilst a fruit-body is growing in nature, so far as I have observed, the pileus is fairly fimly fixed upon the stipe, and does not swing appreciably about its place of attachment during winds. However, to what extent the peeuliar position of its centre of gravity enables it to take up and maintain its most stable position during expansion, still remains to be investigated.

The oldest function of the centric stipe, from the phylogenetic standpoint, is undoubtedly that of providing a free space between the pileus and the ground, so that the falling spores may be carried off by lateral movements of the air. A space of this kind is already present in such primitive fruit-bodies as those of Conterellus cornu- 
copioides, one of the Thelephoreæ, in which the hymenium is smooth and not yet produced into tubes, teeth, or gills. The length of the stipe in a few very tiny fruit-bodies is not much more than a single centimetre, but in general it varies from $5-12 \mathrm{~cm}$. In different species it appears to bear some relationship to the size of the pileus and the usual nature of the environment. In a single species the stipes of individual fruitbodies are often longest when development has taken place in badly lighted places. The power of adjustment in response to conditions of light doubtless finds its significance in the advantage gained from raising up the pileus above surrounding obstacles. In most species the stipe does not elongate when once the gills have become outstretched, but in Coprinus comatus it goes on

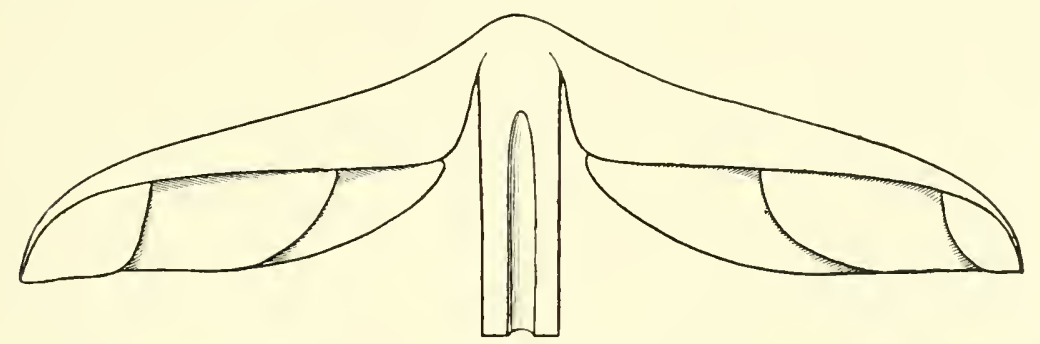

FIG. 15. - Lepiote procera. Section showing mode of attachment of the pileus to the stipe. $\frac{1}{2}$ natural size.

lengthening during the whole period of spore-discharge, so that at the end it is often $30 \mathrm{~cm}$. long. A good explanation can be found for this exception to the general rule, but it will be inore conveniently dealt with in Chapter XIX., where the Coprinus type of fruit-body is deseribed in detail.

In resupinate, dimidiate, and most fruit-bodies with centric stipes, the gills are exposed from their earliest appearance. Guided by this fact, we may regard the formation of a distinct gill-chamber, such as occurs in the genus Amanita, Psalliota, \&c. (Fig. 19), as one of the later developments in the evolution of Agarics. The significance of this structure is probably to be found in the advantage derived from protecting the gills from insects, parasitic fungi, and other enemies until the last possible moment, when their expansion and free exposure to the air, for the purpose of 
liberating spores, beeomes absolutely necessary. Some Mushrooms which were grown for my purposes on a bed of horse manure, whilst still shedding spores, were found to have their gills infested with tiny animals, possibly Acarineat. These, when rumning about, doubtless displaced a great number of spores, and probably also used many of them as food. The extended velum particle must be an admirable means of keeping such ereatures as these away from the young gills, until, by its rending during the rapid expansion of the pileus, the gill-ehamber is broken open. A part of the relum is often left on the stipe in the form of a more or less pronounced ring, as in Coprinus comutus (Fig. 70, p. 199), whilst in Amanita musearia and allied speeies (Fig. 75, p. 212), it hangs down in the form of a curtain. In the latter instance, its position is such that it does not seriously interfere with the falling spores as they are being earried off by air movements. It is the extreme thinness and flexibility of the velum which permits of its falling into the most unobstructive position when it can no longer be of any service to the fruit-body. 


\section{CHAP'TER IV}

ADJUSTMENTS OF FRUIT-BODIES IN THE INTERESTS OF SPORELIBERATION-LENTLNUS LEPIDEUS, PSALLIOTA CAMPESTRIS, POLYPORUS SQUAMOSUS, COPRINUS PLICATILIS, COPRINUS NIIEUS, AND COPRINUS PLICATILOIDES-REACTIONS OF FRUITBODIES TO LIGHT AND GRAVITY-THE PROBLEM OF PILEUS ECCENTRICITY_GEOTROPIC SWINGING-RUDIMENTARY FRUITBODIES

Is order to obtain a more precise knowledge of the means whereby, and the extent to which, a fruit-body is able to adjust itself so as to bring its hymenium into the optimum position for spore-liberation, experiments were made upon Lentinus lepideus, Psalliotu cumpestris, Polyporus squamosus, Coprinus plicatilis, C. niveus, and C. plicutiloides, the sporophores of which differ considerably from one another. The first two species belong to the Agaricinese but oceupy different habitats. Lentinus lepideus is saprophytic on wood and often produces its fruit-bodies on surfaces which are nearly or quite vertical, such as those of logs and stumps; whilst, on the other hand, as every one has observed, the Mushroom comes up in more or less horizontal pastures. Polyporus squamosus is a wound-parasite on trees, and is most frequently found attached laterally to tree trunks or thick branches. Coprinus plicatilis belongs to a highly specialised genus. Its fruit-bodies are of small size and come up in short grass. C'. niveus and $C$. plicatiloides are found on horse dung.

Lentinus lepideus. - The fruit-bodies developed on rotting paving blocks removed from the streets of the eity of Birmingham. Their reactions to external stimuli have already been deseribed in detail in a special paper. ${ }^{1}$ It will therefore only be necessary here to state those results of experiment which bear upon our problen.

${ }^{1}$ Buller, "The Reactions of the Fruit-bodies of Lentinus lepideus to External Stimuli," Ann. of Bot., 1905, vol, xix. pp. 427-438. 
A fruit-body begins its existence in light or darkness as a tiny papilla, directed at any angle to the substratum, but projecting more or less vertically from the surface of the stromatous layer on which it is produced (Fig. 16, A). If developed in the dark the papilla grows out into a long finger-like stipe, which is perfectly indifferent to geotropic stimuli. In the course of six weeks the stipe may attain a length of $15 \mathrm{~cm}$. without showing the least trace of a pileus (D), and sometimes it may become branched (C). In weak light it is positively heliotropic and

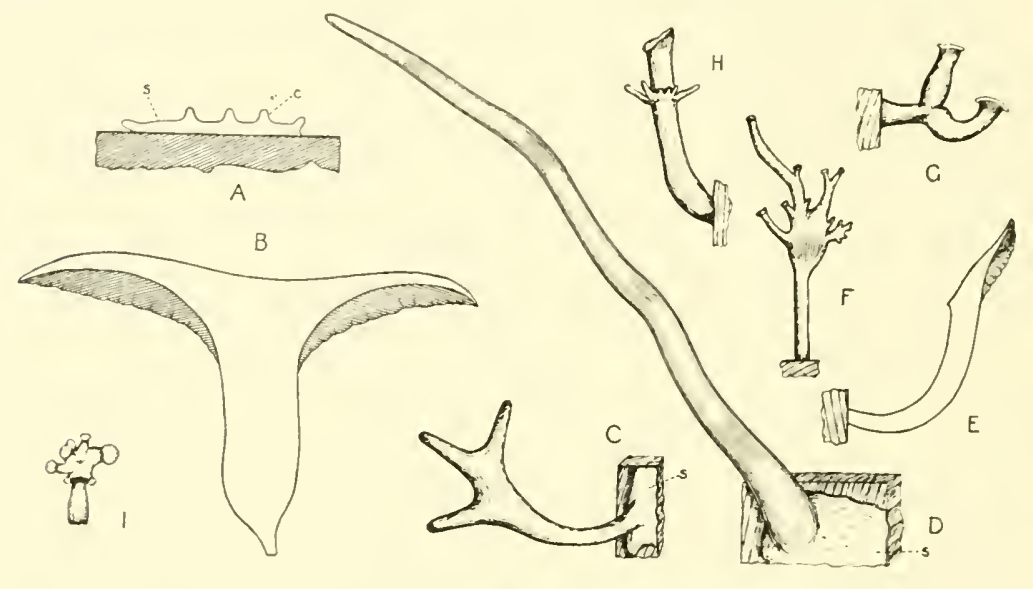

FIG. 16.-The forms of Lentinus lepideus. A, diagram showing the beginnings of fruit-bodies as conical processes, $c$, arising on a stroma, $s$, developed on wood. B, section of a normal fruit-body grown in light. C, sterile and branched fruit-body found growing in darkness. D, sterile and finger-like fruit-body after three weeks' growth in darkness. F, section of a fruitbody with eccentric pileus. F, G, H, and I, branched and feebly-developed fruit-bodies grown iu weak light. All $\frac{1}{2}$ natural size.

thus reacts to this stimulus as if attempting to bring its free end into the best illuminated position. When the tip of the stipe is acted upon by light of sufficient intensity, it flattens and expands in a symmetrical manner, and becomes converted into a pileus. As soon as the development of this structure has been initiated, a remarkable change takes place in the physiological properties of the stipe. Whilst still barren, this was absolutely without response to geotropic stimuli but was positively heliotropic; it now becomes strongly negatively geotropic and entirely loses its power of reacting to light. The rapidly developing pileus 
thus comes to have its axis turned upwards into a vertical position. The gills at the beginning of their development simply grow outwards in directions which are perpendicular to the under surface of the pileus. Their only reaction to external stimuli appears to be that of positive geotropism, which comes into play as soon as they have attained a certain breadth.

The turning movement which is necessary in order to bring the planes of the gills into exactly vertical positions, in the main is accomplished by the stipe, but for its completion the sensitive gills are themselves alone responsible. In the work of securing a proper orientation for the hymenial surfaces, the stipe acts as a coarse adjustment and each gill as a fine adjustment. In their nature and successive action these two adjustments are strictly analogous to those which are employed in focussing the high power of a microscope.

The reactions to external stimuli which have just been detailed are such that:-

(1) The barren stipe grows in a manuer suited to find a way to the open air.

(2) The pileus is never developed in any space which is shut out from daylight, and therefore of such a character that, if spores were liberated into it, they could not be properly disseminated.

(3) As soon as a pileus has begun its development, its hymenium can readily be placed in the optimum position by a suitable curvature of the stipe combined with a subsequent adjustment of the gills.

The fruit-bodies of Lentinus lepideus, when growing out from the side of a piece of wood, to some extent exhibit the phenomenon of eccentricity of development. In extreme cases, under cultural conditions, the pileus flesh may become quite unilateral (Fig. 16, E). I have shown that this is due to a morphogenic stimulus of gravity acting upon a pileus developing upon an oblique stipe. There can be no doubt that the reaction is advantageous in that it permits of the fruit-body developing the chief part of its sporeproducing surface in a situation where the spores will run the least risk of catehing upon the stipe whilst nnaking their escape.

$$
1 \text { Loc. cit., p. } 431 .
$$


We shall retum to the problem of pileus eceentricity in connection with Polyporus squemosus. It may, however, here be pointed out that the power of response to the morphogenic stimulus of gravity varies much in different species of Hymenomycetes. In Psolliote compestrin, in Coprinus, and probably quite generally in ground Agaricinear, it is not present at all; in Lentinus lepideus and certain other comparatively long-stiped Agaricinese it is slightly developed; whilst in the relatively shortstiped Pleurotus ostrentus and Polyporus squemosus, and in the stipeless, bracket-shaped fruit-bodies growing on trees it is very marked.

From the above it seems clear that the fruit-bodies of Lentinus lepideus possess in a high degree the power of adjusting themselves in a manner suited to their environment. In nature it sometimes happens, as I have once olserved, that a fruit-body begins its development on the underside of a $\log$ or other mass of wood. Even then it can still suceed in placing its gills in their optimum position.

Psalliota campestris.-Hushrooms were first of all studied as they came up under natural conditions in a large pasture. The actual amount of curvature which the stipes of the fruit-bodies investigated had undergone in extreme cases during development may be gathered from Fig. 17, in which some field sketehes have been reproduced. The eurvatures had been sutticient to place the planes of all the pilei in a horizontal position. Howerer, in older Mushrooms, it was found that the stipe only acts as a coarse adjustment for the gills. The latter are very thin, fairly deep, and elosely packed; and the fine adjustment of their planes in exactly vertical directions can only be effected by their own delicate reactions to the stimulus of gravity.

When an accident happens to a mature IIushroom so that it becomes tilted, as is often the case in pastures where horses and cattle are browsing, the stipe and pilens remain fixed in their new positions. However, the gills are still in a most sensitive condition and quickly respond to the stimulus of gravity. Each gill grows fister on its upper side than on its lower side and thus gradually enres downwards, so that a large part of it eomes 
to look once more directly toward the earth. The rate and the amount of the reaction depend upon various eonditions, particularly on the stage of development of the fruit-body and the amount of the tilt. The younger the gills and the smaller the tilt, the quicker and more complete is the readjustment in a vertical plane. An expanded Mushroom was placed so that the plane of the pileus was vertical, and those gills which most nearly occupied horizontal planes were then looked at edgewise with a horizontal microscope. The reaction to the stimulus of gravity

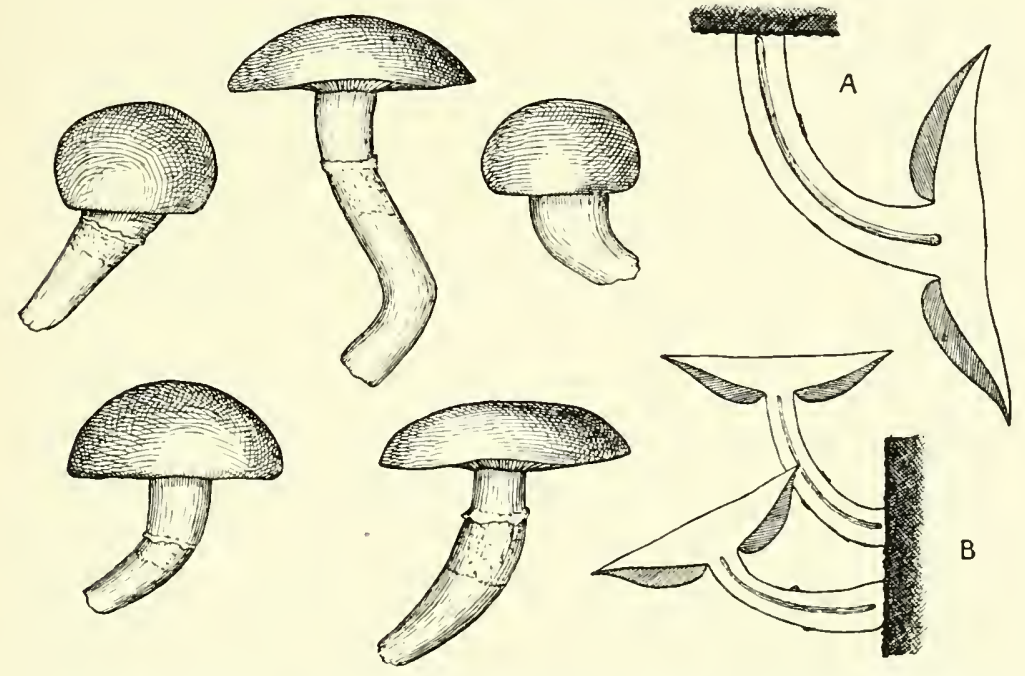

FIG. 17.-Psalliota campestris. Adjustment of the pileus by geotropic curvature of the stipe. A, Mushroom grown upside down in a pot. B, two Hushrooms grown laterally in a pot. To the left, five Husbrooms gathered and sketched in a field. All $\frac{1}{2}$ natural size.

was found to begin in about an hour after the fruit-body had been gathered and tilted. After two hours the downward enrvature of the free edge of the gills was marked and could be detected with the naked eye.

When the plane of a Mushroom pileus has not been tilted up to an angle of more than about $30^{\circ}$, all the gills can adjust themselves again so as to take up vertieal positions. This is permitted by the provision of a suffieient margin of safety in their spacial arrangement. ${ }^{1}$ When, however, the tilt exceeds a certain amount,

${ }^{1}$ Cf. Chap. II. 
some of the gills crowd one another unduly, and only a few of the highest have room to turn so as to give themselves the chance of successfully liberating spores. Some Mushrooms which had undergone symmetrical development on an artificial bed were picked and fixed so that the planes of their pilei were set in a vertical direction. Previous to the experiment the gills looked downwards in the most perfect mamner, and the undersides of the pilei presented the appearance shown in Plate IV., Fig. 25. After being placed in their new positions the gills soon reacted to the stimulus of gravity and attempted to make the usual adjustment. Howerer, owing to the fruit-bodies having been tilted through an angle of $90^{\circ}$, this could not be successfully accomplished. A photograph of the pilei, as they appeared at the end of the experiment, is reproduced in Fig. 18. It will be seen therefrom that only a very few gills at the top of each pileus remained separated from one another. These liberated a few spores, which settled on the upper sides of the extreme tops of the stipes. The rest of the gills had become so crowled that they covered one another up. It is not surprising, therefore, that practically no spore-deposit accumulated on paper placed immediately below the pilei.

It seemed of interest to find out to what extent the stipe of a Mushroom is capable of undergoing curvature when the pileus has been placed by artificial means in a very unfavourable position. Accordingly, some Mushroom spawn was planted in large pots containing horse manure covered with soil. After a few weeks fruit-bodies duly made their appearance, but before they had attained the size of peas their position was altered. Some of the pots were suspended upside down and others fixed horizontally on their sides. The soil was kept in place by the careful use of sticks and wire netting. Under these conditions the fruit-bodies continued to grow, and the stipe of each made an attempt to place the pileus in the usual position. Where the pots had been inverted the attempt proved to be almost a complete failure (Fig. 1\%, A), but where the fruit-bodies grew out from the soil laterally it was attended with a large measure of success (Fig. 17, B). Had the fruit-bodies in the latter instance been larger and of more vigorous growth, probably the success would have been somewhat greater. 
It is evident, however, from these experiments that the stipe of a IIushroom has but small powers of making geotropic curvatures

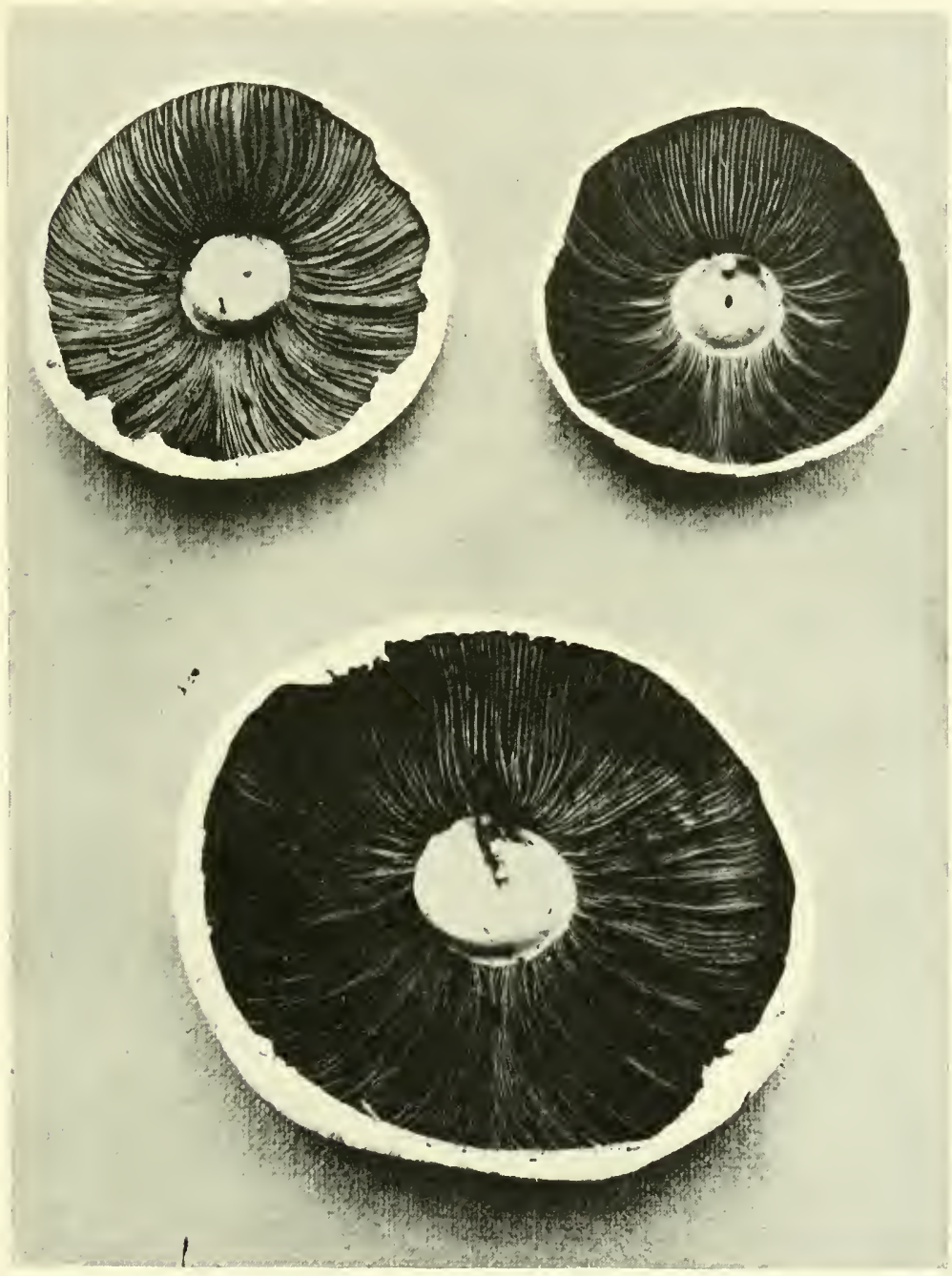

Fig. 18.-Psalliota campestris. Geotropic reaction of the gills. The pilei were fixed with their planes in a vertical position. In the course of about twenty-four hours the gills, in attempting to readjust themselves in vertical planes, took up the positions shown in the photograph. Natural size.

when compared with that of Lentinus lepideus, or those of species of Mycena, Psathyrella, and Coprinus, \&c.; but owing to the fact 
that the pastures where Mushroms grow are always nore or less horizontally disposed, large eurvatures are quite unnecessary. As a matter of fact, in extreme cases in the field, the needs of the pileus can be fully met when the stipe bends through an angle of only about $45^{\circ}$ (Fig. 17, to the left).

It seems probable that the position of the pileus at its origin is simply determined by the direction of the stromatous strand, upon the end of which the fruit-body coneerned comes to be developed. However this may be, there can be no doubt that, as soon as the pilens and stipe have become differentiated, the direetion of further growth of the fruit-body (excluding meehanical resistance offered by grass, ie.) is entirely controlled by the stimulus of gravity; and it is to this, and to this alone, that a Mushroom owes its characteristic position in the field. The stipe, when not yet $2 \mathrm{~cm}$. long, becomes negatively geotropic in a zone just below the pileus flesh: whilst subsequently the gills, after partial development, place themselves very exaetly in rertical planes by growing toward the earth's centre.

When Mushrooms come up in fields the mechanical resistanee offered by the herbage often hinders the stipe, when young, from bending straight upwards. As the stipe gets longer and longer the pileus becomes pushed more and more into freedom. When this has been attained the stipe simply grows direetly upwards, but evidence of its early struggle is still left in its eurved or zigzag form ( $(f$. Fig. 17).

Werner Magnus' observed that when a Mushroom comes up on a sloping bed so that it eatches in the mantre and has to push up against it, the stipe becomes unusually long whilst the pileus remains small. He also found that when a young pileus is prevented from expanding by means of a ring of gypsum, its growth practically ceases and the stipe attains a quite abnormal length. This peculiar correlation in growth between pileus and stipe in nature probably sometimes helps to determine the form of Mushrooms, for these occasionally are to be found pushing their way

1 W. Magnus, "Ueber die Formbildung der Hutpilze," Archiv für Biontologie, 13d. I., 1906, p. 104. 
up against soil, grass, or dung, de., in such a manner that considerable resistance is offered to the free expansion of the pilei. The chief effect of an unusual lengthening of the stipe upon a fruit-body as a spore-produeing organ, eonsists in increasing the chances of the pileus being raised to such a height that it becomes freed from obstacles and ean suecessfully liberate its spores.

Light gives rise in a Mushroom neither to a heliotropic nor to a morphogenic reaction. I have been unable to detect any heliotropic curvatures of the stipes of fruit-bodies grown on artificial beds of horse manure, and a speeial experiment with wild Mushrooms also gave negative results. Eight pieees of turf, containing Mushrooms in an early button stage of development, were taken up from a field and placed in a room in such a way that the buttons were well lighted on one side and in strong shadow upon the other. However, the stipes grew up vertically and exhibited no signs of bending toward the source of light. That Mushrooms do not give a morphogenie reaction to illumination may be deduced from the fact that they develop in form equally well in a perfectly dark cellar and in a sunlit field.

The development of the fruit-bodies of Lentinus lepideus is controlled by light and gravity in suecession, whilst those of Psalliotu cumpestris react to gravity alone. This difference seems to me to be eonnected with the diversity in the habitats of the two species. Lentinus lepideus is a wood fungus. T'he orientation of the surfice of its substratum is indefinite, and may be most varied in respect to the fruit-bodies. Response to both light and gravity under these eireumstanees is, as already explained, of distinct advantage. On the other hand, Prolliota compestris is a ground fungus. The orientation of its substratum is in so far definite that the surface is on the average horizontal. This being so, when a fruit-body has once begun to form on the surface of the ground, a negative geotropic reaction alone is sufficient to enable the stipe to raise the pileus and bring it into the optimum position. Hence, we find that the developinent of the Mushroom is regulated from without simply by the stimulus of gravity. No advantage would be gained by sensitiveness to light, and indifference towards it is therefore easily understood. 
The adjustments by which the hymenial surfaces are placed in the optimum position for spore-liberation in the Mushroom are no less than four in number, and may be summed up as follows: (1) Turning the pilens into an erect position by an upward curvature of the stipe: (2) raising the pileus several centimetres above the ground by growth in length of the stipe; (:3) placing the gills with their long axes horizontal by an expansion of the pilens (Fig. 19): and (t) setting the platmes of the gills in hori-
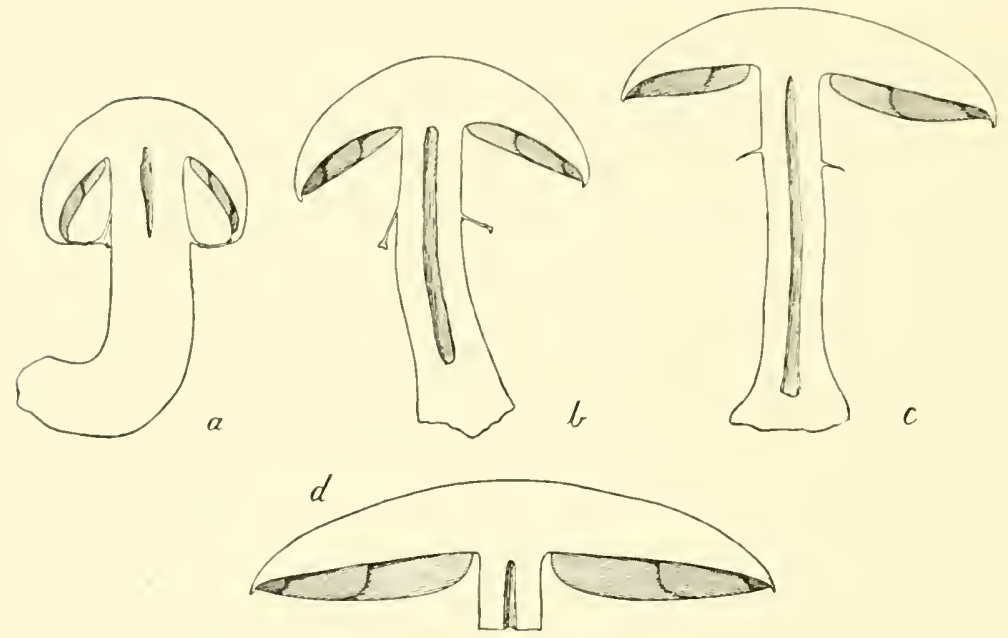

FIG, 19. - Psalliota wrinsis. a-d, sections of four fruit-bodies showing successive stages in the raising of the gills into a horizontal position by the explansion of the pileus. At $a$ the gills are still enclosed in the large gill chamber. All $\frac{1}{2}$ natural size.

zontal positions by the turning of the gills themselves about their directions of attachment to the pileus flesh. Whilst the erection of the pileus and the turning of the gills-coarse and fine adjustments respectively-are controlled by the external stimulus of gravity, the raising of the pileus and its expansion are, doubtless, due to internal developmental forces alone. Proof of the latter statement seems to be afforded by the fact that Mushrooms can elongate their stipes and expand their pilei when growing upside down in the dark ( $f$. Fig. 17, A).

Polyporus squamosus. ${ }^{1}-P$. squemosus, the Great Scaly Poly-

1 (f. Buller, "The Biology of Polyporus squumosnes, a Timber-destroying Fungus," Journ. of Eronomic Biolnyy, 1906, vol. i. pp. 101-138. 
porus or Saddle-Back Fungus, is one of the best known European species of tree-destroying fungi, and it is also found in the United States and Canada. Its large ochraceous fruit-bodies, checkered with brown scales above, are frequently to be seen projecting as brackets, either singly or in groups, from trunks and branches of living trees in woods, parks, and gardens (Figs. 1 and $4-7$, pp. 8 , 28, 29, 32., and 39; also Plate V.).

For the purpose of studying the development of the fruit-bodies under special conditions, several logs which had been half destroyed by the mycelium were procured and removed to an experimental greenhouse. As this was conveniently provided with a dark-room, it was possible to grow the sporophores in total darkness as well as in ordinary daylight.

When the mycelium of the fungus is about to produce fruitbodies, it grows out on to the surface of the tree trunk or branch, usually at a place where the bark has been removed. It there forms a more or less rounded, but somewhat irregular, stromatous knob of firm eonsisteney (Plate V., Fig. 36). When this knob has reached a certain size and is less than twenty-four hours old, one, or usually several, bluntly conical processes arise upon it, grow straight outwards from its surface, and thus come to point in different directions in space (Fig. 21, A; Plate V., Figs. 31 and 37). The development up to this point takes place about equally well under all conditions of light. It is noticeable, huwever, that the knobs produced in darkness are quite white and smooth, whereas those arising in full daylight are somewhat brown and scaly.

When fruit-bodies develop entirely in the dark, the conical processes on the stromatous knobs grow outwards into long sterile, finger-like columms which are usually curved or twisted, frequently flattened toward their ends, and in many cases branched. In the course of three weeks, vigorous fruit-bodies may attain a length of $15 \mathrm{~cm}$. and come to resemble a stag's horn (Fig. 20). The branches grow at their apices only; their ends are pure white, whilst the older parts become deep black, like the base of the stipes in fruit-bodies developed in daylight.

The horn-like processes just described appear to be unaffected, 
in respect to their direction of growth, by both gravity and light. The branches grow in the dark in curves which take the nost

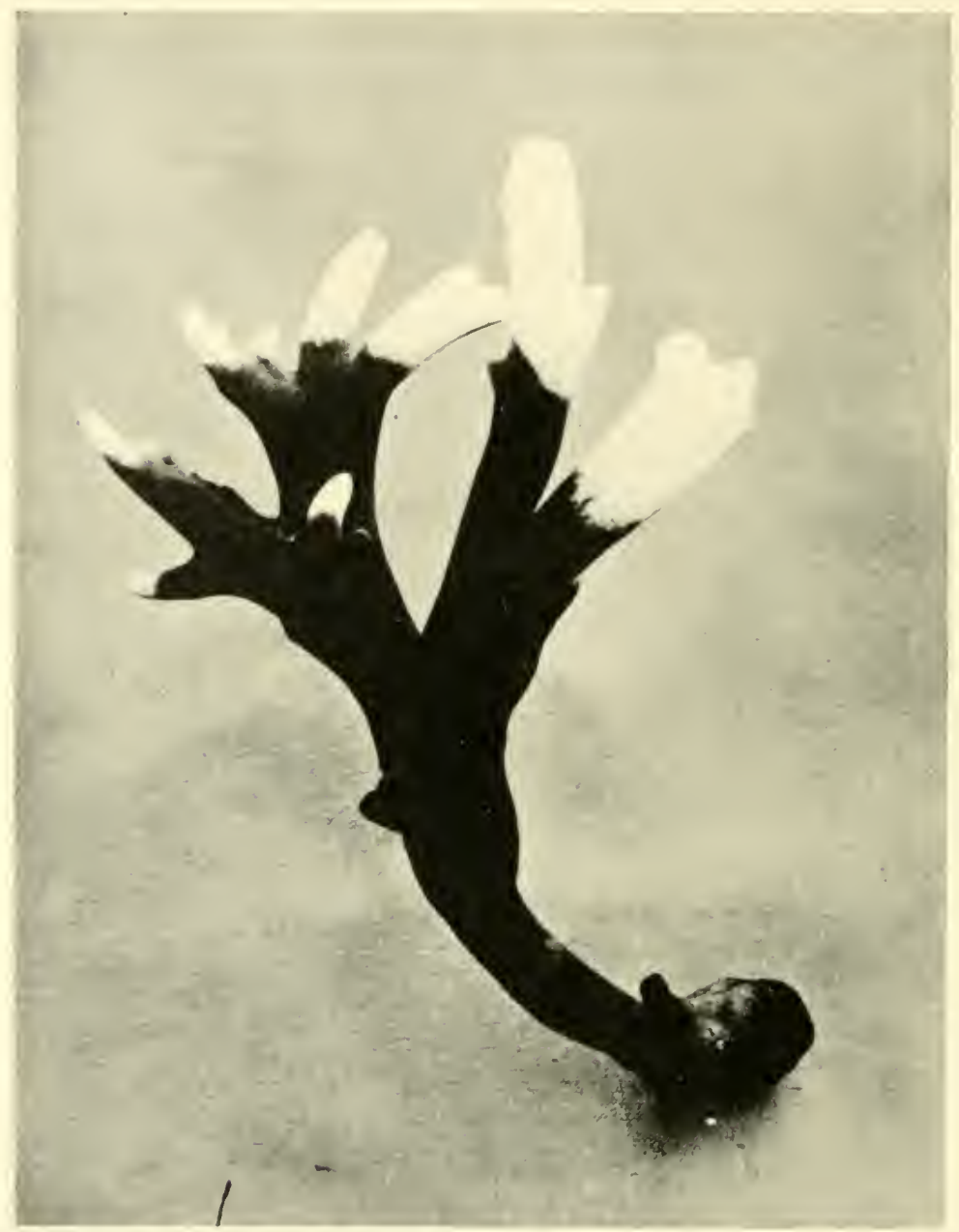

Fis. 20. - Fruit-borly of Polyporus squemosus developerd on a log in entire absence of light, three weeks old. It is branched and sterile: there are 110 signs of a pileus. Cf. Figrs. 1, 1, and 5. Roluced to $\frac{2}{3}$ natural size.

varied directions in space, and show no definite indications that they are either positively, negatively, or transversely geotropic.

light from a small hole cut in the dark-room door was allowed to fall obliquely on to the log upon which some almost fully 
developed sterile fruit-bodies were growing. After varying the intensity of the light considerably and extending the experiment over many days, I was unable to detect any change in the direction of growth of the branches in response to the illuminating rays. In being unprovided with heliotropie properties, the sterile fruitbodies of Polyporus squamosus present a marked contrast with those of Lentinus lepideus.

The formation of the pileus is brought about entirely by a morphogenic stimulus of light. To this kind of stimulus the young fruit-bodies (although not the older sterile ones) are remarkably sensitive, for, when some of them were temporarily exposed to daylight for only a single hour and then replaced in the dark-room, they subsequently produced pilei.

In the development of a pileus, light is only of real importance in the very initial stages. Some fruit-bodies were grown on a $\log$ in ordinary daylight. When they were about two days okl and the pileus on each was yet in a most rudimentary condition, the $\log$ was placed in the dark-room. The fruit-bodies, thus shut off from all illumination, continued their development, attained it considerable size, prorluced hymenial tubes, and liberated millions of spores. Light therefore appears to give a sutticient morphogenie stimulus to a fruit-body within a comparatively few hours after the latter has come into existence. It unlocks developmental forces which, when once set free, become independent of the liberating agent.

In the light, the ends of the conical processes after Hattening or becoming depressed, quickly expand to form small pilei (Fig. 21, B and C; Plate V., Figs. 32 and 33). That part of a process which bears the pileus we shall now refer to as the stipe.

The stipe owes its position in the first instance to accident. However, it quickly becomes negatively geotropic and makes an upward curvature so as to bring the top of the pileus into a horizontal plane (Fig. 21, D). When this has taken place the pileus becomes diageotropic, and now expands rapidly in a direction parallel to the earth's surface (Fig. 21, E; Plate V., Figs. 333 and 34). Subsequently hymenial tubes develop on its under surfice; they are positively geotropic and grow vertically dowuwards. These 
diverse geotropic phenomena were elucidated by placing very young or half-grown fruit-borlies in the dark, tilting them out of their normal positions, and watehing their development. In the alsence of light, stipes eurved upwards, hymenial tubes grew downwards, and the pileus flesh extended itself horizontally (Plate V., Fig. 41).

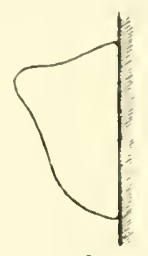

A

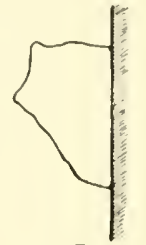

B
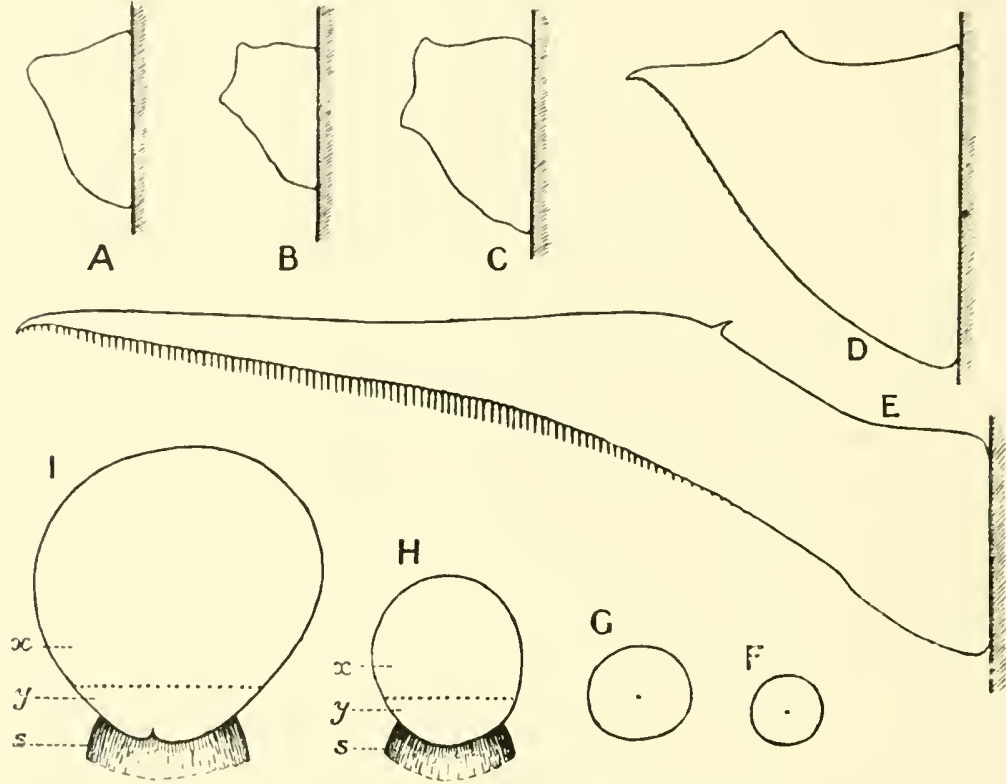

Fir. 21.-Polyporus squamosus. The embrtolngy of fruit-borlies with eccentric pilei. A-E, vertical sections showing successive stages in development. A. a stromatous knob upon which a conical process has arisen. $\mathrm{B}$ and $\mathrm{C}$ show the origin of the pileus by depression and lateral expansion of the tip of a conical process. At D the stipe has made a geotropic curvature so that the top of the pileus has become almost horizontal. The pileus has now hegun its eccentric development. $\mathrm{E}$ is a fully-grown fruit-body. Its pileus is very eccentric and has developed hymenial tubes. F-I, young fruit-boties seen from above. The pilei $F$ and $G$ correspond 10 those seen at $\mathrm{B}$ and $\mathrm{C}$. H, a young fruit-body in which an antering half of the pileus, $r$, may be distinguished from a posterior half, $y$. The stipe, $s$, is laterally placed as at D. I, a young fruit-borly in which the anterior balf of the pileus, $A$, is growing rapidly, whilst the posterior half, $y$, has ceased development. $s$, the stipe. All $\frac{1}{2}$ natural size.

In most fruit-bodies the stipe is lateral (Fig. 4, p. 28), in a few more or less eccentric (Plate V. Fig. 426), and in rare instances quite eentrally situated, like that of a Mushroom (Fig. 22). An attempt will now be male to account for this remarkable variability of form. 
The shape of the pileus seems to be partly decided by the direction of the conical process upon which it develops. When a conical process happens to point vertically upwards (as it very rarely does), the stipe to which it gives rise is vertical and the

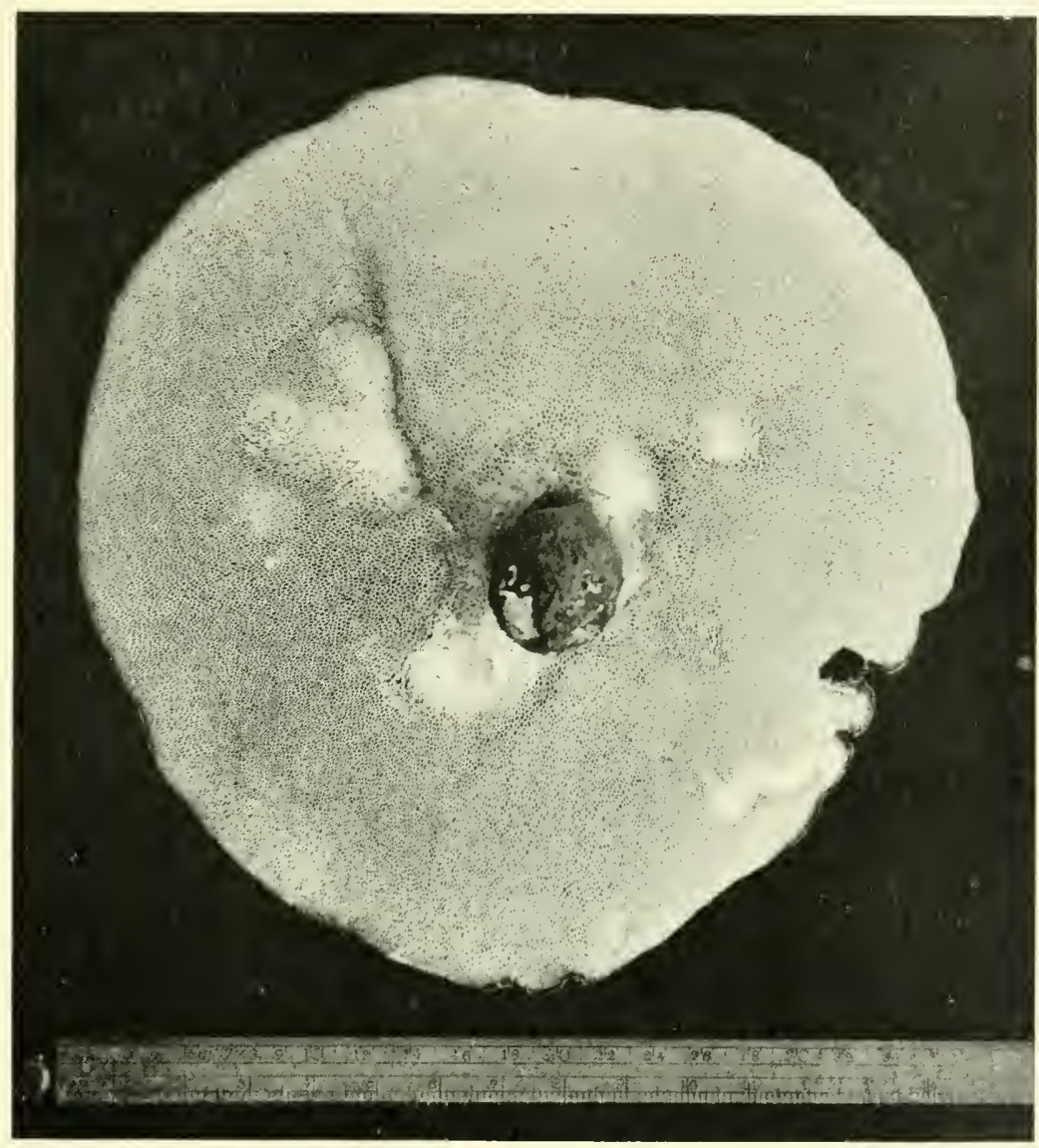

FIC. 22. - Polyporus squumosus. Under surface of a large fruit-body with a central stipe. $\frac{1}{4}$ natural size.

pileus horizontal from the moment of their differentiation (cf. Plate V., Fig. 35). Under these circumstances, since the internal developmental forces are symmetrically disposed, the pileus simply grows at an equal rate all round its periphery. In response to a diageotropic stimulus, it spreads itself out in a horizontal plane. 
When the fruit-body lecomes full-grown, it thus comes to have an mubrella shape like that of an upright, expanded Mushroom (Fig. 2-2). On the other land, if the axis of the conical process upon the stromatoms knob happens to be inclined upwards, let us suppose at an angle of $45^{\circ}$, then the fruit-body at its origin is obliquely set (Fig. 21, B: Plate V., Fig. 32). The young stipe receives a directive stimulus from gravity and grows faster below than above. It therefore gradually bends upwards and only stops this movenent when the top of the pileus has been turned into a horizontal position (cf. Fig. 21, D). We may suppose that a morphogenic stimulus of a special kind is conducted to the pileus from the stipe whilst this is making its geotrojic curvature. As a reaction to this stimulus the pileus undergoes a physiological change: its developmental forees become reorganised. It can now be said to have two distinet halves differentiated from one another. One of them may be referred to as anterior in position and the other as posterior. 'The former is always the half which is furthest away from the bise of the stipe and the latter the one nearest to it (Fig. 2̌1, F-I). The anterior half undergoes rapid and considerathle expansion, but the posterior half soon discontinues its development. In the mature frut-body, in this instance, the pilens has a milateral position like that shown in Fig. 4 , p. 2s, and in Fig. 21, E. Slightly eccentric pilei are formed when their stipes at the begiming happen to be nearly vertical but not quite. The less oblique the stipe, the less will be the physiological differentiation indueed by the stipe in the two halves of the pileus, and the more nearly in the end will the fruit-boly approach the Imbrella form. If the foregoing correctly represents what takes place during development, it follows that the form of a firitbody is indirectly controlled by gravity. The radial symmetry of the pilans is only interfered with when the stipe has responded to a greotropic stimnlus. The degree of eccentricity of the one part seems to be proportional to the amomnt of anvature mudergone by the other part.

Since the milateral pilei of fruit-bedies growing on the trunks of trees are directed away from the trunks or branches, one might be inclined, without investigation, to think that this is due in part to 
the effect of light. However, it was found that when very young fruit-bodies which had just formed pilei in the light were placed in various directions in the dark-room, they continued their development and took up situations relatively to their substratum similar to those observed in nature (Plate V., Fig. 41). Both the position assumed by, and the degree of symmetry of, a fruit-body are governed by gravity alone. However, there can be little doubt. that light exerts a tonic influence upon the pileus during its development. When a half-grown fruit-body which had been exposed to. light in the open for about a week is placed in the dark so that the plane of its pileus is vertical, the flesh grows sharply through a right. angle at its upper margin, and thus the new part takes up a position parallel to the earth's surface. In this case the diagcotropisn of the pileus is very marked. If a very young fruit-body which has developed in the light for only two or three days (cf. Plate $V$., Figs. 32 and 33 ) is set in darkness, the pileus often grows obliquely upwards for some time and its diageotropism is but poorly displayed (Plate V., Fig. 42, $f$ ). If, in response to a light stimulus of about. an hour's duration, a pileus develops upon a branch of a stag's-hornlike structure which is still growing vigorously and is looking upwards, it becomes trumpet-shaped in the dark (Plate IV., Figs. 40 and $42, d$ and $e$ ). If it responds to the stimulus of gravity at all, it. only gives an obliquely geotropic reaction. On the other hand, a symmetrical pileus grown throughout in daylight has a very flat top. and is evidently strongly diageotropic (cf. Fig. 4, p. 28, and Plate V., Fig. 40). It thus appears that the geotropic reaction of the pileus flesh is partly determined by the amount of illumination to which a fruit-body is exposed.

When a stag's-horn-like structure has grown for two or three weeks in the dark, and has almost attained its full extension, it can be caused to form patches of hymenial tubes on its under surface by exposure to sufficient daylight (Plate V., Figs. 38 and 394). The branched fruit-body thus produced presents a remarkable contrast with such normal ones as are found on trees.

A feebly developed, trumpet-like fruit-body which arme to maturity in weak light $(\cdot f$. Plate V., Fig. 40) produced hymenial tubes both on the lower and the upper surfaces of its pilens (Fig. 2:3). A 
similar disposition of hymenial surfaces has been observed in nature hy others for Hydnum rependum. 'Two fruit-bodies of Polyporus varius which were recently lrought to me, had a quite normal appearance exeept for the firet that very shallow hymenial tubes had developed on the tops of the pilei. The canse of the formation of these monstrosities still remains to be elueidated. The abnormal pileus of $P$. squemosus first of all developed hymenial tubes on its under surface. As it continued to enlarge it gradnally fell by

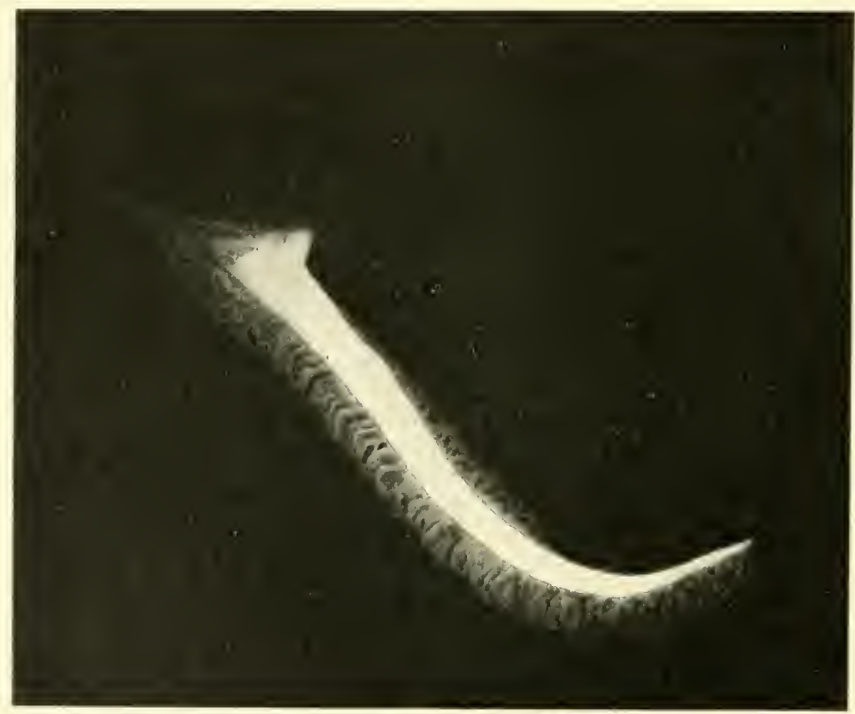

FIG. 23.-Polyporus squamosus. Section through part of a pileus with hymenial tubes on the upper as well as on the lower surface. About $\frac{2}{3}$ natural size.

its own weight, until on one side its plane looked downwards at an angle of abont $45^{\circ}$. At this stage a new layer of tubes grew upwards in an irregular manner on the pilens top. It seems likely that the unusual displacement of the fruit-body in some way initiated this development.

Owing to their wonderful power of undergoing unilateral development, the fruit-borlies of Polyporus squemosus are admirably adapted for securing a successful liberation of their spores. The hymenial tubes come to look downwards upon an open space as far from the tree trunk as possible, and the stipe is so placed that it 
cannot hinder the fall of the spores, or their dispersion by the wind.

We may now sum up the adjustments made in a developing fruit-body by which the hymenial surfaces are placed in the optimum position for spore-discharge. They are five in number: (1) Slight raising of the pileus by growth in length of the stipe; (2) placing the top of the pileus in a horizontal plane by a curvature of the stipe; (?) growth of the pileus parallel to the earth's surface; (t) growth of the pileus with a symmetry suited to the position of the stipe; and (5) the downward growth of the hymenial tubes. The first of these adjustments is doubtless due to internal developmental causes alone, but the other four are controlled by gravity.

A firuit-body of Polyporus squemosus owes the origin of its pileus to the stimulus of light, and in addition it responds in four different ways to the stimulus of gravity. On the other hand, a MLushroom is indifferent to light and has only two reactions to gravity. The difference between the two species in the number of responses made to external stimuli is correlated with the fitct that the one fungus grows on a tree and the other on the ground. In each case the dependence on external forces seems to be of the simplest kind to meet the requirements of the environment in a successful manner.

Coprinus plicatilis.-The small fruit-bodies of this species were found coming ${ }^{11}$ p on a lawn. A single specinren with its surrounding turf was taken indoors, and immediately placed on its side in the position shown at $a$ in Fig. 24. In order to prevent too rapid transpiration, the turf was sprinkled with water and covered with an inverted glass dish. In two hours the plane of the pileus had been turned by the stipe through an angle of $60^{\circ}(b)$, and in three hours it had become almost horizontal $(d)$. To my surprise, however, the stipe continued its curvature for an hour, until the pileus had become tilted quite $20^{\circ}$ too much $(f)$. It then began to bend back again, and in the course of a further hour the pileus was returned for the second time to its optimum position $(h)$. The curvature of the stipe, however, still continued, and became overdone to the extent of about $15^{\circ}(j)$. Again the stipe rebent itself, and for the third time the pileus became erect $(m)$. After this the stipe overdid its curvature 


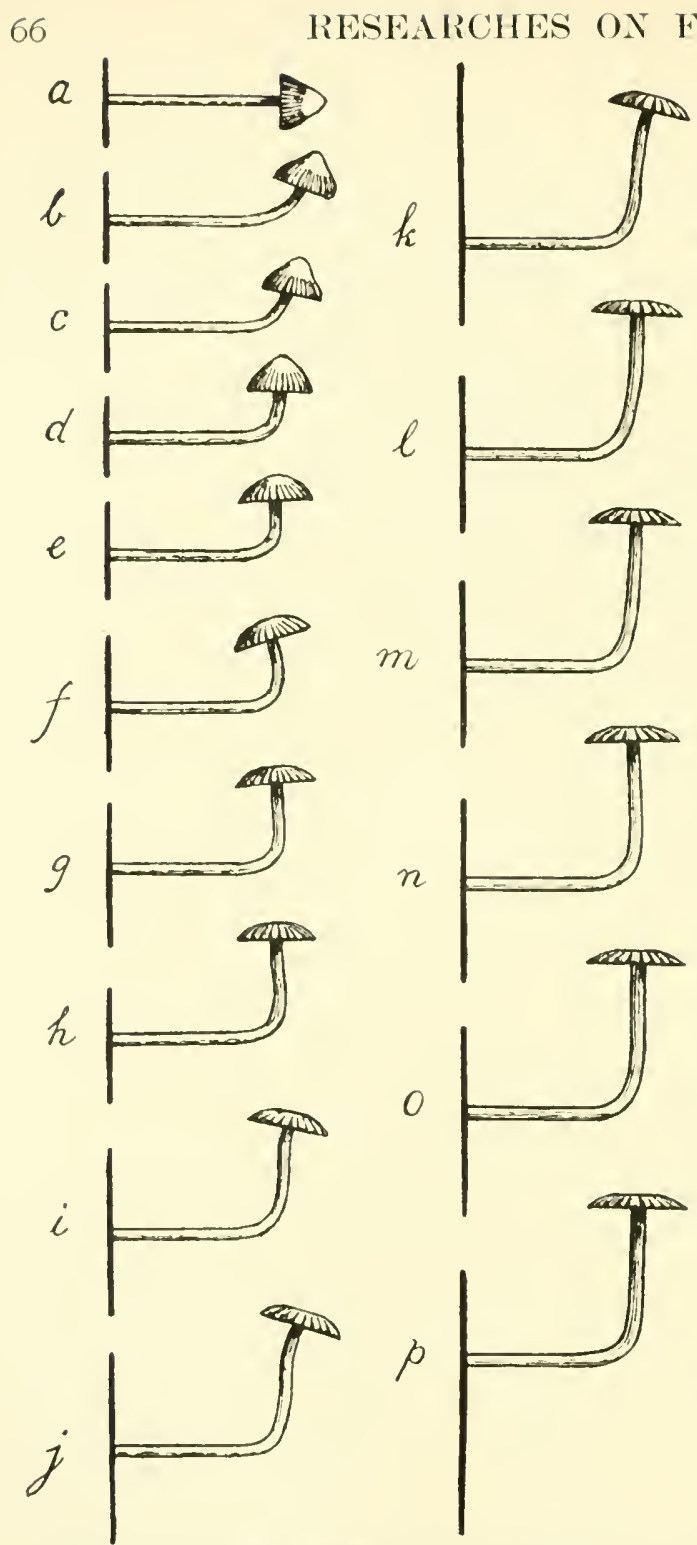

FIn. 24.-Coprinus plicatilis. Feotropie swinging and aujust-

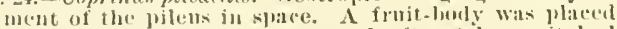
in the boxition shown at $a$, and after 2 hours it hasl assumed the position slown at $b$. The skotehes $b-0$ were male lu snceession at intervals of b:alf-in-hour. $p$ was

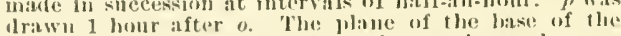
pileus lecane horizontal aftor 3 hours $(d)$, much orer. tilted after thomrs $(f)$, a rain lourizoutal after 5 hours $(h)$, much over-tilted ayin after $6-6.5$ hemrs $(j$ and $k$ ), arain lorizontal after $7 \cdot 5$ hours, very sliehtly over-tilted for the last time after 8 lomirs $(n)$, and finally horizontil after s.5 lowrs (o). The loorizontal josition was still matintained af (or 9.5 hours $(y)$. Natural si\%e. 
menon of geotropic swinging will be recorded in connection with an account of Coprinus plicutiloides.

The adjustments of a fruit-body of Coprinus plicatilis, by means of which the successful liberation of the spores is secured, are three in number: (1) The erection of the pileus by the bending of the stipe: (2) the raising of the pileus by elongation of the stipe; and (3) the adjustment of the gills by the expansion of the pileus. 'The gills do not appear to be positively geotropic. Not only are they small in size, but they split from above downwards in a manner peculiar to many species of Coprinus. When the pileus expands, they open out like the folds of a parasol. It is clear that the hymenium is sufficiently adjusted to a suitable position by the curvature of the stipe and the expansion of the pileus. A reaction of the gills to gravity, like that which occurs in the Mushroom, would be quite unnecessary. The relations of the fruit-bodies with light were not investigated.

For the Coprini generally, there appears to be an absence of geotropic response in the gills. This peculiarity is correlated with a very special mode of spore-liberation which will be described in detail in Chapter XIX.

Coprinus niveus. - This species is eoprophilous, and is frequently found in the autumn upon horse dung in fields. The fruit-bodies which are snowy white, make their appearance at any place on the free surface of the dung balls. At first they are strongly heliotropic and with unilateral illumination simply grow toward the source of light. This heliotropie response enables the stipes to push their unexpanded and conical pilei outwards between, or from under, the dung balls into the open. Growth toward the source of light continues until the stipe is some $3-4 \mathrm{~cm}$. long. Shortly before the pileus begins to expand, the top of the stipe ceases to be heliotropic and becomes negatively geotropic: it makes a new curvature and grows vertically upwards. This adjustment causes the whole pileus with its gills to be placed in the requisite position for the successful liberation of spores. Some horse dung obtained from a field was set so that the fruit-bodies found growing upon it looked directly upwards. The oblique light from a window caused the stipes to make a heliotropic curvature (Fig. 25, to the left). Afterwards, when the 
pilei began to expand, the stipes ceased to grow toward the window, but instead grew vertically upwards. On the right side of Fig. 25 is shown the same group of fruit-bodies as on the left after twelve hours' further development. By comparing the figures, the change
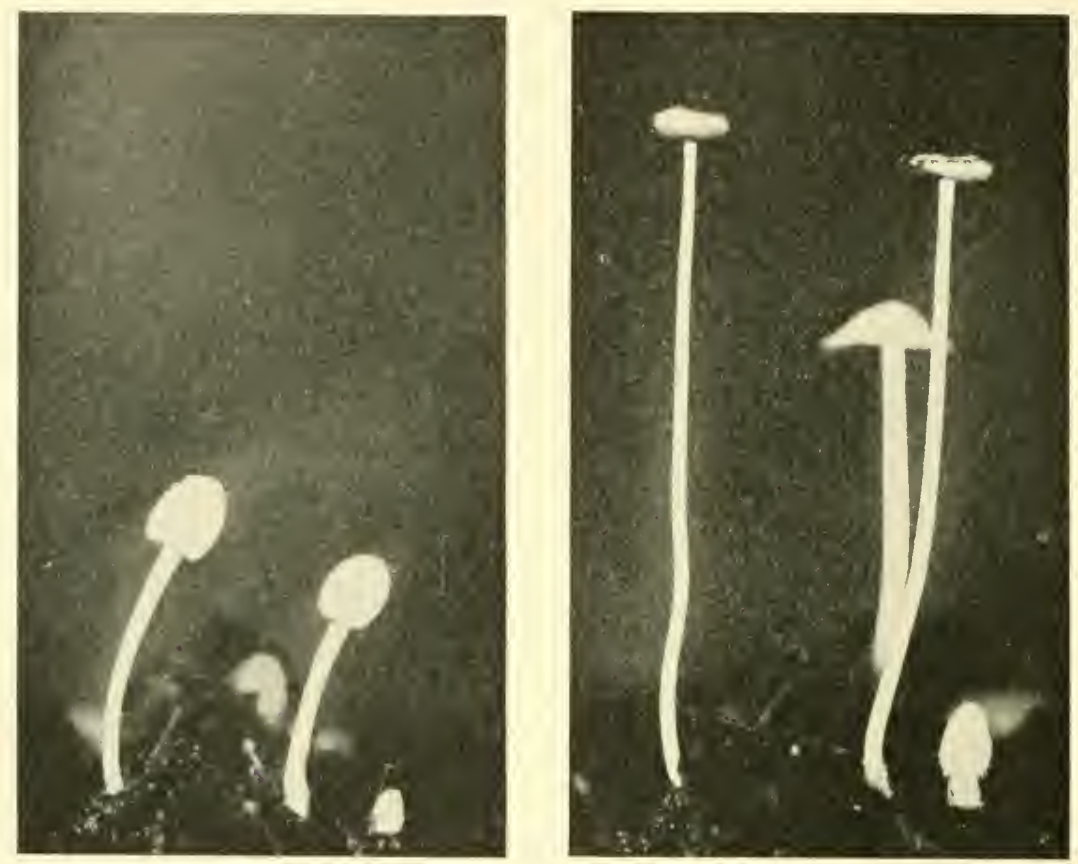

FIG. 25.-Coprinus niveus. Adjustments of the pileus in space. The fruit-bodies grown on horse dung received unilateral illumination from a window. The young stipes, as shown on the left, made heliotropic curvatures. On the right the fruit-borlies are twelve hours older than on the left. As soon as the pilei began to expand, the stipes, in response to a geotropic stimulus, grew vertically upwards. Stages in the raising of the pilens by elongation of the stipe, and in the expansion, auto-digestion, and rolling up of the pileus are also to be seen. Natural size.

which took place in the lirection of growth of the stipes mat be readily realised.

The expansion of the pileus separates the gills from one another, and causes the hymenimm to look downwards in a manner similar to that deseribed for Coprinus plicrtilis. Here, again, the gills do not require to adjust themselves in rertical planes by means of a geotropic stimulus. The part pliayed by the "deliquescence" of the gills and the folling of the pileus rim orer the top of the pileus 
in the process of spore-liberation will be sufficiently discussed in Chapter XIX.

'The adjustments of the fruit-bodies of Coprinus nivens in the interest of successful spore-liberation may be summed up as follows: (1) Heliotropic curvature of the stipe, which causes the pilei to be brought out of crevices in the substratum into the open; (2) erection of the pileus by a negatively geotropic curvature of the stipe; (3) raising of the pileus by elongation of the stipe; (4) adjustment of the gills by the expansion of the pileus; and (5) deliquescence of the gills and the folding of the pileus rim over the top of the pileus.

Coprinus plicatiloides, Buller. ${ }^{1}$ - This species, like the foregoing one, is coprophilous and occurs on horse dung. Its fruit-bodies are often very tiny and rank among the smallest in the whole group of the Agaricinee. I have seen specimens less than $1 \mathrm{~cm}$. long and with the expanded pileus only $2 \mathrm{~mm}$. wide. The average length of the stipe is about $3 \mathrm{~cm}$. and the width of the pileus about $5-6 \mathrm{~mm}$., but in large individuals, produced on sterilised horse dung, these dimensions may be doubled. The fruit-bodies are extremely delicate and can only stretch their stipes and expand their pilei under very moist conditions. When exposed to moderately dry air they wither up in a few minutes. The life-history of the fungus requires but little time for its completion. Some sterilised horse-dung balls were infected with spores and kept in a warm room. On the tenth day after infection young fruit-bodies made their appearance, and by the fourteenth day spores were being freely liberated.

The fruit-bodies of $C$. plicutiloides react in succession to the stimuli of light and gravity in the same manner as those of C. niveus. One evening, a fruit-body which had begun to grow vertically upwards from its substratum was covered over with a cap of stanniol paper opened at one end (Fig. 26, A and B). During the night the upward growth continued. Next morning, in response

1 This name has been given for the sake of convenience in reference. The fungus was obtained at Winnipeg. I have not been able to identify it with any described species, but it much resembles Coprinus plicutilis. Its disc is depressed at maturity, as in C.plicutilis, but it is narrow instead of being broad. The gills are not attached to a collar, and the spores are oval. 
to unilateral illumination, the stipe made a positive heliotropic curvature, and oblique growth toward the souree of light went on all day (C and D). When darkness supervened, the stipe still continued to grow in the direction it had taken up during the previous day. Toward moming on the next diay, it gralually curved vertieally upwards, thereby indicating that it had become geotropically sensitive. After the stipe had been growing away from the earth's centre for about three hours, the pilens expanded in a horizontal plane and discharged its spores (E). Spore-discharge lasted for about an hour and a half. Soon after its completion the fruit-body
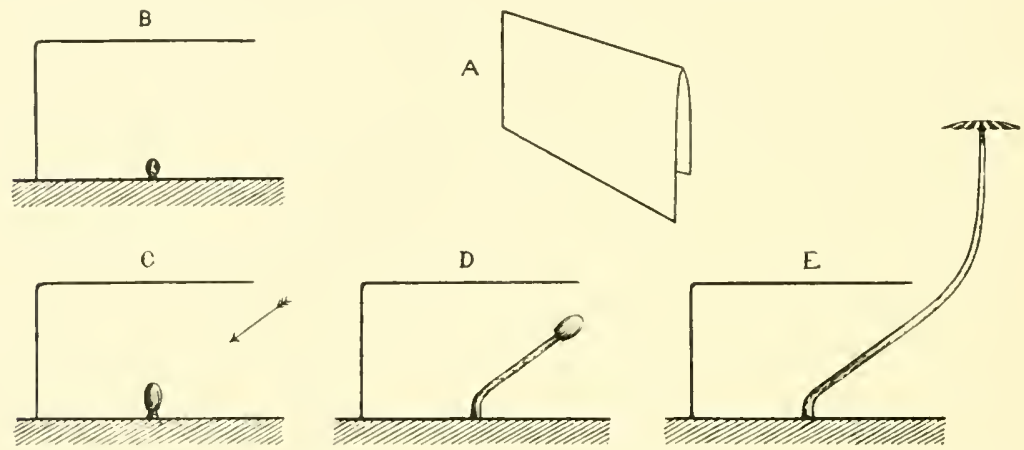

FIG, 26.-Coprinus plicatiloides. Avoidance of an olsstacle by successive reactions to the directive stimuli of light and gravity. A, paper eap shown in $\mathrm{B}-\mathrm{E}$ in section. B, young fruit-body covered with the paper cap on the afternoon of the first day. C, the fruit-body at daybreak on the second day : the arrow shows the direction of the chief incident rays of light. $\mathrm{D}$, the fruit-body at the end of the second day. E, the fruit-boty abont noon on the third day. Natural size.

collapsed. The suceessful avoidance of an obstacle and subsequent uplifting of the pileus, as illustrated by the experiment just reeorded, affords excellent evidence of the biological importance of the reactions of the fruit-body to external stimuli.

In order to test the sensitiveness of the stipe to the stimulus of gravity, a vertical fruit-borly, attached to its dung ball, was tilted into a horizontal position. A distinct reaction was noticed in about 10 minutes, and the pileus was raised into the erect position again in 1 hour 15 minutes. By using specimens a little less developed, a greater sensitiveness was observed: the plane of the base of the pileus was turned from the vertical to the normal horizontal position 
in 45 minutes. After further practice in handling the material and in making observations, I found a fruit-body which curved upwards through a right angle in $17 \cdot 5$ minutes. It gave a distinct macroscopic reaction to the stimulus of gravity after 3 minutes' stimulation, turned through an angle of $10^{\circ}$ in the first 5 minutes, and through a further angle of $80^{\circ}$ in the next 12.5 minutes. 'The pileus, therefore, was turned through almost a complete right angle with an angular velocity greater than that of the minute hand of a clock. This angular velocity is far greater than that known for any Phanerogam or, indeed, any other plant when stimulated by gravity. For a stem to turn upwards through a right angle several hours are usually required, whereas, as we have seen, the stipe of Coprinus plicutiloides can perform this movement in 17.5 minutes. The latent period for roots-the time required for the commeneement of curvature after continuous geotropic stimulation-is, according to Moiseseu, ${ }^{1}$ who experimented on Lupinus albus, Cucurbita, \&c., at least 15 minutes when one observes with the naked cye. On the other hand, the stipe of the Coprinus made a distinct eurvature in 3 minutes. The remarkable rapidity of the geotropic reaction in the fungus is comparable with the reactions of tendrils to the stimulus of touch. ${ }^{2}$

Moisescu ${ }^{3}$ states that with the microscope he could detect a slight downward eurvature of certain roots after one minute of stimulation. In an experiment in which a fruit-body was tilted to an angle of $45^{\circ}$ and the stipe supported on a rest so as to prevent its initial sagging from the weight of the pileus, a distinet upward curvature was observed with a horizontal mieroseope of low magnifieation in one and a half minutes. Probably further experiments

${ }^{1}$ Moisescu, "Kileine Mitteilung ̈̈ber" die Anwendung des horizontalen Microskopes zur Bestimmung der Reaktionszeit," Ber. d. deutschen bot. Gesell., Bd. XXIII., 1905 , p. 366.

2 The movements of very sensitive tendrils in certain species are even more rapid than that observed for the stipe. Thus, after rubbing the inner side of a tendril of a Cucumber and placing the rubbed surface in contact with a stick, I observed that the tendril made a half-turn round its support in five minntes, a whole turn in ten minutes, and one and a half turns in twenty minutes. The temperature was $85^{\circ} \mathrm{F}$. 'The mean angular velocity of the tendril for the first ten minutes was 36 times greater than that of the stipe, althongh after twenty minutes it had become only 5.5 times greater.

${ }^{3}$ Moisescu, loc. cit. 
would show that the latent period for the fungus stipes is quite as short, if not shorter, than that for roots.

Already, in describing the adjustments of Coprimus plicutilis, we have beeome aequainted with the fact that a stipe which has been displaced from a vertical position performs a series of geotropic oscillations before again coming to rest. A similar phenomenon oceurs with Coprimus plicutiloides, but in this species the oscillations sometimes take place in surprisingly short intervals of

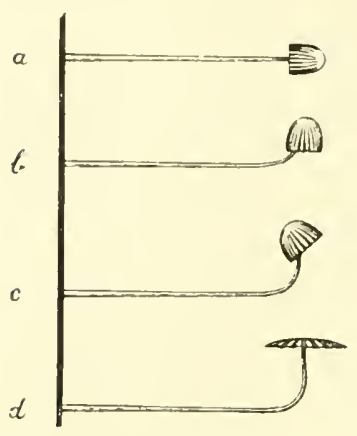

FIG. 27.-Geotropic reaction of the stipe of Coprinus plicatiloides. The fruitbody was displaced from a vertical to a horizontal position, $a$. $b-d$, subsequent positions of the fruit-body : $b$, after 1 hr. li) mins.; $c$, after $1 \mathrm{hr}$. 4.) mins.; $d$, after about 3 hrs. 15 mins. The tilt of the plane of the base of the pileus, shown at $c$, was $41^{\circ}$. Natural size. time. In one experiment a fruit-borly was moved from a vertical to a horizontal position whilst the stipe was rapidly growing in length (Fig. 27, (1). The plane of the base of the pileus became turned upwards through a right angle in 1 hour and 15 minutes $(b)$. However, the curvature of the stipe was continued for half-an-hour until the pileus plane had become tilted up to a maximum angle of $41^{\circ}(c)$. The stipe then began to make a reverse curvature, and in the course of an hour and a half gradually regained its vertieal position. Its oscillatory movements then ceased. The pileus, which at this stage had already become partially expanded, then spread itself out in a horizontal plane and liberated its spores (d). It seems somewhat remarkable that, in the attempt to bring the pileus into its optimum position for liberating the spores, althongh the first geotropic reaction was so renarkably overdone, the second should have resulted in such complete success. The second adjustment was aceompanied by, and probably affeeted by, the opening of the pileus.

The most interesting case of geotropic oscillations was observed with the already mentioned very sensitive fruit-body which turned upwards through a right angle in 17.5 minutes after displacement. The stipe executed no less than five oseillations about its normal position (Fig. 28). The successive geotropic supracurvatures were $28^{\circ}, 8^{\circ}, 3^{\circ}, 1^{\circ}$, and $0^{\circ}$. The swing past the normal position in each 
oscillation was therefore about one-third of the previous swing up to the normal position. Each suceeeding ascillation was made in less time than its predecessor, and the whole series of movements was completed in an hour and a quarter. In making observations upon the amount of eurvature, advantage was taken of the fact that the plane of the base of the pileus, viewed horizontally, appears as a straight line ( $c f$. Fig. 2 7 ). The tilt of this line was measured by placing a sliding lever parallel to it, and then reading off the

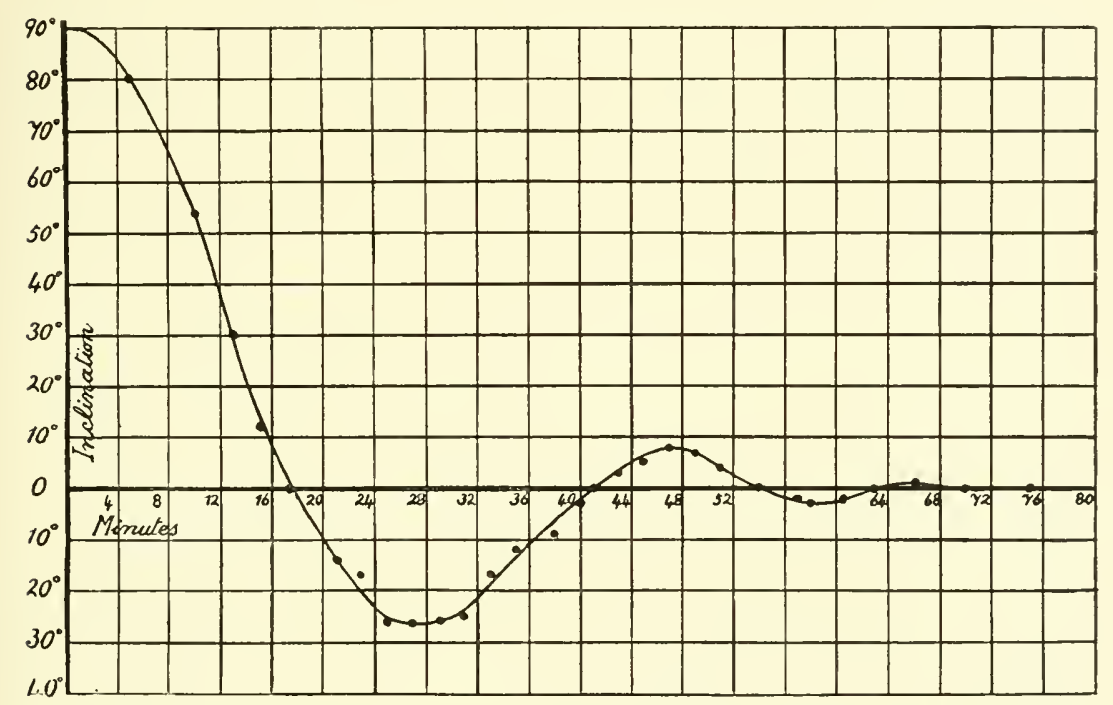

Fic. 28.--Results of observations on the movements of a fruit-body of Coprinus plicatiloides about its normal position in response to the stimulus of gravity. The fruitbody at the beginning of the experiment was turned from a vertical into a horizontal position. The ordinate gives the inclination of the axis of the end of the stipe to the vertical in degrees and the abscissa the time in minutes. The curve drawn through the observation points shows that the fruit-body executed a series of damped oscillations.

deflection from a horizontal plane by means of a surveyor's protractor. Since the axis of the end of the stipe is always perpendicular to the plane of the base of the pileus, the divergence of the latter from the horizontal gives the divergence of the former from the perpendicular. The fruit-bodies, attached to their horsedung balls, were kept in a covered glass vessel in order to prevent loss of moisture. The laboratory temperature was $20^{\circ} \mathrm{C}$. The deflections of the stipe from the vertical at successive periods of 
time are plotted ont in Fig. 28. The resulting curve is one of damped oscillations, roughly resembling that of a pendulum swinging in a viscous medium. Some of the results plotted do not lie on the curve. I bave reason to suppose that this is due not to irregularities of growth, but to errors in making the observations. Greater aceuracy, doubtless, would have been obtained if an assistant had recorded times whilst I recorded angles, but, unfortunately, in the absence of help, it was necessiry for me to make the two sets of measurements by uyself. Both alertness and correctness of judgment are required in order to place a sliding lever parallel to the pileus plane. Practice, however, enables one to make the necessary readings with considerable precision.

In the development of the fruit-bodies in my laboratory an undoubted periodicity was observed. A few fruit-bodies expanded each morning and shed their spores during the mid-day hours, usually between 12 and :3 o'elock. In properly cared for cultures I could never find fruit-bodies opened at night. Successive crops of matme fruit-bodies were thus produced with a diurnal rhythm. A similar rhythen is well-known for Pilobolus: and in Ascobolus a few asei ripen and burst each day. The stretehing of the sporangiophore of Pilobolus, and of a group of asci in Ascobolus, is put off until morning, so that light may be used to direct the growth of these heliotropic struetures toward an open space. If the orientation of the fungus gums were to take place at night, its successful aceomplishment would be simply a matter of chance. In Coprinus plicatiloides the stipe is too massive a structure to be fully developed in one morning. Its partial elongation and curvature toward an open space in response to the stimulus of light, take place on the day previous to spore-discharge. On the next morning it creets the pileus in response to the stimulus of gravity. It is clearly of advantage that the stipe shall begin to elongate in the daytime rather than at night, for the first requisite for the successful functioning of a fruit-body is that the pileus shall be brought into the open. The rhythmic derelopment of the fruit-bodies of all the three eoprophilous fungi seems, therefore, to be of distinet inportance in ficilitating the seattering of the spores. 
A diurnal rhythm in the development of the fruit-bodies of small and ephemeral Coprini occurs not merely in the laboratory but also in nature. I have noticed it more particularly in the case of Coprinus plicutilis growing on a lawn. A few fruit-bodies came to maturity toward each noon for a succession of 20-30 days. Worthington Smith ${ }^{1}$ noticed the same phenomenon for Coprinus redictus growing on a manure heap. He states that "at seven or eight in the evening nothing but immature plants can be seen; about eleven or twelve a rapid growth commences, and by two or three o'clock in the morning perfect maturity is reached. If the morning is moist the plants will remain in perfection till nine or ten o'clock, but if it is dry they will not last after five or six." According to these observations, in nature the fruit-bodies of Coprinus ratictus may shed their spores before daylight appears. If this is so, strong support is given to my view that the importance of the periodic development lies, not in spore-liberation occurring at any particular time, but in the fact that the beginning of the stretching of the stipe is arranged to take place whilst light can be used as a directive stimulus.

The adjustments of the fruit-bodies of Coprinus plicutiloides in the interests of spore-liberation may be summed up as follows: (1) Heliotropic curvature of the stipe, which causes the pilei to be brought out of crevices in the substratum into the open; (2) erection of the pileus by a negatively geotropic eurvature of the stipe; (3) raising of the pileus by the elongation of the stipe; and (4) adjustment of the gills by the expansion of the pileus. There is no deliquescence of the gills, and on this account the fruit-bodies of Coprinus plicatiloides have one adjustment less than those of Coprinus niveus.

General Remarks. - A number of otherwise very different coprophilous fungi resemble one another in reacting to light. Thus we find that positive heliotropic curvatures are made, not only by the stipes of the Coprini, but also by the sporangiophores of Mucor, Phycomyees, and Pilobolus, by the asci of Ascoboli, and by the perithecial necks of Sordarie. These responses to light are admirp. 54.

1 W. Smith, "Reproduction in Coprinus redicetus," Grevilleu, vol. iv., 1875-76, 
ably adapted to permit of organs of reproduction, which are produced on an irregularly disposed substratum, liberating their spores, so that they may freely escape from their place of origin.

Probably all the coprophilons Coprini are heliotropic, sinee they all grow on the same peculiarly irregular substratum. However, Coprinus comutus, which comes up on turf in fields, \&ce, appears to be without response to light. When the fruit-bodies receive milateral illumination, the stipes do not make a heliotropic curvature (cf. Figs. 6?

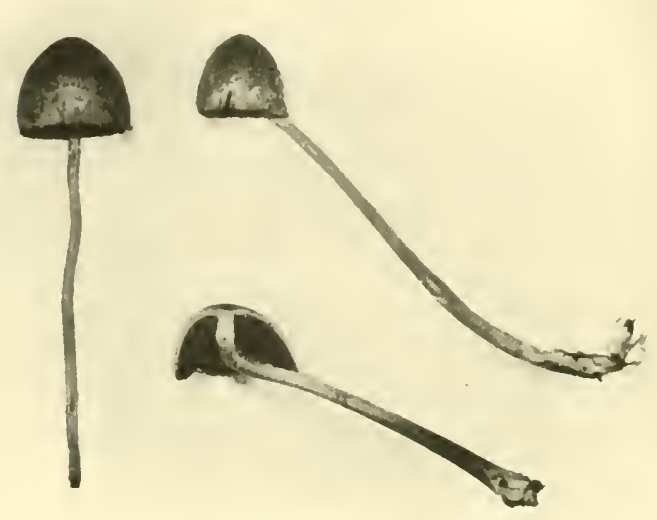

FI(: 29.-Anullarin sopurnta. Geotropic reaction of the stipe. To the left is a fruit-body of a closely allied species, Inandolus platawarum. To the right are two fruit-bodies of Andluria sejurata which resembled in form that on the left. After they had been set in oblique positions the pilei becane readjustel by curvatures made by the tops of $\mathrm{tl}_{\mathrm{u}}$ stipes. $\frac{1}{3}$ natural size. and 70, pp. 198, 199). As with the Mushroom, heliotropism would be without adrantage. The fields in which the fruit-bodies come up are on the arerage horizontally disposed. In order to raise the pilei, so that they become free from surrounding olistacles, response to the stimnlus of gravity is all that is necessary.

Anellarie seperute (Fig. ::2, p. 80)

is also coprophilons in habit, and in general form its fruit-bodies resemble those of coprophilons Coprini. In the field the stipes are usually vertical. When a mature fruit-body liberating spores is tilted, the top of the stipe is still capable of responding to at geotropic stimulus. The peculiar appearance of a full-grown fruit-hody which has been tilted and has readjusted itself is illustrated in Fig. 2"?.

On tilting the very small fruit-bodies of Omplatia fibula which are to be found on lawns, de., I have been mable to detect any geotropic response in the narrow decurrent gills. In this species, 
and probably also in certain others where the fruit-bodies are diminutive, there is only one response to gravity, namely, that of the stipe. This is sufficient to place the tiny pilei so accurately in the erect position that the gills look downwards and successful spore-liberation can take place. In larger ground Agaricinese with deep gills, e.g. the Hushroom, an extra response is requisite, numely, that of the gills themselves. The most complex of all Agaricinere in relation to gravity, doubtless, are certain large species, such as Pleurotus ostreutus (Figs. 2 and 3, pp. 22 and 23), which grow on trees and stumps. These probably have four geotropic reactions similar to those already discussed for Polyporus squemosus: (1) Negative geotropism of the stipe; (2) diageotropism of the pileus flesh; (3) eccentricity of development; and (4) positive geotropisn of the gills.

It is the rule with Hymenomycetes that the mycelium gives rise to a great many more rudimentary fruit-bodies than can possibly come to maturity. On a Mushroom bed one may often observe some hundreds of such rudiments within the space of a few square inches; and even in Polyporus squamosus the rudiments are generally at least twice as numerous as the mature fruit-bodies (Plate V., Fig. :31-34). It generally happens that a very limited number of the rudimentary fruit-bodies obtain the advantage over their fellows and commence to grow rapidly. The food supply is thus drawn to them, and the unsuccessful rudiments at once cease their development and become aborted. The production of a great many rudiments at the beginning of reproduction increases the chance that some of them will be suitably situated for successful development. In some species, it generally happens that a number of rudiments continue their development side by side, so that at maturity the fruit-bodies are more or less crowded. The crowding in Collybie velutipes, Coprinus micueens, and Amillarid mellea (Fig. 30), \&c., may become so excessive that a large proportion of the spores produced are prevented from escaping from the fruit-bodies. Such overerowding seems to be a distinct inperfection in fungus development.

We may summarise the general conclusion from the observattions recorded in this chapter as follows. 'The fruit-bodies of the 
Hymenomycetes during development execute a set of complex growth novements which are partly controlled by internal causes and partly by external stimuli. These movements are correlated with the general structure of the fruit-bodies, and with the

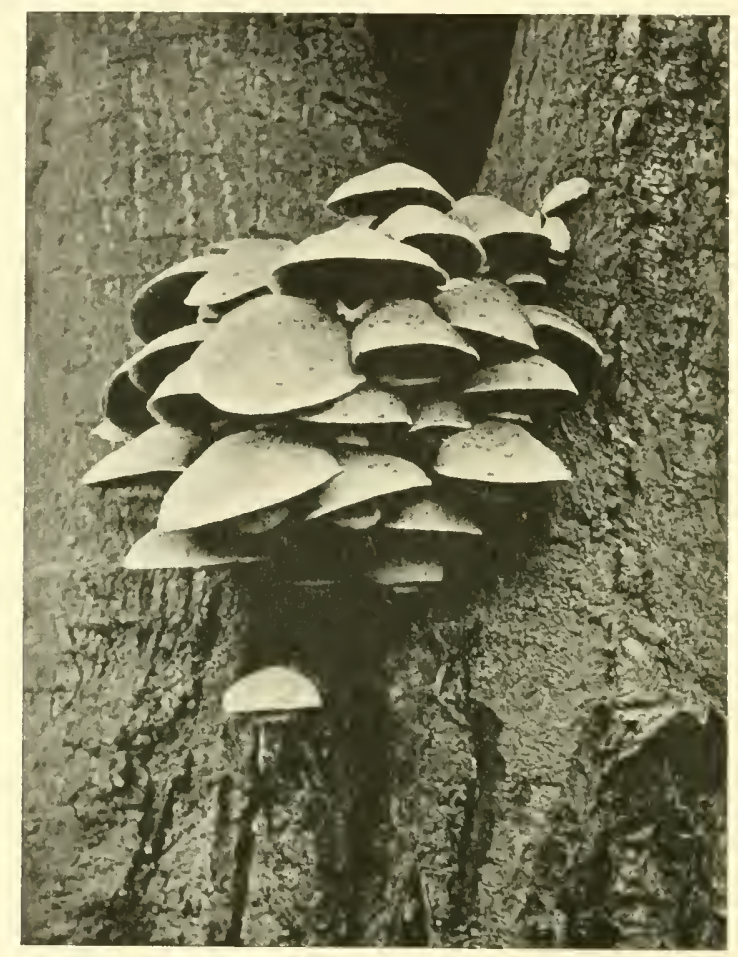

FIs. 30.-Armilleria mellece. Overerowded group of fruitbodies growing on a living Mountain Ash (Pirus A ucuperiu). l'hotographed at Sutton Park, Warwickshire, by J. E. Titley. About $\frac{1}{4}$ natural size.

position of the surfice of the substratum on which each species grows. 'The result of the movements in all cases is to place the hymenimm in such a position that it can discharge its spores, so that they may fall freely downwards into an open space from which they may be carried off by the wind. 


\section{CHAP'TER V}

\section{SPORE-DEPOSITS-THE NUMBER OF SPORES}

Although the spores of Hymenomyeetes under ordinary eireumstances are too small to he seen individually with the naked eye, yet, when collected together in large numbers, they ean readily be recognised in the form of a powder. In order to obtain a spore-deposit of this nature, one simply takes a pileus, from which

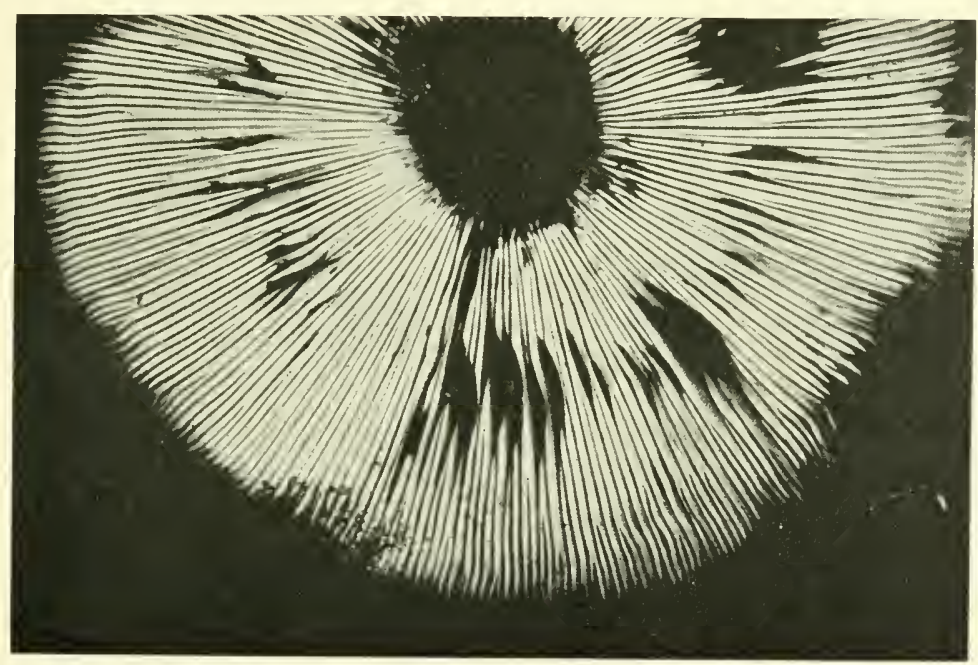

Ficr. 31.-Spore-deposit produced in about twenty hours from a pileus of Lepiotu rachodes. (The central parts of some of the gills were in contact with the paper: hence slight disturbances to the regularity of the deposit.) Natural size.

the stipe has been removed, and places it upon a sheet of paper. On this the falling spores rapidly accumulate. Owing to their pronounced adhesiveness, they eling to one another and to any surface with which they come into contact with considerable tenacity. Spore-deposits cannot therefore be shaken off paper or glass upon which they have been colleeted. 

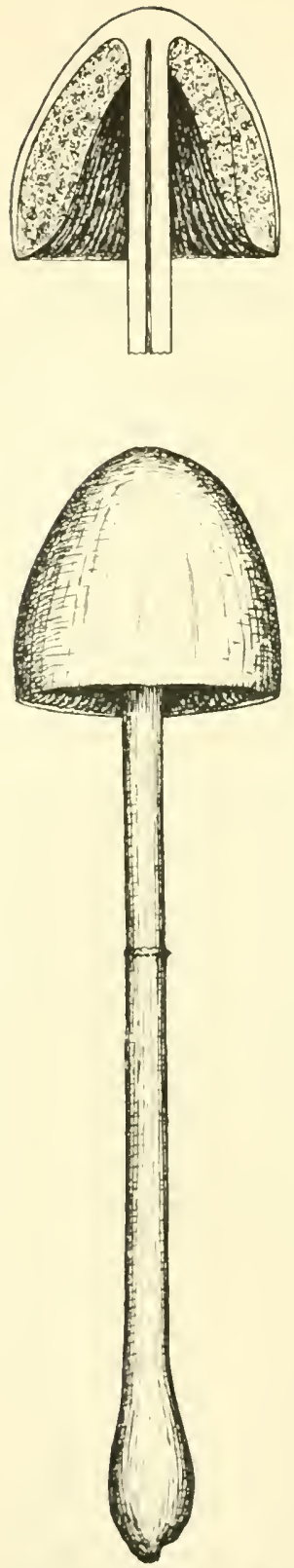

Frs. 32. - Anellaria sepa. rata. After remorill of the stipes, pilei of fruitboulies of this sureein were uned for olstininim

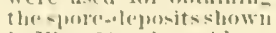
in Fiess. 33 and 38 . Alumt u:ttur:il $\times i z u^{\circ}$.

\section{RESEARCHES ON FUNGI}

In still atir, spores, after leaving the hymenial surfaces, fall vertically downwards at the rate of ahout 1-5 min. per second. ${ }^{1}$ If, therefore, one takes the precaution to eliminate small convection currents by covering the pilei placed on paper with small glass ressels, one can produce a spore print of the gills or hymenial tubes, de. such spore prints are shown in Figs. 31 and $\therefore:$ In the first one the white spores of Lepiota rachorles were collected on black palper, whilst in the second the black spores of Anollurir sepurate were collected on white paper. "The radiating spore lines correspond to spaces between the gills.

The rate of accumulation of a spore-deposit depends on various factors, such as the fungus species, age of the pileus, temperature, \&c. However, one may often obtain a reeognisable spore print in the short space of tifteen minutes (Fig. :3, A). As the spores fall continuously, usually for days together, the deposits become denser and denser as time goes on (Fig. 33, B and C). By moving a pileus from one place to another every hour and thus procuring successive spore prints, one may readily convince oneself of the continuity and regularity of spore-emission.

When a pileus is raised above the paper and spore-deposition takes place under a beaker or relitively large glass vessel, the spore-deposit no longer grives a print of the gills but lats a clondy appearance (Fig. 34,1 ). The reason for this is that the air, through which the spores fall, is not perfectly still but is undergoing slow convection movements. The spores, therefore, are unable to fill quite vertically. In Fig. : $4, A$, is shown a deposit from a pileus of Anellaria separatu raised "2 cm. above the paper. The aceumu1 Vide infra, Chaps. XV. and $\mathrm{XYT}$. 
lation of the spores took place under a large tumbler during a night. In Fig. 34, B, one sees that the gills are not perfectly outlined. In this case the rim of the pileus did not quite touch the paper all round. The pileus was exposed on a table, 1 c

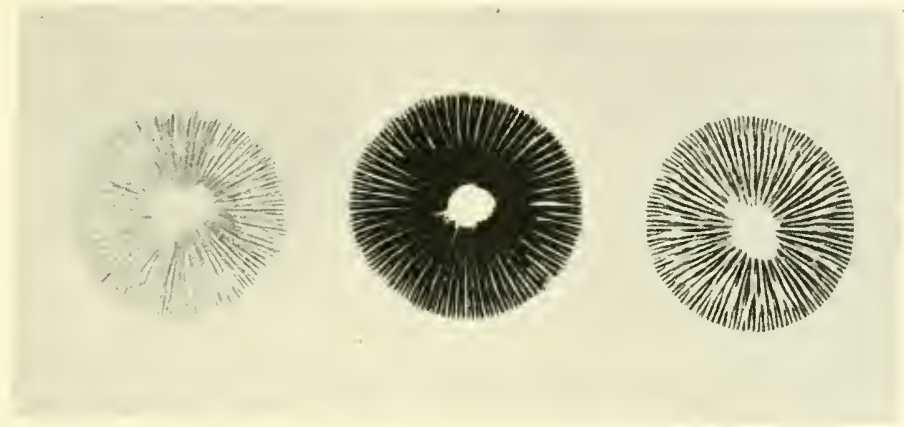

FrG. 33.-Spore-deposits from a pileus of Ancllaria sepurate. A producer in fifteen minutes, $B$ in one hour, and $C$ in six hours. l'hotographed natural size.

and therefore affected by convection currents slowly sweeping beneath it. The result of this was a slight displacement of the falling spores. In Fig. 34, C, there is shown a deposit made under a tumbler in the course of four hours from a perfect pileus, the

A

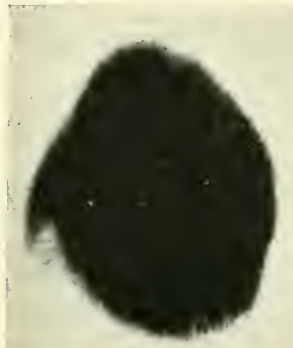

1:

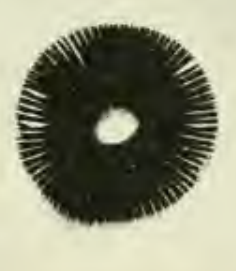

C.

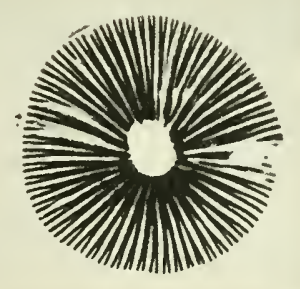

FIG. 34.-Spore-deposits from three pilei of Ancluria scparata showing the effect of convection currents. Explanation in the text. Photographed natural size.

rim of which was in contact with the paper throughout. Here the spores fell vertically downwards, and have therefore given an excellent print of the gills. If one allows spores to fall from small pieces of pilei placed in specially constructed chambers, 
designed to reduce convection currents to the least possible minimum (Fig. 58, p. 167, and Fig. 62, p. 182), spore prints of the gills can be obtained when the gills are 2)-10 cm. above the collecting surfices.

It seemed of interest to determine the number of spores liberated from a few typical fruit-bodies. It has often been stated that Mushrooms, fe., produce spores by the million. That this is no exaggeration will be elear from an account of an investigation into the number of spores produced by fruit-bodies of Psullinta campestris, Comminus comertus, Polypores squemoses, and Diedulia contingose.

Psalliota campestris. - Fruit-bodies just about to liberate their spores were obtained from a field. The stipe of one specinen was ent off, and its pileus, which had a diameter of 8 cm., was placed in contact with a sheet of white paper. A suitable covering was used to keep off ail-currents. In two days the discharge of spores appeared to be completed.

The paper containing the spores was placed in 100 ce. of distilled water, and the whole stirred rigorously until the spores had been washed off the paper and spread evenly through the fluid. A Leitz- Wetzlar comnting apparatus was then employed and the number of spores which settled on the squares carefully counted. As a result of a number of trials, it was calculated that the sporedeposit represented approximately 1,800,000,000 spores. Since all these spores fell within forty-eight hours, we must conclude that on the average about $40,000,000$ fell during each hour of the spore-fall period.

Coprinus comatus.-In calculating the number of spores in this species, a more direct method was employed than that described above. A gill of Compinus comutus can easily be split down its median plane. If, by taking advantage of this fact, one obtains half a gill and then places it in a closed compressor cell so that the hymeniun looks upwarls, one can easily observe the batsidia and spores with the microscope. They form a rery regular and striking pattern (Plate III., Figr. 15). With the aid of a drawing apparatus, it was found that the number of basidia on 0.01 of a square millimetre was 34 , where the spores were ripening. As 
each basidium bears four spores, it was calculated that the number of spores on 1 sq. mm. was 13,600 .

The fruit-body used for this investigation was a large one (cf. Plate I., Fig. 1). The pileus was $12 \mathrm{~cm}$. high and possessed 214 gills. Each gill had an area of hymenial surface on its two sides of $1800 \mathrm{~mm}$. A simple calculation, therefore, showed that each gill had produced about $24,480,000$ spores, and that the number of spores for the whole fruit-body amounted to the enormous approximate total of 5,240,000,000.1 The period of spore-discharge for large fruit-bodies of Coprinus comatus was found, by making field observations, to last about forty-eight hours. On the average, therefore, the fruit-body investigated would have shed 100,000,000 spores each hour of spore-fall.

In the Coprini it is very easy to count the basidia on the gills, for adjacent basidia on any small part of a gill are practically in exactly the same state of development, and are set at regular intervals among the paraphyses. For other Agaricinex, e.g. Psalliota campestris, this method does not succeed owing to the fact that adjacent basidia at any one time are in the nost diverse stages of development.

Polyporus squamosus.-A fresh fruit-body, which had just reached maturity, was removed from a tree and placed with its spores downwards upon a piece of smooth brown paper. Upon this, after falling down the hymenial tubes, the spores gradually accumulated in small white heaps (Plate IV., Fig. 27). A square centimetre of the paper, on which were twenty-six heaps of spores, deposited from as many tubes, was then earefully eut out and stirred up with 25 ce. of water. The number of spores in five drops of the mixture was then eounted with the Leitz-Wetzlar apparatus and, from the data thus obtained, it was ealeulated that the number of spores which had been deposited on the square centimetre of paper was $44,450,000$. On the average, then, each of the twenty-six tubes had produced 1,700,000 spores.

As a control to the above calculation, an estimate was made

1 The average length of the spores in one fruit-body was found to be $12.55 \mu$. Placed end to end, therefore, they would stretch through a distance of forty-one miles ! 
of the number of spores deposited from a single tube of the fruitbody. It was quite easy to cut out a piece of paper bearing a heap of spores of the same size as before. 'This was then stirred up with $5 \mathrm{cc}$. of water. As a result of five readings with the counting apparatus, the number of spores was found to be $1,7,0,000$, which is unexpectedly near the figure indirectly obtained in the previous calculation. Since the whole fruit-body was some $250 \mathrm{sq}$. em. in area, the total number of spores produced by it

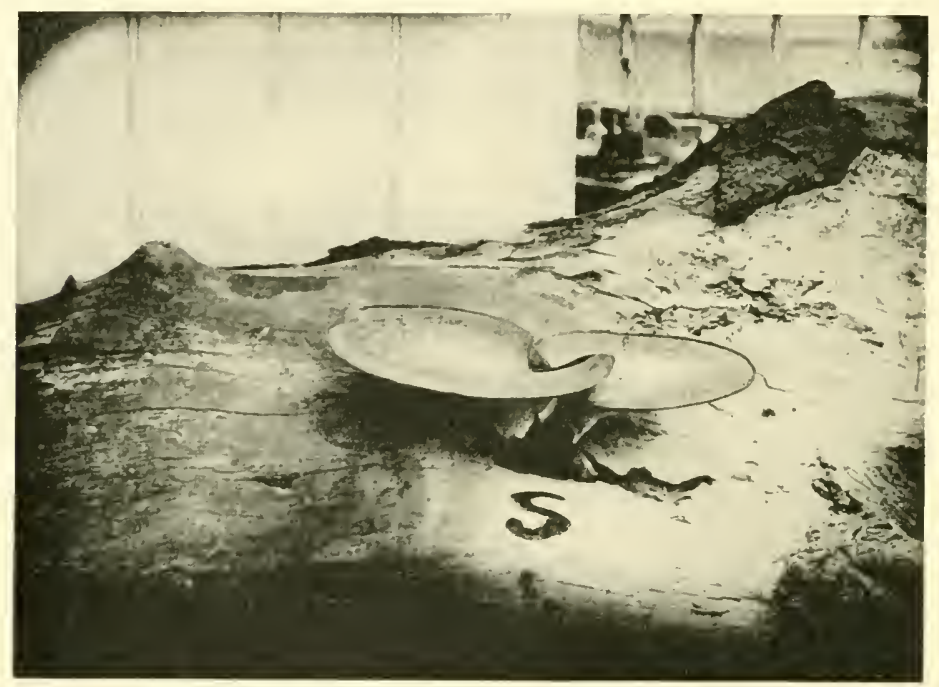

FIG. 35.-Polyporus squnmosus. Two fruit-bodies grown on a $\log$ in an experimental greenhouse. (The early stages of their development are given in Plate $V$. , Figs. 31-34.) A considerable part of the spores has setfled upon the log, giving it a white appearance. The $\mathrm{S}$ was made in the spore-deposit by rubbing with a finger. About $\frac{1}{6}$ natural size.

would be about the magnitude of $11,000,000,000$. 'The fruit-borly' in question, howerer, was only one of a group of about ten upon the same tree. The number of spores produced by a single Polyporus squamosus plant growing in a single tree in the course of a year, therefore, may exceed 50,000,000,000, and probably in some instances be not less than $100,000,000,000$.

Dædalea confragosa.-A fruit-body, about ¿- square inches in area, on being revived, ${ }^{1}$ was observed to shed a remarkably 
dense cloud of spores. These were collected in beakers and then counted. The results given in the Table indicate that the spores were liberated most rapidly during the first twelve hours, and that subsequently the rate of discharge gradually declined. After the first week, spores continued to fall for about three days longer, but they were evidently comparatively few in number and formed but a very thin spore-deposit. Their number was not estimated with the counting apparatus. The total output of spores in the laboratory may be taken as very nearly three-quarters of a billion.

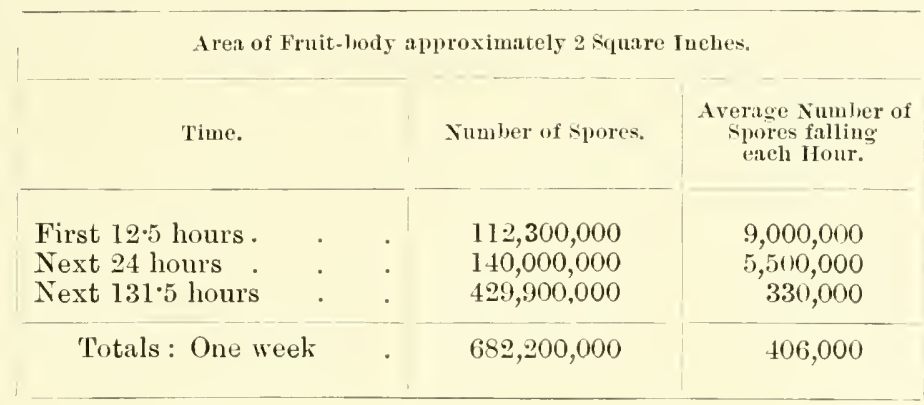

It may be of interest, for the sake of comparison with the Hymenomycetes, to mention the results of a determination of the number of spores produced by two fungi belonging to other groups of Basidiomycetes. As an arerage of ten trials with the counting apparatus, the number of spores contained within a single smutball of Tilletia caries, developed on Wheat, was found to be 12,125,000. The Mushroom mentioned above, therefore, produced as many spores as one hundred smut-balls. But numerous as are the reproductive bodies of a Mushroom, a Coprinus comatus, or a Polyporus squamosus, they pale into insignificance compared with those produced by Lycoperdon bovistu, Linn. (L. giganteum, Hussey), the Giant Puff-ball. A large, dry fruit-body of this fungus, collected by Dr. Wright Wilson and given to the University of Birningham, was found to be $40 \mathrm{~cm}$. long, $28 \mathrm{~cm}$. broad, and $20 \mathrm{~cm}$. high. Its weight was 232 grams. The peridium was removed in one place and 0.1 gram of the intemal, intact gleba carefully taken out with forceps and weighed. To this small portion of the fruit-body $250 \mathrm{cc}$. of methylated spirit were added. 
Upon being stirred, the spores beeame evenly scattered in the fluid. With the counting apparatus, as an average of several trials, the 0.1 gram of the fruit-body was calculated to contain $3,245,000,000$ spores. The whole fruit-body, therefore, was calenlated to contain $7,500,000,000,000$ spores. The fruit-body had a small sterile base and a very thin, although imperfeet, peridium, but a small part of the gleba had been lost by accident. Taking these factors into aceount, it seems fairly safe to state that the putf-ball produced about $7,000,000,000,000$ spores, or as many as would be liberated by about 4000 good-sized Mushrooms. Probably a large Giant Puft-ball which, it is said, may sometimes almost attain the dimensions of a sheep, is the most prolific organism living on our planet.

The foregoing figures will give some idea of the extrnordinary activity of a large hymenomyeetous fruit-body in producing and liberating spores. It is safe to say that a large Mushroom, Coprinu. comutus or Polyporus squmosus, liberates at least a million spores a minute, and keeps up this enormous rate of discharge for several hours or days.

Sinee it may be assumed that the number of fruit-bodies of any given species remains fairly constant from year to year, from the foregoing figures we can obtain a rough estimate for the rate of elimination of the spores or young plants by death. If from the spores of a Mushroom of Pralliota campestris only one Mushroom were eventually produced on the average, then, in aceordance with the figures obtained, it could be stated that only one spore in about 1,800,000,000 ever manages to develop into a mature plant. However, it must be remembered that each spore may produce a wide-spreading mycelium or spawn, and that this may give rise to a number of fruit-bodies. Doubtless also, in nature, the spawn is perennial and often lives for several years in turf, \&e., so that a plant which has arisen from a single spore must often produce a crop of Mushrooms annually. If, in consideration of these facts, we assume that, when a plant sueceeds in produeing fruit-bodies at all, it prorluces altogether on the average ten of them, it may be estimated that only one spore out of about $20,000,000,000$ spores 
ever succeeds in producing a Mushroom plant capable of reproduction.

Since a single large Coprinus comatus fruit-body has been shown to produce about 5,000,000,000 spores, and since the fruitbodies often occur in dense clusters together, and further, since the mycelium in turf is possibly perennial, it seems probable that successful spores do not number more than one in $20,000,000,000$ in this case also. This may well be an under-estimate. For the perennial Polyporus squumosus, which produces fruit-bodies from the same tree, often year after year for several years, it has been shown that in one case about $100,000,000,000$ spores were produced from the fruit-bodies of one plant in a single year. Since making this calculation, I have found that large fruit-bodies of Polyporus squemosus shed their spores continuously for a period of two or three weeks. When collecting the spores on the brown paper for the purpose of estimating their number, the fruit-body was only allowed to remain in position for about two or three days, for I then thought that spore-liberation would be at an end. Hence it seems that I have rather under-estimated than overestimated the number of spores produced. Taking this into consideration, and also the perennial character of the plants, each of which may penetrate through a tree trunk and produce clumps of fruit-bodies upon it in various places, it seems to me that for every spore which succeeds in developing into a mature plant prorlucing reproductive bodies, something like $1,000,000,000,000$ spores are wasted. How slight must be the chances for any given spore of Polyporus squemosus finding a suitable substratum for successful development:

Of thirteen kinds of fish investigated by F. W. Fulton, ${ }^{1}$ the ling proved to be by far the most prolitic in producing eggs. A large specimen of this species, 61 inches long and weighing $5+$ lbs., was found to possess a roe containing $28,361,000$ eggs. Doubtless this represented one year's output in spawn. Supposing that the probable length of life of a spawn-producing ling is as much as twenty years, the individual under discussion might altogether

1 "The Comparative Fecundity of Sea Fishes," Ninth Ann. Rep. Fishery Board for Scotland, 1890. Quoted from Cunningham's Marketable Marine Fishes, 1896. 
have liberated somc $500,000,000$ eggs. Of course, only a fraction of these would have been fertilised and rendered capable of developing into adult ling. We have seen that a single fruitborly of Psulliote campestris produced 1,800,000,000 spores, one of Copminus cometus i,000,000,000, and one of Polypores squemosus 11,000,000,000, and that each fungus plant has a perenuial existence and may produce several fruit-bodies each year. Hence, we may conclude that these fungi are vastly more prolific in the production of cells caprable of reproducing their species than even the most prolific kind of tish. The danger of going astray and dying of starvation or other aceident appears, therefore, to be even greater in the case of a fungus spore, when entrusted to the sportive winds, than in that of a fish's egg when set free in sea-water and left to the mercy of its currents.

Bower ${ }^{1}$ has calculated that the output of spores of a strong plant of Nephrodium Filix-mas in a single season approaches $50,000,000$. On the other hand, as we have seen, a single large fruit-body of Polyporus squemosus produces at least 10,000,000,000 spores. We may conclude, therefore, that the fungus is vastly more prolific than the fern.

${ }^{1}$ F. O. Bower, The Origin of a Land Flord, London, 1998, 1. 23. 


\section{CHAP'IER VI}

\section{MACROSCOPIC OBSERVATIONS ON THE FALL OF SPORES OF POLYPORUS SQUAMOSUS}

Frow the foregoing ehapter it is clear that enormous numbers of spores fall continuously during the spore-fall period of a large hymenomycetous fruit-borly. Nevertheless, the spores are so minute that, as a rule, one cannot observe the spore-clouds with the unaided eyes. If it were not for the exact investigation into the matter, it would be difficult to believe, when one holds up a large ripe Mushroom, that, before one's very eyes but yet unseen, a million spores fall from the gills each minute. However, a visible spore-discharge has occasionally been observed as a rare phenomenon. Thus Hoffman ${ }^{1}$ has recorded having seen sporeclouds leaving the under surface of Polyporus destructor, whilst Hammer $^{2}$ has more recently observed tiny wreaths of spores ascending to a height of 2 or 3 feet from a fruit-borly of Pleurotus ostreatus placed upon a table. Hermann von Schrenk ${ }^{3}$ states that from a fruit-body of Polyporus Schueinitsii, "the spores came off' at intervals as if they were being discharged by some force acting within the tubes." It may be remarked that, from numerous observations of my own made by the beamof-light and other methods ${ }^{4}$ on various species of Polyporese, there seems to me to be no doubt that the spores which von Schrenk observed were falling continuously and regularly by their own weight, and that the intermittent clouds were caused by tiny, irregular air-currents which swept the spores along beneath

'Hoftiman, Jahrb. für wiss. Rot., Bd. II., 1860.

2 Hammer, "A Note on the Discharge of Spores of Pleurotus ostrectus," Torreya, V., 1905, p. 146.

${ }^{3}$ H. von Schrenk, "Some Diseases of New England Conifers," Bull. 25, U.S. Dep. of Agric., 1900, p. 22.

4 Vide infra, Chap. VII. 
the fruit-body at intervals in much the sime manner as steam is swept by air-currents from the surface of hot water.

In the month of July, 1905, I was fortunately enabled to make direct observations upon the falling of the spores from the fruitbolies of Polyporus squamesus. My attention was first called to this matter by Mr. C. Lowe, the laboratory attendant. A log, produeing fruit-bodies of the fungus, had been placed in the experimental greenhouse at the Birmingham Botanieal Gardens. Going into the greenhouse one morning, it appeared to Mr. Lowe that some one had been smoking there. On looking round he observed that the "smoke" was coming from the underside of a freshly-grown fruit-body which was some 10 inches in diameter. From that morning onward until the thirteenth day, every time the greenhouse was entered (morning, afternoon, and as late as nine o'clock in the evening), the clouds of spores were observed coming off from the fungus. On the thirteenth day the elouds were very feeble at nine o'clock in the morning and ceased to be visible about an hour later. Black paper was then placed under the fruit-body and on this the white spores collected. By changing the paper at intervals, I was able to satisfy myself that the spores continued to fall in fairly large quantities for three days more. The black paper was whitened by the spores, but only very feebly on the last day. Altogether, therefore, these observations proved that the spores luad been falling continuously for sixteen duys.

The elouds of spores, which were watched by the hour against a black background, resembled the steam coming off a cup of tea or the finest tobaceo smoke. The wreaths and curls of spores appeared to originate in eddies made by air-currents in passing over the hymenial surface. Tapping the fruit-body so as to nuke it tremble did not appreciably increase or dininish the clouds of spores. The wreaths conld be made by artificial air-currents produced by movements of the hand near the fruit-body. Some of the wreaths could still be seen after they had floated awaty to a distance of two yards. The elouds were distinctly visible on a black background when they were observed at a distance of ten yards from the fruit-body.

The $\log$ upon which the fruit-body was growing was watered 
from time to time, but the air of the greenhouse was dry. It seemed of interest to find out whether or not moist air causes a diminution in the rate of spore-fall. Accordingly, the log was removed to the Hymenophyllum house after this had been so well syringed that its warm atmosphere appeared to be saturated with moisture. The spores, however, continued to fall for two hours quite as rapidly as in the dry greenhouse. Wreaths and curls of spores floated slowly away from the fruit-body. The $\log$ was then taken back to its former dry situation, where the visible fall of spores went on unabated. Ordinary variations in

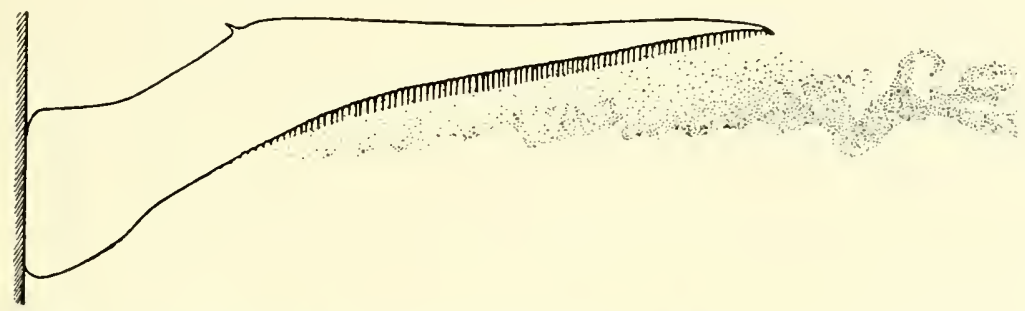

FIG. 36. - Spores leaving a fruit-body of Polyporus squamosus and being carried away by slow air movements. $\frac{1}{2}$ natural size.

the hygroscopic state of the atmosphere, therefore, do not appear to affect appreciably the fall of the spores.

Some very young fruit-bodies which just showed the earliest indications of the development of hymenial tubes were found growing upon a $\log$ of wood in the open. The $\log$ was immediately removed and placed in a dark room. Under these conditions the hymenial tubes developed in a normal manner ( $c f$. Figs. 5, 6, and 7 , pp. 29, 32, and 33), and on the fourth day abundant sporeclouds were produced. These continued to fall for eleven days, at the end of which time the fruit-body had begun to wither. The production and liberation of spores, therefore, appear to be carried on quite independently of light.

The hymenial tubes begin their development as saucer-shaped structures on the underside of the pileus. The walls of the tubes, which are positively geotropic, then grow vertically downwards for some days. By elongating in this manner, the tubes, although often shorter, may attain a length of a centimetre (Fig. 7 , p. 33). 
Their polygonal pores are shown in Fig. 6, p. 32. By making suitable sections and using the mieroscope, it was found that ripe spores were being discharged when the tubes on a young fruitbody were only $1 \mathrm{~mm}$. long. These observations lead me to suppose that, in the case of the fruit-body for which it was found that the spore-fall period lasted sixteen days, spore-emission had already been in process for about a week before the spore-clouds were discovered. Probably, therefore, in that instance the total spore-fall period extended over about three weeks.

By placing black paper beneath a ripe fruit-body for the purpose of collecting the spores, it may easily be proved that each tube emits spores continuously for several days. It may also be shown that, except for a small zone about $1 \mathrm{~mm}$. high at the mouth where no spores are developed, every part of a tube produces spores. A very large fruit-body, $2 \mathrm{ft}$. 2 in. across, was gathered from a tree and a rertical section made through the pileus (Fig. 7, p. 33). The section was placed on black paper. In twenty-four hours each half-tube had produeed a spore-deposit. The tubes were on the average about $9 \mathrm{~mm}$. long, and the spore-deposits, which were of an even character, $8 \mathrm{~mm}$. long, spores not having been produced by a zone round the tube mouths. A photographic reproduction of the deposits is shown in Plate IV., Fig. 28; and Plate IV., Fig. 22 2 , grives a spore-deposit collected from the mouths of hymenial tubes disposed on a square inch of the pileus. We may draw the conclusion from these macroscopic observations that each hymenial tube during its development liberates spores for several days from every part of its spore-producing surface.

The chicf reason why one can see the clouds of spores so easily in Polyporus squemosus is that the spores come off from the fruithodies in such vast numbers. In one case, as already stated, a single square centimetre of a fruit-body produced at the very least $44,450,000$ spores in two or three days. A spore-clond resembles a stean cloud: the whole becomes visible owing to the vast number of the microscopic constituent particles. The spores, too, are tomparatively large $(14 \cdot 6 \times 5 \cdot 1 ; \mu)$ and also colourless. They absorb very little of the light falling upon them, but reflect and refract most of it, so that they glisten. Like all other particles, the spores 
fall by their own weight in the air. Since the rate of fall in quite still air is uniform and only about $1 \mathrm{~mm}$. per second, ${ }^{1}$ whilst aircurrents and convection currents beneath the fruit-bodies have proportionately a much greater speed, which amounts, even in a quiet greenhouse, to several feet per minute, it is not astonishing that the spore-clouds appear to float away from the fruit-bodies as if they were not sinking at all.

${ }^{1}$ Vide infra, Chaps. XV. and XV1. 


\section{CHAP'TER VII}

THE DEMONSTRATION OF THE FALL OF SPORES BY MEANS OF A BEAM OF LIGH'T

ArTer I had made the observations upon Polyporess squemenses which have just been described, it occurred to me that it might be possible to see the clouds of spores falling from any hymenomycetous fungus with the aid of a sufficiently strong beam of light. Accordingly, a large Horse-mushroom (Pxolliote urensis) wats obtained and placed as a cap on an open glass box. The light from an electric are was allowed to pass through a small hole in a dark screen, and the rays were then collected and turned into a strong parallel beam ly means of a biconvex lens. The beam was then directed so that it passed through the glass box. At once a very striking and remarkable result made itself apparent. On looking at the bean of light in the box, one could see the spores floating in the air in countless thousands. It seemed as if, in miniature, a heavy brown-flaked snow-stom was taking place. Curls and wreaths of spores, formed by convection currents, were constantly proceeding from the gills, and the air in the box quickly became densely laden with spores. In the course of a few minutes the density of the spore-clond in the box became constant. At this stage, doubtless, just as many spores settled on the bottom of the box as were given off at the top by the Iushroom gills. The spores were not to be seen merely as elonds. One could elearly perecive any individual spore floating in the light, and follow its course for some distance. ${ }^{1}$ It has thus fitlen to my lot, by using a very simple method, to be the first actually to observe the

${ }^{1}$ On the same principle that one can see a star, although it has no appreciable dise, or a spider's weh in strong sunlight at a distance of several yards. One does not perceive the dimensions and slape of a spore owing to the insufficient resolving power of the eye. One is simply atware that it sends ont light. 
fascinating spectacle of millions of spores leaving the gills of a Mushroom.

It must not be supposed that the ordinary dust particles, which are always present in the air in comtless numbers, were mistaken for spores. With a concentrated beam of light it is very easy to see the dust particles. In my laboratory they are roughly of two classes: the coarser ones are comparatively rare and consist of fibrous matter, \&e, whilst the finer ones are extraordinarily numerous and doubtless of the most varied origin. The coarser particles alone can be mistaken for spores, but a very little experience is sufficient to prevent confusion. These dust particles never occur in the form of wreaths or curls, and only oecasionally float. into the beam of light. Further, they are irregular in shape and rarely affect the light in the same manner as a spore. The finer particles are distinctly smaller than spores, never so regular in size, and more numerous. They are also somewhat difficult to see individually, for they do not glisten in the light nearly so brightly as spores. It is evident, therefore, that spores and ordinary dust particles can be distinguished in a beam of light with great. ease.

After finding that the beam-of-light method could be applied with so much suceess to a Ilushroom, I made general use of it in investigating the spore-fall of a large number of other species. It has proved of great service in determining whether or not sporedischarge was taking place in any particular fruit-body, in finding out the length of the spore-fall period, and in studying the effeet of various external conditions upon spore-liberation.

It may be stated quite generally that, whenever spores are falling from a fruit-body, they can be observed with the unaided eye in a strong beam of light. So far as my experience goes, there are no species of Hymenomycetes of which the spores are too small to be seen in this macroseopic manner. Even a very slight discharge from a fruit-body may be detected. Sufficient evidence of its oceurrence is provided by a dozen spores streaning through a beam.

It was found convenient in my own department to carry out observations with the beam-of-light method in the following manner. The lecture-theatre lantern, provided with an electric are, was set 
upon a suitable wooden stand, so that the front lens was about 5 feet above the ground. To the lens was attached a black cap, in the middle of which a round aperture, one and a half inches in dianeter, had been made. $\Lambda$ bull's-eye condenser-a plano-convex lens mounted upon a stand adjustable for any position, such as is con!monly used for illuminating opaque objects-was then placed in front of, and close anginst, the aperture so that, when the are was turned on, the condenser formed a coneentrated beam of light. The chamber into which the spores were liberated usually consisted of a beaker, 6 inches high and 4 in diameter, closed above by a circular glass plate (Fig. 37). A piece of sheet cork was fixed on to the middle of one side of the plate by means of sealing-wax. A living fruit-body, to be tested, was pinned on to the cork so that, when the plate was placed on the beaker, the fruit-body had its normal orientation, the hymenial side looking downwards. The beaker was then set close in front of the condenser in the beam of light.

If a fruit-body is active, a stream of spores can be detected coming from it within a few seconds after it has been placed in position above the beam. The stream is carried slowly round and round in the leaker by convection currents. It gradually breaks up so that in a few minutes the spores are well seattered (Fig. 3i). A maximum density of spores is soon attained. At this stage as many . spores settle as are liberated. If one directs the beam of light so that it passes through the air just beneath the gills or hymenial tubes, ic., one can observe the spores slowly emerging into riew. They are then simply falling by their own weight, at the rate, in many species, of 1-2 $\mathrm{mm}$. per second. ${ }^{1}$ Convection currents sweep the spores, as they emerge from the gills, hymenial tubes, ic., slowly in one direction, and it is thus that a steady stream of spores arises. The density of the stream remains very regular for hours or even days. There is no evidence whatever that the spores are discharged intermittently. The most remarkable thing about the liberation of the spores is just its constancy for eonsiderable periods of time. An unbroken stream of spores was olserved to be emitted from the fruithodies of species of Polystictus, Lenzites, Schizophyllum, Stereum, Se., for days and in some cases for more than two weeks.

1 Tide infru, Chaps. XV. and XVI. 
The spores of white-spored species stand out in the beam of light as distinct white particles, whilst the purple-brown ones of the

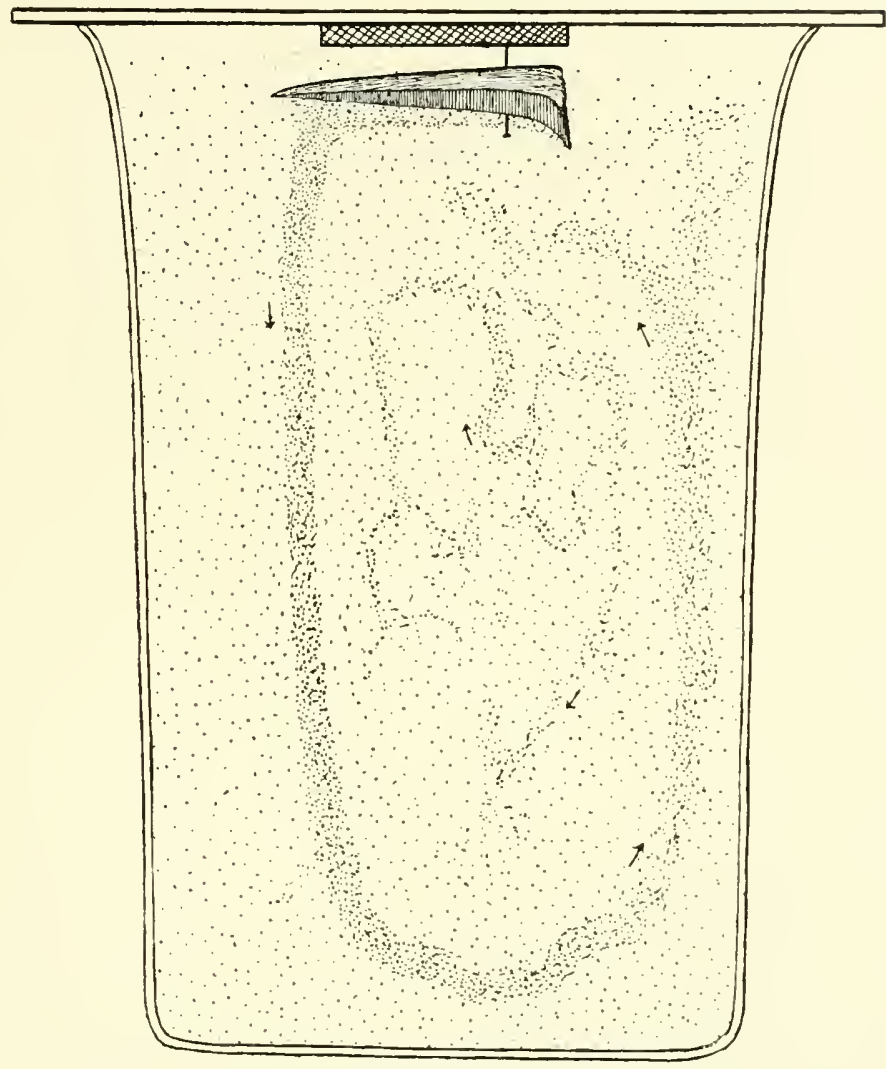

FIG. 37.-Diagram illustrating the discharge of spores from a fruit-body of Polystictus icrsicolor as seen by the beam-oflight method. The fruit-body is pinned in its natural position to a piece of cork attached to a circular glass cover placed upon a beaker. A stream of spores is carried round within the beaker very slowly by convection currents and gradually breaks up so that the spores become scatterer fairly uniformly. Reduced to about $\frac{2}{3}$.

Mushroom and the black ones of Coprini present brownish and dull metallic appearances respectively.

It has been determined, by methods to be explained subsequently, that very small spores, such as those of Collybiu dryopleild, in still air fall at the rate of about $0.5 \mathrm{~mm}$. per second, and that the very largest, such as those of Coprinus plicutilis, fall at the rate of about 
5 mmm. per second. Mushroom spores fall at a speed of about $1 \mathrm{~mm}$. per second. It is not surprising, therefore, that convection currents carry the spores romnd in the beakers for a considerable time before they settle down, and that the spores become spread fairly uniformly in the air of any small elosed chamber. In one experiment I placed a piece of a Mushroom (Psullioter errmpestris) at the top of one end of a box which was 107 cm. long, 7 mm. wide, and 1:; em. high, and which was illuminated with a parallel beam of light sent through it lengthwise. 'The spores were gradually seattered in the enelosed air. Some were even carried to within a few centimetres of the end of the box opposite to that in which the fungus bad been placed. This observation shows that very small convection currents are capable of carrying the spores orer a metre from a fruit-body in the lateral direction.

From observations which I have made upon the fall of spores in glass chambers of various sizes, it seems that convection currents are such that the spores in a sufticiently large chamber (large beakers, fe.) tend to spread themselves uniformly within its contained air, so that equal numbers of them come to neeupy cach available unit of space. Richard Falck ${ }^{1}$ observed the spore-deposits made by fruit-bodies placed in chambers provided with vertical series of small paper shelves, and he found that the shelves, even when they had been placed one above the other at short intervals, became equally covered with spore-dust. My own observations upon falling spores, made by the beam-of-light method, have enabled me to explain Falck's results in the following manner: Convection currents are usually of such strength in the chambers that the spores are noved about by them so that equal numbers come to occupy each unit of space. As a result of this, there is the same number of spores in the layer of air inmediately over each shelf. As the spores are falling by their own weight at the rate of about 1. 1 mm. per second, ${ }^{2}$ a certain number settle each second. Since the conditions for the settling down of spores over each sholf are

${ }^{1}$ R. Falck, "Die Sporenverbreitung bei den Basidionyceten," Beitring" sur Biologie der Pflan:en, Bd. IX., 1904.

2 The rate varies according to the species; of. the Table of relocities in Chap. XV. 
approximately the same, the shelves must eventually all become uniformly covered with a spore-deposit.

Falck has also called attention to the fact that, when the pilei of certain fungi are suspended in a glass chamber, one sometimes obtains curious and fantastic spore-deposits on paper placed at the bottom of the vessel. These irregular spore-deposits are in my opinion entirely due to the nature of the convection currents in the glass vessels. Observations with the beam-of-light method have taught me that, when the velocities of the convection currents are high compared with the constant rate of fall of the spores due to gravity, the spores become evenly distributed in each unit of space in the chamber, and that a uniform spore-deposit collects in consequence upon the bottom of the chamber, shelves, \&c. If, however, the spores, such as those of various species of Coprinus, are large and heavy, and fall at the rate of several millimetres per second, and if, in addition, the convection eurrents are not strong compared with this rate of fall, then we have the conditions for the formation of a localised and irregular spore-deposit at the bottom of the chamber. In general it may be stated that the appearance of any spore-deposit is decided partly by the speed and nature of the movements of the air through which the spores have fallen, and partly by the rate of fall of the spores themselves.

The pileus of a small Coprinus fruit-borly which came up on horse dung and was liberating its spores, was suspended at the top of a elosed glass chamber which was about 6 inches high, $t$ inches wide, and covered below with white paper. The chamber was placed in front of the condensing lens of the lantern. It was observed that a black spore-deposit was accumulating on the white paper along one side of the base of the chamber. After about an hour it was assumed that the chamber had taken on the room temperature. The arelight was suddenly turned on, and with the beam a stream of spores could be seen leaving the gills, falling obliquely at a rate of several millimetres per second, and settling where the spore-deposit had been accumulating. Owing to the sides of the ressel becoming warmed by heat accompanying the bean of light, new and marked convection currents were soon formed. The result was that the stream of spores 
became deflected into a new path, and the spores became scattered fairly regularly. In quite still air in very small chambers, Coprinus spores fall quite vertically. ${ }^{1}$ These observations seen to me to warlint the belief that the localised and irregular spore-deposit formed by the Coprinus in the first instance was due to convection currents which kept cireulating in a constant path, thereby deflecting the rapidly falling stream of spores out of the rertical toward one sille of the jar. It is scarcely necessary to discuss how regnlar convection currents might arise in the closed system which was employed, but it may be pointed out that the living and actively respiring Coprinus pilens might well be responsible for them.

Falek arranged tiers of circular paper dises, one above the other, in a tall eylindrical glass chamber where a pileus was liberating its spores. Under these conditions he often obtained very eurious radiating spore-deposits on each dise. Here, again, the assumption that convection currents taking regular paths existed in the chamber, seems to me quite sufficient to give a basis for an explanation of the results. As one may readily observe by means of the beam-of-light method, the spores are carried atray from the underside of the pileus in the form of a comparatively thin, dense, and continuous stream. The stream which reveals the presence of convection currents, doubtless, would be carried along slowly, first orer one surface, then over another, dividing here owing to this obstacle, and turning back there owing to another, until finally it would be broken up. Where on any surface a dense trail of spores has accumulated, it may be assmed that the spore stream took a regular path just above. If the convection currents are only fairly constant in their directions, then owing to the fict that the spores in the first instance are swept awity from the pileus in the form of at strean, fantastic spore-patterns seem to be just what should be expected under the conditions provided by Falck's experiments.

In concluding my remarks in this chatpter, I wish to recommend the demonstration of spore-fill by the beam-of-light method to all those who give lectures or lathoratory courses which include a treatment of the fruit-bodies of Hymenomycetes. It is difticult 1 Till infru, Chap. XY. 
for a student to realise that millions of spores are filling each hour from a ripe Mushroom before his or her very eyes, and yet unseen. A single demonstration of the kind that I have described is likely to impress the fact indelibly on the memory. The demonstration can be carried out on any day in the year, even in the depth of winter. Subsequently, it will be shown that there are many species belonging to the genera Lenzites, Polystictus, \&c., which can be kept dry in bottles for months or even years, and which yet shed spores again for days after they have been revived by being placed for about six hours under moist conditions. A stock of such fruit-bodies may be kept in the laboratory, and revived at any time with great ease and certainty by placing wet cotton-wool on the pilei. Instead of a strong artificial beam of light, sunlight, let through a slit in a dark room, is equally effective for the purpose of illumination. 


\section{CHAP'IER VIII}

THE SPORE-FALL PERIOD

'THe spores of a hymenomyeetous fruit-body, under fuvourable conditions, are liberated continuously at a fairly constant rate. They are never all discharged simultaneously or set free in intermittent showers. The falling spores may be compared to raindrops steadily falling from the clouds on a wet day. The process of spore-diseharge often requires a considerable period of time. This may be eonveniently called the spore-fall period.

In any griven fruit-body, the spore-fall period varies in length according to the rate of development of the spores. This repends on internal organisation and also upon external conditions, more particularly of temperature. For many corky or leathery fruithodies, such as those of Lenzites, Polystictus, Steremu, \&c., which readily become dried up in a dry atmosphere and quickly absorb free water through the upper surfaces of their pilei, rainfall and dew formation are distinctly favourable to the discharge of spores, whilst drought must often temporarily inter'rupt it.

It has already been recorded ${ }^{1}$ that a large specimen of Polyporus squmosus, growing on a $\log$, was observed to shed its spores continuously for sixteen days. Reasons were also given for supposing that in this case the spore-fall period must have extended over at least three weeks.

'The length of the spore-fall period was determined for a number of xerophytic fruit-hodies by means of the beam-of-light method. The fruit-bodies which had been detacherl from the substrata and allowed to dry up were revived in a damp-chamber, suspended in beakers, and examined usually several times a day with a beam from an arc-light. The beakers were kept in a well-heated labora- 
tory. Moisture was supplied to each fruit-body by means of wet cotton wool placed on the upper surface.

An apparently full-sized fruit-body of Schizopleyllum commune, less than a square inch in area, shed its spores for sixteen days continuously. The density of the spore-stream leaving the gills seemed to remain almost constant from a few hours after its formation onwards, until about three days before the end of the spore-fall period, when it began to grow distinctly feebler.

A small fruit-body of Polystictus versicolor shed spores for sixteen days, and one of $P$. hirsutus for five lays. A large specimen of Lenzites betulina gave a copious shower for ten days. A number of other fruit-bodies, such as those of Stereum hirsutum, S. purpureum, Dicdalea unicolor, Merulius corium, \&e., were seen to discharge their spores for several days. A complete investigation into the spore-fall period in all these species, doubtless, would add much to its length. In order to carry it out, it would be necessary to examine a fruit-body growing upon its substratum from the time it begins to levelop its hymenium onwards. It has already been found that a very young fruit-body of Polystictus hirsutus, grown in the laboratory on a stick, began to shed a few spores when its hymenial tubes had only attained the size of hemispherical depressions. From this observation, and also from the fact that both small and large fruit-bodies of Schizophyllum, Lenzites, Polystictus, \&e., liberate spores when kept moist, it seems probable that spore-fall takes place in species belonging to these genera in a manner similar to that exhibited by Polyporus squamosus, i.e. the discharge of spores begins soon after the fruit-bodies have expanded horizontally, when the hymenium begins its development, and continues until the pilei have grown to their full extent. This may be in some cases a matter of days, in others certainly of weeks, or in yet others possibly of inonths.

For Psalliotu campestris and allied fruit-bodies spore-fall does not begin until the pileus has expanded and the gills have become more or less horizontally outstretched. By placing paper close beneath the pilei of some Mushrooms growing on an artificial bed, and thus collecting the spores, it was found that the spore-fall periorl continued for two or three days. 
A fully expanded fruit-body of Pleurotus ulmurius, when confined in a large beaker in the laboratory, was observed by the beam-of-light method to shed spores for seventeen days continnously. During the last few days the gills gradually turned mouldy. Since the fruit-body appeared to be of full size and expansion when gathered, it seens probable that, had it been left to continue its existence under matural conditions, its spore-fall period might have exceeded three weeks.

Coprinus crmatus sheds spores from the moment "ileliquescence" begins at the base of the gills until these have disappeared. For sone large specinens, growing in a field under favourable weather conditions, the spore-fall period was found to last about two days and two nights. Snaller species of Coprinus, such as Ct. plicutilin, sher their spores in a few loours.

The continuous discharge of spores for dilys or weeks is certainly a remarkable fact which requires further elucidation from the point of view of development. It must be remembered in this eonnection that adjacent basidia in most fruit-bodies are in rery various stages in regard to the production of spores. The fact that after the spores on a hasidium have attained their full size and final colour, they remain on the sterigmata but a very short time, seems to show that they are discharged as soon as ripe. There must be some means by which a succession of developing basidia on any given part of the hymenium is provided. Possibly the discharge of spores from one basilium serves as a stimuhs for the derelopment of one or more neighbouring basidia. It is certain, however, that the process is heautifully regulated, for thus only could a Polygurus squemosus,

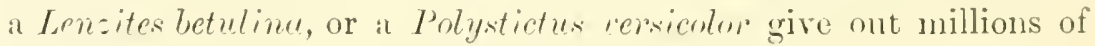
spores in such stealy streams for many days without intermption. 


\section{CHAP'TER IX}

\section{DESICCATTON OF FRUIT-BODIES-A XEROPHYTIC FUNGUS FLORA-THE GENUS SCHIZOPHYLLUM}

Hitherto the retention of vitality by fruit-bodies after desiccation does not appear to have been thoroughly investigated. In systematic works on fungi, it is stated that fruit-bodies in the genera Marasmins and Collybia revive after being dried up when they obtain access to moisture, but beyond this general fact nothing further seems to have found its way into botanical literature. However, probably most field mycologists have noticed that leathery and corky firuit-bodies occurring on sticks and logs of wood become fieshened up in rainy weather.

A test for retention of vitality is not afforded by the fact that a dried fruit-body, when viewed macroscopically, apparently regains its turgidity on access to moisture, for a number of dead fruit-bodies swell up in this way, e.g. Lensites betulina. The swelling in this and many other species is simply due to the expansion of the hyphal walls. A slow oxydative change going on in a dried fruit-body would also be an umreliable test for retention of vitality, for Paul Becquerel ${ }^{1}$ has shown that seeds which were killed by heating and then dried, "respired" more actively than dried seeds still capable of germination. If, however, when supplied with moisture, a fruit-body again begins to shed spores, then we have a clear and convincing proof that it is still living. A fruit-body which has been killed never sheds any spores. Even when a fruit-body which is actively discharging spores is placed under the influence of ether vapour, ${ }^{2}$ spore-fall ceases immediately. The liberation of spores, therefore, is an active process, the carrying out of which may be taken as sure evidence that the fungus concerned is still living.

${ }^{1}$ P. Becquerel, "Sur la nature de la vie latente des grains et sur les veritable charactires de la vie," Comptes liendus, T. 143, 1906, p. 1177.

2 Tide infro, Chap. $\mathrm{X}$. 
Experience has shown that spores which have just been liberaterl ahways have a fresh and turgid appearance when observed in water. They give one the impression that they are capable of germination. That spores, newly shed from a fruit-body which previously has been kept desicented for a long period, niay germinate readily under suitable conditions, has been proved for the only two species so far tested, namely, Daddede unicolor and Schisophyllum commune. A fruit-body of the former species was kept dry for three years, and one of the latter for one year. 'They both recovered when wet cotton

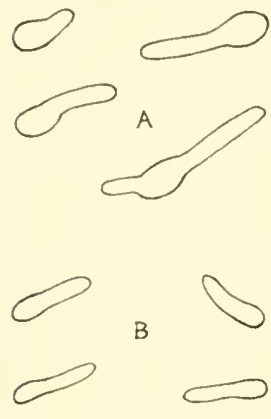

F] . 3S. - Spores, which were shed from revived fruit-bodies. in comrse of germination after twenty-four hours in a nutrient merlium. A, Didalee micolor. B, Schizophyllum commune. Magnification, 700. wool was placed on their upper surfaces. Spores liberated within ten hours after the fruit-hodies had been moistened gemminated readily within a further twenty-four hours in hanging drops of a nutrient medim containing meat extract, grape-sugar, peptone, and gelatine (Fig. 38). These observations seem to afford strong evidence in farour of the view that, whenever spore-emission is taking place from a fruit-body, the emitted spores are living.

It not infrequently happens that a desiceated fruit-body, separated from its substratum and allowed access to water, in addition to liberating spores also recommences growth. Such growth in species of Polyporese may lead to a slight elongation of the hymenial tubes or even to the production of very shallow new ones at the edges of the fruit-bodies. Renewed growth of this kind can easily be detected macroseopically, and it has been observed in Polypoms rigons, Polystictus hirsutus, and Glwoporus conchuiters. The fruit-bodies in question had been kept dry for a year before being moistened.

Most sucenlent fruit-bodies, such as those of species belonging to the genera Psalliota, Amanita, Coprinus, Boletus, de., are mable to survive even partial desiccation. The Marasmii are exceptions to this rule. Fruit-bodies of Haramius meates were gathered from a "fairy ring" in a tield and, when tested in the laboratory, were found to be freely liberating spores. They were then well drierl by means of hot air. During the drying process the fleshy pileus becine quite 
stiff and white, and the gills shrivelled up (Fig. 40, A, B, and C). After the fruit-bodies had been kept in the dried state for twentyfour hours, free water was allowed to come into contact with the upper surfaces of the pilei and with the stipes. It was readily absorbed. The fruit-bodies became swollen, and completely resumed their normal appearance in the eourse of a few hours ( $D$ and $F$ ). At the end of this time they were actively shedding spores. Thick spore-deposits collected beneatlı the pilei on black paper (E), and the discharge of spores from the sterigmata was watehed by means of microscopic sections. Convincing proof was thus obtained that the fruit-bodies of Murasmius oreades, after complete desiccation, are capable of reviving on aceess to moisture and of resuning their normal activities. The retention of vitality in the dried-up condition, however, is only temporary. It was found by subsequent experiment that fruit - bodies which had been kept stiff

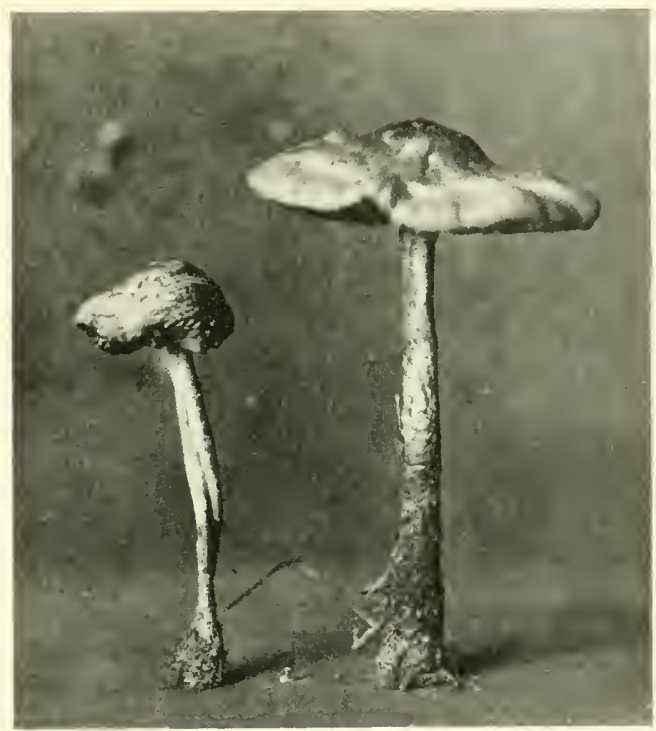

Fig. 39.-Marasmius oreades. To the left a fruitbody shrivelled up during drought. 'T'o the right a fruit-body which after becoming shrivelled up was revived under moist conditions and is again shedrling spores. Natural size.

and hard were still capable of recovery after six weeks but not after three months.

Fruit-bodies of Marasmius peronatus and of Collybia dryophila were allowed to dry on a laboratory table. They were then tested at intervals for revival. The tests showel that recovery was possible when the desiceated condition had lasted for only a few days, but not when it was continued for a month.

On hot days in summer and early autumn, one not infrequently sees shrivelled-up fruit-bodies of Marasmius oreates in "fairy rings" 
in mealows (Fig. 89). The fruit-bodies are developed during a spell of wet weather, but, when the air and soil become reduced in moisture, and especially when the radiation of the sun is intense, they slowly dry up and cease to shed spores. As soon as rain eomes again, water is quickly reabsorbed throngh the top of the pileus, and the spore-liberating function is resumed. There ean be no doubt that the revival of the fruit-bodies of Marasmiii after desiccation is an advantageons adaptation which prevents a great loss of spores.

1

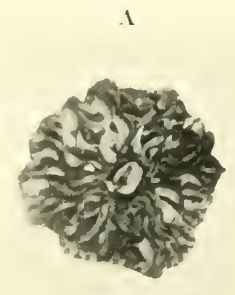

1)
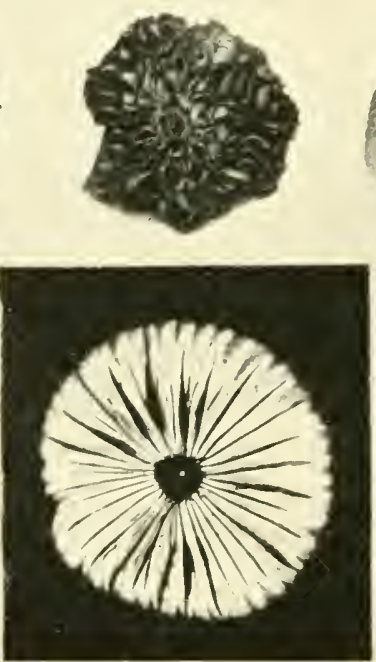

Is:
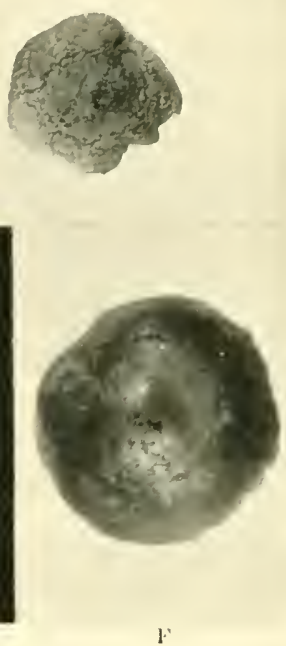

Fig. 40.-Marasnius omades. A and B, the under surfaces, and $C$, the upper surface of the pilei of three fruit-bodies after lesiccation. D and $\mathbf{F}$ are the pilei $A$ and $C$ respectively three hour after the commencenent of revival by absorption of water through their upper surfaces. E, a spore-deposit from the pitens D) (A revived). Natural size.

During dry weather in early antumn I have several times gathered shrivelled-up specinens of collybiu dryoplitu growing among leaves in woorls. Upon being wetted, the pilei soon became fully expanded again, and spore-liberation was then actively resmmed. It is evident that the fruit-bodies of collybia dryophle retain their vitality atter

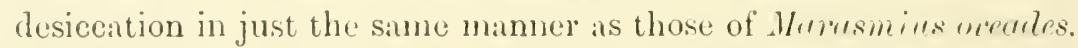

As a result of experiments upon a considerable number of typical speeies, the nanes of which will shortly be given in a Table, it seems 
safe to state that very inany, and possibly all, of the small leathery and corky fruit-bodies of Hymenomycetes which are to be found developing on fallen logs and sticks in woods, are capable of complete recovery after desiccation. In a number of instances they can be kept dry for months or even for several years, apparently without the smallest detriment to their power of liberating spores alter absorbing water once more. Among the species in question one may mention those belonging to the following genera: Schizophyllum, Lenzites, Trogia, Diedalea, Polyporus, Polystictus, Merulius, Phlebia, Stereum, and Corticium. These fungi must be regarded as xerophytes, for their fruit-bodies are capable of withstanding drought by drying up without any loss of vitality and of reviving again under moist conditions.

Fruit-bodies of Lenzites, Polystictus, \&c., which were required for testing, were gathered during October and November from stumps, logs, and sticks in the woods near Wimnipeg, and placed on a table in the laboratory. There the air was very dry, so that desiccation took place rapidly. A dried fruit-body, still living, revived when it had been set in a damp-chamber and wet eottonwool had been placed on the top of its pileus. It quickly absorbed the free water, expanded, and soon came to have a fresh appearance. After a few hours spore-liberation was resumed. This was proved in iny first experiments by eollecting spore-deposits on paper, but subsequently this method was discarded and the beam-of-light method used instead. It has already ${ }^{1}$ been made sufficiently clear that a strong beam of light, directed beneath a fruit-body in a closed beaker, readily enables one to determine whether or not spore-fall is taking place.

As a rule, only a very few hours are required for a dried-up fruit-body to regain its spore-liberating function. A specimen of Schizopleyllum commune, kept dry for six months, recovered in three hours. Herulius corium and Polystictus versicolor, kept dry for six months, and Lensites betuline, kept dry for two years and six months, all required about four hours to recover. In other cases it was found that spore-fall usually recommeneed within six hours after the fruit-bodies had been placed under moist conditions. A 
fruit-body of Dietuled unicolor, kept dry for two years and six months, recovered in ahout four hours, but another fruit-body of the same species, kept dry for four years, recovered in about $7 \cdot 5$ hours. 'This observation indiates that those fruit-bodies which have been kept longest in the desiccated eondition are the slowest to revive.

All the fruit-hodies tested were found to retain their vitality for several months, some of them for more than two years, and one, namely, Dorduled unicolon, for more than four years. Only in a few species, owing to lack of material old enough, has it been possible for me to determine within what period death oceurs. Howerer, the investigation seems to indicate that erery dried fruit-body exposed to the air loses its vitality in the course of a few months or years, just as does a seed.' In the Table opposite is given a list of the fungri which were tested, and also the results of tests made after various periods of desicention.

Some well-grown specimens of Lenzites betulina and of Schizophyllume commune were collected. Doubtless, they had ahready shed an abundance of spores before they were gathered. They were kept dry for a whole year, and then revived in a dimpchamber, whereupon they shed elouls of spores. Again, by drying, they were put to rest for another year, and at the end of this second period of desiccation they were again allowed acess to free water. They revived and shed spores once more. A similar revival was found to take place even after desiceation for a third year, but an attempt to revive the fruit-bodies after a fourth year of desiccation Was unsuccossful: the fruit-bodies became diseolonred and putrid without shedding any spores.

Sticks, dead branches, and logs in woods are all liable to become dried up. When this happens the mosses, lichens, and fungi upon them must gradually dry up too. It is not surprising, therefore, that these plants are adapted to withstand temporiry desiccation.

1 Panl Becquerel (loc, rit., p. 1178) found that dried seeds of varions kinds placed in pure and dry nitrogen in the dark for a year, did not liherate a trace of carbon dioxide, and yet germinated subsequently. It will be of interest to determine whether or not dried fruit-bodies of fungi are also eapable of retaining their vitality without any evidence of respiratory activity. If life may become latent in dry seeds, it may atso do so in dried fruit-bodies. 
They survive through periods of drought by drying up and retaining their vitality. The hymenomyeetous stick or $\log$ flora is therefore xerophytic.

While it has now been demonstrated that many of the fruitbodies of wood-destroying fungi are able to withstand desiccation unharmed, the resistance of the mycelium to dry conditions still requires an experimental investigation. Quite possibly in some

List of Hymenomycetes with Fruit-bodies which can become Desicrated without losing their Titality.

\begin{tabular}{|c|c|c|c|}
\hline Family. & species. & $\begin{array}{l}\text { Recovered after } \\
\text { Desiceation for }\end{array}$ & $\begin{array}{l}\text { Failod to lecorer } \\
\text { after luesiceation for }\end{array}$ \\
\hline \multirow{4}{*}{ Thelephorest } & Corticinm lave & 1 year & ... \\
\hline & Steremm hirsutum & 1 year & $\ldots$ \\
\hline & , purpurem & 1 year & I year 6 months \\
\hline & " bicolor & 1 year 6 months & 2 years \\
\hline \multirow[t]{2}{*}{ Hydnere. } & $\begin{array}{c}\text { Foneda preala } \\
, y \text { zonata }\end{array}$ & $\begin{array}{l}- \text { years months } \\
1 \text { year }\end{array}$ & $\begin{array}{l}4 \text { years } 4 \text { months } \\
3 \text { years } 6 \text { months }\end{array}$ \\
\hline & Merulins corium & 2 years & $\ldots$ \\
\hline \multirow{8}{*}{ Polyporese } & Gloeoporus conchoides & 1 year & $\cdots$ \\
\hline & Dredalea unicolor & 4 years & $\cdots$ \\
\hline & , confragosa & 1 year & $\cdots$ \\
\hline & $\begin{array}{l}\text { quercina } \\
\text { Polyporus conchifer }\end{array}$ & $\begin{array}{l}1 \text { month } \\
4 \text { months }\end{array}$ & $\begin{array}{l}5 \text { years } \\
5 \text { months }\end{array}$ \\
\hline & , rigens & 2 years & $\ldots$ \\
\hline & , carneus & 2 years & $\ldots$ \\
\hline & Polystictus versicolor & 2 years & 4 years \\
\hline &,$\quad$ hirsutus & 3 years & .. \\
\hline \multirow{8}{*}{ Agaricinea } & ," pergamenus & 1 year & … \\
\hline & $\begin{array}{l}\text { Trogra crispa } \\
\text { Schizophyllum commune }\end{array}$ & $\begin{array}{l}+ \text { months } \\
2 \text { years }\end{array}$ & $\begin{array}{l}1 \text { year } \\
16 \text { years }\end{array}$ \\
\hline & Lenzites betulina & 3 years & 5 years \\
\hline & , scepiaria & 4 montlis & ... \\
\hline & Crepidotus sp. (:) & a few weeks & $\cdots$ \\
\hline & Marasmius oreades & 6 weeks & 3 months \\
\hline & , peronatis & a few days & 1 montli \\
\hline & Collybia dryophila & 1 week & 1 month \\
\hline
\end{tabular}

cases the xerophytism of a fungus is only partial, so that desiccation is fatal to the inycelium but harmless to the fruit-bodies. However, the rapidity with which fruit-bodies, on the advent of rain, develop upon sticks which have been dried up for weeks in summer, points to the conclusion that the mycelimm in the wood must very frequently retain its vitality in a state of desiccation. A somewhat striking laboratory experiment with Polystictus versi- 
color lends considerable support to these general tield observations. A stick, about $4 \mathrm{~cm}$. thick and $30 \mathrm{~cm}$. long, bearing a number of fruit-bodies of the fungus in question, was gathered by myself and kept in a dry state as a museum speeimen. After an interval of four years it was found that the fruit-bodies, on being moistened in the usual manner, did not shed any spores, but appeared to be discoloured and to have lost their vitality. The stick was then given to Miss J. S. Bayliss for certain investigations which she was then carrying on. It was set in a damp-chamber with one end in water. Four weeks later Miss Bayliss observed that a number of new fruit-bodies of Polystictus iresicolon had begun to develop upon it. In the course of a few weeks some of them attained considerable size. ${ }^{1}$ This observation seems to me to prove conclusively that the mycelium in the rood must hare retained its vitality for four years in the desiccated condition.

It is well known that the mycelium of Psolliente rempestris, when kept dry as "spawn" in compressed horse-dung bricks, retains its vitality for years. According to Falek," the mycelium of Cominus sterquilinus is still able to continue its development after the horse-dung balls, in which it has existed, have been kept dry for a year. In both these instanees the vegetative part of the fungus is resistant to desiecation, whereas the reproductive part is not.

The xerophytic, hymenomycetous fruit-bodies growing on logs, such as those named in the Table, have several features in common. This is only what might be expected when it is remembered that they are all adapted to the same external conditions, i.e. to develop on a wooden sulstratum chiefly in the cool and late autumn months. The points of agreement are as follows:-

1. They retain their vitality for months or years after desiceation.

2. They are all firmly built and resemble in consistency leather, cork, or wood. Their toughness renders them inedible to slugs and firours their persistence through periods of drought and frost.

1 Miss J. S. Riyliss, "The Biology of P'olystictus mestolur (Fries.)," Jounn. of Eronomir Bioloy!l, vol. iii., 1904, 1. 20.

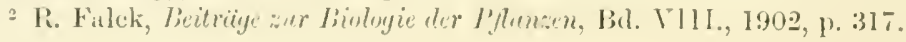


3. The upper surface of the pileus is usually hairy or woolly. A means is thus provided for the rapid absorption of water on the advent of rain. Free water placed at one edge of the pileus quickly passes by capillarity over the entire upper surface. Since in many species the fruit-bodies more or less overlap one another, this arrangement may be of advantage in hastening recovery after desiccation. 'The hairs, like those on the leaves of certain xerophytic Phanerogams, are doubtless of some service in diminishing the rate of transpiration in dry weather. Direct evidence of this is afforded by an experiment made by Miss J. S. Bayliss, ${ }^{1}$ who found that the removal of the hairs from the upper surface of a pileus of Polystictus versicolor increased the rate at which the process of drying took place.

4. They are able to withstand prolonged and severe frost (such as oecurs at Winnipeg).

5. They shed their spores at low temperatures. A number of them can perform this function even at $0^{\circ} \mathrm{C} .^{2}$

6. Their attachment is unilateral. This is connected with the fact that they grow on stumps, sticks, and fallen logs. 'The dimidiate form of the fruit-bodies is as well adapted to the position of the woody substratum as the radial form is to the position of the earth in the Mushroom and Boleti, \&c.

The Genus Schizophyllum.-'The genus Sehizophyllum is unique among the Agraricinese in that it is characterised by possessing gills which are either partially or completely divided down their median planes into two parts. We shall now proceed to interpret this remarkable morphological fact in the light of observations made upon schizophyllum commune.

Schizophyllum commune is a speeies eomparatively rare in England but extremely common in Manitoba, where it is found on sticks, logs, and stumps. The fruit-bodies, which are usually attached laterally, attain a width of about $3 \mathrm{~cm}$. They oceur singly or, more firequently, in imbricated groups. Their general appearance is shown in Fig. 41, A and B, and Fig. 42. The gills are in distinct fasciculi, each pair of deeper and longer ones being

1 Miss J. S. Bayliss, loc, cit., p. 17.

2 Vide infru, Chap. $\mathrm{X}$. 
separated by from three to five others which are shallower and shorter (Fig. 41, E). The upper layer of the pileus presents a
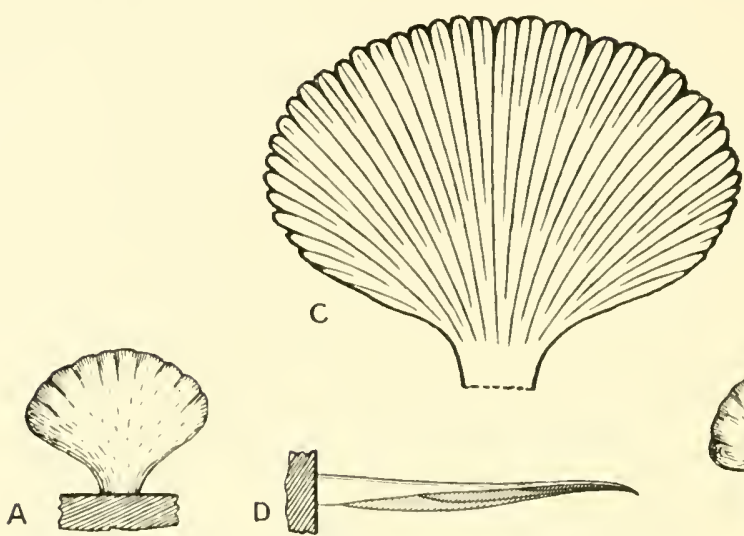

A

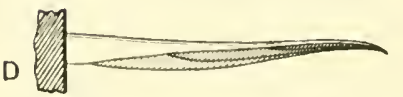

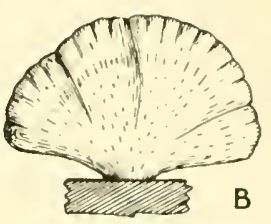

$E$

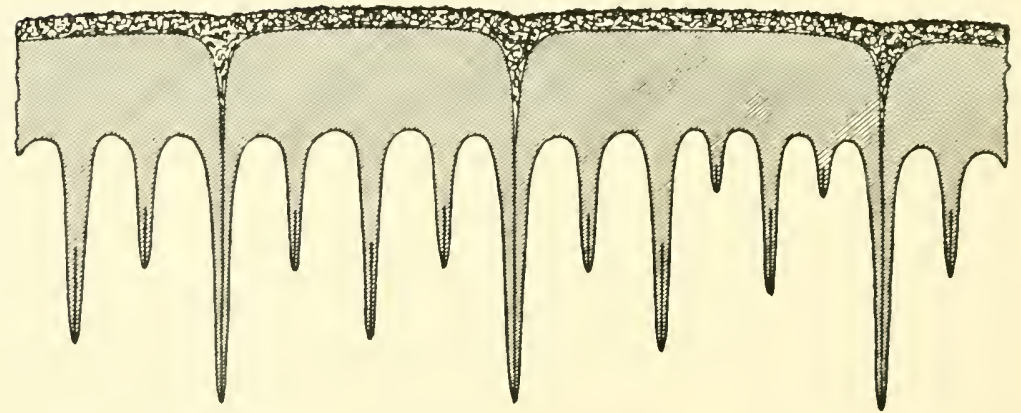

$F$

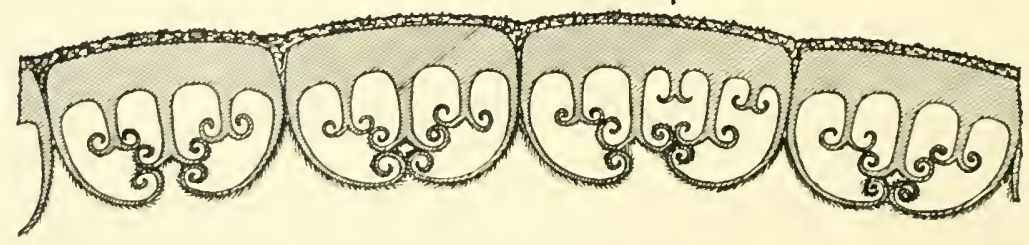

FIG. 41.- Schizophyllum conmune-a specialised xerophyte. A and l3, fruit-bodies seen from ibove growing on wood. Natural size. C and D, two fruit-borlies seen from lielow and in section respectively. About twice natural size. E, section through a pileus during wet weather showing the gills. which are split down their merlian plines. F, section through a pileus after desiccattion. E and $\mathrm{F}$ about 12 times the natural size.

woolly appearance and is made up of tangled hyphe which extend downwards towards the median planes of all the deeper gills. 
The under layer of the pileus, the firm flesh which is produced
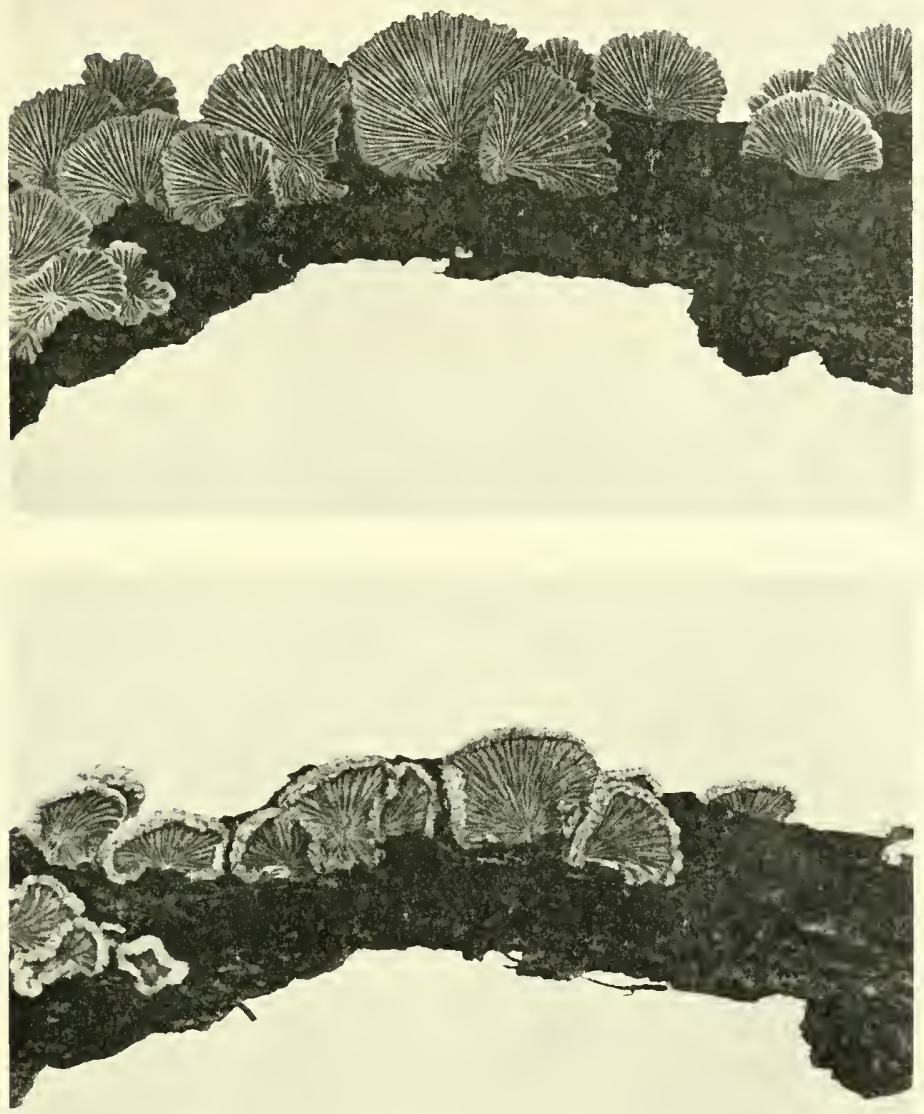

FIG. 42.-Schizophyllum commune. 'The lower photograph shows a group of fruit-bodies in the desiccated condition. The gill-fasciculi are closed up. Natural size. The upper photograph shows the same group of fruit-bodies after being revived. 'l'he gill-fasciculi are now open. About $\frac{5}{6}$ natural size.

downwards to form the gills, thus becomes divided into radiating portions (Fig. 41, E). 
The area of a fruit-body is increased by marginal growth. The peripheral walls of the interlamellar spaces protrude outwards as crenatures, and more or less resemble the heels of slippers placed side by side in a row (Fig. 43). These erenated walls ronstitute growing regions by means of which the older gills are

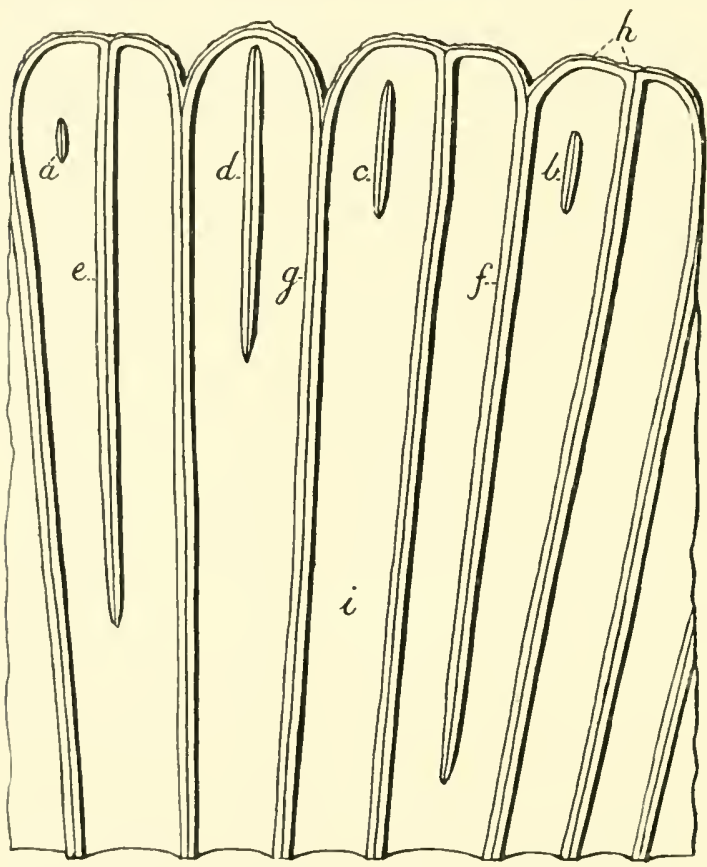

Fig. 13.-Sichizphyllum commum. Piece of a pileus seen from below showing the arrangement of the gills. $a-g$, stages in gill development; $h$. part of the woolly layer covering the top of the pileus and here extenderl over the pileus margin; $i$, interlamellar space. Semidiagrammatic: the gills are represented as cut through transversely so that the surfaces of seetion lie in one plane. About 13 times llse natural size. lengthened and new ones added. Whilst a pileus is extending by marginal growth, the interlamellar spaces gradually widen. When a space has attained a certain width, it becomes divided into two down the middle, owing to the formation within it of a new gill which arises as a short median downgrowth from the pileus flesh (Fig. 43, a). The upper half of every new gill is undivided, but the lower half is made up of two plates, the inner surfices of which are in contact and clothed with loose hyphe (cff. Fig.41,E). A gill, whilst still very short, occupies an isolated, sub-

terminal position within the interlamellar space in which it has been formed. However, as growth proceeds, its distal end gradually approaches the pileus margin and eventually joins with it (Fig. 4.), $a-e$ ). All gills at their first-formed, stipe ends are shallow and only partially divided. However, at their peripheral growing ends they gradually become deeper and more divided, 
until at length they come to consist solely of two deep, apposed plates. After a young gill has become connected with the pileus margin, its two plates separate from one another slightly at their peripheral ends. This separation of the gill plates, as growth proceeds, becomes more and more marked, and at length involves the pileus flesh. The peripheral end of every long and deep gill thus comes to resemble in cross section the deepest gills shown in Fig. 41, E. 'The whole gill system may be regarded as being made up of branched fasciculi.

Schisophyllum commune, as we have already seen, is a xerophyte. In moist weather the gills all look vertically downwards, as in the Mushroom, and spore-discharge takes place for days from their hymenial surfaces (Fig. 41, E). When dry weather comes, and the wooden substratum gradually loses its water, desiccation of the fruit-body sets in. The emission of spores soon ceases, and the two halves of each gill begin to diverge below (Fig. 44). As desiccation proceeds, the gill plates become curled outwards at their edges. When a fruit-body has become quite dry, one finds that the longest gills which have separated into two halves to their bases, have covered in

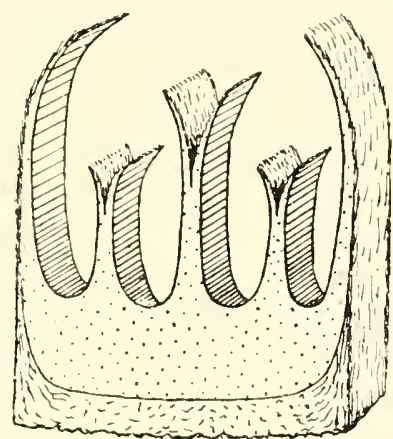

FIG. 44.-Section through a fasciculus of gills of sichizophyllum commune showing an early stage in the divergence of the gill plates. About 8 times the natural size.

the shorter ones. Each fasciculus of gills in eross section now presents a very curious appearance (Fig. 41, F). It is evident that the relative sizes and amounts of splitting of the different gills are admirably adapted to facilitate the closing up of the fasciculi. In a state of desiccation a fruit-body has its hymenium completely hidden from external view, and the pileus is temporarily provided below with a hairy eovering.

Whilst in the dried condition a fruit-body can retain its vitality for at least two years, and, with intermittent revivals, for at least three years. When rain comes again, the woolly upper surface of the pileus sucks water in by capillary attraction, and the gill halves at once begin to unroll and reappose theinselves 
in pairs. In the course of two or three hours the gills become perfectly reconstructed, and they are then directed downwards in the normal manner (Fig. +1, E, and Fig. +2). The hymenial layer resumes its activity, and, after three or four hours of access to moisture, the emission of spores is vigorously recommenced.

'The mechanism involved in the elosing and opening of a pileus can be partially explained from anatomical considerations. The main mass of each gill plate consists of downwardly running

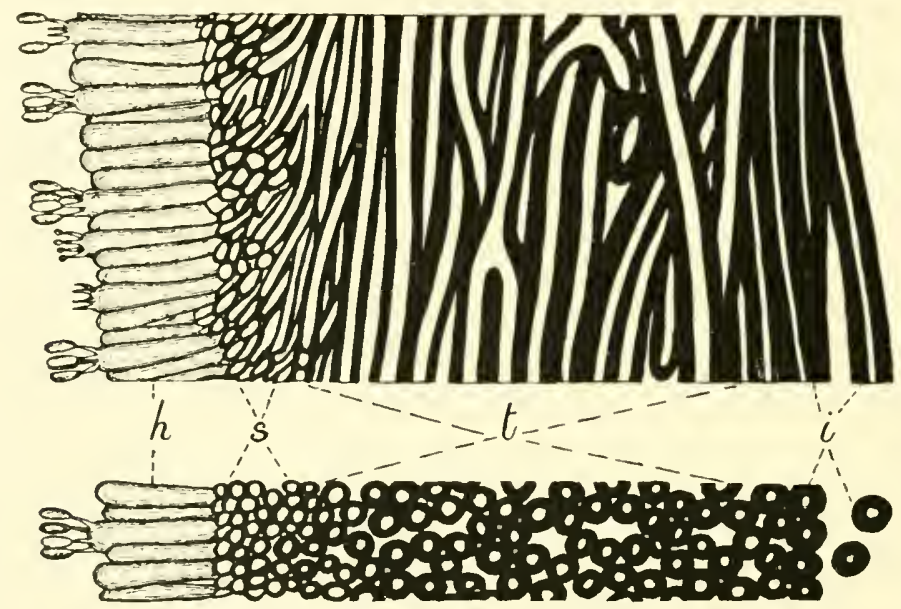

FIG. 4.5.-Schizophyllum commun. Above, a transverse section through a half-gill taken in a vertical direction; below, another transverse section taken in a horizontal direction. $h$, the hymenium; $s$, the subhymenium; $t$, the trama; $i$, the inner free hairy surface of the half-gill which becomes exposed on desiccation of the fruit-body. Magnification, 688 .

tramal hyphe, which have very thick walls and are strongly attached together at intervals. On the other hand, the hymenium and subhymenium are composed of elements with relatively very thin walls (Figs. 4i). When a fruit-body dries up, the cell-walls of the hymenial and subhymenial layers contract much more strongly in the vertical direction than those of the tramal layer. This being so, the curling up of each gill plate, when water is lost from it, is a mechanical necessity. When a gill reabsorbs moisture, the walls of the hymenial and subhymenial layers expand to a greater extent than those of the trama. The tramal hyphae are 
thus permitted to straighten themselves again. The straightening out of the gill plates, however, is brought about by something more than mere cell-wall imbibition and stretching. This is proved by the fact that the dry gills of dead fruit-bodies are not capable of becoming entirely uncurled. Partial recovery of the gills was observed: (1) In fruit-bodies which had lost their vitality when kept for sixteen years in the dried condition, and (2) in fresh fruit-bodies which were dried and then caused to absorb a solution of 1 per cent. corrosive sublimate through their upper surfaces. The first and major part of the straightening out of the gills we may regard as a mechanical process connected with the swelling of cell-walls. On the other hand, the final apposition of the two plates of each gill appears to be brought about by the resumption of turgidity by the hymenial and subhymenial elements. The finer part of the whole readjustment, according to this interpretation, is traceable to the semipermeable properties of living protoplasm.

The division of the gills of Schizophyllum into two plates is significant in that it permits of the hymenial surfaces being protected during periods of dronght. The rapid curling up of the gill plates on the advent of dry weather must serve to check the rate of loss of water from the fruit-body by limiting the amount of gill surface exposect to the outer air. This closing off' of most of the transpiring gills at the beginning of desiccation, finds its analogy in the curling up of the leaves of many xerophytic Phanerogams under similar atmospheric conditions. However, I am not inclined to think that reduction in the rate of transpiration is the chief advantage gained by the opening out of the gill plates. Periods of drought are often very long, and when they occur it may be of considerable advantage for a fruit-body to have its delicate hymenial surfaces, covered as they are with millions of spores, made as inaccessible as possible to various small marauding animals. However, the exact ecological significance of the opening ont of the gill plates would best be elucidated in the tropics, where the genus Schizophyllum is richest in species. 


\section{CHAP'TER X}

EXTERNAL CONDITIONS AND SPORE-DISCHARGE-THE EFFECTS OF LIGHT, GRAVTTY, HYGROSCOPIC CONDITION OF THE AIR, HEAT, ALTERATION IN THE GASEOUS ENVIRONMENT, AND OF ANASTHETICS

LikE all other active processes of living organisms, the discharge of spores ean only be earried on when external conditions are favourable. It is now neeessary to consider these conditions in detail.

The Effect of Light.- Whilst in some species, e.g. the Mushroom, the fruit-bodies can undergo perfect development in total darkness, in a number of others the pilei cannot be produced without a morphogenic stimulus given by light. Among the latter are Lentinus lepideus and Polyporus squemosus. When a fruitbody of either of these species is grown entirely in the dark, it develops into a horn-like process without the least trace of a pileus or hymenium (Fig. 16, D, p. 48, and Fig. 20, p. 58). It was found for Polyporus squemoses, however, that, when the development of the pileus has once been initiated in response to the stimulus of light, if the fruit-body is then placed in the dark, finther development continues in a normal manner: the usual hymenial tubes are produced and the hymenium gives rise to ordinary basidia which liberate spores in continuous clouds. The production of spores in clouds in the dark, which in one instance lasted for eleven days, proves conelusively that, for Polyporus squemosus at least, the liberation of spores is quite independent of light conditions. For species of Polystictus, Lenzites, Schizophyllum, de., spore-discharge was found to be quite continuous. The alternation of night and day appeared, as judged by the beam-of-light method, to make no difference whatever to the rate at which spores left the truit-bodies. It is probably correct to state quite generally for the Hymenomyeetes that, whilst the morphogenic stimulus of light may or may 
not be necessary for the production of the hymenimm, when once the hymenium las begun its development, the basidia discharge their spores quite independently of light conditions.

In the case of certain Ascomycetes, e.g. Ascobolus, it has long been observed that spore-discharge is periodic, a certain number of asci ejecting their spores each day. This phenomenon has come inore particularly under my notice in the case of Ascobolus immersus growing on horse dung. The periodicity depends on the alternation of day and night, and can be given an easy ecological explanation. It is important for the purpose of distribution that the ejected spores should be thrown clear of obstacles, e.g. dung balls, \&c. The asci are positively heliotropic, and during the day always turn themselves in response to the stimulus of light, so that they point toward open spaces. Such an adjustment would be impossible at night. The periodic discharge of asei each day is therefore of advantage in that it ensures that these structures shall burst only after the light has caused them to take up the most favourable positions for sporedissemination. On the other hand, as my observations have made clear, spore-discharge in the Hymenomycetes is continuous and does not take place at internittent periods. The general arrangement of a Mushroom or Polyporus is such that, under normal conditions, the basidia never face obstacles. All that is required for the successful liberation of the spores is that the basidia shall shoot them straight outwards from the hymenium for a minute distance. After being violently expelled from their sterigmata, the spores drop into the spaces between the gills, in the hymenial tubes, \&c., and thus fall from the fruit-body and are carried off by air-currents without coming into contact with any impediment. ${ }^{1}$ Almost without exception in the Hymenomycetes, the orientation of the hymenium, and with it the direction of spore-discharge, is finally determined by the stimulus of gravity, and is of such a nature as to ensure that the spores shall fall out of the fruitbody. The perfect indifference to light as regards spore-discharge by the fruit-bodies of Hymenomycetes in comparison with certain Ascomycetes is thus elucidated.

1 Tide infra, Chap. XVII. 
The Effect of Gravity.-Gravity is the chief orienting stimulus acting on the fruit-bodies of Hymenomycetes. In Polyporus squemosus, for instance, as we have already seen from the discussion in Chapter IV., it causes: (1) The stipe to turn the rudimentary and terminal pileus into a horizontal position, (2) the pileus to grow with a symmetry suited to the position of the stipe, (ii) the pileus flesh to grow parallel to the earth's surface, and (4) the hymenial tubes to grow towards the earth's centre. The stiped Agaricinear usually have stipes which are negatively geotropic and gills which are positively geotropic.

Although the stimulus of gravity is of the greatest importance in orienting the hymenium and the basidia which it contains, it appears to have no direct effect on the process of spore-discharge. When a hymenium has once started its development, ripe spores continue to be developed and separated from the basidia, independently of the direction of gravitational attraction. Thus, if a gill be placed so that the Lasidia on one side look upward or downwards or at any angle with the vertical whatsoever, spore-discharge takes place equally well in all cases. Evidence of this was obtained by watching spores leave their sterigmata with the nicroscope, and will be given in the next chapter, which deals with the riolent projection of spores from the hymenium.

The Effect of the Hygroscopic Condition of the Air.- It has been mentioned already ${ }^{1}$ that for Polyporus squemosus, so fir as it was possible to judge from the spore-clouds seen by daylight, the liberation of spores takes place equally well both in a dry and in a saturated atmosphere. For this species, therefore, ordinary variations in the hygroscopic state of the atmosphere do not appear to appreciably affect the rate of discharge of the spores.

When a small portion of a pileus of Polyporus squamosus, Psulliote compestris, or Amenitopsis rerginute, \&e., was placed in a rertically disposed compressor cell (cf. Fig. is, p. 167, and Plate IV., Fig. 29), so that the fall of spores conld be watehed with a horizontal microseope, it was found that spores fell continuously when

$$
1 \text { Chap. VI. }
$$


the chamber was saturated with moisture. When crystals of calcium chloride were placed in the cell, the spores continued to fall for some time, until the piece of pileus had shrunk appreciably and was evidently drying up.

It can easily be observed with the beam-of-light method that, if a fruit-body of Polystictus versicolor, Lenzites betulina, \&c., is allowed to dry up slowly, when a certain amount of water has been lost, the rate of spore-discharge becomes slower and slower. As desiccation proceeds spore-fall ceases altogether. Insufficient access to water must often, in nature as in the laboratory, especially in the case of the xerophytic fruit-bodies growing on $\operatorname{logs}$ and sticks, lessen the rate of spore-discharge and lead to a corresponding increase in the length of the spore-fall period.

The general conclusion, to which numerous observations of the kind just deseribed have led me, is that, so long as a fruitbody has sufficient moisture in itself, the dryness or dampness of the atmosphere without makes no appreeiable difference to the rate of spore-discharge.

The Effect of Heat.-The liberation of spores, like all other vital processes, can only be carried on within certain limits of temperature. Doubtless each species has its own partieular minimum, optimum, and maximum for this function.

In all the species so far investigated, the discharge of spores takes place rapidly at ordinary room temperatures. It slackens, however, when the temperature is sufficiently lowered; but in several instances it was found to continue even at the freezing point of water, although with much diminished vigour. A slowing down of the rate of spore-discharge also occurs when the temperature is gradually raised above the normal; and when a certain temperature has been reached, the hymenium becomes altogether inactive. The maximum temperature for the discharge of spores, however, is appreciably lower than the maximum for vitality.

For the purpose of determining whether spore-fall still continues at freezing point, a cold-room was made use of. The room had two doors, one opening out-of-doors and the other into a passage within the University building. The temperature of the room 
remained for hours, and sometimes for days, between $0^{\circ}$ and $3^{\circ} \mathrm{C}$. By opening the outer boor for a few minutes the air of the room conld easily be reduced to $0^{\circ} \mathrm{C}$, and this temperature was often maintained for several hours.

So far experiments have been limited to species which grow upon wood and have proved capable of withstanding uninjured the prolonged and severe frost of the Manitoban winter. Dried fruit-bodies of Lensites botulinu, Polystictus rersicolor, I'. hirsutus, badulee unicolor, and schisophyllum commune were placed in a damp-chamber with wet cotton-wool upon the upper surfices

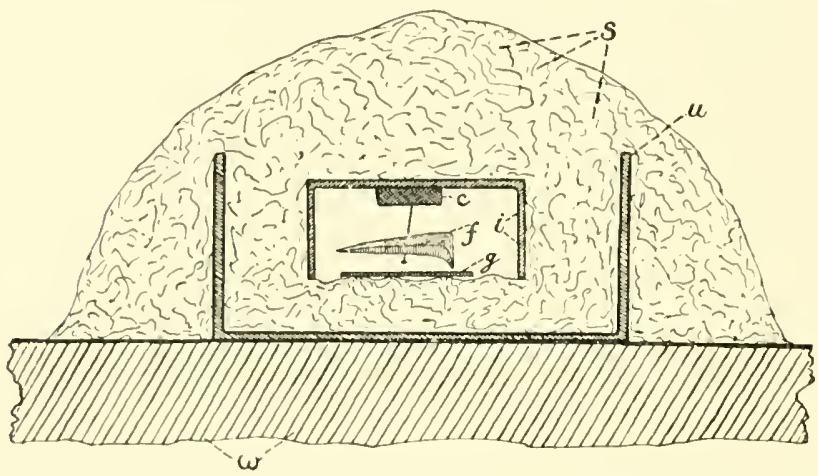

Fic. 46. - Apparatus for demonstrating the fall of spores from fruit-bodies at $0^{\circ} \mathrm{C}$. A glass dish $u$ is placed on a woorlen shelf $w$ in the cold-room. An inverterl glass dish $i$ is parked round with snow $s$ so as to leave the space within it unfillerl. 'To the cork $c$ is attached the fruit-borly $f$, below which is placed a glass slide $g$ for the purpose of eatching the falling spores. Abont $\frac{1}{1}$ actual size. of their pilei. 'They soon revived, and at the end of six hours, upon being examined with a beam of light, they were found to be vigorously sheddingrspores. A fruit-body, to be tested, was taken to the cold-room and pinned to a cork attached by means of sealing-wax to the bottom of a small erystallising dish. This was then inverted and packed round with melting snow contained in another and much larger erystallising dish, as shown in Fig. 46. After two hours, when the fruit-body had become cooled to freezing point, the cold-room air was reduced to $0^{\circ} \mathrm{C}$. by opening the outer door for a few minutes. The inverted erystallising dish, to which the fruit-borly was attached, was then lifted out of the snow, so that fresh spore-free air at $0^{\circ}$ C. entered it. A glass slicle (Fig. $46, y$ ) was then placed so that when the erystallising dish was replaced in position, the fruit-body had its natural orientation, its under, spore-producing surface looking directly down on the glass slide. 
After two hours the slide was removed and exanined under the microscope. Any spores which had fallen upon it could be detected with ease.

The results, obtained from a number of experiments of the kind just described, have served to convince me that Daduleu unicolor, Lensites betulina, Polystictus versicolor, and P. hirsutus eontinue to shed their spores at the freezing point of water. However, the comparatively small number of spores which settled upon the glass slides each hour showed that spore-discharge is not nearly so active at $0^{\circ} \mathrm{C}$. as at higher temperatures. From a succession of tests it was found that Lenzites betulinu continued to shed its spores at $0^{\circ} \mathrm{C}$. for at least three days. A fruit-body of this species, whilst enclosed in the snow-chamber, set free sufficient spores in a few hours to make a distinct, although faint, macroscopie pattern of the gills upon a glass slide. Probably, in all species which shed spores at $0^{\circ} \mathrm{C}$., the discharge of spores. continues for an indefinite period of time until the fruit-bodies become exhausted. No spore-deposit was detected as being produced by Schizophyllum commune at $0^{\circ} \mathrm{C}$, although spores were vigorously shed by this species at $5^{\circ} \mathrm{C}$.

Ontogenetic study shows that the basidia of a hymenium come to maturity successively, and part with their spores as soon as these are ripe. The shedding of spores by Lenzites betulinci, Drdale unicolor, \&e., in a snow-chamber indicates that in these fungi the development of the hymenium can still continue at the freezing point of water. At first, the fact that growth is still possible in a hymenomycetous fruit-body at $0^{\circ} \mathrm{C}$., may seem surprising, but parallel instanees of growth at this and even lower temperatures in other plants are by no means unknown. Thus in Pfeffer's ${ }^{1}$ list of cardinal points for growth, the minima for Sinapis alba (Kirchner and de Vries), Ulothrix sonutu (Klebs), and Bucillus cyuno-fuscus (Beyerinck) are given as $0^{\circ} \mathrm{C}$., and on Aretic coasts, according to Kjellmam, ${ }^{2}$ alge flourish in sea-water whose temperature falls to -1.8 and perhaps never exceeds $0^{\circ} \mathrm{C}$. The fruit-bodies of species of Stereum, Corticium, \&e., often appear

1 Pfeffer, Physiology of Plents, translated by A. J. Ewart, vol. ii., 1903, p. 77.

${ }^{2}$ Kjellman, Bot. Zeit., 1875, p. 171. 
to be at their best in the middle of an English winter, from which fact it seems justifiable to conclude that cold weather is favomiable to their development.

The effect of high temperatures upon spore-discharge has been investigated only in the case of Lensites betulinu. The fruit-body to be tested was first determined to be freely shedding spores by the beam-of-light method. It was then pinned to a cork fixed to a glass plate, after which the plate was placed over a beaker, so that the fruit-body assmmed its normal orientation ( $\%$. Fig. 37, p. 97). This beaker with its cover, and another similar but uncovered beaker, were then placed in the incubator, the air of which had been raised to the desired temperature. After from thirty minutes to two hours, when doubtless the fruit-body had assumed the temperature of the inenbator, the plate was quickly taken from the first beaker and set upon the second. The air within the second beaker before this operation was, of course, free from spores, whereas that of the first might still have contained spores which had been liberated by the fruit-body before this had become heated. After another fifteen or thirty minutes, the second beaker was removed from the incubator and immediately examined by the beam-of-light method. If spores had been liberated into it, they could easily be seen floating in the air.

As a result of experiments of the kind just described, it was found that the discharge of spores took place slowly at $29^{\circ} \mathrm{C}$., but not at $33^{\circ}, 43^{\circ}$, or $46^{\circ}$. The fruit-bodlies, however, were not killed by exposure for forty-five minutes to these high temperatures, for when they were afterwards placed in a moderately heated room, in the course of several hours they recovered and shed spores again in abundance.

The modes of action of extreme cold and of extreme heat are donbtless different. Extrene cold must slow down the metabolism and henee prevent spore development. No injury in the case of Lenzites, Diedalea, and other similar fruit-bodies growing on logs, results from a long exposure to very low temperature, c.g. from $-15^{\circ}$ to $-40^{\circ} \mathrm{C}$., such as occur often for weeks together in the course of winter at $W^{r i n n i p e g . ~ A s ~ s o o n ~ a s ~ a ~ f r u i t-b o d y ~ i s ~ w a m e d ~ s u f f i c i e n t l y, ~}$ spore-fall begins anew. Fruit-bodies of Lenzites betulinu, Stereum purpureum, and Schisophyllum commune were gathered from a wood- 
pile in March at about $-17^{\circ} \mathrm{C}$. after being exposed for several months to severe frost. When brought into the laboratory they soon began to shed their spores, and within a few hours produced well-marked spore-deposits. ${ }^{1}$ On the other hand, extreme heat probably causes a heat rigor, for when some fruit-bodies of Lenzites betulina were exposed to a temperature of $39^{\circ} \mathrm{C}$. for half-an-hour and then cooled to an ordinary room temperature, two hours passed by before the fall of spores was resumed.

The range of temperature which permits of spore-discharge-for lensites betulina about $0^{\circ}$ to $30^{\circ}$ C.- probably coincides with the range of temperature permitting the growth and development of the spores. As soon as the spores are ripe they are probably shot off. If one watches the discharge of spores from the basidia with the microscope, one finds that spores which look ripe, i.e. which have attained their full size and proper colour, do not long remain on their sterigmata. The rate of spore-discharge seems, therefore, to be an indication of the rate of spore development.

So far, opportunity has not been found for determining the range of temperature within the limits of which the liberation of spores is possible for succulent, non-xerophytic, ground Agarics which flourish during summer. It seems to me probable, however, that for many species, e.g. the Mushroom, the minimum temperature for shedding spores is several degrees above the freezing point of water. To what extent frost is fatal to the reproductive organs of Hymenomycetes still requires investigation.

The Effect of Alteration in the Gaseous Environment.-The pileus of a small fruit-body of Marasmius orecules, about 1 ineh in diameter, was divided into three portions. One of them was placed in a suitable glass vessel of about 0.75 litres eapacity, through which a strong stream of hydrogen was made to flow for ten minutes. The stop-cocks were then closed. By similar means the second portion of the pileus was surrounded by an atmosphere of carbon

${ }^{1}$ Possibly the fruit-bodies began to shed their spores immediately they had been unthawed and raised to the temperature of the laboratory. Unfortunately, when these experiments were made, I had not developed the beam-of-light method, and the formation of a macroscopic spore-deposit was relied upon as a test for the liberation of spores. 
dioxicle, whilst the third was set in a chamber containing ordinary air. Glass slicles were employed to catch any spores which might fall.

The piece of pilens in air shed abundance of spores, a grood deposit outlining the gills being collected in the short space of ten minutes. A thick deposit had formed in an hour, and in the course of twenty homis tens of thousinds of spores had collected. The piece of pileus placed in hydrogen shed a few spores during the first hour. At the end of this time it was removed to a new position on the glass slide. During the subsequent nineteen hours scareely a spore fell. The few spores found on the slide with the microseope certainly did not make up one tive-hundredth part of the number which fell from the piece of pileus placed in air. A similar result was obtained with the piece of pileus placed in carbon dioxide. During the first hour in that gas a few spores were liberated. The picee of pileus was then pushed to a new position on the glass slide. During the subsequent nineteen hours practically no further spores hecame deposited.

The conclusion to which the experiments just described appear to point is that, in the absence of oxygen, spore-discharge soon ceases. Doubtless for some time after a piece of pileus has been placed in hydrogen or carbon dioxide, the basidia have access to a certain amount of oxygen diffusing ontwards from the pileus through the hymenium. Possibly it is on this account that a few spores still continue to be liberated for a short time after the oxygen has been removed from the surrounding atmosphere. We may conchule by analogy that the direct action of hydrogen on the pileus is harmless, but that that of carbon dioxide may possibly be poisonous.

Removal of oxygen from the atmosphere probably caluses cessation of growth of the basidia. With this cessation of growth the fall of spores must cease, for the continuous raining down of spores from the gills depends on the sucessive development of the basidia.

Two small pilei, one of Huramius orearles and the other of I'silorybe jomiserii, were halved. One piece of each was covered by a glass vessel containing air, and the other pieces were pliced in a 
chamber of 0.75 litres eapaeity, through which a strong stream of oxygen was made to flow for some minutes. The stop-coeks were then elosed. 'The pieces of pileus were set on glass slides so that any falling spores might be caught.

After an hour, apparently equally thick deposits of spores had been shed both in air and in the pure oxygen. The half-pilei were then placed in new positions on the glass slides. During this operation air was kept out of the oxygen chamber by means of a strong stream of oxygen passed through it. Five hours subsequently the new spore-deposits were examined. They appeared to be equally thick in both air and pure oxygen. The half-pilei were again placed in new positions on the glass slides. These were once more examined after an interval of eighteen hours. Heavy spore-deposits resembling each other had again formed both in the air and in the oxygen.

This experiment seems to prove that, in an atmosphere of pure oxygen, the fruit-bodies of the two speeies examined eontinue to develop their basidia and to shed their spores in the usual manner. This need not occasion surprise, for many even of the higher plants develop normally in pure oxygen or under a pressure of five atmospheres of air. ${ }^{1}$

The Effect of Anæsthetics.-An observation with an anæsthetic has already been made by Falck. He found that a fruit-body of Agaricus nebularis, on being subjected to chloroform vapour, ceased to shed spores, and he drew the conclusion from this fact that spore-liberation is an aetive process. ${ }^{2}$ Experiments with anæsthetics, however, do not deeide whether the spores are set free by a process of growth and thus simply fall when ripe like apples, or whether, on the contrary, they are shot outwards from their sterigmata with force. In the next chapter this matter will be dealt with in detail.

In order to test the effect of ether vapour upon the liberation of spores, the following inethod was resorted to. A piece of eork was:fixed by means of sealing-wax to the middle of a circular

1 Pfeffer, Physiology of Plants, vol. i. p. 540.

${ }^{2}$ R. Falck, "Die Sporenverbreitung bei den Basidiomyceten," Beitrüge zu" Biologie ter Pflansen, Bd. IX., 1904, p. 27, footnote. 
plate of glass, and to it a fruit-borly to be tested was pinned. The glass plate wias then placed on the ground top of a eylindrical glass jar of 1.25 litres calpacity, so that the fruit-body had its natural orientation ( $e f$. Fig. 37, p. 97$)$. A piece of blotting-paper was attached with sealing-wax to the bottom of the jar.

The fruit-body was first tested in the usual way with a bean of light to find out whether spore-discharge was taking place. In all cases a cloud of spores could easily be seen coming from the lower surface. When it had thus been determined that spores were being freely liberated, the glass cover, with the fruitbody attached, was removed, inverted, and placed on a table. Fresh spore-free air was caused to enter the now open jar. By means of a pipette $0.5 \mathrm{cc}$. of Syuibb's ether was then quickly dropped on to the blotting-paper in the jar and the latter immediately inverted over the glass cover, to which it became closely attached by means of vaseline. When a fruit-body is upside down it is unable to liberate any of its spores into the air in a glass chamber. So long, therefore, as the fruit-body was kept inverted, the air in the jar above it remained spore-free. When it was desired to find out whether spores could still be liberated, the antsthetised fruit-body was tumed into the normal position again by neans of another inversion of the jar. The air beneath the now downwardly-looking hymenium was then examined for spore contents with a beam of light. It was found that, when the jar was placed upright again two minutes after its first inversion, no spores fell into the air within. The ether vapour, therefore, caused cessation of spore-diseharge in two minutes.

When the ether was added to an upright jar, and the eover, bearing a normally oriented fruit-body, was placed on the top, at first the spore clouds could easily be seen coming off from the underside of the fruit-body with the beam of light; but the spore stream quickly diminished in density and its emission ceased after about two minutes. The spores which had already entered the jar then spreat themselves evenly in the air which it containerl.

When the jar in the first deseribed experiments was placed in the upright position a few minutes after the ether had been 
added, the fruit-body was always found to have lost its power of shedding spores. Not a single spore could be seen floating in the beam of light, nor, so long as the fruit-body remained subjected to the anæsthetic, were any spores liberated. When, however, the fungus was removed from the glass jar and exposed to ordinary air, it gradually recovered. It was found that, even after treatment with ether vapour for a week, recovery could still take place and active spore-discharge be resumed. The length of time during which fruit-bodies were exposed to ether vapour, and the length of time required for recovery of the spore-liberating function after removal from the anrsthetic, are given in the following table:-

\section{Lenzites betulina.}

0.5 ce. Squibb's ether in a 1.25 litre jar.

Length of Exposure to the
Et her Vipour.
5 minutes
30 minutes
12 hours .
24 hours
7 days

Time taken for Recovery of the sporeliberating Function after Removal from Ether Vapour.

Less than 30 minutes.

More than 2 hours.

About 3 hours.

( More than 3 hours 45 minutes.

( Less than 4 hours 35 minutes.

6 hours 30 minutes.

It is clear that the longer the fruit-bodies were exposed to the anæesthetic, the longer was the time required to recover from the effects.

The chief result of these experiments is to show that sporedischarge may be inhibited by ether without any apparent permanent injury to the fruit-body. The shooting off of the spores, and probably their development, ceases under the influence of ether just as does protoplasmic movement in the cells of higher plants and the reactions to mechanical stimuli in the leaves of Mimose pudicu, the stamens of Berberis, \&c. As in these cases, the active process is resumed again when normal conditions are allowed to supervene.

Chloroform has a similar effect to ether. $0.5 \mathrm{cc}$. of chloroform was introduced into the 1.25 litre jar in the manner already deseribed. Under these conditions the liberation of spores ceased in about one minute. The fruit-body was exposed to the chloro- 
form vapour for five minutes and then placed in ordinary air. Recovery of the spore-liberating function took place after about fifteen minutes. It might be expected from analogy that chloroform would prove more poisonous to the frut-bodies than ether. No attempt, however, has been made to obtain an experimental basis for this assumption. 


\section{CHAP'IER XI}

THE VIOLENT PROJECTION OF SPORES FROM THE HYMENIUMMETHODS I., II., III., IV., AND V.'

Ix order to understand the arrangements for liberating the spores from the fruit-bodies of Hymenomycetes, it is of great importance to bear in mind that the spores are very adhesive. After they have settled on paper, glass, a pileus, or stipe, the nost violent shaking will not separate them from the surface to which they have become attached. They cling to each other with great tenacity, for from spore-deposits one may scrape up spore ribbons several millimetres long. If a ripe Mushroom or other fruit-body be turned upside down so that the spores after leaving the sterigmata settle upon the basidia and paraphyses of the hymenium, when the fruit-body is again placed in the natural position not one of the fallen spores succeeds in freeing itself. One can see with the microscope that the spores remain fixed where they fell. When a fruit-body is inverted for an hour, some millions of spores leave the sterigmata and settle on the gills. If the spores were not adhesive, on replacing the fruitbody in its natural position and observing with the beam-of-light method, one should be able to see these millions of spores falling in the form of a dense and very temporary cloud. No such eloud, however, can be detected. These and other observations of various kinds have convinced me that, if a spore after leaving its sterigmata happens to touch the hymenium in its fall, even when it strikes it very obliquely, it immediately gets stuck there, and never succeeds in reaching the outer air.

In discussing the general structure of the fruit-bodies it was pointed out that in many cases the hymenium is disposed for the most part in almost vertical planes. In the Agaricinese it is situated on the surfaces of very acutely wedge-shaped gills, and in the Polyporere it lines the surfaces of very slightly eonical tubes. In 
many fruit-bodies of Agaricinea the declination of the gill surfaces from the rertical is only from one to three degrees.

Whilst reflecting on the adhesiveness of the spores and the reltical position of the hymenial surfaces, I asked myself the question : By what means are the spores enabled to fall from the basidia without contact with one another, and in such a manner that they find their way down hymenial tubes or between gills without becoming attached to the sides? Taking into consideration that the horizontal basidia are crowded one above the other (cf. Fig. 56, p. 165, and Plate I., Fig. 3), it was argued that if the adhesive spores inerely fell from the sterigmata in a passive manner, they would very frequently fall upon one another, and that of necessity they would fall rather inwards toward the hymenial surface than outwards, owing to the tendeney they would have to swing beneath the sterigmata. On the assumption of passive fall it seemed impossible to imagine how the adhesive spores could be liberated. Before any observations were made, therefore, it appeared to me highly probable that in some manner the spores must be projected for a short distance straight out from the hymenium in which they are produced. This deduction has been verified in various ways. My observations seem to indicate that violent spore-projection is of general oceurence throughout the Hymenomycetes.

So far as I am aware, hitherto Brefeld alone has made observations on the separation of spores from the basidia. In the case of Amrenitu muscrmir" he simply says, "In diese [the spaces between the gills] werden die Sporen durch schwache Ejaculation geworfen und fallen dann zu Boden." In a footnote in his account of the life-history of Coprinus stercorcerius, ${ }^{2}$ he states that the spores are shot outwards in consequence of the bursting of the sterigmata. He believes himself to have seen small drops left on the sterigmata, and also on the spores after spore-discharge, and states that all four spores are shot off from a basidium simultaneously. With regard to violent spore-ejaculation being a fact, I am in entire agreement with Brefeld, but am unable to confirm his deseription of the process in detail. The spores, so far as my experience with several species of

${ }^{1}$ Brefeld, Botanische Untersuchungen über Schimmelpitise, III. Heft, p. 132.

2 Brefeld, loc. cit., pp. 65, 66 . 
Coprinus and of many other genera goes, are never shot off simultaneously. I have also not been able to obtain any evidence that the spores are projected forwards owing to ejaculation of the contents of the basidia. The mechanism of spore-discharge, however, will be discussed more conveniently in the next chapter.

Several methods have been used to determine whether or not the spores are shot off the sterigmata. The first one, which seemed for some time to give convincing evidence of spore-projection, led to the discovery of an unexpected optical illusion.

Method I._The first method employed for observing spore-fall microscopically was that of placing hymenial surfices in vertical planes and observing them from above with an ordinary upright microscope.

Through the middle of some of the hymenial tubes of a freshly grown fruit-body of Polyporus squamosus, a transverse section 1-2 mm. thick was made (Fig. 47). This was then placed on a glass slide, covered with a cover-glass, and looked down upon from above with the low power of the miero-

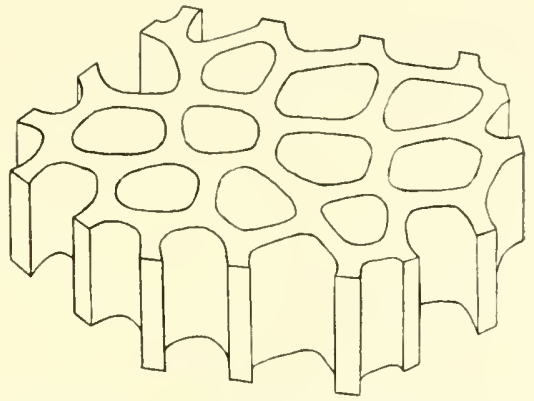

FIG. 47.-Diagram to show the shape of a transverse section through the hymenial tubes of Polyporus squamosus. About 6 times natural size. scope. Immediately the remarkable fact was observed that the spores were apparently being shot outwards from the hymenium towards the middle of the tubes. Apparently one could see them taking part of their curved and outward course through the air. They were also seen to settle below on the glass slide on the average at a distance of $0 \cdot 1-0 \cdot 2 \mathrm{~mm}$. (6-20 times their own length) from the hymenium. In this way the spores collected in a zone about $0.5 \mathrm{~mm}$. wide around the base of each tube. In the course of a few minutes I watched the discharge of hundreds of spores. Not only to myself, but to others, the apparent bombardment of the spores into the lumina of the tubes seemed to afford clear and convincing proof of the violent projection of the spores from the basidia.

Similar observations to those just recorded were then made upon 
other species of Polyporus, and also upon speeies of Polystictus, Dadalea, and Boletus. The hymenial tubes of many members of the Polyporea are extremely narrow. 'Thus with the aid of the drawing apparatus and a stage mierometer, it was found that the diameters of the tubes at the nouths were on the average: for Polyporus liveutus, 0.3-0.4 mm.; for Fomes vegotus, 0.15-0.2 $\mathrm{mm}$.; for Fomes igniarius, $0.15 \mathrm{~mm}$; and for Polystictur versicolor, 0.2$0.25 \mathrm{~mm}$. In Polyporus liresutus and Polystictus versicolor, for which speeies alone fresh material was available, the spores seemed to be bombirded from the hymenium just as in the case of Polyporus squumosus. They appeared to be projected outwards from the hymenium and were scen to descend near the centres of the tubes, at the mouths of which they collected in heaps. Polyporus lirsutus had tubes in the centre part of its fruit-body $2 \mathrm{~cm}$. long. However, by making transverse sections at different heights it was observed that the spores were discharged throughout the whole length of a tube. For Polystictus iersicolor the tubes were often only $0.2 \mathrm{~mm}$. wide. Yet even in these the spores seemed to be shot outwards from the hymenium. They appeared to travel a distance of about $0.1 \mathrm{~mm}$. toward the middle of the tubes before the horizontal velocity had been reduced to zero.

'The species of Boletus investigated and the dianeters of their pores, as given by Massee, ${ }^{1}$ were as follows: Boletus chrysenteron, 1-1.5 mm.; B. felleus, up to $1 \mathrm{~mm}$.; B. fluvus, $\frac{2}{3}-1 \mathrm{~mm}$.; B. subtomentosus, $\frac{2}{3}-1 \mathrm{~mm}$; B. scaber, 0.5-1 mm.: B. badius, 0.5-1 mm. Here, again, seetions 1-2 $\mathrm{mm}$. high were taken transversely through the hymenial tubes, and looked into from above with the low power of the microscope. In each, again, the spores were apparently shot off from the hymenium into the tubes. In the wider tubes the spores were seen to collect at the mouths in a zone around the walls, and in the narrower ones they gradually formed a central heap. The inpression gained was that the spores were projected horizontally on the average $0.2-0.1 \mathrm{~mm}$, or about the same distance as for Polyporus squamosus. Daclalea unicolor (a very common fungus at Winnipeg) behaved like the Boleti.

In order to observe the fall of spores in nembers of the Agari-

1 G. Massee, British Fungus-Floru, 1892, vol. i. 
ciner, tangential sections about 1-2 mm. thick were made through the pilei, so as to cut the gills transversely. 'The sections were then placed on a microscope slide, by which means the hymenial surfaces took up a vertical position (Fig. 48). Sometimes the sections were placed in a glass cell closed with a cover-glass, but this precaution for keeping off air-currents was usually found unnecessary in a quiet room where the air was still. The spores appeared to be violently projected from the hymenium into the spaces between the gills in all the species which were examined. As in the case of Polyporus squamosus, however, only part of the path of each spore could be observed, owing to the fact that only one plane can be focussed at one time by the microscope. The discharge of the spores could usually be detected almost immediately the section had been made, and continued for some minutes until loss of water from the gills interfered with the process. In small, closed glass chambers, where loss of water vapour was prevented, the discharge of spores continued in some instances for several hours. The spore zone of discharged spores on the glass slide between two

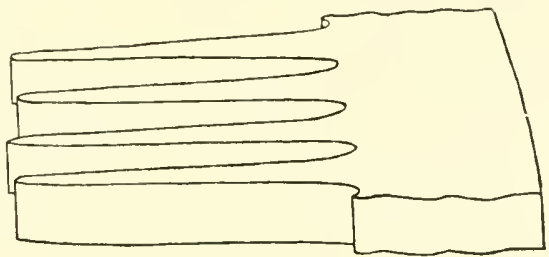

FIG. 48.-Diagram to show the shape of a section from the pileus of an Agaric with gills. The hymenial surfaces are vertical. About $t$ times natural size.

gills and adjacent to the base of each was in most eases about $0.2 \mathrm{~mm}$. wide. The impression was gained that the spores had been projected about $0.1 \mathrm{~mm}$. before the horizontal motion was destroyed. The Agaricinere used as material for these observations consisted of thirty-one species common in the Midlands of England, and included in the following genera: Psalliota, Stropharia, Anellaria, Galera, Amanitopsis, Amanita, Lactarius, Russula, Pancelus, Psilocybe, Collybia, Cantharellus, Laccaria, Hygrophorus, Nolanea, Hypholoma, Marasmius, Entoloma, Mycena, and Armillaria.

The first method of observing spore-fall with the microscope in the Polyporee and Agaricines appeared to yield two facts in favour of the supposition that the spores are violently discharged from the sterigmata: (1) The spores could apparently be seen travelling horizontally away from the basidia, and (2) the spores 
settled some distance from the vertically-placed hymenium. 'The latter fact I regard as good evidence of spore-projection, but the former, which for some time seemed to yield convineing proof of the phenomenon, has been found by subsequent investigation to be misleading and based upon a eurious optical illusion. As a result of further olservations and calculations it can be shown that the spores are really projected from the basidia with a high velocity, but nevertheless it is most improbable that one should observe directly the horizontal motion of a spore becalse it is
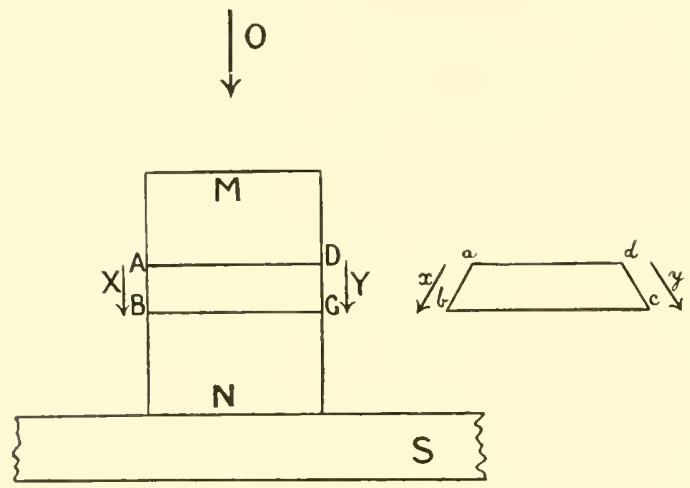

Fig. 49,-Diagram of a tiny cylinder MN on a glass slide $S$, viewed from above in the direction of the arrow $O$ with the low power of the mieroscope. $A B C D$ is a section of the eylinder within the range of focus. $\mathrm{X}$ and $\mathrm{Y}$ show the paths of two spores falling vertically. To the right is shown how the section and the paths of the spores appear to the observer. performed too rapidly. The apparent travelling outwards of a spore from the verticallyplaced hymenium, which one can observe so easily in Agaricineat and Polyporese, is really no travelling outwards at all. The spores, when seen in motion, are in reality falling vertically. For some months this illusion deceived ne, as, indeed, it had deceived others to whom I hard shown it. However, the possibility of the apparent fact of horizontal movement of the spores being in some way deceptive, caused me, after a while, to make a careful study of the appearance of vertical surfaces under the microscope.

A tiny brass cylinder was constructed, placed upright on a glass slide, and observed from above with the low power of the microscope. It was found that, wherever placed in the field, any part of the vertical surface observed appeared to slope at an angle from the vertical. The result of the observations may best be made clear by means of a diagram (Fig. 49). Let MN be the eylinder standing vertically upright on the glass slide $S$, and let the arrow $O$ indicate 
the direction in which the cylinder is viewed with the microscope. Let $\mathrm{ABCD}$ be a section of the cylinder placed within the range of focus. 'Then to the observer the section will have the appearance of a truncated cone, $a b c d$. The truly vertical sides of the section of the cylinder will appear inclined as shown in the figure. ${ }^{1}$ Now let the arrows $\mathrm{X}$ and $\mathrm{I}$ indicate the truly vertical paths of two spores falling parallel to the sides $A B$ and $C D$ of the cylinder. Then, when observed with the microscope, the course of the spores will appear to be as indicated by the arrows $x$ and $y$, i.e. the illusion will be created that the spores are moving more or less horizontally outwards from the cylinder.

The apparent bombardment of the spores into the spaces between the gills, which one sees on looking vertically downwards upon a section like that in Fig. 48, may now be explained. Let AA in Fig. 50 represent a vertical section taken transversely through three of the gills, and let the arrows placed parallel to, and at a little distance from, their vertical sides, represent the true paths of six spores falling vertically. 'Then, as shown at $\mathrm{BB}$, when the low power objective of the microscope is placed in the position of the arrow $\mathrm{O}$, one apparently observes spores being shot outwards from both sides of the gill immediately below, and, when one observes in the direction

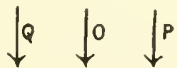

A
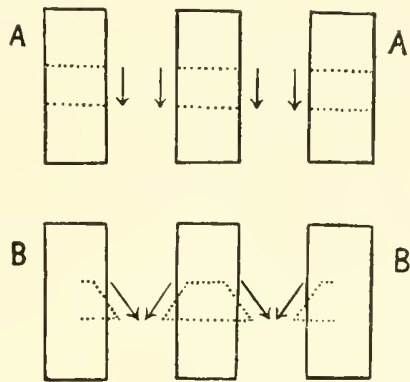

FIG. 50.-Above at AA is shown a transverse and vertical section through three gills of a piece of a pileus like that in Fig. 48 . When observed from above in the directions of the arrows 0 , $\mathrm{P}$, and $\mathrm{Q}$, the range of focus is supposed to be between the dotted lines. The four arrows between the gill-sections indicate the paths of four spores falling parallel toandabout onetenth of a millimetre from the hymenial surfaces. Below at $\mathrm{BB}$ is shown the apparent shape of the parts of the gills in focus and the apparent paths of the spores. The latter, although falling vertically, appear to be shot outwards from the hymenial surfaces iuto the spaces between the gills. indicated by either of the arrows $\mathrm{P}$ or $\mathrm{Q}$, one apparently sees the spores being shot outwards from two gills into the interlamellar spaces.

1 The explanation of the phenomenon seems to be due to the fact that the area of the objective is large compared with diameter of the cylinder, so that different parts of the objective, as it were, can see different parts of the cylinder. With the low power of the microseope one can see simultaneously both sides of an ordinary glass slide placed vertically. 
It is now clear to me that the apparent shooting out of spores from the vertically-placed hymenium in the many Agarieineie and Polyporese observer by my first method is simply an illusion. During the apparent bombardment of hundreds of spores into a cross section of a tube of Polyporus squamosus, or into the spaces between two gills in a Mushroom (which one sees in looking down upon such sections as those represented in Figs. 47 and 48 ), one does not really see a single spore performing any part of its horizontal motion. 'The spores are falling vertically as soon as ever perceived. By methods to be described in Chapter XVII. it has been found that for Amanitopsis veryimete the total horizontal distance to which the spores are projected, namely, about $0.2 \mathrm{~mm}$., is accomplished in approximately only $\frac{1}{400}$ second, and that the initial velocity with which each spore is shot forward is about $400 \mathrm{~mm}$. per second. From a consideration of these remarkable figures, and also the fact that the spores must be considerably magnified in order to be seen at all, it seems to me very improbable that the human eye, aided as it must be by the microscope, will ever be able to detect the horizontal motion of a spore. Whether or not it is possible to do so must be left to the experimental psychologist. That the downward motion of a spore, which is performed at a constant speed in response to gravity, should be observed as described is easily understood, for it is performed relatively much more slowly and for a much longer distance than the horizontal motion. In the case of Amunitopsis vaginutu the terminal vertical velocity is only about $\overline{5} \mathrm{~mm}$. per second. In most other species, where the spores are smaller, the velocity is usually only $1-2 \mathrm{~mm}$. per second. ${ }^{1}$ 'These theoretical considerattions, which it has been necessary to introduce in this place in order to explain the results of observations with Method I., will doubtless become elearer to the reader when the curious nature of the "sporabola" has been discussed in a subsequent chapter.

Observations, with the special object of sceing the horizontal flight of particular spores on leaving the sterigmata, were made with sections of Polyporess squemosus like that in Fig. 47 on several occasions, but they gave only negative results. With a rertical 
mieroseope a ripe spore on its horizontal sterigma was carefully watched until it was discharged. One moment it was in view: the next it had disappeared, but in what direction could not be detected. The eje had not been able to follow the motion.

Method II. - The second method employed to determine whether or not violent spore-projection takes place was as follows: A piece of a gill, 4-.5 $\mathrm{mm}$. high and $2-3$ $\mathrm{nm}$. broad, was cut from a ripe fruit-body of Amanitopsis raginata and placed in a vertical, but inverted, position on a tiny glass shelf in a vertically-disposed compressor cell. A horizontal microscope, with a magnification of about 25 diameters, was then employed to observe the fall of spores from the piece of the gill when seen end-wise $(c f$. Plate IV., Fig. 29). 'The gill segment thus came to be so placed that the sides bearing the hymenium were inclined to the vertical, as shown in Fig. 51. The hymenium, therefore, looked very slightly upwards. Usually it was found convenient to concentrate the attention on one side of the gill, and in all cases, by tilting the compressor cell held in a clamp, the side in question was made to incline distinctly upwards at a slight angle from the vertical. It was argued that, if the adhesive spores only drop off' the sterigmata passively, they would never be seen in the air, whereas, if indeed they are projected violently outwards, although one might not be able to see them in their horizontal flight,

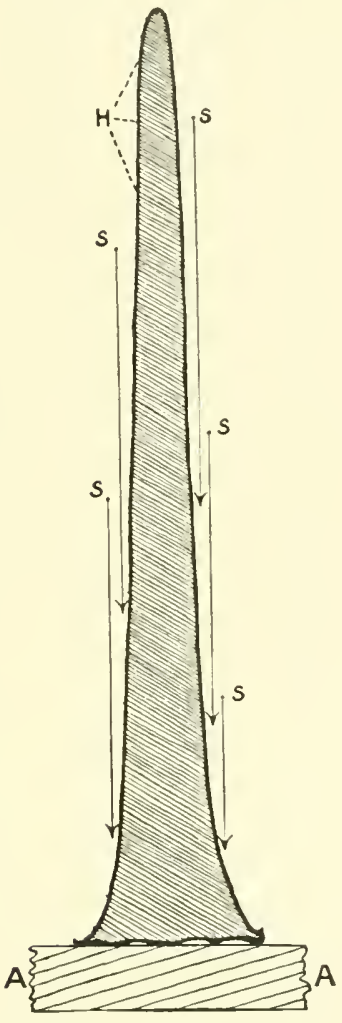

FIG. 51.-Diagram showing a piece of a gill inverted and placed on a tiny horizontal shelf. AA, in a vertically. disposed compressor cell. The piece of gill is seen edgewise with the horizontal microscope. $\mathrm{H}$ is the hymenium. S, S, show the paths of the spores when seen falling. 'The spores first come into view about one-tenth of a millimetre from the hymenium. About 20 times natural size. yet one should 'often be able to see them falling vertically at a little distance from the gill surface.

On actually making the observations, it was found that the 
spores came suddenly into view at a distance of $0 \cdot 1-0.2 \mathrm{~mm}$. from the gills. As soon as seen, the spores were falling vertically at a constant speed.' 'The diagram, Fig. 51, shows the courses of a few spores as seen with the horizontal microseope. These observations seem to me to afford conclusive proof of violent spore-projection. They may be repeated withont difficulty. One may have to wait a few seconds or mimutes before a spore springs into view, but this is merely a question of patience. The species used for these observations, in addition to Amanitopsis rengmata, were: Psulliota compestris, Marusmius oreudes, and Polyporess squamosus. For the Polyporus a piece of the wall between two hymenial tubes took the place of a piece of gill.

The horizontal distance from the hymenium, at which a spore, when first perceived, appeared to be, was compared with the distance between tiny irregularities on a silk thread of the Ramsden ejepiece of the horizontal microscope. The latter distance was then carefully measured with a standard micrometer scale. After a number of observations had been made in each case, the conclusion was arrived at that the spores of Amanitopsis iaginata are often shot to a horizontal distance of $\frac{1}{5} \mathrm{~mm}$., and that those of the other three species are often shot $\frac{1}{10}$ min. and sometimes a little further.

Method III.-The third method employed for demonstrating the violent projection of spores from the sterigmata is perhaps the most conchusive of all. It can be carried out most certainly and easily with fruit-bodies of the Coprini. Coprinus plicutilis was made chief use of in these experiments, but C. comutus and $C$. mirceeus gave similar results. One takes a gill that is shedding spores and lays it flat in a closed compressor cell, and observes it from above with the low power of an ordinary microseope. Under these conditions the basidia are pointing upwards. One can then very readily observe the disippearanee of the spores from the sterignuata near the "deliquescing" gill elge, for it is here and here alone in the Coprini that active discharge of spores takes place (Plate 11., Fig. 12). If one focusses a plane at a little

1 The air in a compressor cell is practically quite still. The spores fall rertically in it, and are not carried abont hy convection currents. 
distance above the plane of the hymenium, so that the basidia are just out of view, one finds that spores spring into view and inmediately disappear again. This proves conclusively that the spores have been projeeted violently upwards from the sterigmata. The fine adjustment screw of the microscope was carefully calibrated by the glass plate nethod, and it was then found by measurement with it that in the case of Coprinus plicutilis the spores were projected upwards, so that they came into view in a plane $0 \cdot 0 \mathrm{~s}-0.12 \mathrm{~mm}$. above the plane of the spores on the sterigmata.

It has been found possible to observe the upward projection of spores in the Mushroom, and also in a species of Psilocybe. In these cases, however, observations can only be made with considerable difficulty. In the Coprini the spores in a zone parallel with, and adjoining, the deliquescing gill edge are all being discharged almost simultaneously (Plate II., Fig. 12). The gills of Coprini are also very thin and allow ample light to pass through them. In all other species of Agaricinece, however, the spores are discharged irregularly over the whole surface of a gill and there is no special region of activity. Adjacent basidia are in very various stages of development. When one looks down on a piece of gill of one of these fungi, one but rarely sees the spores disappear from a basidium. This is due to the fact that the ripe basidia are relatively far apart. The gills are also much thicker than in the Coprini and allow but little light to pass through them.

The observations on the Mushroon were carried out in the following manner. A fresh specimen was obtained from a field and part of one of the pink gills placed flat in a closed compressor cell. The latter was then placed on the stage of the microscope and this tilted to an angle of about $45^{\circ}$. The tilting ensured that if a spore was shot off a sterigma in the field of view, it would remain longer in view than it would if the microscope were vertical. A plane situated a short distance above the hymenium was focussed so that one could not see any of the basidia distinctly. After several hours of watching, on three separate occasions a spore was clearly seen to come into view in the plane above the hymenium and to travel a little way across the field of view hefore disappearing. The only explanation of these observations seems to be that the 
spores had been shot off the sterigmata just as in the Coprini. A species of Psilocybe yichder a similar result.

Method IV.-A piece of a gill of a Mushroom was placed flat in a closed compressor cell and observed from above with an ordinary vertical inieroseope. An endeavour was made to see the spores leave the sterigmata of individnal basidia. It was argued that, if the spores merely fall passively from the sterigmata, after liberation they ought to lie below their respective sterigmata, whereas, if they are diseharged violently, they should often take up other positions.

Apparently ripe basidia were focussed and watched. After some

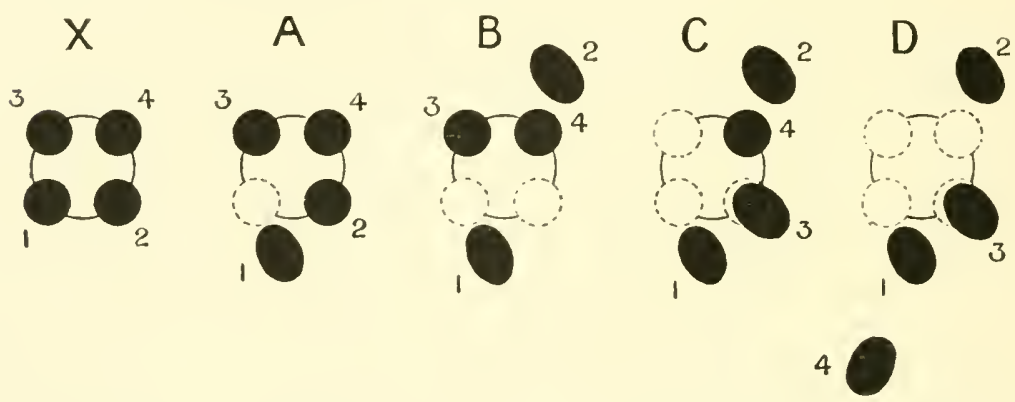

FIG. 52.-The successive and violent discharge of the four spores from the basidium of Psalliotu compestris. Part of a gill was laid flat in a compressor cell. The basidium looked upwards and was observed from above. $X$ the basidium, with its four ripe spores. The appearance of the basidium imme. diately after the discharge of spores $1.2,3$, and 4 is shown at $\mathrm{A}$. B, C. and D respectively.

hours had been spent at this task, a basidium was seen to discharge all its spores. Sketches were made after the discharge of each spore and are reproduced in Fig. 52. When one watehes the discharge of a spore, all that one can see is that the spore suddenly disappears from its sterigma and immediately appears again in a new position on the hymenium. In Fig. 52, X shows the appearance of the four spores on the basidium before discharge, and A, B, C, and D illustrate what was seen immediately after the discharge of spores Nos. 1, 2, ?3, and 4 respectirely. It is clear that the spore No. 2- (B) must have jumped over No. 4 to get into the position it came to occupy after discharge. Similarly, No. 4 (D) must have jumper over No. 3. A study of this case 
and many others, where only the last spore or the remaining two or three spores were observed to be discharged, has convinced me that the spores when liberated must be shot upwards for a little distance before falling on to the hymenium. Doubtless the spores were shot not quite vertically upwards, but nearly so. Hence the various positions of the spores after settling.

In the Coprini, it is exceedingly easy to observe the discharge of spores from the basidia near the edge of a "deliquescing" gill. As before, it is necessary to place the gill or piece thereof flat in a closed compressor cell to prevent too rapid loss of water and consequent collapse of the basidia. With the low power of the microscope one can then observe large numbers of basidia actively shedding their spores (Plate II., Fig. 12). The phenomenon has quite a fascination of its own. The spores, after disappearing from the sterigmata, very frequently immediately reappear on the hymenium at some distance from the basidia on which they have been developed. There is no essential difference between the Mushroom and the Coprini in regard to what one sees by using Method IV. Fig. 52 might equally well apply to the basidium of a Coprinus comatus or C. plicatilis.

One fact which is yielded by the above observations, and has an important bearing in explaining the mechanism of spore-discharge, is that the four spores of a basidium are not shot off their sterigmata simultaneously but successively. The succession of discharges in the particular instance shown in Fig. 52 occupied twenty minutes. There was an interval of a few minutes after each one before the next took place. It is quite certain that usually the four spores of a basidium are not discharged together. When one looks at the hymenium of a Mushroom gill in face view, it is easy to observe that many of the ripe basidia have only one, two, or three spores left upon them. In many instances the successive discharge of two or three of the spores was actually watched. In Coprinus comatus one can make similar observations with great ease. I have watched hundreds of basidia discharge their spores in this species, yet never once have I seen all four spores of a basidium discharged together. Here, as in the Inshroom, the four spores of a basidium disappear from their sterigmata one by one, in the course of one or a few minutes. 
The same results were obtained with Comminus plicutilis and C. micaceus. In the alreary-mentioned footnote to Brefold's description of $(\because$ stercomius, it is stated that the spores ale all discharged simultaneously. Although I have not had an opportunity of examining this species, I think it highly probable that it discharges its spores in the same mamner as other Coprini, and that Brefeld's statement will not be corroborated by further observation.

Whilst using Method I. it was often easy to observe single ripe basidia and to watch the disappearance of some of the spores. Thus,

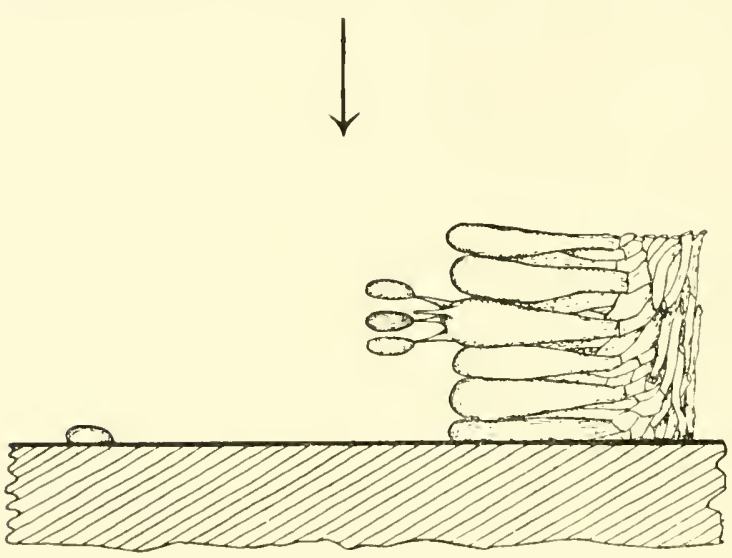

FIG. 53.-Diagram showing the appearance of part of the hymenium at the base of a section of a hymenial tube of Polyporus squamosus ( $f$. Fig. 47, p. 13j). The arrow indicates the direction of observation. A basidium bearing four ripe spores and the top of the glass slide were included in the range of focus. The figure shows the position of one of the spores on the glass slide after being discharged to six times its own length from the basidium. in the ease of Polyporus squamosus, in one instance three spores left a basidium at intervals of twenty seconds, whilst the fourth remained on its sterigma for some minutes afterwarls and was not seen to disappear. In another instance two of the four spores left a basidium within a few seeonds of one another. A large number of observiltions, obtained by using Methods $I$. and $1 V$., have convineed me that in very many species the spores are discharged from a ripe basidium, not simultaneously, but successively one atter the other. It seems to me highly probable that this is a general rule throughout the Hymenomycetes.

Method V.-A transverse section through the hymenial tubes of Polyporus squumosus (Fig. 17) was mate and placed on a glass slide in the same manner as was done for Method I. The basidia thus came to occupy their nomal horizontal positions. The discharge of spores was watched with the ordinary vertical microscope. I con- 
centrated my attention upon a ripe basidium which projected horizontally from the hymenium in one of the tubes at a very short distance above the glass slide (Fig. 53). So near was the basidium to the slide that I was able to have both spores and glass surface within the range of focus at the same time. After I had watched for a long time, one of the spores suddenly left the basidium and became deposited on the glass slide some six times its length from the basidium. It had therefore been shot along just above the glass surface for a distance of $6 \times 13 \mu$ or $0.078 \mathrm{~mm}$. The observation just recorded, although the only one of its kind that I have been able to make, seems to give another convincing proof of the fact of violent spore-projection. The actual movement of the spore from the basidium to its place of rest on the glass slide was not seen, although I was watching with concentrated attention for the express purpose of observing it. However, certain mathematical considerations soon to be treated of, indicate that it is highly improbable, if not impossible, that one should perceive the horizontal motion, however carefully one might make one's observations. 


\section{CHAP'IER XII}

THE MECHANISM OF SPORE-DISCHARGE

Ix the last chapter it was shown that the spores of Hymenomyeetes are discharged from the sterigmata in a violent manner. The mechanism by which this process is brought about will now be diseussed.

Brefeld, ${ }^{1}$ in a footnote to his account of the life-history of Coprinus stercorarius, has stated that all the four spores of a basidium are discharged simultaneously, and that, immediately after a discharge, small drops are left upon the vacant sterigmata and also on the spores. He came to the obvious and apparently sufficient conclusion that the spores are shot forward on account of the bursting of the sterigmata and the ejaculation of their contents. However, after studying the discharge of spores in several species of Coprinus, as well as in Polyporus squamosus, Psalliote campestris, \&c., I find myself unable to confirm Brefeld's observations. The facts brought forward in the last chapter ${ }^{2}$ afford conchusive proof that the four spores of a basidium are diseharged not simultaneously but suecessively. By applying my Method IV. ${ }^{3}$ to the examination of a gill margin (Plate II., Fig. 12) of a ripe Coprinus fruit-body, any one may observe the sucessive diseharge of the four spores from seores of basidia in a fer minutes. The shooting off of all four spores usually oceupies from about one to several minutes. At the moment of discharge of the spores from the basidia of Coprinus comutus, Polyporus squamosu., \&c., I have endeavoured to observe drops on the vacant sterigmata, but without success; nor, by using my Method I., ${ }^{4}$ have I been able to deteet drops on any spores as

\footnotetext{
Brefeld, loc. cit.

${ }^{3}$ Chap. XI.
}

2 Ender Method IV.

4 Chap. XI. 
soon as they have settled on glass immediately after leaving the basidia. ${ }^{1}$

For the purpose of finding out the mechanism of sporedischarge, a transverse section through the hymenial tubes of Polyporus squamosus was cut, and the horizontal basidia looked down upon with the vertical microscope as already described for Methods I. and V. ${ }^{2}$ A particular basichium, bearing four apparently ripe spores, was carefully focussed. After a watch had been kept for some time, one of the spores suddenly disappeared. The end of the sterigma left racant was then seen to be pointed and entirely devoid of any drop of fluid (cf. Fig. 53, p. 146 ; also Plate I., Fig. 3, and Plate III., Fig. 16). The vacant sterigma also appeared to be quite as long and as turgid as the other three still bearing spores. The basidium did not seem to have altered in volume. There was nothing to suggest that the sterigma had opened and discharged a mass of fluid through its very fine neck. The end of the sterigma, which is only about $0.5 \mu$ wide, gave the impression of being closed. Subsequently two further discharges of spores were observed. There was an interval of a few minutes between two successive discharges. Again, each sterigma, immediately after discharging its spore, appeared to be pointed at its end and devoid of any terminal drop of fluid. Even when three spores had been discharged, I was unable to observe any collapse of the basidium. All four sterigmata appeared to be equally turgid. The fourth spore remained on its sterigma for more than half-an-hour after the discharge of the third and was not seen to disappear. In several other instances one or two

1 Massee, in his Text-Book of Fungi (London, 1906), says: "In the Hymenomycetes the mature spore is cut off from the apex of its sterigma by a transverse wall. The sterigma retains its parietal protoplasm after the spore is cut off, and its elastic wall continues to stretch as the tension due to the accumulation of water increases. When the tension reaches a certain point, the wall of the sterigma ruptures in a circular manner just below the septum at its apex; the elastic wall of the sterigma instantly contracts and forces its contained water to strike the apical transverse wall, which is thus thrown off along with the spore seated upon it." The reader is unfortumately left in doubt as to the anthority upon whom reliance has been placed for these statements. The account of sporedischarge, however, is similar to that of Brefeld and merits the same criticisms.

${ }^{2}$ Chap. XI. 
spores were observed to be discharged from the sterigmata in precisely the same manner as that described. Similar results were obtained with Murusmius oreudes and Coprinus comutus.

The small size of the basidia and the difficulty of seeing the narrow neck of a sterigma where it is joined on to a spore, make it extremely difficult to observe what physical change takes place at the end of the sterigma at the moment of spore-discharge. However, after consideration of all the observed facts, it scems to me that some conclusion as to the mechanism of the process niay be drawn.

The first theory of spore-discharge which we may consider is, that the four spores are shot off the sterigmata owing to the latter breaking at their ends and discharging drops of fluid consisting of cell-sap driven out of the basidium by the contraction of the cell-wall. ${ }^{1}$ I fail to find any facts in favour of this conception. No drops could be detected on the sterigmata or spores immediately after discharge. The disappearance of the spores did not lead to any observable collapse of the sterigmata or basidium. A strong adverse argument may also be derived from the fict that the spores are discharged successively. A basidium is unicellular. If, when a spore was discharged, the sterigma broke across and a drop of fluid was forced out, the hydrostatic pressure in the basidium would be very considerably lessened. There would be a puncture in the cell. Under such conditions it seems difficult to imagine how the pressure could be used again for the successive discharge of the three remaining spores.

It seems to me that the clue to explain the mechanism of spore-discharge can be obtained from comparative studies in other groups of fungi. In the Ascomycetes, e.g. Ascobolus, the spores are evidently driven out of the ascus by the pressure of the cellwall upon the cell-sap. The end of the ascus suddenly breaks open, the ascus collapses, and the eight spores are discharged simultaneously along with the cell-sap. A similar mechanism is to be found for Pilobolus and Empusa Musce. There is, however,

1 We may suppose hy analogy with other plant cells that the pressure of the cell-sap upon the protoplasm and wall of the basidium is due to the process of osmosis, and amounts to several atmospheres. 
another way in which the hydrostatic pressure may be used as a driving force. This is illustrated in several Entomophthorinee. In Empusc Grylli, according to Nowakowski, ${ }^{1}$ the wall separating the conidium from the basidium is double. There is a tiny columella projecting into the former. When the conidium is ripe, the two walls separate by mutually bulging in opposite direetions in response to hydrostatic pressure both in the conidium and the basidium. In consequence of the bulging taking place very rapidly, the spore is shot forwards to some distance. It thus happens that the basidium is not punctured in discharging its spore, and therefore does not lose any eell-sap. The basidium merely alters its shape. It becomes slightly enlarged terminally, whilst doubtless contraetion takes place laterally. Probably during this process the hydrostatic pressure of the cell-sap upon the cellwall becomes slightly diminished. We have a process which we may distinguish as the jerking discharge as opposed to the squirting discharge of Empusc Musce and Ascobolus, Se.

It appears to me very probable that the four spores are discharged from the basidia of Hymenomycetes by a jerking process essentially similar to that just described. This hypothesis involves the assumption of a double wall separating the sterigma and spore, and that the two walls mutually bulge so as to press against one another when spore-discharge takes place. That such a double wall in each sterigma must be present seems to be proved by the fact that both spore and sterigma are turgid after discharge. The pointed "tail" of each spore and the pointed end of the sterigmata after becoming naked are facts in favour of the idea of a mutual bulging of the two walls which were in contact. The hydrostatic pressure in the basidium would be only very slightly diminished as each spore was shot off and would be available

1 Quoted from Ilie Pflansen-familien of Engler and Prantl, who reproduce Nowakowski's figures. 'Teil 1, Abteil 1, Entomophthorinex, p. 135.

2 In Basidiobolus runarum we have both squirting and jerking processes in succession. The basidium first breaks across, and the outer end with the spore is shot away by the squirting process. The spore is then shot off the collapsed end of the basidium by the jerking process. The spore-wall at the place of attachment bulges ont so as to become pointed. In Conidiobolus utriculosus, apparently, sometimes the squirting process is used and sometimes the jerking. see Engler and Prantl, loc. cit. 
for the diseharge of them all. The great difficulty in verifying this hypothesis is that of observing what happens to the end of the sterigma at the moment of spore-diseharge. However, the following facts seem to be distinctly in its favour: (1) Successive discharge of the four spores, (2) absence of drops on the end of the sterigmata or on the spores immediately after discharge, (3) apparent closed condition of the sterigmata after ejecting their spores, and (4) non-collapse of the sterigyata and basidium as the spores disappear. 


\section{CHAP'TER XIII}

\section{THE SPECIFIC GRAVITY OF SPORES}

THE measurements described in this and the following chapter were made chiefly with the object of testing Stokes' Law.

In order to determine the specific gravity of spores, the heavyfluid method was employed. Owing to the minute size of the spores and their very slow rate of fall even in water, and also in order to reduce convection currents to the least possible minimum, it was found necessary to use a special small chamber with which to carry out the tests. After several chambers had been tried, the most suitable one proved to be an ordinary Leitz-Wetzlar counting apparatus, such as is used for estimating the number of blood-corpuscles in drops of blood. In the chamber in question the distance between the cover-glass and the central disc is only $0.1 \mathrm{~mm}$.

The mode of procedure in making the experiments was as follows: A fresh fungus was obtained, and its pileus was cut off and placed on a piece of glass or paper, where, in the course of a few minutes or hours, a spore-deposit collected. Some drops of the solution to be tested, namely, calcium chloride of known specific gravity, were then poured into a small beaker. Spore masses were scraped up from the spore-deposit with a needle and placed in the solution. This was then stirred vigorously, so that the spores became well separated and fairly evenly suspended in it. A drop of the fluid containing the spores was next placed in the Leitz-Wetzlar apparatus and the cover-glass applied. If the spores were heavier than the incdium in which they were suspended, they gradually sank and collected on the bottom of the chamber. If they were lighter, they gradually rose and collected beneath the cover-glass. The end-result by this means could usually be determined in a few minutes. Convection currents 
are practically redneed to nothing in the chamber, and the spores had to travel at most upwards or downwards only a distance of $0.1 \mathrm{~mm}$. By focussing and watching an individual spore in the thuid, one could quiekly decide whether it was falling or rising.

The results of the tests for Psalliota cumpestris, Coprinus plicutilis, and Amanitopsis vaginatu are given in the following table, where $R$ indieates that the spores rose in the fluid, $S$ that they sank, and RS that about equal numbers rose and sank respectively:-

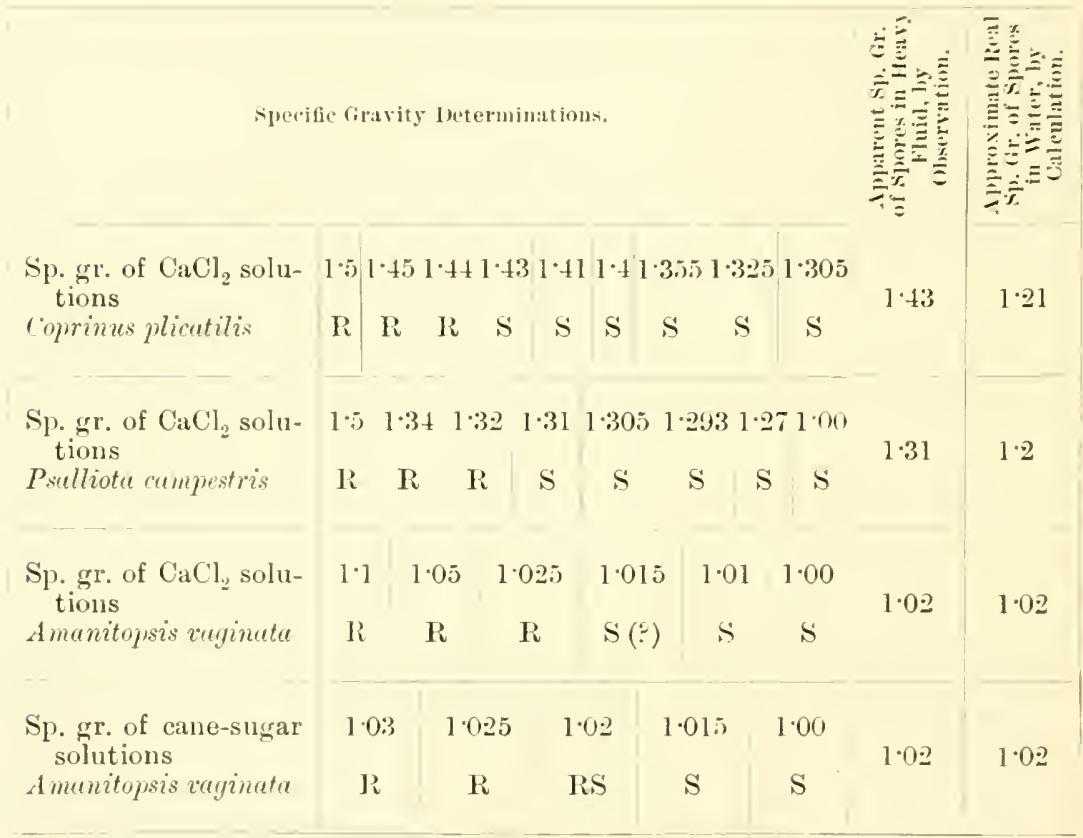

When fresh spores are placed in water they are turgid and fully expanded, and present the same appearanee as they have when just about to be liberated from their sterigmata. However, in solutions of calcium chloride the spores decrease in size. In many species they become obviously deformed. 'The spores of Psulliota cumpestris in a caleium chloride solution of sp. gr. 19.92 are indented on one side, and the spores of Coprinus plicatilis in a solution of sp. grr. 1.4 have the shortest of their three axes (cf. Fig. 55, A, p. 16\%) redueed to nearly one-half. The decrease 
in volume, if such there is, in spores of Amanitopsis vaginata in a solution of sp. gr. 1.02 is so small as not to be observable. The heavy-fluid tests only give us the apparent specific gravity of the spores. There seems to be little doubt that the decrease in volume is due to loss of water which passes out from the spores by osmosis in accordance with well-known laws. Loss of water from the spores must of necessity increase their speeific gravity, for the salts and other bodies heavier than water must thereby become concentrated. We can conclude, therefore, that the apparent specific gravity of the spores in the heavy fluid is greater than the specific gravity of the spores when fully expanded in water. The tests with the solutions inform us that the true specific gravity of the spores is between 1 and 1.43 for Coprinus plicatilis, between 1 and 1.32 for Psalliota campestris, and between 1 and 1.02 for Amanitopsis vaginata. In the last-named species the result obtained with calcium chloride was confirmed by means of a solution of canesugar.

By determining the loss of volume of spores of Coprinus plicatilis when placed in a calcium chloride solution of sp. gr. 143, I have been able to caleulate approximately the true specific gravity of the spores in water.

With the aid of a Poynting Plate Mierometer the spores were measured with a considerable degree of accuracy. Ten long, ten short, and ten intermediate axes were measured, each measurement being made on a different spore. The average size of the spores was thus found to be-

$$
\begin{aligned}
& \text { In water . . . . . . . } 12.54 \times 10.33 \times 8.14 \\
& \text { In } \mathrm{CaCl}_{2} \text { solution, sp. gr. } 1.43 \quad \text {. } 11.76 \times 10 \cdot 18 \times+5
\end{aligned}
$$

By multiplying the three axes together we can ealculate that on the average for each spore-

(volume in water) : (vol. in $\mathrm{CaCl}_{2}$ solution, sp. gr. 1.43) : : 1054 : 538.

We may conclude, therefore, that when a spore is taken from water and placed in the calcium ehloride solution, its volume is approximately halved.

Now, it may be shown that

$$
(1-x) v s+x v s^{\prime \prime}=v s^{\prime}
$$


where $x$ represents the fractional loss of volume in the heavy fluid, $v$ the volume of the spore in water, $s$ the apparent specifie gravity of the spore in the heavy fluid, $s^{\prime}$ the trie specific gravity of the spore in water, and $s^{\prime \prime}$ the specific gravity of water itself.

Since $x=\frac{1}{2}, s=1 \cdot 43$, and $s^{\prime \prime}=1$, we find that $s^{\prime}=1 \cdot 215$, or the true specitie gravity of the Coprinus spores in water is approximately $1 \cdot 21$.

In the case of the Mushroom, owing to the spores becoming indented on one side, the exact loss of volume of the spores in a calcium chloride solution of sp. g1. 1.31 could not be measured directly. However, it was estimated by inspection as being from about one-third to one-half of the volume in water. On this assumption we may calculate from the equation already given that the specitic gravity of Mushroom spores is approximately $1 \cdot 2$.

The Amanitopsis spores did not show any appreciable contraction in the calcium chloride solution or cane-sugar solution of sp. gr. 1.02. Since we have already found that the real speeific gravity of the spores in water must lie between 1 and 1.02 , we may take it that the real specifie gravity is approximately 1.02 . This approximation must certainly be correct to within 1 per cent. of the actual specific gravity.

Another method for estimating the specific gravity of spores is that of measuring the rates of fall of the spores in air and in water. The data so obtained are then used in the following equation, which can be deduced from Stokes' Law which must be assumed to be true:-

$$
\frac{r^{\prime}}{v}=\frac{\rho-1}{\rho} \times \frac{\mu}{\mu^{\prime}}
$$

where $v^{\prime}$ is the velocity of the fall of spores in water, $v$ the velocity of fall in air, $\mu$ the viseosity of air, $\mu^{\prime}$ the viscosity of water, and $\rho$ the specific gravity of spores.

A counting apparatus, with a chamber $1 \mathrm{~cm}$. square above and below and $0.2 \mathrm{~mm}$. deep, was used for estimating the rate of fall of the spores in water. The chamber was filled with water holding spores in suspension and eovered with a cover-glass. A microseope was then turned into the horizontal position and the counting apparatus elamped down to the now vertically-placed stage. The 
convection currents in the chamber, although not entirely absent, appeared to be negligible. In the case of Coprinus plicatilis, ten spores were carefully timed in falling through a field of $1.6 \mathrm{~mm}$. in width. On the average each spore took 2 mins. 57 secs. to fall this distance. The velocity of the fall of the spores in water was thus found to be $0.00090 \mathrm{~cm}$. per second. The velocity of fall of the spores in air was found by finding the time required for them to fall vertically through a distance of $4.55 \mathrm{~mm}$. from pieces of gills placed in a small compressor cell. ${ }^{1}$ The speed was found to be $0.429 \mathrm{~cm}$. per second.

Putting $v^{\prime}=0.0009, v=0.429, \mu=1.8 \times 10^{-4}$, and $\mu^{\prime}=1.2 \times 10^{-2}$, we get $\rho$, the specific gravity of the Coprinus spores, $=1 \cdot 16$.

With ILushroom spores it was found that $v^{\prime}=0.00025$ and $v=0 \cdot 13$, whence $\rho=1 \cdot 15$.

Both results are within 6 per cent. of those obtained by the other method. The present method seems to me to be less reliable than the first on account of its indirectness and the assumptions involved. Stokes' Law was assumed to be true: the spores were not spherical. Possibly the errors in estimating the rates of fall of the spores in water are quite appreciable. Nevertheless, the result may be correct to within 10 per cent.

If we take the results given by the heavy-fluid method to be fairly reliable, we may conclude that the specific gravities of the spores are as follows: for Coprimus plicatilis 1221, for Psalliota campestris 1.2, and for Amanitopsis vaginata 1.02. The spores of the last-named species are much lighter than those of the other two. This is probably due to the very large amount of oil which the spores of Amanitopsis contain. The oil is certainly a very light constituent of each cell, for, when a spore is falling in water, the large oil mass, as seen with the horizontal microscope, occupies the highest position possible. On account of the spores of Amanitopsis vaginata having about the same specific gravity as water, it was not found possible to measure the rate of their fall in that medium. Their motion was so slow that even minute convection currents proved to be a serious source of error in making the measurements.

1 Vide infra, Chap. XV. 


\section{CHAP'TER XIV}

\section{THE SLYE OF SPORES-POYNTINGS PLATE MICROMETER}

Each species produees spores of a definite shape and size. The spores vary in size about a mean, doubtless in accordance with the now well-known laws of continuous variation. The variations as a rule are within fairly restricted limits, so that fungus spores, when observed with a microscope, appear to resemble one another very much as do eggs laid by a fowl. By measuring the diameters of twenty-five spores of any fruit-body, one can obtain an arerage size which is eorrect to within a very small percentage of the real a verage for all the spores. It must not be assumed, however, that all the individual fruit-bodies of a speeies have spores of the same arerage size. Thus, for instance, three specimens of Amanitopsis raginata, obtained from the same wood on different days, possessed spores with an average diameter of $11.65 \mu$, $10.87 \mu$, and $10.19 \mu$ (Fig. 55, B, C, D, p. 162). It is not surprising that the spore sizes for species as given by systematists often disagree.

For the purpose of measuring spores rapidly and accurately I have made use of Poynting's Plate Micrometer, ${ }^{1}$ a simple and exact piece of apparatus which should come into general use in all investigations where it is necessary to measure the sizes of numerons small bodies. Sinee it seems that I am the first to apply the Plate

1 The Plate Micrometer with which 1 worked was Professor Poynting's original instrument. My thanks are due to him for kindly permitting me to use it in his laboratory. It was exhibited at an Optieal Convention held in London four yeurs ago. In the I'roremlings of the Oytiral Contrution, No. 1, Londom, 1905, a one-page accomt of the principle of the micrometer is giren, but this would be of little use to any one wishing to understand how the measurements of spore dimensions were made. Profossor Poynting has informed me that he has not yet published an adequate description of the Plate Hicrometer as applied to the mieroseope, but he has consented to my attempting to slow how the instrument may be used in practice. 
Micrometer in a biological research, a brief description of it here will not be out of place.

The apparatus is provided with a stand, Plate IV., Fig. 26, st, attached to which is a horizontal arm, $a$, bearing at its end a rertical seale, $s c$. The scale is divided into fifty parts, with the zero at the top. A carefully prepared plate of glass, $6 \mathrm{~mm}$. thick, $p$, with parallel upper and lower faces, is attached to a horizontal rod, $r$, which is fixed to the stand so that it can be rotated about its axis by means of a lever, $l$. The end of the lever carries a small framework in which is placed a piece of glass. On the latter is scratched a fine line parallel to the arm of the lever. The line serves to indicate the position of the lever on the seale. The microscope is provided with a mechanical stage. It also has a slot, $s l$, in the tube above the objective, of such a size that the glass plate can readily be inserted into it. The eyepiece contains a transverse silk thread.

When the apparatus is about to be used, the glass plate is inserted into the slot so that it becomes entirely enclosed in the microscope tube, which, however, it does not touch. The eyepiece is then rotated until its silk thread comes to be parallel to the rod, $r$, bearing the glass plate.

The seale, $s c$, is calibrated as follows. The lever is first raised until the line in the terminal framework exactly crosses the zero of the scale. A stage micrometer is then placed on the microscope stage so that its dividing lines are parallel to the thread in the eyepiece. By using the mechanical stage one of the micrometer lines is made to coincide with the thread of the eyepiece. The lever is then depressed. This causes the glass plate to rotate slightly. As one looks down the inicroscope, the micrometer line appears to move parallel to itself away from the eyepiece line. By depressing the lever far enough, one can make a second stage mierometer line coincide with the eyepiece line. Let us suppose that the distance between the two micrometer lines is $10 \mu$, and that the lever has been moved downwards through twenty-six divisions on the vertical scale, it is then elear that each scale division has the value $\frac{5}{13} \mu$. By making ten measurements between ten successive divisions of the 
stage micrometer, one can obtain a very accurate value for each division of the plate micrometer scale.

When the scale has been calibrated by the method just described, one proeeeds to measure the size of spores. 'These are mounted in water on a glass slide and covered with a cover-glass in the usual way. The lever is placed at zero. One then finds a spore with the axis to be measured directed at right angles to the eyepiece line. ${ }^{1}$ Let us suppose that one wishes to measure the long axis. With the mechinical stage one moves the spore so that one end of it just tonches the eyepiece line (Fig. it). One then depresses the lever

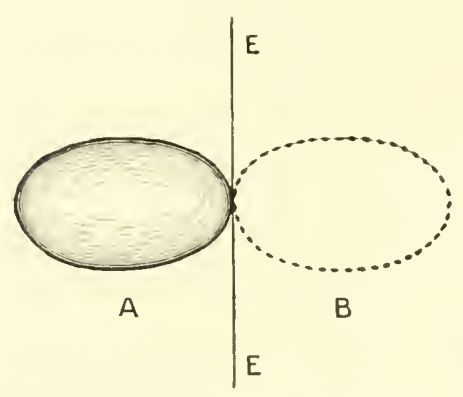

Fic. 54.-Measurement of a spore by means of the Poynting Plate Micrometer. By depressing the lever the spore appears to move across the eye-piece line EE from position A to position B. from the zero of the scale, and as one does so the spore appears to move across the eycpiece line from left to right, until finally it comes to touch it with its other end. At this point one ceases to depress the lever and reads off the number of divisions on the scale through which it has been moved. By measuring twenty-five spores in this way, one can obtain a very good average on the scale for the dimensions required. Since the actual value of a plate micrometer scale division has previously been found by calibration, the dimensions of the spores can readily be calculated.

The advantages of the apparatus are: (1) Its optical soundness - each division on the vertical scale has the same value; (2) the apparatus is entirely detached from the mieroscope, so that, when the lever is moved, the microscope cannot be shaken in any way (3) the accuracy with which the scale can be calibrated; (4) its simplieity: (5) the speed and ease with which large numbers of observations can be made with it.

The range of variation in the sizes of spores may be gathered

1 With the addition of a rotating stage one conld place any spore with its axis in the desired direction. My microscope, unfortunately, was without this refinement. There is, however, very little difticulty in finding as many spores as one requires with their axes in the right direction. 
from the following example, which gives the plate micrometer scale figures obtained for the diameters of 100 fresh spores of Amanitopsi. vaginata (Specimen III.) measured in water :-

\begin{tabular}{rrrrrrrrrr}
$41 \cdot 0$ & $43 \cdot 0$ & $40 \cdot 1$ & $45 \cdot 5$ & $40 \cdot 7$ & $41 \cdot 3$ & $40 \cdot 8$ & $47 \cdot 5$ & $38 \cdot 5$ & $42 \cdot 7$ \\
$39 \cdot 5$ & $41 \cdot 5$ & $39 \cdot 5$ & $36 \cdot 0$ & $43 \cdot 6$ & $43 \cdot 0$ & $38 \cdot 6$ & $40 \cdot 2$ & $43 \cdot 1$ & $39 \cdot 0$ \\
$40 \cdot 0$ & $36 \cdot 5$ & $43 \cdot 4$ & $42 \cdot 0$ & $47 \cdot 0$ & $42 \cdot 7$ & $37 \cdot 4$ & $38 \cdot 0$ & $40 \cdot 0$ & $41 \cdot 8$ \\
$45 \cdot 0$ & $38 \cdot 0$ & $35 \cdot 0$ & $39 \cdot 5$ & $40 \cdot 7$ & $36 \cdot 8$ & $44 \cdot 7$ & $36 \cdot 0$ & $45 \cdot 0$ & $43 \cdot 0$ \\
$40 \cdot 2$ & 45.5 & $39 \cdot 2$ & $40 \cdot 8$ & $43 \cdot 5$ & $42 \cdot 5$ & $39 \cdot 8$ & $43 \cdot 4$ & $39 \cdot 8$ & $39 \cdot 4$ \\
$42 \cdot 8$ & $41 \cdot 5$ & $39 \cdot 0$ & $44 \cdot 0$ & $42 \cdot 3$ & $39 \cdot 7$ & $39 \cdot 8$ & $48 \cdot 0$ & $41 \cdot 4$ & $46 \cdot 2$ \\
$35 \cdot 6$ & $38 \cdot 0$ & $38 \cdot 7$ & $41 \cdot 0$ & $43 \cdot 4$ & $35 \cdot 2$ & $43 \cdot 0$ & $39 \cdot 5$ & $40 \cdot 4$ & $36 \cdot 1$ \\
$40 \cdot 8$ & $39 \cdot 4$ & $40 \cdot 0$ & $41 \cdot 0$ & $40 \cdot 5$ & $36 \cdot 1$ & $40 \cdot 0$ & $41 \cdot 0$ & $42 \cdot 1$ & $41 \cdot 3$ \\
410 & $38 \cdot 4$ & $42 \cdot 0$ & $43 \cdot 6$ & $40 \cdot 7$ & $39 \cdot 2$ & $40 \cdot 5$ & $38 \cdot 0$ & $38 \cdot 1$ & $41 \cdot 0$ \\
$41 \cdot 6$ & $42 \cdot 5$ & $41 \cdot 4$ & $40 \cdot 5$ & $40 \cdot 8$ & $45 \cdot 4$ & $43 \cdot 9$ & $40 \cdot 8$ & $39 \cdot 4$ & $36 \cdot 6$ \\
\hline $407 \cdot 5$ & $404 \cdot 3$ & $401 \cdot 5$ & $413 \cdot 9$ & $42 \cdot 2 \cdot 6$ & $404 \cdot 9$ & $408 \cdot 5$ & $412 \cdot 4$ & $407 \cdot 8$ & $407 \cdot 1$
\end{tabular}

The average seale measurement for the spore diameters of 100 spores was found to be 40.905 . The ealibration figures for ten successive distances of $10 \mu$ each on a stage micrometer were as follows : ${ }^{1} 345,36 \cdot 1,35 \cdot 0,35 \cdot 1,36 \cdot 0,34 \cdot 5,34 \cdot 5,35 \cdot 4,36 \cdot 0,34 \cdot 5$, whence it was calculated that $\mu=351$ plate micrometer seale divisions. The average diameter of 100 spores, therefore, $=\frac{40.505}{351}=11 \cdot 65 \mu$.

The Table on page 162 gives some of the results of measurements with the Poynting Plate Mierometer. Each measurement given is the average of 25 or 50 measurements of 25 or 50 spores respectively. The last column gives the value Jlong axis $\times$ short axis.

Illustrations of all the spores in the Table are given in Fig. 55.

From the Table the general range in size of the spores of Agaricinex may be gathered.2 The very large spores of Coprinus. plicatilis are about twenty-two times the volume of the very small spores of Collybia dryoplita. In all eases, however, and this may be stated quite generally for the Hymenomycetes, the spores are so small that they must fall in the manner indicated by Stokes' Law, i.e. almost immediately after liberation (within a very small

1 The differences between these readings are due to errors in the construction of the stage micrometer, and not to any want of delicacy on the part of the Plate Micrometer.

2 The largest spores of any known Agaric are those of the exceptional Copminus gigasporus, which measure $28-30 \times 14-16 \mu$. G. Massee, "A Revision of the Genus Coprinus," Ann. of Bot., vol, 10, p. 123. 
fraction of a single second) they must fall without acceleration at a uniform speed. The size of the spores is also such that this

\begin{tabular}{|c|c|c|c|c|c|}
\hline speries. & & & 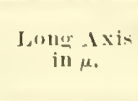 & $\begin{array}{l}\text { Short } A x i s \\
\text { in } \mu \text {. }\end{array}$ & $\begin{array}{c}\text { Geometrical } \\
\text { Mlatin of the } \\
\text { 'Jwo Axose } \\
\text { in } \mu \text {. }\end{array}$ \\
\hline Collylia dryophila & - & . & $5 \cdot 44$ & $3 \cdot 23$ & $4 \cdot 2$ \\
\hline Pluteus cervinus. & . & . & $5 \cdot 9.5$ & $4 \div 57$ & $5 \cdot 2$ \\
\hline Paxillus involutus & . & . & $7 \cdot 48$ & $4 \cdot 98$ & $6 \cdot 0$ \\
\hline Psalliota campestris : & & & & & \\
\hline Grown on a bed, I. & . & . & $7 \cdot 17$ & $5 \cdot 41$ & $6 \cdot 25$ \\
\hline$, \quad, \quad, \quad$ II. & . & . & $7 \cdot 26$ & $5 \cdot 35$ & $6 \cdot 25$ \\
\hline$, \quad, \quad, \quad$, III & & . & $7 \cdot 32$ & $5 \cdot 64$ & $6 \cdot 4$ \\
\hline From a lield, IV. & & . & $9 \cdot 7$ & 580 & $7 \cdot 4$ \\
\hline Marasmius oreades & . & . & 995 & $5 \cdot 6$ & $7 \cdot 4$ \\
\hline Boletus badius . & . & . & $12 \cdot 8$ & $4 \cdot 29$ & $7 \cdot 4$ \\
\hline Amanita rubescens & . & . & $9 \cdot 38$ & $6 \cdot 5.3$ & $7 \cdot 8$ \\
\hline Galera tenera . & . & . & $10 \cdot 47$ & $6 \cdot 06$ & $7 \cdot 96$ \\
\hline Russula emetica. & . & . & $8 \cdot 8:$ & $7 \cdot 50$ & $8 \cdot 2$ \\
\hline Polyporus squamosus & . & . & $14 \cdot 6$ & $5 \cdot 1: 3$ & $8 \cdot 7$ \\
\hline Coprinus comatus & & . & $(2 \cdot 5 \%$ & 7.48 & $9 \cdot 8$ \\
\hline Amanitopsis vaginata, & I. . & . & \multicolumn{2}{|c|}{$10 \cdot 19$} & $10 \cdot 19$ \\
\hline ,, & II. . & . & \multicolumn{2}{|c|}{10.87} & 1087 \\
\hline " $\quad "$, & III. . & . & \multicolumn{2}{|c|}{$11 \cdot 65$} & $11 \cdot 65$ \\
\hline Coprinus plicatilis & . $\quad$. & . & $12 \cdot 9$ & $7 \cdot 9$ & $11 \cdot 8$ \\
\hline
\end{tabular}

uniform speed is only about $0 \cdot \tilde{J}-6 \mathrm{~mm}$. per second. The spores, therefore, are so tiny that even the slightest air-currents can

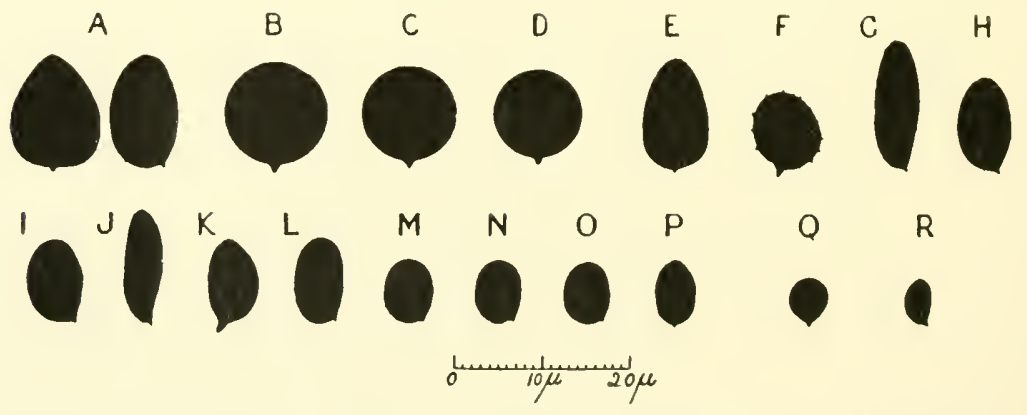

FIG. 55.-The average spore's of individual fruit-bodies of ritrions species of Hywenomycetes, A, Coprinus plicatilis; B. C. and D, three indiriduals of Amanitopsis vaginata; L. Coprinus comatus; F. Russula rmetica: G, P'olyporns squemosus: H, Gulere teneru; I. Amunita rubeserns : J, Boletus badius ;

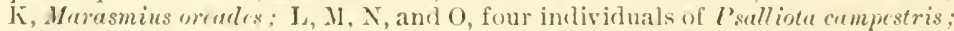
P, P'uxillus involutus: Q, l'luteus crreinus; R. Collybie dryophila.

carry them long distances away from the fruit-bodies upon which they have been developed. 
The difference between the average size of the spores for individual fruit-bodies is indicated by the results obtained for Psalliota campestris and Amanitopsis vaginata. The field Mushroom probably belonged to a variety distinet from that of the cultivated ones. It was eharacterised not only by relatively much longer spores but also by much deeper gills.

The average diameter of the spores for Speeimen III. of Amunitopsis vaginata was 14.3 per cent. larger than the average size for Speeimen I. It is clear from this instance that fruitbodies of the same species may have eonsiderable individual variability in regard to the average size of their spores. 


\section{CHAP'TER XV}

THE RATE OF FALL OF SPORES AND STOKES' LAW-APPENDIX

So long agro as 1851 Stokes" published a paper called "On the Effect of Internal Friction of Fluids on the Motion of Pendulums." In the course of a mathematical treatment of his data, he dedueed an equation expressing the relations between the density of a falling microscopic sphere, the size of the sphere, the velocity of its fall, the density of the fluid through which it may fall, and the viscosity of the fluid. The equation represents what is known as Stokes' Law:"

$$
V=\frac{2 \rho-\sigma}{9} \mu a^{2}
$$

where

$$
\begin{aligned}
& V=\text { the terminalivelocity, } \\
& \rho=\text { the density of the falling sphere, } \\
& \sigma=\text { the density of the medium, } \\
& g=\text { the acceleration due to gravity. } \\
& a=\text { the radius of the falling sphere, } \\
& \mu=\text { the riscosity of the medium. }
\end{aligned}
$$

For more than forty years this equation remained untested for the fall of small particles in air and other gases. 'This, no doubt, was due to the technical difficulties of procuring mieroscopic spheres of known density and size, and of dropping them through gascons media in such a manner that their rate of fill could be measured. 'The verification of Stokes' Law by means of such experiments has recently become of some importance owing to the necessity of assuming it in investigations upon the electronic charge as made by J. J. 'Thomson ${ }^{3}$ with the elond method.

The only evidence hithertos adrhced to show that Stokes' Law

1 G. Stokes, C'amls. Phit. Trmus., vol. ix., Part II., l. \&.

2 'f. the Appendix to Chap. XVII.

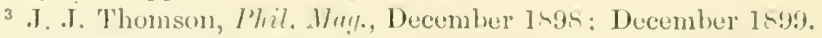

4 This was written in 190\%. Since then \%eleny and M'Keehan have recorded experiments with lycopodium powder. File the Appendix. 
holds for the fall of small spheres in air appears to be that obtained by J. J. Thomson, whose value of the electronic charge, obtained by Wilson's ${ }^{1}$ cloud method involving the assumption of Stokes' Law, was found to agree with the generally accepted value of the electronic charge as calculated by application of the kinetic theory

A

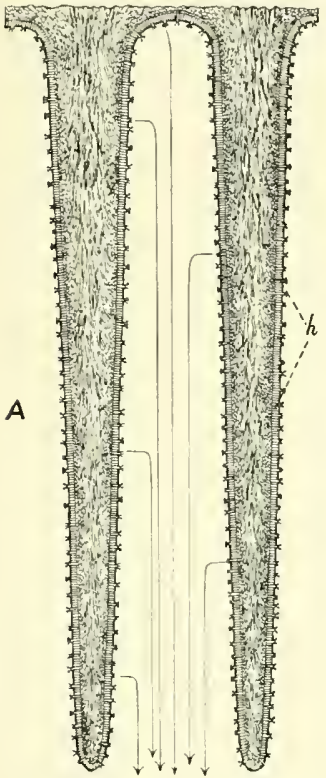

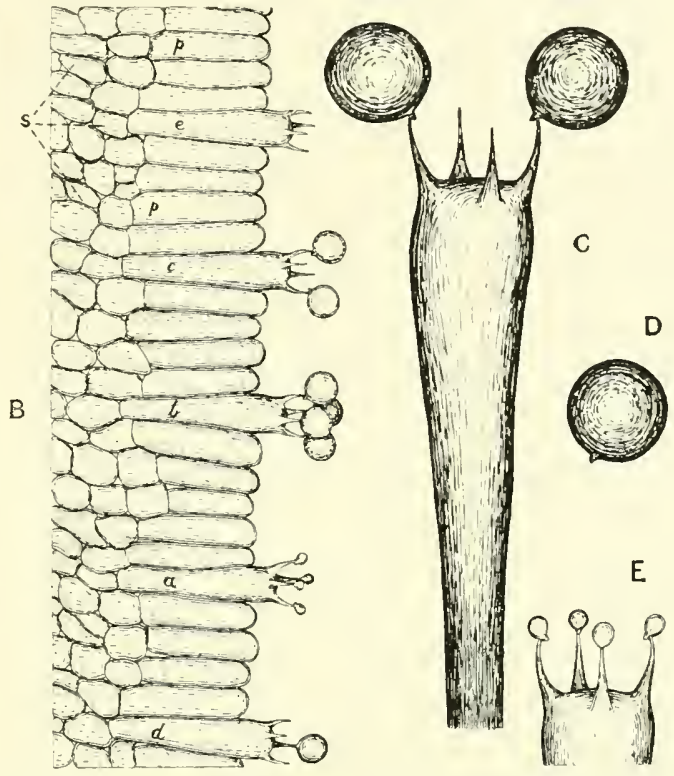

FIG. 56.-Amanitopsis raginutu. Relations of the spores to the fruit-body. A, transverse section through two gills showing the hymenium, $h$, from which basidia are projecting. The arrows indicate the paths of spores which, after discharge from their basidia, have fallen in still air. Maguification, 15. B, vertical section through the hymenium and subhymenium. $p$, paraphyses: $a-\ell$, basidia; $a$, with rudimentary spores; $b$, with ripe spores; $c$, with two spores discharged; $d$, with three spores discharged; $c$. with all the spores discharged: $s$, the subhymenium. Magnification, 370. C, isolated basidium with two spores discharged showing mode of attachment of spores to their sterigmata. Magnification, 1110. D, discharged spore. Magnification, 1110. E, basidium with rudimentary spores. Magnification, 1110.

of gases. This verification of the applicability of Stokes' Law is, of course, very indirect.

It seemed to me of interest to attempt to determine experimentally whether the spores of Hymenomyeetes fall in accordance with Stokes' Law. It was hoped that, by making three separate measurements of the specific gravity, size, and velocity of fall of

1 C. T. R. Wilson, Plit. Trans., 1897. 
the spores, one might obtain a direct test. It was also thought that an actual determination of the rate of fall of spores would throw light upon the distrilution of bacteria, spores, and other organic particles in air, and also help to explain fruit-body structure.

A considerable amount of preliminary experimentation was undertaken, during which observations were made upon the rates of fall of spores of rarious shapes and sizes in still air. The spores of Amenitopsis vagimuta were then chosen as material for a critical test of Stokes' Law for the following reasons: (1) They are spherical except for a tiny "tail," and smooth-coated (Fig. 55, A, B, and C, p. 162). (2) They are comparatively large, so that one can measure

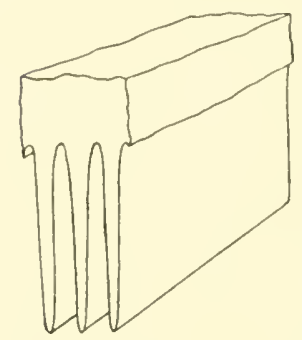

Fig. 57.-Diagram to show the shape of a section from a pileus placed in the com. pressor cell. The gills are directed vertically downwards. their diameters, which are about $10 \mu$ wide, very accurately with the Poynting Plate Micrometer.

(3) Their density is almost that of water, and can be measured within 1 per cent. of accuracy. ${ }^{1}$ (4) They could easily be procured, for the fruit-bodies of Amanitopsis vaginata came up in sufficient abundance in Sutton Park, which was not many miles from the laboratory. Fresh fruit-bodies (Plate IV., Fig. :30) could be obtained throughout August and September, during which time the critical experiments were made. The relations of the spores to the fruitbody are shown in Fig. 56.

An experiment to measure the rate of fall of Amanitopsis spores was carried out in the following mamner. A fresh fruit-body was obtained from the woods and used within a few hours of heing gathered. Due care was taken in earrying the fruit-bodies to the laboratory, upon reaching which they were immediately placed upright in a wet sand-bath and covered over with a large bell-jar.

A small picee of the pilcus, including portions of three gills, was then dissected out (Fig. 57) and placed in a compressor eell in the position shown in Fig. 58, $p$. 'lo prevent the falling spores from drying, two soaked picees of hlotting-paper or cotton-wool, l, and a few drops of water, $w$, were then added. Upon the cap being adjusted, the piece of fungus became fixed by slight compression and hermetically 
sealed in the dise-shaped chamber of which the base and top consisted of glass. The compressor cell was then placed in the vertical position (i.e. with the glass plates vertical) and clamped by one end to a stand. By this means it was possible to cause the gills to look vertically downwards in the natural manner. Thus enelosed in the chamber, the gills continued to rain down spores for some hours.

In order to observe the falling spores, a special microscope on a stand of simple construction ${ }^{1}$ was employed. The microseope tube was placed in the horizontal position (Plate IV., Fig. 29), and could be screwed upwards and downwards by means of a rackwork on the stand. The amount of rise or fall could be read off on a vertical scale to which a vernier was attached. The microscope tube was arranged at such a height and at such a distance from the chamber as to foeus a field (shown by the dotted ring in Fig. 58 ) immediately below the gills where the spores were falling. To illuminate the microscope, diffuse daylight, obtained from the glass roof, was reflected into
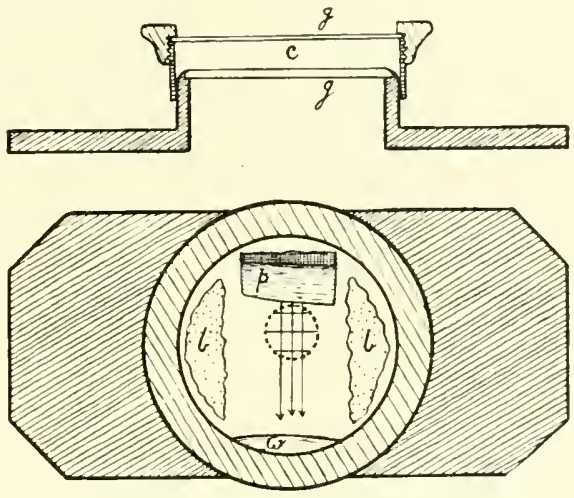

F1G. 58. - The compressor cell used for measuring the rate of fall of spores. A section of the cell is shown above: the chamber $c$ can be varied in size by raising or pressing down the cap. g, glass. Below is shown the cell when in use. $p$, a piece of pileus with gills looking downwards (ef. Fig. 57); b, b, wet blotting. paper or cotton-wool; $w$, a free drop of water. The dotted circle shows the field of view of the lorizontal microscope when focussed just beneath the gills. The three arrows show the courses of three spores falling from between the gills and crossing the field. The horizontal lines in the latter are produced by three silk threads in the Ramsden eye-piece. Actual size. the tube by means of a plane nirror (Plate IV., Fig. 29). The observations were made in a basement room where the temperature was very constant for eonsiderable intervals of time.

The horizontal microseope was provided with a Ramsden eyepiece. Three fine silk threads were attached to it so as to cross the field of view. The distance between the extreme threads, as seen in the field of view when the microseope was focussed, was $455 \mathrm{~mm}$.

${ }^{1}$ Made by Pye \& Co. 
(Fig. 59), while above and below them there was a further space of $05 \mathrm{~mm}$. The magnification, nancly, about 25 diameters, was obtained by using a No. 1 Leitz objective and extending the drawtube.

On viewing a field just below the gills, spores wan be seen as distinct but only just visible, very minute, dark objects, steadily crossing the field in a vertical direction, apparently from below upwards. Every spore so falling is not in focus, but, when the fungus material is in good condition, spores in focus cone into view at least

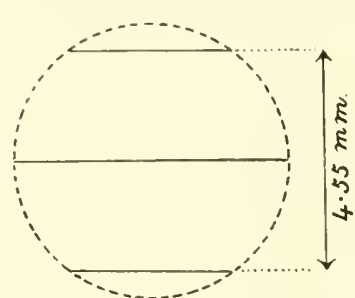

Fig, 59.-The field of the horizontal microscope. The apparent distance apart of the upper and lower horizontal threads in the eye-piece when seen in the field of view was $4.55 \mathrm{~mm}$. every five seconds. Often one can see three, four, or five spores in focus at the same time.

The spores fall vertically downwards (apparently upwards). In the small chanber employed, convection currents are reduced to a minimum and produce no apparent disturbing effects on one's observations. Doubtless, there are very slow air-currents in the chamber, but I have no reason to suppose in my eritical experiments with the large spores of Amanitopsis that they produced an error in the record of speeds of 2 per cent. Even with the small spores of Collybice dryoplitu, which often take eleven seconds to cross the field, the direction of the paths of fall is vertical and there is practically no swerving from the course.

The records of the velocity of fall of the spores whilst crossing the field of the horizontal microscope were made with the aid of a large drum, which was driven by electricity and provided with a delicate regulator (Plate IV., Fig. 29). A recording fountain-pen produced a continuous spiral line upon the paper as the drum rotated. To the pen was attached an electric tapping key, which could be placed in a convenient situation near the microseope. When the knob of the contact apparatus was depressed, the pen immediately deviated from its course upon the paper.

When the apparatus was ready, the drum was set going and the 
fall of spores watched through the microscope. As soon as a spore clearly came into view at the bottom of the field, it was followed

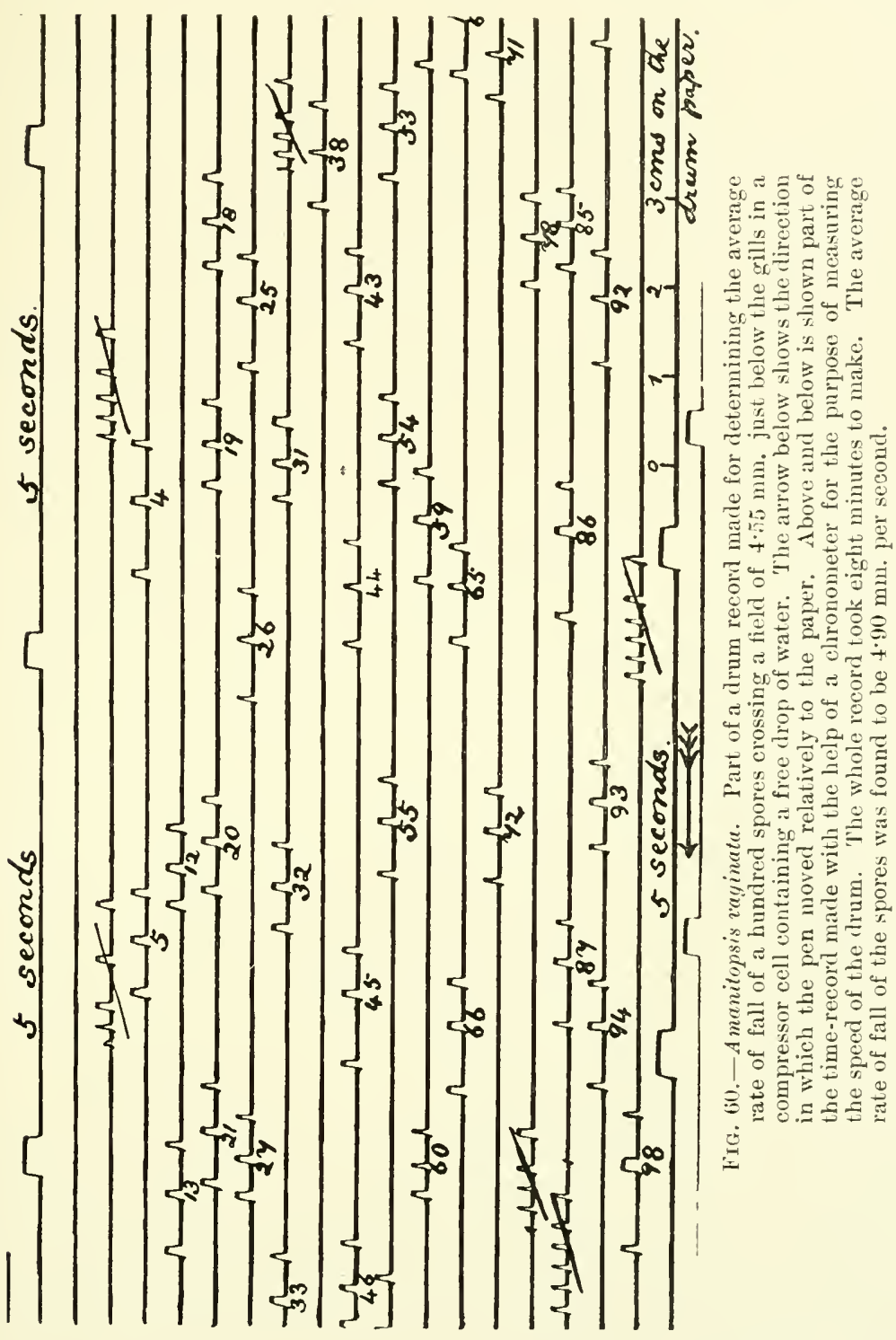

with the eye. When it crossed the first line of the field, a contact was made with the finger by depressing the key. Similarly, 
second ${ }^{\mathrm{I}}$ and third contacts were made as the spore crossed the

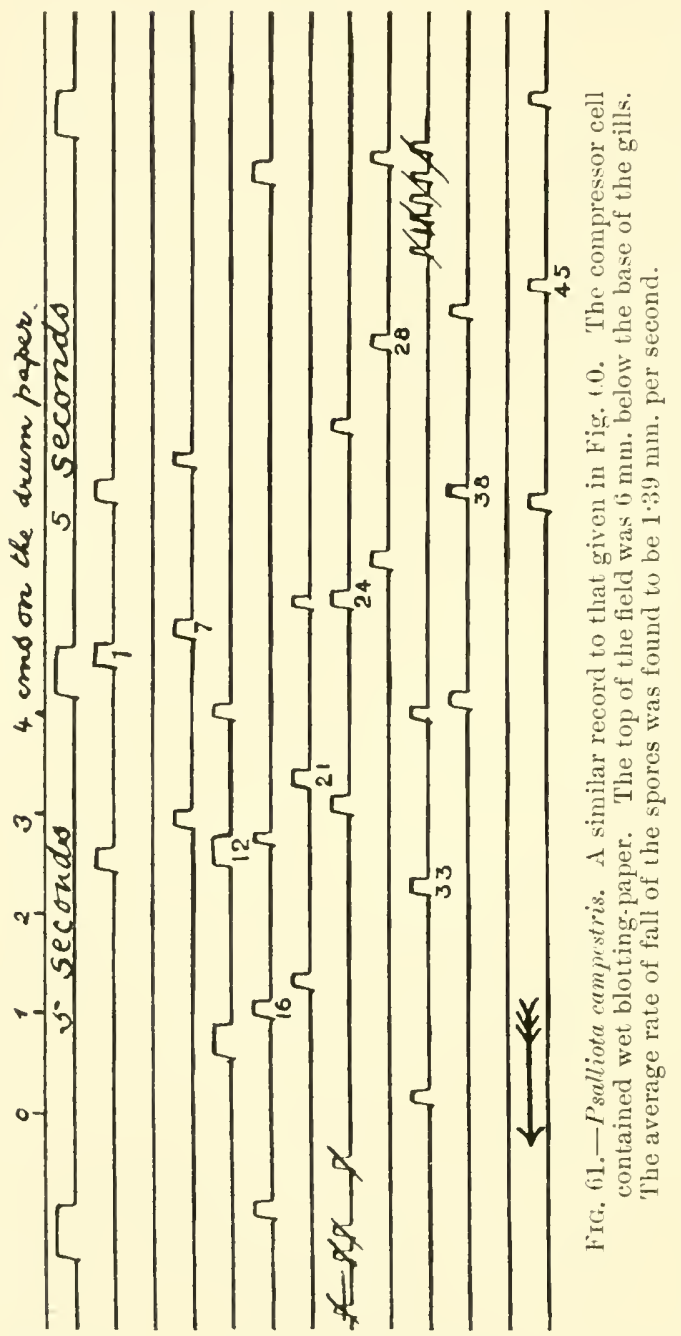
secont and the third lines respectively. 'Thus for the fall of each spore the pen deviated three times from its normal path on the paper of the drum (Figs. 60 and 61). The fall of about 100 spores was recorded in this way as rapidly as possible, the entire record usually being completed in less than fifteen minutes. A time record of ten seconds was always made on the drum before and after each series of observations by means of a chronometer ticking half-seconds. The drum kept up a very constant peripheral velocity, which was usually $1 \cdot 16$ cm. per second. When the records had been made, they were measured off on the drum by means of a steel tape, added up, and the average taken. $B y$ measuring the distance

rum by the drum in ten seconds, the speed of the drum conld be determined. The average length of time represented by the average

1 There was no absolute necessity to record the passing of the midclle line by a spore, but it was found convenient to do so for the purpose of distinguishing the individual spore-records from one another on the drum. Every eflort was made to make the first and third eontacts precisely at the times the upper and lower lines were being crossed; but the second eontact, heing of quite second:ry importance, was naturally not always recorded so acenrately. The middle line wis $2.2 .2 \mathrm{~mm}$. from the upper line and $2.33 \mathrm{~mm}$. from the lower line. 
record of the spores on the drum could then be calculated. Since this average time was that required for the spores to fall through a distance of $4.55 \mathrm{~mm}$, the average velocity of fall of the spores could be calculated.

The following figures give the drum records of 200 spores of A manitopsis raginatu. ${ }^{1}$ 'The first series of 100 took about twelve minutes to record. After an interval of forty minutes, the second series of 100 was made. The drum records, measured on the drum by means of a steel tape, are given in centimetres.

SERIES I.

\begin{tabular}{|c|c|c|c|c|c|c|c|c|c|}
\hline & & ERIES & & & & & RIES 1 & & \\
\hline 0.85 & 0.80 & 0.85 & 0.95 & 0.88 & 0.70 & 1.05 & $0 \cdot 85$ & 0.74 & 0.8 .5 \\
\hline $0 \cdot 9.5$ & 0.86 & 0.87 & $(1) \cdot 97$ & 0.89 & $1 \cdot 03$ & 0.91 & 11.75 & $0 \cdot 68$ & 0.84 \\
\hline $0 \cdot 95$ & 0.89 & $0 . \$ 9$ & 0.93 & $0 \cdot 65$ & $0 \cdot 88$ & 0.88 & 0.75 & 0.75 & (1).85) \\
\hline $0 \cdot 95$ & 0.90 & 0.78 & 0.91 & 0.75 & 0.96 & 0.76 & 0.99 & 0.76 & 0.80 \\
\hline $0 \cdot 84$ & 0.80 & $0 \cdot 88$ & 0.90 & 0.89 & 0.80 & 0.81 & $1 \cdot 00$ & 0.80 & 0.74 \\
\hline 0.71 & $0 \cdot 88$ & $0 \cdot 82$ & 0.95 & 0.90 & $0 \cdot 80$ & 1.05 & 0.75 & 0.84 & 0.76 \\
\hline 0.85 & 0.95 & 0.85 & 0.75 & 0.82 & $1 \cdot 01$ & 0.94 & $0 \cdot 99$ & 0.86 & 0.77 \\
\hline $0 \cdot 92$ & 0.89 & 0.86 & 0.99 & 0.78 & 0.95 & 0.94 & 0.75 & 0.87 & 0.76 \\
\hline 0.84 & 0.85 & 0.94 & 0.82 & 0.84 & $0 \cdot 90$ & 0.75 & 0.79 & 0.79 & 0.82 \\
\hline $0 \cdot 96$ & 0.89 & $0 \cdot 90$ & 0.93 & 0.90 & 0.99 & 0.85 & 0.83 & 0.80 & 0.94 \\
\hline 0.84 & $0 \cdot 80$ & $0 \cdot 9=2$ & $0 \cdot 89$ & 0.94 & 0.93 & 0.85 & $0 \cdot 68$ & 0.92 & 0.88 \\
\hline 0.80 & 0.94 & 0.94 & 0.99 & $0 \cdot 64$ & 0.92 & 0.80 & 0.92 & 0.91 & 0.89 \\
\hline 0.73 & 0.94 & $0.8 ! 9$ & 0.78 & 0.7 .5 & 0.95 & 0.84 & 0.89 & 0.88 & 0.92 \\
\hline $0 \cdot 82$ & 0.99 & 0.85 & 0.81 & 0.72 & 1.08 & $0 \cdot 90$ & 0.85 & 0.92 & 0.96 \\
\hline 0.84 & $0 \cdot 89$ & 0.82 & 0.85 & 0.74 & 0.93 & 0.65 & 0.85 & 0.80 & 0.94 \\
\hline $0 \cdot 84$ & 0.89 & 0.85 & 0.84 & 0.92 & 0.96 & 0.85 & 0.75 & 0.85 & 1.04 \\
\hline 0.97 & 0.93 & 1.00 & 0.79 & 091 & $1 \cdot 04$ & $0 \cdot 91$ & 0.81 & 094 & 0.89 \\
\hline $0 \cdot 90$ & 0.89 & 0.97 & 0.85 & 0.85 & 0.99 & 0.95 & $0 \cdot 90$ & $0: 91$ & $0 \cdot 95$ \\
\hline $1 \cdot 00$ & $0 \cdot 90$ & 0.8 .5 & $0 \cdot 7+$ & $0 \cdot 60$ & 0.91 & 082 & 0.90 & $0 \cdot 94$ & 0.88 \\
\hline 0.77 & 0.87 & $0.9 \overline{7}$ & $0 \cdot 90$ & 0.95 & $1 \cdot 00$ & 0.90 & $0 \cdot 90$ & 0.90 & 0.81 \\
\hline $17 \cdot 33$ & $17 \cdot 75$ & $17 \cdot 68$ & $17 \cdot 54$ & $16 \cdot 32$ & $18 \cdot 73$ & $17 \cdot 41$ & $16 \cdot 90$ & 16.86 & $17 \cdot 29$ \\
\hline & in of & cals. & $\begin{array}{l}17 \cdot 3 \\
17 \cdot 7 \\
17 \cdot 6 \\
17 \cdot 5 \\
16 \cdot 3\end{array}$ & & & $\mathrm{Im}$ of & tals & $\begin{array}{l}18 \cdot 7 \\
17 \cdot 1 \\
169 \\
16.8 \\
17.0\end{array}$ & \\
\hline & rand $t$ & al. & $86 \cdot 6$ & $\mathrm{~cm}$ & & rand $t$ & al. & $\cdot 87 \cdot 1$ & $\mathrm{~cm}$. \\
\hline $\begin{array}{r}\text { Aver } \\
=0.86 \\
\text { Aver } \\
\text { seeond } \\
\text { Hen } \\
\text { spore } \\
\mathrm{mm} .=\end{array}$ & $\begin{array}{l}\mathrm{cm} \text { dist } \\
\mathrm{cm} \text {. } \\
\text { avera } \\
\text { fallin } \\
47 \mathrm{sec}\end{array}$ & $\begin{array}{l}\text { of on } \\
\text { trume } \\
\text { throng } \\
\text { hds. }\end{array}$ & $\begin{array}{l}=1 \cdot 16 \\
\text { a field }\end{array}$ & $\begin{array}{l}\text { ries I. } \\
\text { 17. per } \\
\text { each } \\
4.55\end{array}$ & $\begin{array}{r}\text { Ave } \\
\text { II. =0 } \\
\text { Ave } \\
\text { second } \\
\text { Her } \\
\text { spore } \\
\text { mm. }\end{array}$ & $\begin{array}{l}\text { ge dis } \\
719 \mathrm{~cm} \\
\text { ge spe } \\
\text { aver } \\
\text { fallin } \\
752 \text { se }\end{array}$ & $\begin{array}{l}\text { of on } \\
\text { of dru } \\
\text { throne } \\
\text { thrs. }\end{array}$ & $\begin{array}{l}\text { drum i } \\
n=1 \cdot 1 \\
\text { of fall } \\
\text { a fiel }\end{array}$ & $\begin{array}{l}\text { Series } \\
\text { m. per } \\
\text { f each } \\
\text { f } 4.55\end{array}$ \\
\hline $\begin{aligned} & \text { Hen } \\
= & 6.09\end{aligned}$ & avera & veloci & of $\mathrm{fa}$ & $\frac{4.55}{0.7+7}$ & $\begin{aligned} & \text { Hen } \\
= & 6 \cdot 0 \overline{5}\end{aligned}$ & avera & velocit & $y$ of $\mathrm{fa}$ & $\begin{array}{l}4.55 \\
0.752\end{array}$ \\
\hline
\end{tabular}

Hence average velocity for both Series together $=6 \cdot(0 \overline{\mathrm{mm}}$. per second. 
The lable on the next page grives a summary of the data obtained for testing Stokes' Law with falling spores of Amonitopsis verginuta. The velocities given are the average velocities of 200 spores in Specimen I., of 100 in Specimen II, and of 50 in Specimen III. The densitius are certainly correct to within 1 per cent. 'The diancters are the average diameters for at least 50 spores, these being spherical. The measurements were made with a Poynting Plate Mierometer in the manner alleady deseriber. The spores of Sipecinen I. were those collected at the botton of the compressor cell whilst observations on the fall of some of then were being made. The spores of specimen II. were obtained from another part of the fruit-body from which the piece had been dissected out for velocity observations in the compressor cell. The spores of Specimen III. ${ }^{2}$ were those collected from the piece of fungus used for the velocity records, but collected from it immediately after these had been taken. It is clear, therefore, that I was unable to measure the diameters of exactly those spores for which the velocity of fall had been recorded. 'This is a defeet in my method. Howerer, the defect seems to me of little importance, for it was found that any 50 spores, taken at random from any part of a siugle fruit-body, have the same average size. In order to obtain the average size of the spores of which the velocity had been recorded, it was therefore only necessary to measure the average size of any 50 spores obtained from the fruitborly.

In making calculations with Stokes' equation, the viscosity of air ${ }^{3}$ was assmmed to be $1 \cdot S \times 10^{-4}$ and its density negligible compared with that of a spore. The value of $g$ was taken as 981.

From the 'Table it is elear that the figrures obtained by ouservation for the rate of fall of the spores ale of the same order of magnitude as those demanded ly Stokes' Law. However, the Law is not confirmed in detail, for as an average for the three cases it was found that the actual velocity of fall of the spores was 46 per cent. greater than the calculated.

1 Vide Chap. XIII.

${ }^{2}$ For actual measurements, vide Chap. XIV.

${ }^{3} 1.8 \times 10^{-1}$ is the value usually taken for dry air at room temperatures. The effect of moisture is to very slightly reduce the viscosity. 


\section{Amanitopsis Taginata}

Chamber, containing soaked blotting-paper or cotton-wool and free water below, closed for half-an-hour before observations for velocity were taken. Field of microscope close under gills.

\begin{tabular}{|c|c|c|c|c|c|c|c|}
\hline & 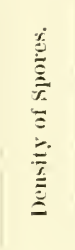 & 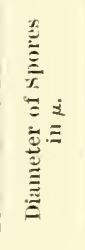 & 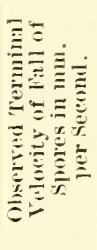 & 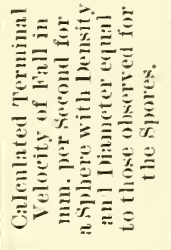 & 递 & 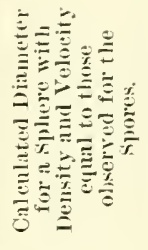 & 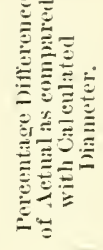 \\
\hline Specimen I. & $1 \cdot 02$ & $11 \cdot 65$ & 6.07 & $4 \cdot 14$ & 47 & $14 \cdot 0$ & \\
\hline Specimen II. & $1 \cdot 02$ & $10 \cdot 19$ & $4 \cdot 85$ & $3 \cdot 21$ & 51 & $12 \cdot 52$ & -18.6 \\
\hline Specimen III. & $1 \cdot 02$ & $10 \cdot 87$ & $5 \cdot 11$ & $3 \cdot 64$ & 40 & 1299 & \\
\hline
\end{tabular}

It is diffieult to explain why the observed velocities of fall should be nearly 50 per cent. greater than that demanded by Stokes' Law. However, perhaps the explanation has some connection with the fact (to be discussed more fully in the next chapter) that, even in an apparently saturated chamber, the spores in falling even such a small distance as $5 \mathrm{~mm}$. lose a certain amount of water. It was found that after leaving the gills, the rate of fall of the spores slightly deereases. Further experiment showed that this was due to the contraction in the volume of the spores consequent on drying up. ${ }^{1}$ It has been suggested to me by Professor Poynting, that the loss of water by a spore during its fall might lead to an evaporation pressure of such a kind that the spore would be foreed more quickly downwards than would be the case if no loss of water were taking place. Owing to the impossibility of employing perfectly dry spores in my experiments, there seems to be no way at present to test this hypothesis.

That the speed of fall on the average was found to be 46 per cent. greater than that given by Stokes' Law may possibly be accounted for by surface slip. With very minute particles Stokes 
has calculated that the maximum effect of slip is to increase the terminal velocity by 50 per cent. Therefore, if we assume that the slip actually takes place, the discrepancy between observation and theory would be fully accounter for. It seems, however, that the spores are not small enough to permit of our assuming slip to the extent required.

'The most serious objection to my method for testing Stokes' Law seems then to be that it has so far been found impossible to get the spores to fall with a quite constant speed in an apparently saturated chamber. Now the spore diameters were measured when the spores were in water, i.e. when fully turgid, just as spores are upon the sterigmata immediately before their fall. In order, therefore, to observe the fall of the spores when they were in as turgid a condition as possible, the two precautions (1) of placing the field of the microseope immediately under the gills, and (2) of saturating the chamber so far as possible with water-vapour, were taken. If the velocity of the spores could have been measured immediately they left the sterigmata instead of when they came into view beneath the gills, probably it would have proved even greater than that recorded.

All the measurements for density, size, and relocity of the spores could be made with great exactness. It seems to me most unlikely that the large discrepancy between theory and observation ean be due to errors in these measurements. Unless loss of water from the spores in some way is capable of accelcrating their rate of fall, for the present it would seem as though the spore-fill method of testing Stokes' Law shows that the actual velocity of fall of spheres about $10 \mu$ in diameter is some 50 per cent. greater than the Law demands.

The appended Table, giving the results of observations upon the rates of fall of spores of various speeies, was compiled before the tests for Stokes' Law were made. 'The air in the ehamber of the compressor cell was not saturated and simply contained the required piece of fungus. The field of the mieroseope was usually near the gills. The rates of fall of spores of a single fruit-body, as the spores dry up, gradually decrease after the spores have left the gills. The tigures given in the Table serve merely 
to show the speed of fall of the spores at a certain distance from the gills in the unsaturated air of the chamber. If $V$ be the velocity of a spore when fully expanded by osmotic pressure, i.e. just after liberation, and $V^{\prime}$ be the velocity of the same spore when it has dried up, then the velocities given in the Table lie between $V$ and $V^{\prime}$. 'The value of $V$, as further experiments have shown, may be as much as $3 \mathrm{~V}^{\prime}$. It will doubtless be different for each species, but it is evident, from results given in the Tables in the next chapter, that up to 60 per cent. should be added on to the velocities given in the present Table in order to obtain approximately the true rate of fall of the fully turgid spores of which the dimensions are given. On the other hand, if one wishes to calculate the velocity of the spores when dried up, as they must often be in nature within one or a few minutes of leaving the fruit-body, one must subtract up to 60 per cent. of the relocities determined.

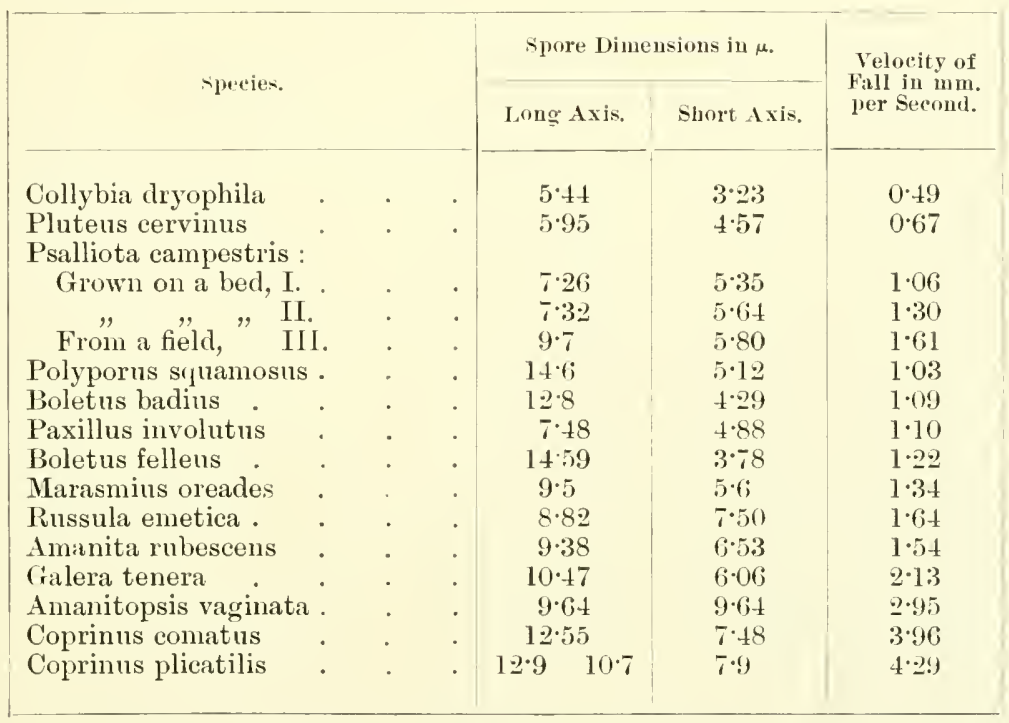

It was found possible to measure the rates of fall of individual spores over longer distances than $4.55 \mathrm{~mm}$. in the following manner. A field just below the gills in the compressor cell was focussed with the horizontal microscope. When a spore erossed the upper line, a drum contact was made by depressing the knob 
of the tapping key with the left hand. The microscope was then lowered with the right hand by means of a rackwork on the stand so that the spore was still kept in view. When the field arrived at the bottom of the compressor cell after having been lowered in this way for about $\& \mathrm{~mm}$., the spore crossed the lower line of the field, whereupon a second drum contact was made. The time of fall could therefore be calculated from the drum record in the usual way. The distance of fall could be determined by adding to the distance between the upper and lower lines of the field, namely $4.55 \mathrm{~mm}$, the distance through which the microscope had been lowered. The latter was found in each case by reading a vertical scale which was situated on the microscope stand and provided with a vernier. From the time and distance data thus obtained the velocity of fall could be calculated at once.

Fifty measurements with the spores of Boletus felleus were made in the manner just described. The average observed distance of fall was $12.05 \mathrm{~mm}$. and the average time required to fall through it 10.57 seconds. Hence, the average velocity of fall through $12.05 \mathrm{~mm}$. below the gills was $1.14 \mathrm{~mm}$. per second. Doubtless by this method the rate of fall of small particles might be measured through greater distances than $12 \mathrm{~mm}$.

Whilst measuring the rates of fall of spores the magnification was kept as low as practicable, so that the observed distance of fall should be as large as possible. Under those conditions the spores were seen merely as just visible specks, the shape of which could not be determined. It seemed, however, of interest to attempt to find out what positions the spores assumed whilst falling. The magnification of the microscope, therefore, was increased by using a No. \& Leitz objective. Into the much lessened field of view, spores in focus fell relatively less often. and in passing across the field appeared to fall with a relatively much greater veloeity. However, the shape of the spores could often be distinctly observed. It was found that the spores, whilst falling the first few millimetres after leaving the grills, often turn round and round upon themselves in an irregular manner. Longer spores often oscillate from side to side and probably fall in very 
steep corkscrew-like paths. Special attention was paid to the fall of the spores of Polyporus squemosus, which are nearly three times as long as they are wide. It was found that on emerging from the hymenial tubes many of them have their long axes nearly vertical, and that whilst falling they often appear to turn over and over on themselves or to rock from side to side. However, by following the spores individually with the help of a meehanical stage, it was plainly seen that after falling about $5 \mathrm{~mm}$. they were almost without exeeption nearly or quite horizontal, and that they then rotated in a horizontal plane very slowly or not at all. The final position which the spores took up in still air was therefore such that the greatest surface was presented to the resistance of the air. We may eonclude, therefore, that long spores tend to fall in a similar manner to that assumed for the simple, prismatic ice-crystals which cause the phenomena of sun-dogs, \&e., in northern regions.

\section{APPENDIX}

The compressor-cell method of measuring the rate of fall of spores was devised in 1905. I then came to the conclusion that the spores of Hymenomycetes fall at a rate which is roughly in accordance with Stokes' formula, and this fact was announced by A. J. Ewart in his translation of Pfeffer's Physiology of Plants. During the summer of 1906, I carried out a large number of measurements of the size, specific gravity, and terminal velocity of spores, and in 1907 Chapters XIIL., XIV., and XV. were communicated to the Royal Society as sections of a paper which I subsequently withdrew. ${ }^{2}$

Recently Zeleny and II'Keehan ${ }^{3}$ of the Cniversity of Minnesota have announced that they have made a direct test of Stokes' formula by using lycopodium power. Their method of measuring terminal velocity consisted in allowing the jowder to fall in wide tubes and noting the rate of movement

1 Tol. iii., 1906, p. 416.

2 The paper called "The Production, Liberation, and Dispersion of the Spores of Hymenomycetes" was accepted for publication in the Plilosophical Transactions of the Royal Society, but on conditions which I was unable to aceept.

${ }^{3}$ John Zeleny and L. W. M'Keehan, "An Experimental Determination of the Terminal Velocity of Fall of Small Spheres in Air." A paper read at the meeting of the American Association for the Advancement of Science, held December 1908. Abstract in Science, March 19, 1909. 
of the centre of the cloud. They came to the conclusion that for lycopodium spores the formula gives veloeities 50 per cent. in excess of those observed.

My method for testing Nitukes' formula appears to have varions advantages over that used by Kcleny and I'Keehan for the following reasons. Amanitopisis spores have smooth walls and are practically truly spherical, whereas lyeopodium spores have seulptured walls and are four-sided. Amanitopsis spores have a diameter only about one-thirl as great as lyeoporlium spores. In the tube method convection eurrents cannot be eliminated, and it must surely be somewhat difficult to decide the exact centre of the spore clouds. By my method of using a very small chamber, the difficulty of convection eurrents was reduced so as to be negligible, and the velocities of the individual spores could be measured with considerable aceuracy. Amanitopsis spores are liberated spontaneously by the fungus, whereas lycopodim powder requires to be set in motion by artificial means.'

1 The substance of this Appendix is contained in a letter to Nature on "The Rate of Fall of Fungus Spores in Air," April 14, 1909. 


\section{CHAP'TER XVI}

THE EFFECT OF HUMIDITY ON THE RATE OF FALL OF SPORES

IT can be shown on mathematical grounds that, when bodies the size of spores are allowed to fall freely in still air, they reach their constant terminal velocity before they have gone their own diameter or a distance of less than $10 \mu{ }^{1}$ It was expected at first, therefore, that a spore would fall through the space in a compressor cell, i.e. a distance of about $13 \mathrm{~mm}$, at a uniform speed. Accordingly, in order to test this supposition, the rate of fall of spores through a field of $4.55 \mathrm{lnm}$. at different distances below the gills was measured. It was soon discovered that the velocity of a spore gradually diminished as the spore fell after emerging from the gills. It was suspected that this was due to the gradual diminution in size of the spore owing to loss of water from it by drying. Comparative experiments with the air in the chamber in different states of humidity were then undertaken. The air of the chamber was first made as moist as possible by means of soaked blotting-paper, next the ordinary air of the laboratory was employed, and finally the air was dried as far as possible with crystals of calcium chloride. A different piece of the same fruit-body was used in each case. The results of the observations are recorded in the Tables on p. 180. The figures give the velocities in millimetres per second.

From these results we may conclude that, as a general rule, the spores fall most rapidly on leaving the gills, and that the rate of fall gradually diminishes. This appears to be so, even in chambers which contain a free drop of water and soaked blotting-paper (Fig. 58, p. 167), and in which the air must therefore be saturated with moisture. The tiny oval spores seem to be capable of giving off water vapour in an atmosphere saturated so far as flat surfaces are concerned.

$$
1 \text { Vide infra, Chap. XVII. }
$$


It is also evident that the dryer the air, the more slowly do the spores fall. At the same distance from the gills, for Collybie dryoplitu, the velocity of fall in a dry chamber was only about

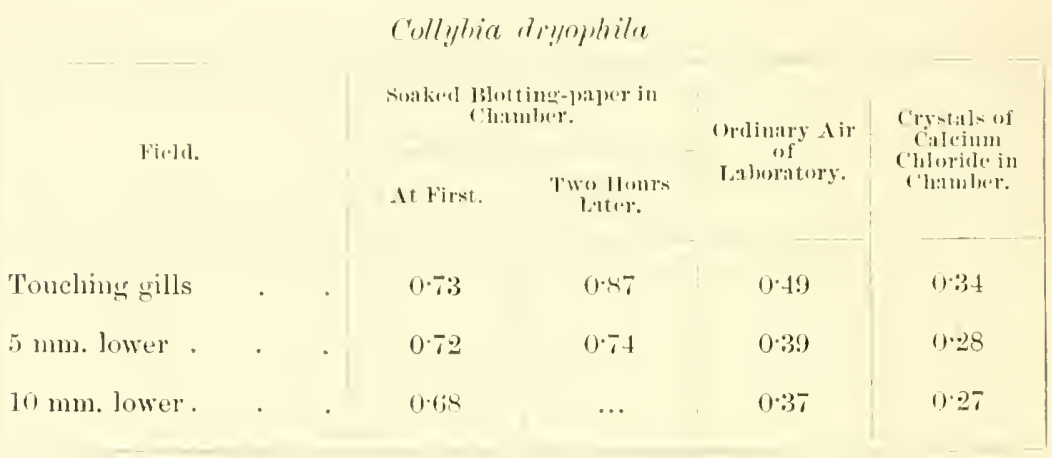

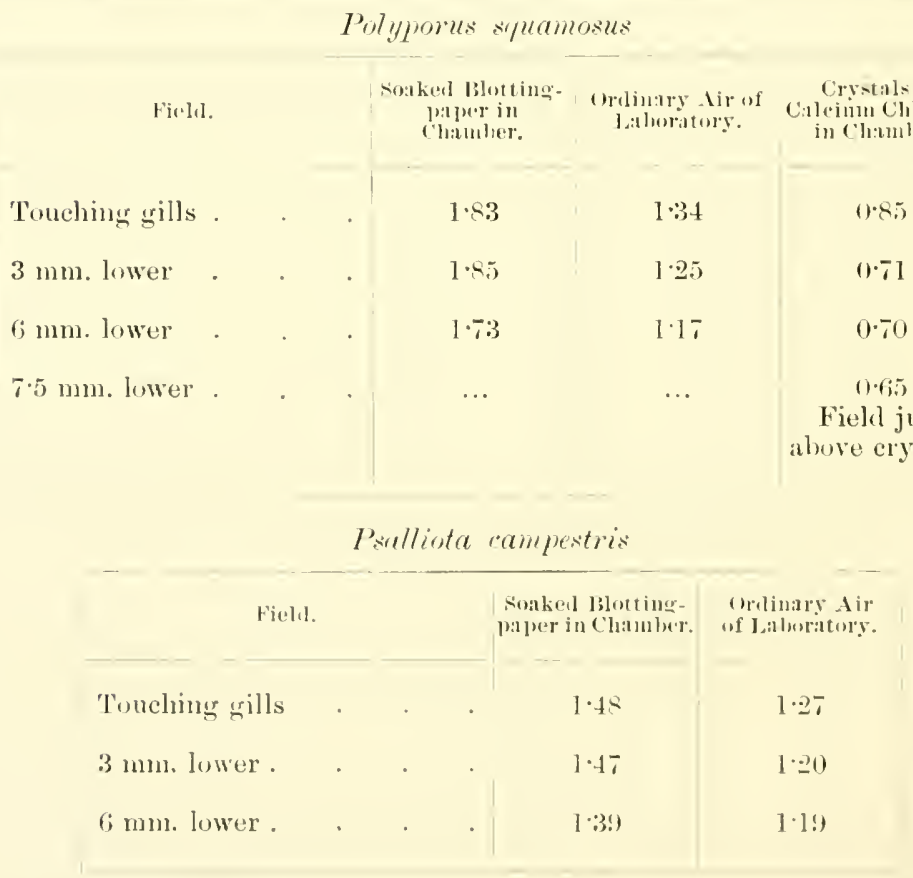

one-half of that in a moist chamber containing wet blotting-paper. In the most dried condition the spores were falling at only onethird the speed at which they fell in the most moist condition.

The obvious explanation of the decrease in speed of spores 
after leaving the gills, seems to be that the spores diminish in size owing to the loss of water. According to Stokes' Law the velocity varies as the square of the radius of a sphere. One must remember that a spore has an enormous surface eompared with its mass, and therefore, when falling, can readily and quickly part with some of its contained water. In falling $5 \mathrm{~mm}$. in ordinary air, when leaving the gills, spores of Collybic dryophile (the smallest with which I have yet worked) were found to lose 20.4 per cent. of their velocity; in falling $6 \mathrm{~mm}$. the spores of Polyporus squamosus lost 12.7 per eent, and those of Psalliota campestris 6.3 per cent. The results are collected in the following Table :-

Diminution in Velocity of Falling Spores

\begin{tabular}{|c|c|c|c|c|c|}
\hline Species. & & & $\begin{array}{l}\text { Wistance of } \\
\text { Fall in } \\
\text { Millimetres. }\end{array}$ & $\begin{array}{l}\text { Time in } \\
\text { seconds. }\end{array}$ & $\begin{array}{l}\text { bininution of } \\
\text { Velocity } \\
\text { expressed in } \\
\text { Perecutaue of } \\
\text { lnitial Velocity } \\
\text { observel. }\end{array}$ \\
\hline Collybia dryophila . & - & . & 5 & $11 \cdot 4$ & $20 \cdot 4$ \\
\hline Polyporus squamosus & - & . & 6 & $4 \cdot 8$ & $12 \cdot 7$ \\
\hline Psalliota campestris & - & . & 6 & $4 \cdot 8$ & $6 \cdot 3$ \\
\hline
\end{tabular}

Further observations were then made upon decrease in velocity when spores were allowed to fall through a distance of $15 \mathrm{~cm}$. For this purpose a brass chamber (Fig. 62) was constructed. The space within it was $16 \mathrm{~cm}$. long, $1.1 \mathrm{~cm}$. wide, and $0.6 \mathrm{~cm}$. deep. To one side of the chamber a glass plate was fixed with cement, and to the other side a long cover-glass could be affixed with vaseline. A piece of the fungus fruit-body, which included parts of three or four gills, was placed in the chamber at one end. When the latter was set in the upright position, spores fell from top to bottom. With the horizontal microscope, observations on the velocity of the spores were made at different distances from the gills.

The retardation in the velocity of fall was found to be most rapid immediately after the spores had left the gills, and to 
continue in a more or less marked manner for about $10 \mathrm{~cm}$. A final, terminal, and fairly uniform veloeity was then reached,

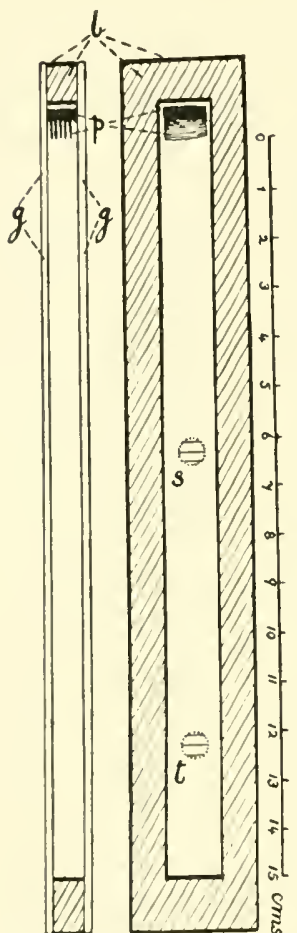

Fir. (i2.-Plan and section of a long chimber used for ineasuring the rates of fall of spores at different distances from the gills. b, briss: $g$, glass: $/ \prime$, piece of jileus. $\mathrm{At} s$ and $t$ are shown two fields as seen with the horizontal microscope $(i$ $\mathrm{cms}$. and $12 \mathrm{cms}$. below the grills respectively. Onebalf actual size. the time required for its attaimment being less than half a minute after the spores had been liberated from the gills. The following curves (Fig. 6:i) give the results of the observations. Each velocity plotted is the average of about twenty-five relocities recorded in sequence.

The curve for the Mushroom spores is remarkable in that it first of all sinks and then rises again. Possibly this is accounted for on the supposition that the spores buckle up after a certain stage of desiccation has been reached. Such a mode of contraction would decrease the surface exposed in falling, and thus increase the velocity. As a matter of fact, Mushroom spores, when drying on a glass slide, rapidly become indented on one side so that they more or less assume the form of a boat.

A general conclusion which may be arrived at from the data contained in this chapter is, that in nature spores fall most rapidly almost immediately after liberation from the sterigmata whilst they are passing out from the fruit-bodies between gills, down tubes, \&e., and that after they have drifted in the convection currents of the outer air for about half a minute, they reach a steady terminal velocity eonsiderably less than the initial. We can only suppose that at the moment of liberation the spores are fully turgid, and that by the rapid loss of water they become dried up in less than a minute. It is certainly a grool arrangement that the spores should fall down between the gills or in hymenial tubes, se., with the greatest velocity, for they thus escape from the fruit-bodies with the least risk of 
very small convection currents causing them to touch the hymenium, to which, owing to their adhesiveness, they would become firmly attached. After liberation from the fruit-body

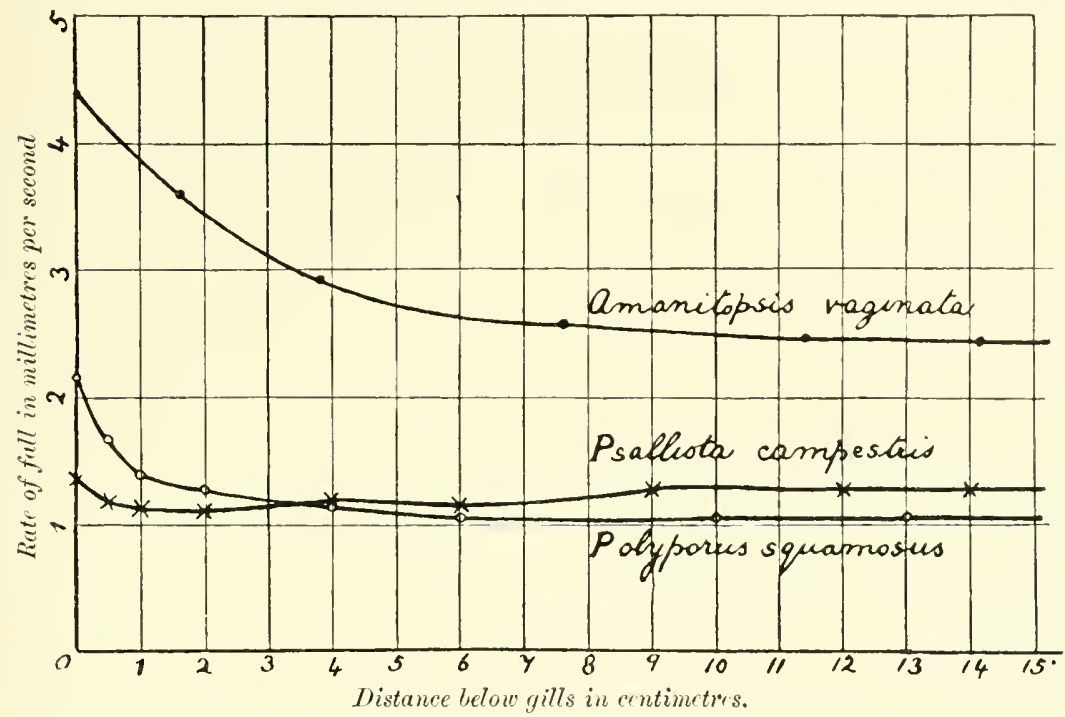

FIt. 63.-Curves showing the rate of fall of spores at various distances below the gills in a long chamber.

the spores fall much more slowly. This enables the wind to carry them much further than would be possible if no decrease in velocity were to take place.

Note.-The gradual decrease in the rate of fall of spores in a chamber saturated with water-vapour finds its readiest explanation in the supposition that the spores gradually become smaller owing to loss of water. The assumption that the spores lose water in a saturated atmosphere is in harmony with the well-known fact that the vapour pressure of a drop of liquid depends on the amount of curvature of its surface. The greater the curvature, the greater is the vapour pressure. This is illustrated by the following experiment. If a small piece of sulphur is placed in a tube which is then evacuated and sealed, and if the tube is gently heated near the sulphur, the latter condenses on the cool part of the tube in the form of a great number of very small drops of different sizes. In the course of a day or so, one finds that the larger drops have become still larger, and that they have a clear space round them. The clear space gradually grows bigger. The explanation of this plenomenon is that the smaller drops with the greater vapour pressure distil over into the larger drops with the smaller vapour pressure. Similarly we may suppose that the large free drop of water in the compressor cell (Fig. 58, w, p. 167) grows at the expense of water lost by the minute falling spores owing to the great difference in the curvature of the surfaces. 


\section{CHAP'TER XVII}

THE PATH OF 'THE SPORES BETWEEN THE GILLS, ETC.-THE SPORABOLA-APPENDIX ON THE MOTION OF A SPHERE IN A VISCOUS MEDIUM

BY methods already explained, it has been shown that it is possible to determine by observation (1) the maximum horizontal distance to which a spore travels when it has been shot out horizontally from a basidium lying in the hymenium of a gill, ${ }^{1}$ and (2) the terminal vertical veloeity with which the spore falls toward the earth. ${ }^{2}$ With a knowledge of these data, and assuming that the resistance of the air is proportional to the velocity, it is possible to calculate the initial velocity with which a spore is shot off its sterigma, and also to map out the trajectory described.

The initial velocity with which a spore leaves its sterigma, when projected in a horizontal direction, may be ealeulated as follows :-

Let $\quad V=$ the terminal vertical velocity,

$\mathrm{X}=$ the maximum horizontal distance of projection,

$\mathrm{H}=$ the initial horizontal velocity, and

$g=$ the acceleration due to gravity.

It ean be shown ${ }^{3}$ that

$$
\mathbf{H}=\frac{g \mathrm{X}}{\mathrm{V}} \text {. }
$$

For spores of Amanitopis reginutu, it has been observed that $\mathrm{X}=0.02 \mathrm{~cm}$. and $\mathrm{V}=0.5 \mathrm{~cm}$. per second approximately, whence

$$
\mathrm{H}=\frac{981 \times 0.02}{0.5}=40 \text {, }
$$

i.e. the spores are projected in the horizontal direction from the sterigmata with an initial velocity of approximately $40 \mathrm{~cm}$. per

1 Method II., Chap. XI.

2 Chap. XY.

3 A note on the motion of a sphere in a viscons medimn is given in the Appendix to this chapter for convenience of reference. 
second. Since the maximum horizontal distance of projection is $0.02 \mathrm{~cm}$, it is clcar that in travelling only this short distance the horizontal velocity of a spore is rectuced from $40 \mathrm{~cm}$. per second to zero. This will not seem surprising when the ratio of the surface to the mass of the spore is taken into account.

Since the spores are shot outwards horizontally, they describe a curved trajectory in falling toward the earth. The trajectory is a peculiar one. In future it will be referred to as the sporabola.

It can be shown that the equation for the sporabola is

$$
y=\frac{\mathrm{V}^{2}}{y}\left\{-\log _{e}(1-x)-x\right\}
$$

where $\mathrm{V}=$ the terminal vertical velocity,

$\mathrm{X}=$ the maximum horizontal distance of projection,

$y=$ the acceleration due to gravity,

$y=$ the distance of a point on the sporabola below the highest point, and

$x=$ the distance of a point on the sporabola from the rertical axis.

Since $\mathrm{V}, \mathrm{X}$, and $g$ are known, by assuming values for $x$ corresponding values for $y$ can be calculated and the sporabola plotted out. The a c com panying figure represents the sporabolas for Amanitopsisuagimete and Psalliote compestris (Fig. 6t).

The sporabola is remarkable in that the horizontal part passes very sharply into the vertical part. The horizontal and vertical motions appear to be al-

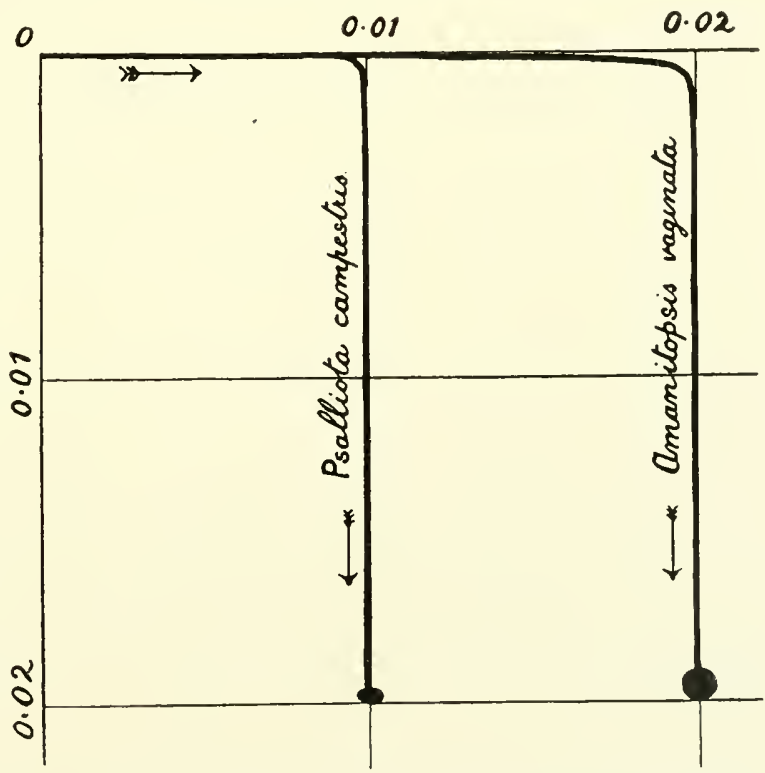

FIG. 64.-The sporabolas of two spores shot out horizontally from the hymenium. The spores, drawn to scale, are shown below. 'The scale is in centimetres.

most independent of one another. Direct inspection of the curve 
indicates that the horizontal velocity is reduced to zero by the time the spore has fallen through a distance only about equal to its diameter.

It must often happen that spores are not shot outwards in exactly the horizontal direction but at a greater or less angle thereto. The paths of spores projected with equal velocities at various angles can be deduced mathematically, and are indi-

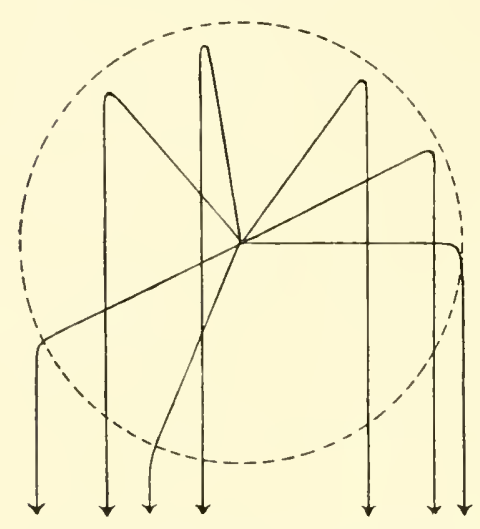

FIG, 65.--Sporabolas of spores shot outwards from a point at various angles with the vertical and with equal initial velocities. cated diagrammatically in the adjoining figure (Fig. 65). That the sporabola appears to consist of two parts, one due to violent projection of a spore and the other due to gravitation, again becomes obvious. We may conclude that, if a basidium looks upwards, it will shoot its spores to a height approximately equal to the maximum horizontal distance to which it would have projected them if it had been placed horizontally instead of vertically. Quite generally, the sudden bend in each sporabola takes place at approximately the same distance from the point of projection at the surfice of a limiting sphere (Fig. 65).

Before attaining its steady terminal velocity, a spore requires to fall but a very minute distance. This may be shown as follows:-

Let $\mathrm{X}=$ the maximum hori\%ontal distance of projection,

$x=$ the distance of a point on the sporabola from the vertical axis,

$V=$ the terminal vertical velocity, and

$v=$ the vertical velocity at any time.

Then it may be deduced that

$$
\stackrel{x}{\mathrm{X}}=\frac{v}{\mathrm{~V}}
$$

By substituting the value of $\frac{x}{\mathrm{X}}$ in the equation for a sporabola we get

$$
y=\frac{V^{2}}{g}\left\{-\log _{e}\left(1-\frac{v}{V}\right)-\frac{v}{V}\right\}
$$


Let us assume that the vertical velocity at any time is within 1 per cent. of the terminal velocity, and that $y$ is the distance the spore has fallen before attaining this velocity, then putting $\log _{e}=2 \cdot 3 \log _{10}$ and $\frac{v}{V}=0.99$, we get

$$
y=\frac{\mathrm{V}^{2}}{\mathrm{~g}}\left\{-\log _{10}(0 \cdot 01) 2 \cdot 3-0.99\right\}
$$

For Amanitopsis vuginata, since $\mathrm{V}=0.5 \mathrm{~cm}$. per second, we find that

$$
y=0.0009 \mathrm{~cm} .=9 \mu .
$$

The diameter of a spore is approximately $10 \mu$. Hence we can state that the distance fallen by a spore of $A$. vagimute before reaching its terminal velocity (within 1 per cent.) is less than its diameter.

The length of time required for any spore after being set free to attain its terminal vertical velocity within 1 per cent., can be shown to be equal to $0.0047 \times \mathrm{V}$, where $\mathrm{V}$ is the terminal velocity. For Amanitopsis vaginate the terminal velocity may be taken as 0.5 $\mathrm{cm}$. per second. It can be calenlated, therefore, that a spore would attain its terminal vertical velocity in approximately $\frac{7}{400}$ second. The terminal velocities of fall of the spores of other species are of the same order as that of Amanitopsis vaginata. We are therefore justified in drawing the general conclusion that the spores of Hymenomycetes attain a uniform velocity of fall practically at the instant of their liberation.

We can also ealculate the length of time required for a spore to arrive within 1 per cent. of the total horizontal distance to which it is projected. At the end of the time in question, the position of the spore on the sporabola will be $x$ cms. from the vertical axis and $y$ cms. below the highest point. According to our assumption $\frac{x}{\mathrm{X}}=0 \cdot 99$. By substitution in the equation for a sporabola we find that

$$
y=0.0009 \mathrm{~cm} .=9 \mu .
$$

It has been shown, however, that a spore falls through this distance in approximately $\frac{1}{400}$ second. We may conclude, therefore, that the spore will have travelled for only $\frac{1}{400}$ second before arriving 
within 1 per cent. of the total horizontal distance to which it is projected. An important conclusion which may be drawn from this calculation is that it would be extremely difficult, if not impossible, to observe the horizontal flight of the spores. The horizontal movement is completed in $\frac{1}{40}$ second. It is very questionable if the human eye conld olserve such a movement of a dark body at all, and particularly under the conditions of observation necessitated by the size of the spores, the position of the basidia, and the uncertainty of the time of spore-discharge. 'These theoretical considerations fall in line with my observations, for I have never yet succeded in watehing the horizontal flight of a spore from its sterigma.

The results of the investigations upon the motion of a spore of Amanitopsis vaginatu, $10 \mu$ in diameter, when projected from its sterigma in a horizontal direction, may be summed up as follows:-

By observation-

Maximum horizontal distance of projection $=0.02 \mathrm{~cm}$.

Terminal velocity of fall $=0.5 \mathrm{~cm}$. per second.

By calculation-

The terminal velocity of fall is reached after a distance of $9 \mu$ (which is less than the dianeter of a spore) has been traversed.

The terminal velocity of fall is reached in $\frac{1}{400}$ second approximately.

The spore arrives within 1 per cent. of its total horizontal flight (i.e. it goes $0.0198 \mathrm{~cm}$.) in $\frac{1}{400}$ second.

The initial horizontal velocity is $40 \mathrm{~cm}$. per second.

When one compares the movement of a spore with that of a pebble projected in like manner, the differences at first appear to be remarkable. However, it must be remembered that a spore has an enomous surface in proportion to its mass as compared with a pebble. The air, therefore, in proportion to their masses, offers a vastly greater resistance to the movement of a spore than to that of a pebble.

In Plate I., Fig. t, the paths of spores between the gills of at Mushroom are shown, whilst in the text-figures 56 (p. 165) and 66 similar illustrations are given for Amomitopsis raginata and P'olyforus squamosus respectively. It is evident that the spores are shot outwards from the hymenium in such a mamner that they are projecterl clear of the hymenium and yet not far enough to strike the opposite gill. The air is a delicate regulator in this matter. 
The structure of a Mushroom is such that the spores are shot out into the spaces between the gills, where they fall down freely in response to gravity. They thus escape from the fruit-body without danger of tonching, and thereby adhering to, the hymenium.

The hymenium on the side of a gill may be likened to a battery. The basidia are the gums and the spores the projectiles. Each gun is capable of shooting off four projectiles in succession at intervals of a few seconds or minutes. The battery is so splendidly organised that the guns are brought forward, mounted, and fired off in succession. Thus a heavy and continuous bombardment is maintained for days or weeks, and only ceases when the ammunition has become exhausted. The object of the miniature gunnery is to drop the spores into the spaces between the gills, so that they may fall out from the fruit-body without touching one another or any part of the hymenium. The suceess with which a large Mushroom or Polyporus is able in the course of a few days to liberate thousands of millions of spores, and entrust them to the seattering winds, may well excite our admiration.

In a few rare instances, owing to

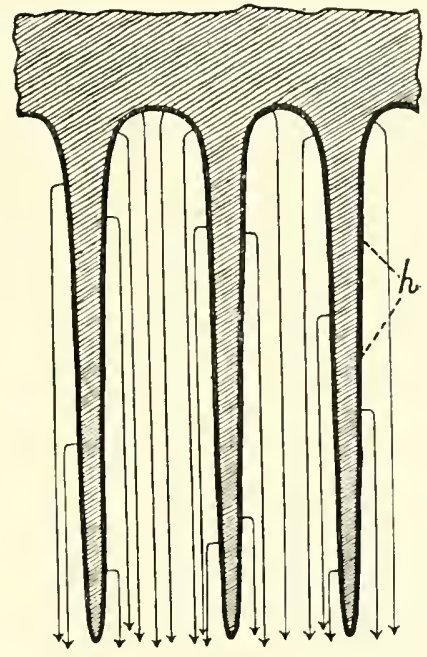

Fic. (66.-Tertical section through two hymenial tubes from the pileus of Polyporus squamosus. The arrows show the sporabolas described by the spores when they are discharged. $h$, the hymenium. About 8 times natural size. imperfection in the structure of the pilei, the spores are not all able to escape into the outer air. Thus, for example, in Nolunen Imscue the gills often become locally powdered with the red spores. This is due to the fact that the gills are somewhat wayy, and therefore not properly disposed in vertical planes. The adhesive spores, when falling, catch and stick on the projecting parts. 


\section{APPENDIX \\ THE MOTION OF A SPHERE IN A TISCOU'S MEDIUM \\ Contributed by Dr. GuY Baklow.}

(The notation is the same as that employed in chapters $\mathrm{XI}$. and $\mathrm{X} \mathrm{VII}$.)

As shown by Stokes, the resisting foree on a sphere of radius $a$ when moving with veloeity $r$ is given by

$$
\mathrm{F}=6 \pi \mu a v
$$

Since the force is directly proportional to the velocity, it is evident that the component of this force in any direction is also directly proportional to the component of the velocity in that direction. The motion of the sphere when projected under gravity can therefore be regarded as comprounded of the independent horizontal and vertical motions, and these may be conveniently investigated sejarately.

1. Fall from rest under gracity.

The equation of motion is-

$$
m \frac{d v}{d t}=m g-6 \pi \mu r x,
$$

where $m$ is the mass of the sphere and $v$ its velocity downwards at time $t$. The density $\sigma$ of the medium is here neglected.

This equation may be written

$$
d v=y-e v .
$$

where

$$
c={ }_{m}^{i \pi \mu r} \text {. }
$$

When the steady terminal state is reached, $\frac{d v}{d t}=0, v=\mathrm{V}$, hence from (2),

$$
\mathrm{V}=\frac{y}{c}
$$

Substituting value of $c$ and 1 utting $m={ }_{3}^{4} \pi a^{3} \rho$ we obtain Stokes' expression for the terminal veloeity

$$
V=\begin{array}{lc}
2 & g \rho r^{2} \\
! & \mu
\end{array} .
$$

Equation (2) may now be written-

$$
d r=c(\mathrm{~V}-v) \text {. }
$$

Integration with initial eondition $\gamma=o$ when $t=0$ gives

$$
v=\mathrm{V}\left(1-e^{-c t}\right) \text {. }
$$


Putting $v=\frac{d y}{d t}$ and integrating again with condition $y=0$ when $t=0$ we get

$$
y=\mathrm{V}\left\{t-\frac{1}{c}\left(1-e^{-c t}\right)\right\} \quad . \quad . \quad . \quad .
$$

2. Horiantal motion with initial velocity $\mathrm{H}$.

If $u$ is horizontal velocity at time $t$, the equation of motion is now simply

$$
\frac{d u}{d t}=-c u,
$$

or

Therefore

$$
u \frac{d u}{d x}=-c u
$$

and hence

$$
d u=-c d x,
$$$$
\mathrm{H}-u=c x
$$

But $\imath^{\prime}=\mathrm{X}$ for $u=0$, therefore $\mathrm{H}=c \mathrm{X}$.

From the last expression and (3) we obtain

$$
\mathrm{H}=\frac{g \mathrm{X}}{\mathrm{V}}
$$

Proceeding with the integration, from $(7)$ we have

$$
\begin{aligned}
\frac{d x}{d t} & =u \\
& =\mathrm{H}-c x \\
& =c(\mathrm{X}-x) .
\end{aligned}
$$

Integration with initial condition $x=0$ when $t=0$ leads to

$$
x=\mathrm{X}\left(1-e^{-c t}\right)
$$

3. The equation of the path of a sphere projected horizontally under gravity is obtained at once by the elimination of $t$ from the two equations (6) and (9): and replacing $c$ by its value $\frac{g}{V}$ we have finally

$$
y=\frac{\mathrm{V}^{2}}{g}\left\{-\log _{\nu}\left(1-\frac{x}{\mathrm{X}}\right)-\frac{x}{\mathrm{X}}\right\} . . . .
$$




\section{CHAP'TER XVIII}

\section{THE ELEOTRIC CHARGES ON THE SPORES}

Althougu the matter maly be of but small hiological interest, it seemed desirable to aseertain whether or not the falling spores carry electric charges, and, if so, of what kind. The apparatus for the investigation of the problem was constructed as follows. A brass chamber, shown at B by two sections in Fig. 67 , was supported on a rod, $\mathrm{R}$, and covered in front and behind with glass dises, GG'. At its centre were fixed two brass plates, $\mathrm{PP}^{\prime}, 1 \cdot 2 \mathrm{~cm}$. wide and $\because \mathrm{cm}$. high, so that they were parallel to one another and about $1.5 \mathrm{~mm}$. apart. The plates were attached to wires introduced through lateral holes in the chamber, insulation being secured by means of glass tubing, 'TT', and sealing-wax, $S$. Above the plate was suspended a piece of the pileus of a Mushroom, F, with the gills looking downwards. This was held in position by means of a pin stuck into a cork, $K$, covered with tinfoil, N. The brass chamber, and thus also the piece of fungus, was earefully earthed by means of a wire attached to a gas-pipe at E. By means of other wires the two plates were connected with a mereury connutator, C. The latter was then connected on one side with the gas-pipe, E, and on the other with the eity main, II, of 220 volts. The lamp, L, was placed in the eircuit for the purpose of detecting any accidental flow of current. By moving the handle of the commutator to the right, both the piece of fungus and the brass plates were earthed and therefore rendered neutral, whilst by moving it to the left the plates were given charges of opposite signs.

A vertical plane, passing between the plates towards their centres, was focussed and observed by means of at horizontal mieroscope with a magnitication of about 25 and a field of view 55 mm. in diancter (cf. Plate IV, Fig. 29). When the 
handle of the commutator was turned to the right so that the plates were uncharged, the spores could be seen falling vertically downwards between them at the rate of about $1 \mathrm{~mm}$. per second. No attraction of the spores to the plates could be detected. When spores were observed to have reached the centre of the space between the plates, the handle of the commutator was suddenly turned to the left so that one of the plates beeame positively and the other negatively eharged. Immediately the paths of most of the spores were altered (Fig. 68, A). Some spores were attracted to one plate and some to the other, the majority going to the one

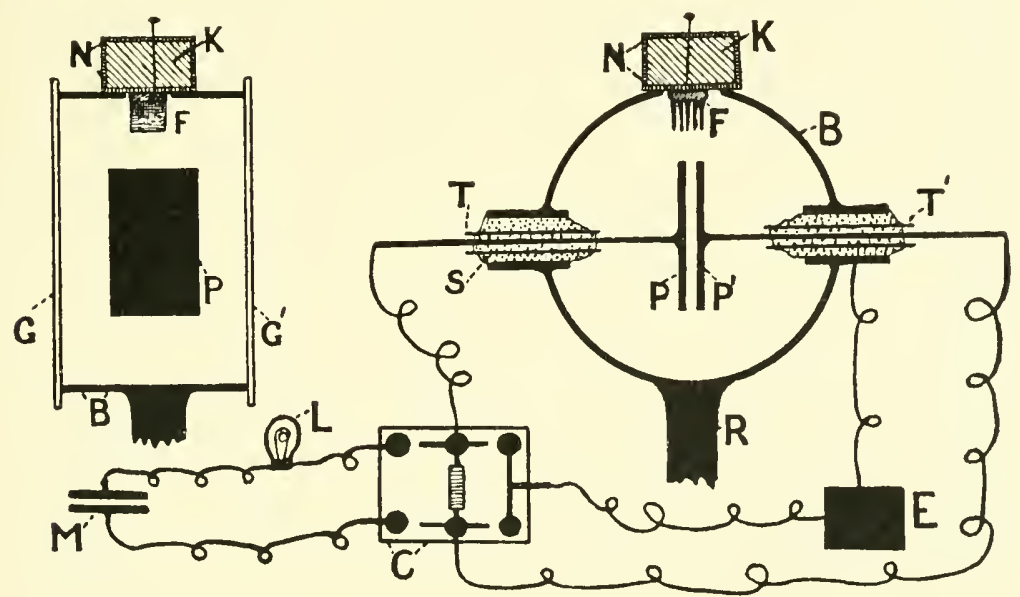

FIG. 67.-Apparatus with electrical attachments for detecting the electrical charges on falling spores. The brass chamber B, natural size. Description in the text.

with a positive charge. A few continued their motion vertically downwards. A number of spores appeared to turn at right angles to their former courses and they then moved with great rapidity to the plates. These must have been the spores which were relatively the most highly charged. Others made their way to the plates at a more or less gentle angle to the vertical and with a less accelerated velocity. Doubtless they were less highly charged. A certain number of spores which were not appreciably affected by charging the plates were probably not electrified at all.

On reaching one of the plates, each spore became charged with electricity of the same sign as that on the plate, and in consequence 
tended to be repelled from the latter. Owing to their adhesiveness, however, the spores were unable to leave the plates after having once come in contalet with them. When the plates were left charged for some hours, the spores, which fell in large numbers from the piece of pileus, gradually formed simple or branching chains which sometimes stretched almost from one plate to the other, thus indicating the direction of the lines of force between them. The formation of chains not only demonstrated the

C

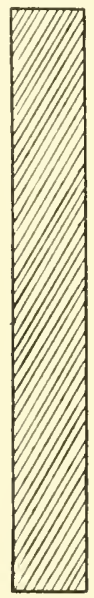

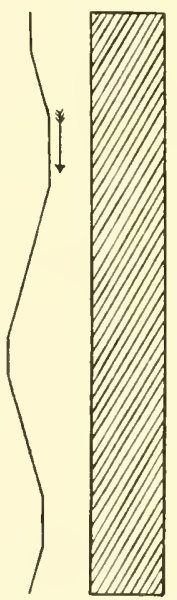

B

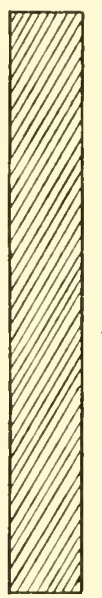

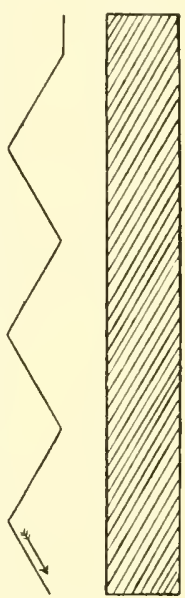

A

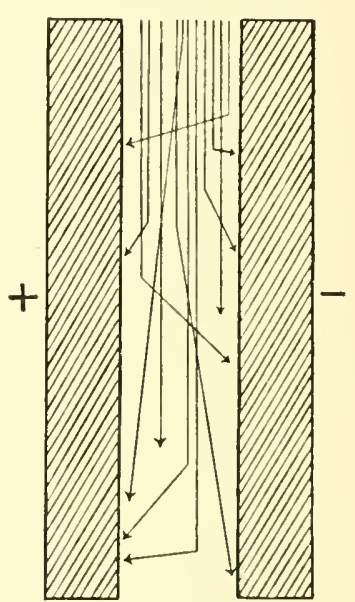

FIG. 68. - The paths of spores falling between two brass plates. A, shows how the spores deviate from the vertical when the plates are suddenly electrified with charges of opposite signs. B, zigzag path of a spore produced by alternately reversing the charges on the plates. $\mathrm{C}$, path of a spore produced by charging the plates, making them neutral, giving them reversed charges, \&c., in succession.

tendency of the spores to be repelled from the plates and from one another, but also the fact that the spores strongly adhere to surfaces with which they may come in contact.

When the plates were suddenly charged, it was found that proximity of a spore to one plate rather than the other was not a factor deciding to which of the two plates the spore should move (Fig. 68, A). There seems to be no escape from the conclusion that, either at the moment of discharge from the sterigmata or within a very few seconds afterwarts whilst fatling through the air, the majority of spores receive positive or negative electric 
THE ELECTRIC CHARGES ON THE SPORES I95

charges of different strengths, whilst a certain number do not become charged at all.

By another arrangement of the commutator, it was possible to reverse alternately the charges on the plates or to remove them. By reversing the charges alternately a spore can be made to take a zigzag path across the field like that shown in Fig. 68, B. By successively charging the plates $+-, 00,-+, 00,+-$, \&c., one can make the path of a spore still more irregular (Fig. 68, C).

Several other species beside Psalliota campestris were tested, among them being Polyporus squamosus. In all cases the spores behaved like those of the Mushroom, the majority appearing to be charged, either positively or negatively.

That the spores bear electric charges during their passage through the air may be regarded as a physical fact of no apparent biological importance. There seems to be no reason to suppose that in nature the spores, in consequence of being electrified, settle on one surface rather than another. It therefore appears improbable that the charges are of use to the spores in enabling them to obtain advantageous locations for germination.

A further investigation as to the manner in which the spores originally become charged and into the conditions which determine the gain or loss of charges by them was thought unnecessary for my present purpose. 


\title{
CHAP'TER XIX
}

\author{
THE COPRINUS TYPE OF FRLIT-BODY
}

"And agaries and fungi with mildew and mould

Started like mist from the wet ground cold ;

Pale, fleshy, as if the decaying dead

With a spirit of growth had been animater:

Their moss rotted off them, flake by flake, Till the thick stalk stuck like a murderer's stake, Where rags of loose Hesh yet tremble on high, Infecting the winds that wander by."

-Shellex. ${ }^{1}$

The Coprini are especially eharacterised by the fact that the gills "deliquesce" on maturity, and that drops of an inky-looking fluid are often formed on the pilei. Sio far as I am aware, however, although many figures and photographs ${ }^{2}$ of members of the Coprinus genus have been published, no one hitherto has explained the real significance of the fact of "deliquescence" or the general structural arrangement of Coprinus fruit-bodies. In what follows, I hope to be able to show how admirably a Coprinus fruit-body is constructed when regarded as a highly efficient spore-producing and spore-libernting organ.

One of the best known and largest of the Coprini is Coprinus comutus. It often comes up in great abundance in fields (Plate IV., Fig. 21). It "deliquesces" in a typical manner. Fruit-bodies of this species afforded me admirable material for a study of the structure of a Coprinus in relation to spore-fill.

1 The second of these two verses evidently refers to a species of Coprinus. The poet had probably noticed the remarkable changes which take place in the conspicuous fruit-bodies of Coprinus comatus.

${ }^{2}$ A series of excellent photographs of this species his been published by G. F. Atkinson, "Studies and Illustrations of Mushrooms : Il.," Bull. 168, Cornell Univers. Agric. Experiment Stution, 1899: also, Mushrooms-Edible, Poisonous, d'c., Ithaca, 1901, pp. 33-41. 
An unripe pileus which has attained its full length is more or less barrel-shaped (Plate II., Fig. 7; Plate IV., Figs. 21 and 22, to the right). The gills are white in colour, closely packed together, and with very few exceptions equal in length.

Upon beginning to open out, the pileus alters its form from that of a barrel to that of a bell (Plate IV., Figs. 21 and 22; Plate I., Fig. 1). It breaks away from the stipe below and leaves the latter encircled with an annulus. Whilst the gills are moving radially outwards from the stipe, they become slightly separated from one another. The rim of the bell-shaped pileus now turns slightly outwards (Plate I., Fig. 1). 'This results in a further separation of the lower ends of the gills, so that the spaces which have thus arisen between them are similar to those between the gills throughout their whole length in the case of a Mushroom (cf. Plate IV., Figs. 2:3 and 20). Except at their lower ends, adjacent gills at this stage in development are united by interlocking cystidia along their margin, and are just as closely packed as they were when the fruit-body was barrel-shaped. The separation of the lower ends of the gills is accompanied by the beginning of the process of "deliquescence."

Whilst the pileus is changing from the barrel to the bell form and is separating the lower ends of its gills, the basidia are rapidly developing their spores. As these ripen they turn pinkish and finally black. Just before "deliquescence" begins, it can clearly be made out that the spores ripen on the gills from below upwards. The lower parts of the gills blacken tirst (Plate I., Fig. 1). The black zone passes into a pink zone higher up, and this in its turn, toward the top of the pileus, gradually shades into white.

Whenever a gill has become black, a small piece of its surface, when seen in face view with the microscope, has the appearance shown in Plate III., Fig. 15. The pattern presented to the eye is very regular and pleasing. Each basidium bears four black spores, and is separated from adjacent basidia by paraphyses. The four spores of a basidium are so attached to the sterigmata that they are separated from one another as much as possible. They are thus prevented from touching, and consequently from adhering to, one another both during development and discharge. 
The paraphyses are present in just the right proportion to prevent the spores of adjacent basidia from coming in contact. A glance at Plate III., Fig. 15, shows that the spacing of the adhesive spores is brought about so economically that it would be difficult to imagine how more of them could be developed simultancously on any given area of a gill surface. A cross-section through a gill (Plate III., Fig. 16) shows that the basidia project considerably beyond the paraphyses and are all directed perpendicularly outwards from the gill surface.

When the pileus is still barrel-shaped and until spore-fall

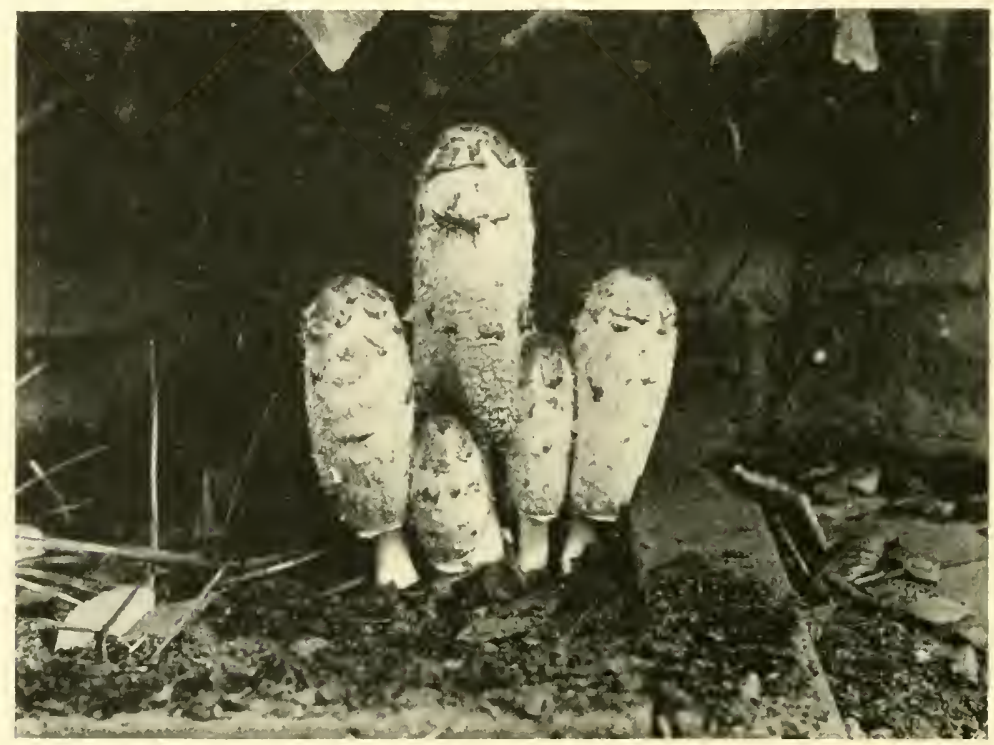

FIG. 69.-Coprinus comutus. Fruit-bodies in an early stage of development. In the tallest the fall of spores and autodigestion have just begun. The four others are a few hours younger: the pilei are separating from the stipe below and the gills are still intact. Photographed at Sutton Park, Warwickshire, by J. E. Titley. About $\frac{1}{3}$ natural size.

begins, the inner edges of the gills towards the stipe, throughout their entire length and for a width of about $0.25 \mathrm{~mm}$, appear to the naked eye as white bands (Plate I., Fig. 1, $m$; Plate II., Figs. 8 and 9, $m$ ). These are especially inflated portions of the gills, entirely devoid of basidia and covered over by large, colourless, unicellular cystidia (Plate III., Figs. 13 and 14). The 
thickened marginal bands of adjacent gills are in contact with one another, so that a solid white eylinder is formed which ensheaths the stipe. It is important to notice that the gills, except where they join at the membranous flesh of the pileus and are in contact by means of the inner inflated marginal bands,

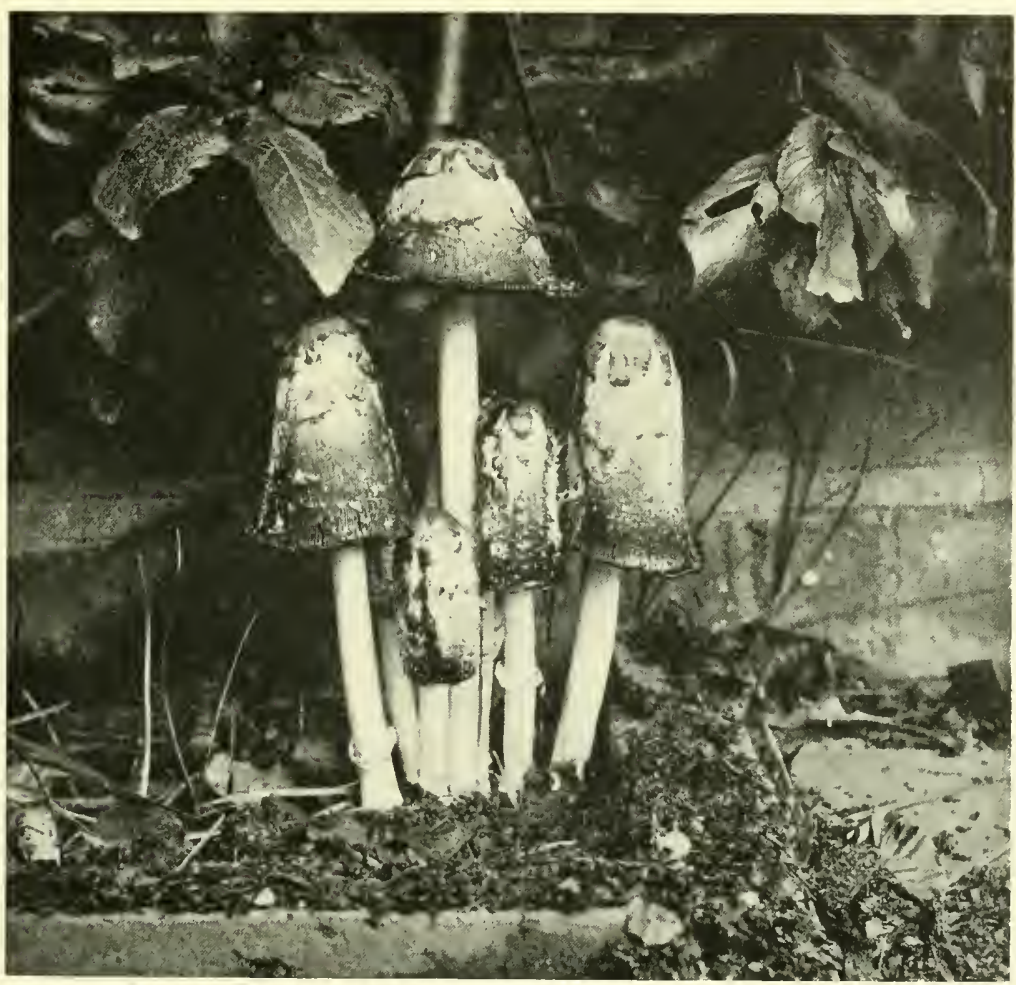

FIG. 70.-Coprinus comatus. Same fruit-bodies as shown in Fig. 69, twenty-two hours older. All are shedding spores and undergoing autodigestion. The pileus of the tallest has become reducer to one-half its original size and a few drops of inky fluid have fallen from its recurved rim on to the pilei below. The stipes have lengthened considerably. Photographed at Sutton Park, Warwickshire, by J. E. 'T'itley, About $\frac{1}{3}$ natural size.

are separated throughout their entire length (Plate I., Fig. 5). In the spaces thus provided between the gills, the projecting basidia can freely develop to maturity (Plate III., Fig. 14). It thus happens that the spores of basidia, which belong to adjacent gills, are never in danger of coming into actual contact and eon- 
sequently of adhering to one another. The significance of the marginal bands with their eystidia seens to be, therefore, that they secure that the faces of adjaeent gills, i.e. the hymenial surfaees, shall be suitably spaced during development. ${ }^{1}$

The so-called "deliquescenee" of a Coprinus fruit-body has nothing in common with the phenomenon of deliquescence of crystals known to the chemist. The phenomenon with whieh we have to deal is really a proeess of autudigestion. The solid parts of the gills beeome fluid, in all probability through the ageney of digestive enzymes. There is not the slightest reason to suppose that the fluid is derived from the water-vaponr of the air.

Autodigestion of a gill always begins at its base, along the free edge where the gill is separating or has just separated from its neighbours (Plate II., Fig. 8, *). The marginal cystidia are first involved. They simply break down, become fhid and indistinguishable. After the destruetion of the eystidia, the autodigestion proceeds obliquely upwards and gradually destroys the whole gill (Plate II., Figs. 8, 9, 10, and 11). The entire destruction of the gills from below upwards in large fruit-bodies was observed to take about two days, whilst in smaller ones the process was carried out in little more than twenty-four hours ( $c f$. Figs. 69, 70 , and 71$)$.

As the gills get shorter and shorter owing to their destruetion from below upwards, the pileus gradually opens. It passes from the bell shape to the helmet shape (Plate II.. Fig. 9), and at length, as it becomes smaller and smaller, flattens out into a disc like that of a Mushroom (Plate II., Fig. 10; Plate IV., Figs, 21 and 22). The remains of the gills thus come to be held out horizontally. In this position they disappear in their entirety, so that merely the naked central flesh of the pileus is left behind (Plate II., Fig. 11). When a fruit-body has eompletely lost its gills, the stipe often bends in two toward the middle, so that the pileus flesh, which has now become very discoloured and ragged, either hangs down or

${ }^{1}$ It might perhaps be shown that the provision of spaces, so that the basidia can develop their spores in air without contact with any obstacle, is a prineiple of development applying not only to the Coprini, Psalliota, Polyporus, de., but to the Basidiomycetes generally. 
comes in contact with the ground. The further destruction of the fruit-body appears to be completed by putrefaction. From the first appearance of a very young fruit-body above the ground up to the giving way of the stipe, the interval was found to be about seven days.

It sometimes happens that, shortly after autodigestion has
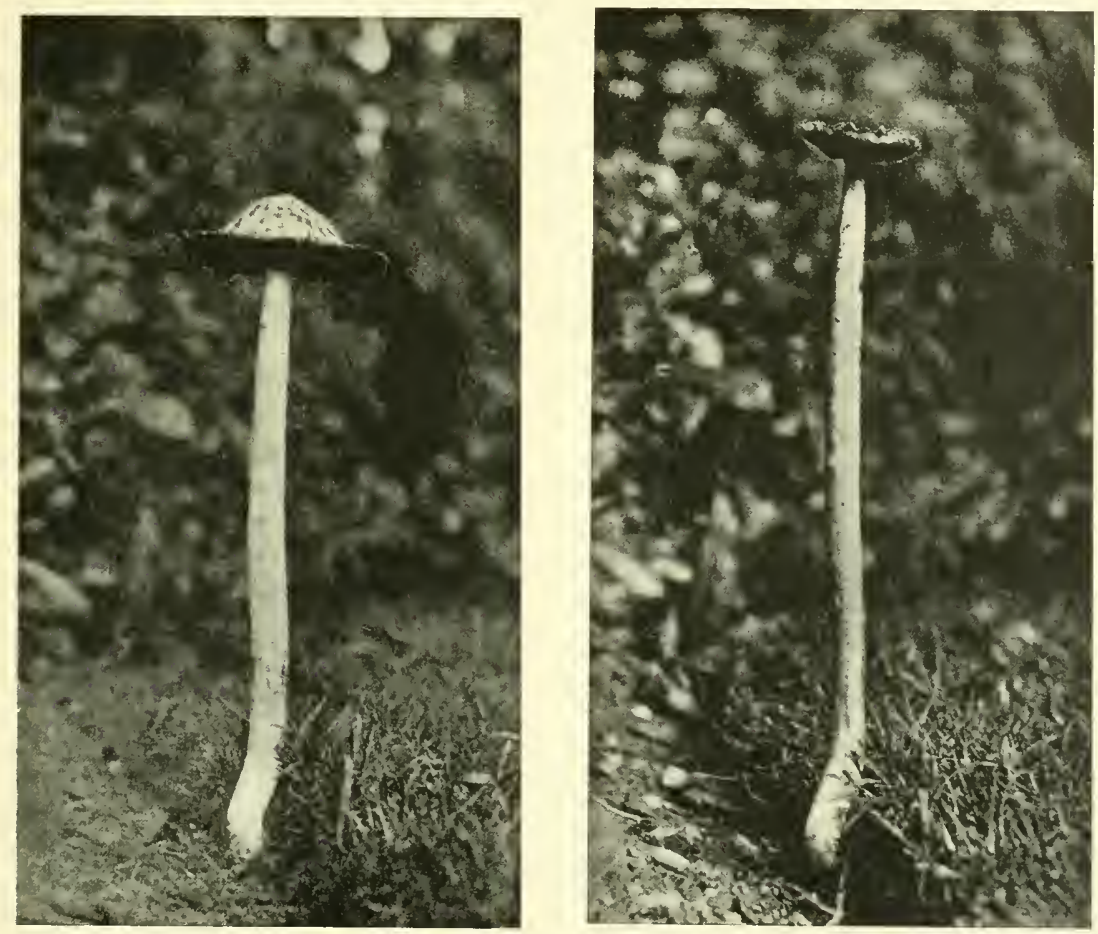

FI(. 71.-Coprimus comatus. Last stages in antodigestion. The fruit-body to the left has lost about three-fourths of its pileus but is still shedding spores. The same fruit-body, twenty-four hours older, is shown on the right. The gills bave now practically disappeared and spore-emission has ceased. Photographed by P. Grafton. $\frac{1}{3}$ natural size.

begun, the free margin of the pileus presents a rayed or ragged appearance. This is due to the fact that, at intervals round the base of the pileus, the lower ends of individual gills have split along their median planes from without inwards, and that the two halves of each gill so divided have been pulled apart laterally (Plate IV., Fig. 23). The fissures seen at the bottom of the pileus 
from without correspond, therefore, not to spaces between adjacent gills, but to spaces between half gills pulled asunder.

During autodigestion, the oblique free edge of each gill is black and covered with a liquid film. From this edge evaporation takes place and no actual drops of inky fluid form upon it. The spaces between the gills, therefore, do not become choked up, but remain open just as in a Mushroom (Plate IV., Fig. 2:3). As autodigestion proceeds, each gill, when seen in face view, gets narrower and narrower below, until it is almost reduced to nothing (Plate II.. Fig. 8). The membranous flesh of the pileus bearing the remains of the gills often curls outwarts and upwards so as to form a neat and curious circular roll (Plate IV., Figs. 22.2 and 24; Plate III. Figs. 9 and 10). Sometimes, however, it simply hangs downwards, in which case the pileus looks ragged and untidy (Plate II., Fig. 8: Plate IV., Fig. 21). With the continuance of autodigestion, the now useless material just described is gradually converted more or less completely into drops of inky-looking fluid, which may often be seen hanging from the rim of the pileus (Plate II., Fig. 10: Plate IV., Fig. 24). It will shortly become clear that the formation of the circular roll on the top of the pileus is to be regarder as an admirable method of securing that that part of the pileus which has ceased to have any functional significance shall be as far removed as possible from the paths of the falling spores, and thus prevented from hindering spore-disposal by the wind.

If one allows an upright fruit-body, with its stipe placed in wet sand, to shed its spores under a bell-jar, one finds by microscopic examination that the inky drops, produeed by autodigestion, consist of a brown fluid containing granules but practically free from spores. The fluid, therefore, is not made black by spores. The colour is probably due to an oxydase which unites the oxygen of the air with some substance liberated from the dying cells, for it was found that the colourless juice squeezed from an unripe pileus turns brown in a few hours. ${ }^{1}$ The drops collect only on the rim of the pileus, where they do not interfere with the liberation of the spores into the air. If paper is placed round the base of the stipe,

${ }^{1}$ Cf. A. H. R. Buller, "The Enzymes of Polyporus squamosus," Ann. of Bot., vol. xx. p. 51 . 
a black spore-deposit collects upon it, which is similar to that produced under the same conditions by an ordinary Agaric.

In nature, the fluid produced by autodigestion is largely got rid of by evaporation. The amount of it adhering to the pileus rim varies considerably according to the state of the weather. In very dry weather, it often happens that actual drops are not formed at all. On the other hand, dripping is favoured by a saturated atmosphere, and was found to take place regularly with fruit-bodies placed in a damp-chamber.

Two independent observers have informed me that they have been surprised by finding that the drops hanging from the pileus of certain fruit-bodies were red instead of black. In one case the colour was described as "just like that of red currants." I, myself, have never seen any red drops, but can scarcely doubt their occasional occurrence. Possibly the red drops were merely excreted from the exterior of the pileus like those given out by Fistutina hepatica or Lentinus lepideus, and they may have had no connection with the process of autodigestion.

A fruit-body begins to liberate its spores as soon as it has become bell-shaped and the lower ends of the gills have separated. The spores are projected violently from their sterigmata into the spaces between the gills, where they describe sporabolas, and thus escape into the outer air. Proofs that the four spores of a basidium are shot off in succession in the course of a few seconds or minutes have already been given. ${ }^{1}$ The nature of a sporabola has likewise been dealt with. ${ }^{2}$ Convineing proof that the spores are liberated into the air may be obtained, not only by collecting the thick black sporedeposit on white paper, but also by the beam-of-light method. When a fruit-body is placed upright in a closed beaker, the beam of light reveals clouds of spores emerging from the gills and becoming scattered by convection currents in the enclosed air. ${ }^{3}$

Spore-discharge from a gill is not general all over its surface as in a Mushroom, but extremely local. It begins on both sides simultaneously, towards the base along two opposite and very narrow zones (Plate II., Fig. 8, s), which run parallel to and adjoin the oblique, free, inner gill edge. We may refer to a part of

\footnotetext{
1 Chap. XJ., Method IV.
}

${ }^{2}$ Chap. XVII.

${ }^{3}$ Cf. Chap. VII. 
the hymenimm where spore-discharge is actively taking place as the sone of sporedischerye. Such a zone may be two or more centimetres long, but it is only a fraction of a millinetre wide. A zone of a gill, where spore-discharge is taking place rapidly, becomes entirely spore-free owing to the fact that all the basidia within it discharge their spores almost simultaneously. The two opposite zones of spore-discharge on a gill gradually move upwards together and parallel to themselves. Thus, in the course of about two days, all the spores on a gill are successively discharged from below upwards.

With the commeneement of spore-discharge, or possibly just previously thereto, the marginal eystidia bordering the zone of sporedischarge break down, and become tluid and unrecognisable. The discharge of spores leads to the production of a zone of spore-free gill surface. Before this has become $0.5 \mathrm{~mm}$. wide, it becomes subjected to the process of autodigestion. The basidia at the gill edge, which were the first to discharge their spores, together with the paraphyses between them, rapilly lose their sharp contours, become entirely disorganised, and tum into fluid. The subhymenial cells and those of the trama break down in a similar manner. Thus the gill edge, for a distance of about two centimetres, becomes converted into a dark liquid film (Plate II., Fig. 8, u). We can now distinguish five zones on each surfice of a gill, running parallel to its oblique edge (Plate II., Fig. 12). Highest of all is a zone with basidia bearing ripe spores. Below this is the narrow zone of sporedischarge, where the basidia are all rapidly freeing themselves of their spores, by shooting them out one by one into the interlamellar spaces. Further below, there is a narrow zone of spore-freed surface where the basidia all have naked sterigmata. Below this again is the zone of autodigestion where the basidia and paraphyses are becoming disorganised and liquefied. Finally, ocenpying the extreme gill edge, there is a dark-coloured, adhesive, liquid film.

By watching a piece of a gill like that represented in Plate II., Fig. 12, when placed in a closed compressor cell, it is casy to determine that the zone of autodigestion follows hard upon the zone of spore-freed surface. However, it never invades the zone of spore-discharge, although it is always less than a single milli- 
metre behind it. The five zones described, retain the same relations to one another during the whole two days or so required for the complete discharge of the spores. They move upwards simultaneously from the bottom to the top of each gill (Plate II., Figs. 8, 9, and 10). The zone of spore-free basidia, and the adjacent portions of the zones of spore-diseharge and autodigestion, ean often just be distinguished with the naked eye upon a gill, for together they give the appearance of a very thin whitish line next to the thin black liquid film on the gill edge and separating this from the general gill surface which, owing to the vast number of spores borne by the mature basidia, is uniformly black.

It is evident that autodigestion plays a very important part in spore-discharge. Its function is wholly mechanical. It destroys the spore-freed portions of the gills and so elears them out of the way. Only by the removal of these obstacles could the pileus gradually turn outwards and thus cause the production of spaces between the lower ends of the gills higher and higher up as these become shorter and shorter. Such spaces are absolutely necessary to pernit of the liberation of the spores from the zones of sporedischarge. The basidia shoot out their spores horizontally into the spaces between the gills (Plate III., Figs. 16 and 17). The maximum horizontal distance to which the spores travel, before their horizontal motion is reduced to zero by the resistance of the air, is about $0.1 \mathrm{~mm}$. After making the usual sporabolie curves, the spores fall vertically downwards with a steady teminal velocity of about $4 \mathrm{~mm}$. per second. ${ }^{1}$ Since the zones of sporedischarge are so near the gill edges, the spores have only to fall a distance of about $0.5 \mathrm{~mm}$. between two gills in order to effect their escape. The risk of the spores striking the gill sides is thereby reduced to a minimum. As the spores fall below the pileus, doubtless they lose water rapidly. ${ }^{2}$ Their veloeity probably diminishes to about $2 \mathrm{~mm}$. per second in the course of a minute. On leaving the fruit-body, the spores are carried off by air-currents which seatter then far and wide. The discharge of spores into the air takes place day and night continuously. It has already been mentioned that a large fruit-body was found to

$$
{ }^{1} \text { Chap. XY. }{ }^{2} \text { Chap. XVI. }
$$


produce about 5,000,000,000 spores. ${ }^{1}$ Since the entire discharge of the spores from a large pileus usually takes about 48 hours, it seems safe to state that in this case more than $1,000,000$ would have been liberated upon the average each minute. One need not therefore be surprised at the rapidity with which a black

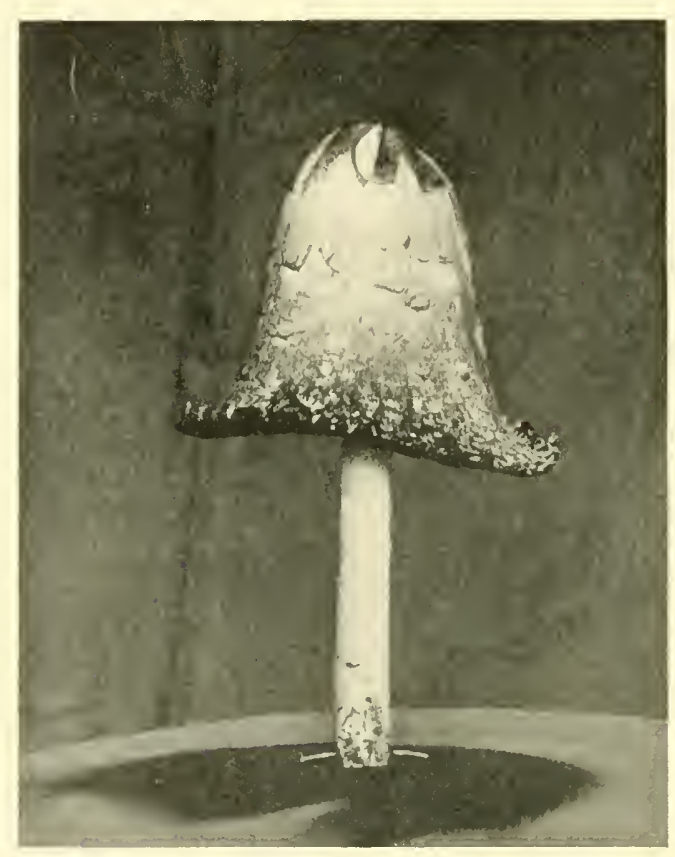

FIG. 72.-The liberation of spores by Coprinus comatus. The fruit-body was gathered in a field and then set in a vertical position under a bell-jar. As the pileus expander below, spores began to fall. The black spore-deposit upon the paper around the base of the stipe was formed in the course of three hours. P'hotographed hy P. Grafton. natural size. spore - deposit collects upon white paper, when this is placed beneath a fruit-body which has its natural orientation under a bell-jar (Fig. 72).

Hy own observations seem to point conclusively to the fact that the spores of Coprinus comutus, like those of the Mushroom and all other Agaricinea, are distributed by the wind. However, another, and I believe quite erroneous, explanation of this matter, has found its way into botanical literature. It seems to have been suggested originally by Fulton, ${ }^{2}$ and is now given in various text-books. ${ }^{3}$ It has been stated that the gills turn into an inky mass, that the fluid so produced contains the spores, and that insects visit the fruit-bodies, lick up the ink, earry off the spores, and thus spread them from place to place. This suems to me

${ }^{3}$ Chap. $\mathrm{I}$.

2 T. IV. Fulton, "The Dispersal of the Spores of Fungi by the Acrency of Insects, with special reference to the Phalloidei," A m of Bot., rol. iii., 1889-90, 1\%. 215-216. I fail to follow Fulton in finding a resemblance between the pilei of ('oprini and the capitula of Compositie.

3 E.y. E. M. Freeman, Minnestete Plant Iliseuses, 1905, P1). 178-179. 
to be nothing more than an assumption based on an imperfect analogy with the phenomena of spore-dispersion in Phallus impudicus and other Phallinese. I have carefully watched autodigesting fruit-bodies of Coprinus comatus in the field and have failed to observe any inseets risiting them. The absence of any red or suggestive colour on the exterior of the pileus and the scarcely noticeable and inoffensive odour, are additional facts pointing to the conclusion that the fungus has no special arrangements with insect visitors. The chief evidence in refuting the inseet theory, however, is that the liquid drops which in moist weather hang from the margin of the pileus, contain practically no spores. The few which are present, doubtless, have got into them by aceident. It seems quite certain that the majority of the spores are always carried off by the wind.

Upon gathering "deliquescing" fruit-bodies of Coprinus comatus, mycologists usually find it convenient to lay them more or less horizontally in the collecting tins in order to bring them to the laboratory. Under these conditions, in the eourse of an hour or so, the lower ends of the gills, where autodigestion is taking place, become hopelessly stuck together and the spaces between their ends blocked up. The dark fluid then becomes laden with spores. The delicate mechanism for seeuring the liberation of spores into the air thus becomes entirely spoiled. Possibly, the sight of the gills stuek together in an inky mass in this way has given rise to the erroneous impression that the spores in nature become involved in the putreseent fruit-body. In order to study the phenomenon of spore-liberation in its normal course, the best plan is as follows. One gathers a large fruit-body which is opening out below and has therefore reached a stage in its development just previous to the beginning of autodigestion. One lays the fruit-body in a vaseulum in any convenient position and, on arrival at the laboratory, one plants it upright in wet sand by means of its stipe, so that it comes to have the same orientation that it had when growing in nature. In the course of a few hours normal autodigestion begins at the bottom of each gill and progresses upwards just as in the field. The spaces between the ends of the gills remain open, and, if the fruit-body is covered with a 
bell-jar, the spores discharged into the air can be collected on paper.

Spore-deposits can be collected on paper from any of the Coprini. I have obtained spores in this way not only from

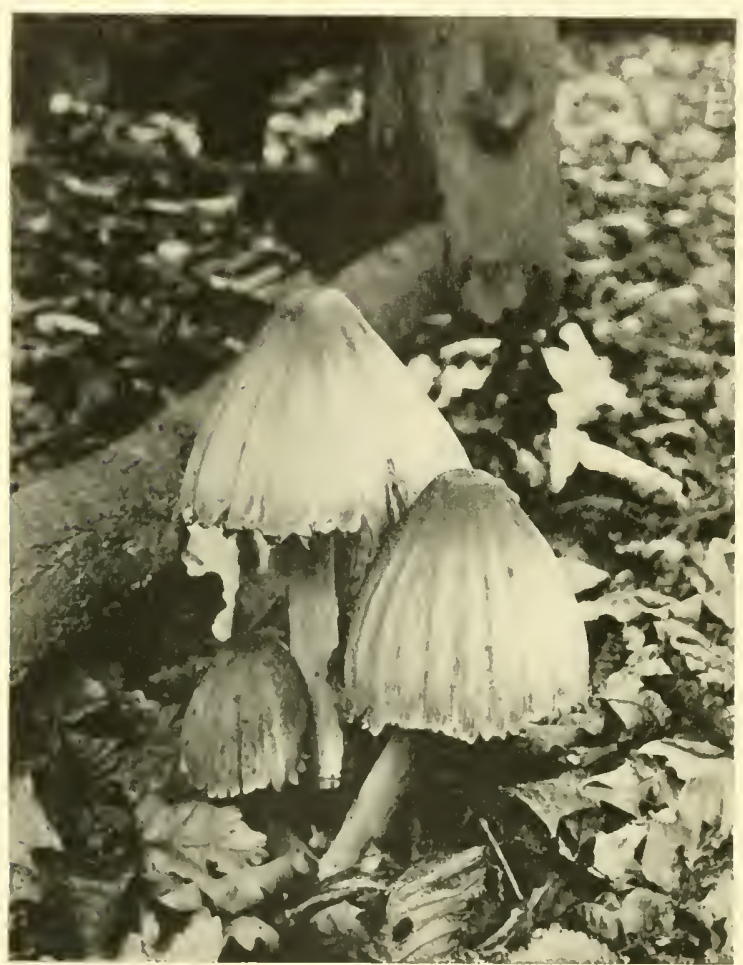

FiG. 73.-Fruit-bodies of Coprinus atrumentu ius shedding spores. Although the lower parts of the stipes are oblique, the upper farts are vertical, so that the gills lie in vertical planes. The lower jarts of the pilei are splitting so as to permit of the reguisite separation of the gills which are undergoing autorligestion. l'hotographed at Sutton Park. Warwick-hire, by J. E. Titley. Rerlueer to about $\frac{2}{5}$.
Coprinus: romatus but also from $C$. atrumenturius, ${ }^{\prime}$. micrereus, r' fimrturius, var.rimereus, as well as from a number of smaller species. Duggar ${ }^{1}$ is therefore in error when, in discussing the means of making pure cultures of edible Hymenomyectes, he says "nuembers of the genus Coprinus are deliqueseent, and here it is implacticable to procure spores by the sporeprint method." With the exereise of a little care, one can obtain as dense a spore-deposit from a Coprinus rometus as from a MushI'OOM.

Copminus atrmenturius. (Fig. 73) and C'. micuceus (Fig. Tt) were found to shed their spores in essentially the same manner as C. comatus. C. plirutilis, and other very small species, behave

13. M. Dugerar, "The Principles of Mushrom Growing and Mushroom Spawn Making," U.S. Lep. of Agric., Burmu of I'lent Iminstry, Bulletin No. 85, 190.5, p. 22. 
somewhat differently. The gills ripen and shed their spores from below upwards. As the pileus opens out, the necessary interlamellar spaces widen from below upwards. However, the entire opening of the pileus, which eventually becomes disc-shaped, is accomplished without "deliquescence." Each gill splits vertically from above and the two halves become pulled out laterally. The expansion of the pileus and the necessary spacing of the gills is thus satisfactorily brought about without autodigestion, which process in these tiny fruit-bodies would be superfluous.

Massee ${ }^{1}$ has recently stated that "Many species included in Coprinus as C. plicatilis and others having dry, non-deliquescent gills, have no real affinity with this genus." Now that the function of autodigestion has been discovered, this view can no longer be regarded as tenable. Autodigestion alone is not a decisive test for placing a species in the genus Coprinus. In its absence in the smaller species, such as C. plicatilis, Coprinus characters, e.g. thimness of the flesh, general structure and splitting of the gills, protuberant basidia separated by paraphyses of a special type, and particularly the ripening and discharge of the spores in succession in a direction proceeding from the pileus margin to the pileus centre, are still sufficiently obvious. Even in C. plicutiloides (Fig. 26, p. 70), one of the smallest of all Coprini, where the expanded parasol-like pileus is often only $5 \mathrm{~mm}$. or even less in dianneter, the process of spore-discharge proceeds centripetally. It always begins tirst, and is completed first, around the periphery of the pileus, and the last spores to be set free are those in the neighbourhood of the stipe. The gradual progress of spore-discharge is therefore essentially similar in the diminutive $C$. plicatiloides and in the relatively gigantic C. comatus. This seems to me to be strong evidence that both species have been rightly placed within the same genus.

There can be little doubt that some of the smaller and more delicate species of Coprinus are largely dependent on the weather for suceess in liberating their spores into the air. In very dry weather, especially when it is windy, I have noticed that fruitbodies of C. plicatilis, growing on a lawn, and those of

$$
1 \text { G. Massee, Tert-Brook of Fungi, London, 1906, p. 364. }
$$


Coprimus micuesus, shrivel up before spore-discharge has been completed, and sometimes, indeed, without its beginning at all. Doubtless this is dne to too rapid transpiration from the gills and upper surfice of the pileus. In moist weather the gills of C. mirmeres undergo the typical process of autodigestion, which has the same relation to the zones of spore-discharge as in C. comutus. Stages in the opening out of the pilens and in

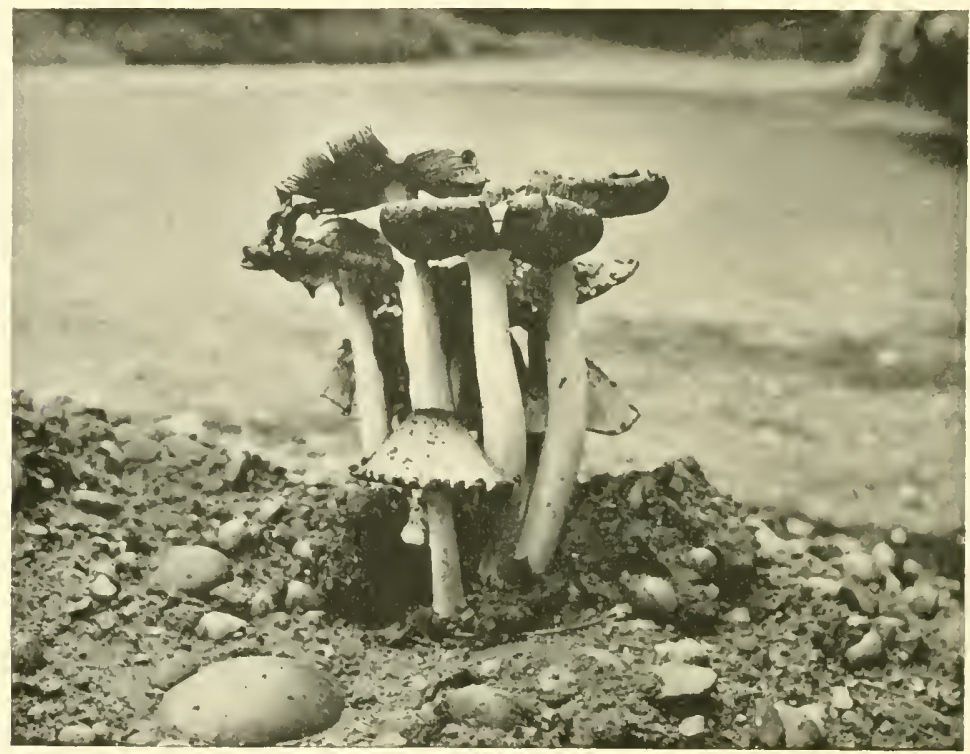

FIG. 74.-Coprinus micaccus. A group of fruit-bodlies in a late stage of development. The gills have almost disappeared owing to autodigestion. The rim of the pileus in the foreground is markedly recurver. Photographed at Sutton Park, Warwickshire, by J. E. Titley. About $\frac{1}{2}$ natural size.

the disappearance of the gills of $C$. micaceus are shown in Plate III., Figrs. 18, 19, and 20.

As a result of my investigations, I have come to recognise two distinct types of spore-producing and spore-liberating fruit-bodies in the Agaricince. One is represented ly the Mushroom and the other by $c$. comotus. The former is by far the more common and includes all ordinary Agaricinee, whilst the latter is restricted to the "deliquescing" Coprini. The significant 
points of difference between the two types may be tabulated as follows:-

\begin{tabular}{|c|c|c|}
\hline Xo. & P'salliota campestris. & Coprinus comatus. \\
\hline 1 & Flesh thick. & $\begin{array}{l}\text { Flesh very thin or mem- } \\
\text { branous. }\end{array}$ \\
\hline 2 & $\begin{array}{l}\text { Gills more or less hori- } \\
\text { zontally outstretched at } \\
\text { matmrity. }\end{array}$ & $\begin{array}{l}\text { Gills more or less vertically } \\
\text { placed at maturity. }\end{array}$ \\
\hline 3 & $\begin{array}{l}\text { Spores not at all ripe or } \\
\text { all discharged simultane- } \\
\text { ously on any part of a } \\
\text { gill. }\end{array}$ & $\begin{array}{l}\text { Spores all ripen and are } \\
\text { all discharged simultane- } \\
\text { ously in a narrow zone } \\
\text { which progresses slowly } \\
\text { from the base to the top } \\
\text { of each gill. }\end{array}$ \\
\hline 4 & $\begin{array}{l}\text { Gills do not undergo a pro- } \\
\text { cess of autodigestion. }\end{array}$ & $\begin{array}{l}\text { Gills become destroyed by } \\
\text { antodigestion from below } \\
\text { upwards. }\end{array}$ \\
\hline 5 & $\begin{array}{l}\text { The stipe has attained its } \\
\text { full length before the } \\
\text { spores are liberated. }\end{array}$ & $\begin{array}{l}\text { The stipe elongates con- } \\
\text { siderably during libera- } \\
\text { tion of the spores. }\end{array}$ \\
\hline
\end{tabular}

For each fruit-body the five facts are correlated and only find their full significance in reference to each other.

Doubtless, within certain limits, there has been a tendency for the survival of those fruit-bodies which produce and successfully liberate the maximum number of spores with the least expenditure of fruit-body substance and energy. In both our types this desideratum has been met in part by the production of central tubular stipes, symmetrical radiate pilei, closely packed basidia, tiny spores, and a much folded hymenium situated on the platelike gills. Further arrangements, however, in the two types present marked differences.

In the Mushroom, adjacent basidia on any part of a gill mature successively and shed their spores as soon as these are ripe ( $c f$. Plate I., Fig. 3). Every square millimetre of hymenial surface on each gill, therefore, sheds a certain number of spores each minute throughout the entire spore-liberating period of the fruit-body. This necessitates that sufticient space shall be provided between adjacent gills throughout their whole length by the time 
spore-discharge begins. These spaces atre provided for a maximum number of gills by the long axes of the latter becoming horizontally outstretched at maturity (Plate 1., Fig. 2; Plate 1V., Fig. 25). In order to tix the gills in this position (with their planes vertical), the whole fruit-body must have the necessary rigidity. This is given by the thick flesh.

In a fruit-body of Coprinus comatus there is much more gill-

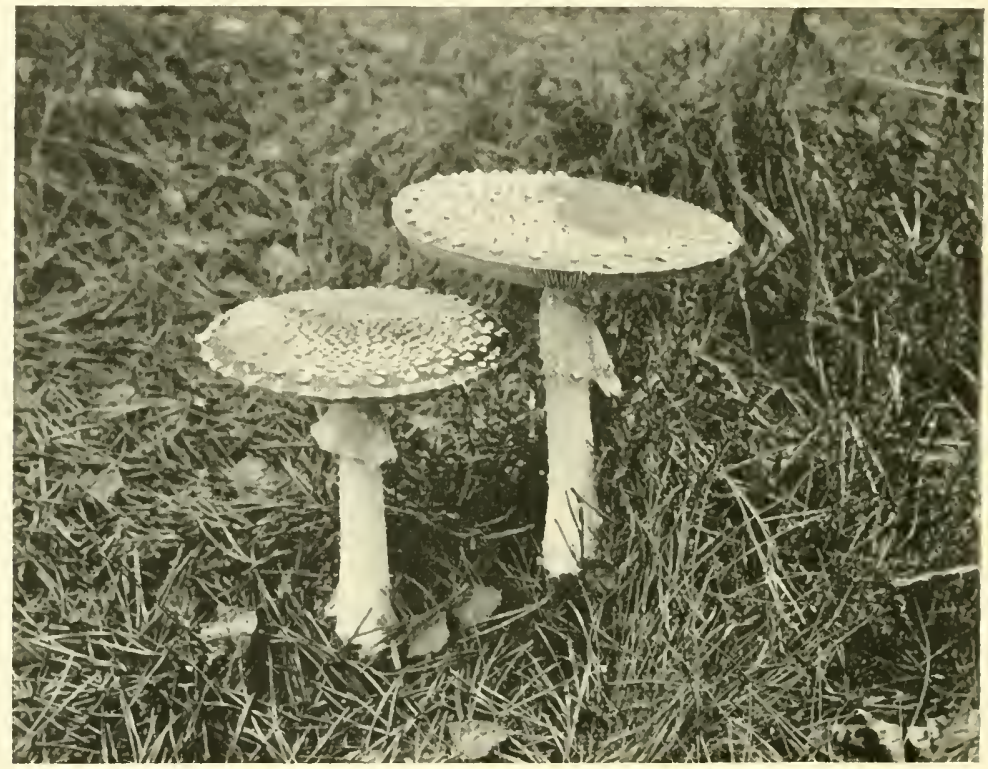

FIG. 75.-Amanitu muscariu. I'wo fruit-bodies having the Psullinta compestris type of spore-discharge. The gills are horizontally outstretched. 'The space provited by the stipe beneath the pileus allows air-currents to readily bear away the falling spores. In nature the tops of the pilei, which bear white squamula, are coloured a brilliant red. l'hotographed at Sutton Park, Warwickshire, by J. E. Titley. About $\frac{1}{2}$ natural size.

surfice in proportion to the whole mass than in a Mushroom. The former, therefore, has solved the problem of developing the maximum anount of spore-bearing hymenimm with the least. possible expenditure of fruit-body sulstance and energy, much more suecessfully than the latter (ef. Plate I., Figs. 1 and 2 ).

The Coprinus hats such extremely thin flesh to its pilens that it would be neehanicilly impossible for it to supprort its gills at maturity with their long axes in the horizontal position. Associated 
with the extremely reduced flesh, we find that the long axes of the gills are almost vertical when spore-liberation begins. This arrangement reduces the strain on the flesh to a minimum. The pileus simply presses downwards on the stipe. When the gills have become vertical at maturity they are then closely packed together throughout their entire length except for their extreme lower ends, where the change of shape of the pileus from the barrel form to the bell form has caused them to separate. It would be quite impossible for spores to be liberated from the long vertical gills throughout every part of their whole length simultaneously as in the Mushroom, for the gills are too close together. If wide spaces were provided between them, not only would this necessitate a large reduction in the number of the gills, but a large number of spores would require to fall vertically downwards between the gill-plates a distance of several centimetres. In that case, unless the gill-planes were quite vertical, a considerable proportion of the spores would strike the hymenium on falling, adhere there, and be wasted. Granted, therefore, that the gills are closely packed and vertically extended at maturity, it is obvious that a different arrangement for spore-liberation has to be adopted to that found in the Mushroom. As a matter of fact, as we have already seen, the Coprinus sheds its spores from a narrow zone of spore-discharge which passes on each gill from below upwards. At the zones of spore-discharge, the gills are always sufficiently far apart (about $0.2 \mathrm{~mm}$.) to permit of the spores, when violently projected from their sterigmata, describing the usual sporabolic paths unhindered. To enable the gills to move apart from one another higher and higher up as the zones of spore-discharge ascend upon them, the process of autodigestion comes into play. This causes the removal of the spore-freed portions of the gills and thus allows the fruit-body to gradually open out and thereby separate the gills higher and higher up. Without autodigestion it would be difficult to imagine how the necessary interlamellar spaces could be provided at the moving zones of spore-discharge. Toward the end of the period of sporedischarge, the much shortened gills become horizontally outstretched like those of a Mushroom. At this stage, the pileus 
requires to be disc-shaped in order to permit the parts of the gills nearest the stipe to obtain the requisite spaces for sporedischarge between them. The very thin flesh is also now quite sufficient to support the much reduced burden of the gills in the horizontal position.

During the process of spore-discharge, the stipe of Cominus comutus elongates consideribly. It adds a number of centimetres to its length and often becomes a foot long (Plate IV., Fig. 22). As the fluid produced during autodigestion is gradually lost by eraporation and dripping, the weight of the pileus, i.e. the load which the stipe has to support, undergoes progressive reduction. The higher the pileus can be mised with mechanical safety, the better will be the ehance of the spores eseaping obstacles and being carried off by the wind. It seems clear that the gradual raising of the pileus by the elongation of the stipe is correlated with the progressive diminution of the pileus weight. In the Nushroom, on the other hand, the burden to be borne by the stipe does not alter during spore-liberation. In keeping with this we find that in this type of fruit-body the stipe attains its maximum length before spore-discharge begins.

If the Coprimus and the Mushroom types be compared, I think it must be admitted that the former is superior to the latter in producing the maximum number of spores. with the minimum of fruit-body substance and energy. A Coprinus fruitbody with its extreme reduction of flesh, rertical position of the gills, successive ripening of the spores from below upwards, and its beantifully regulated antodigestion, may be thought of as having been evolved from a more generalised fruit-body of the Mushroom type, with thick flesh, horizontal gills, irregular ripening of the basidia, and absence of autodigestion. The special features of a typical Coprinus fruit-body are bound up with its umbrella shape. It seems to me that only after this had been attained could the special Coprinus arrangements have been developed and become effective. For this reason I regard the genus Coprinus as haring been derived cntirely from a fungus having fruit-bodies of the Mushroom type with central stipe and a symmetrically-placed, gill-bearing pileus. At the present day there are no Coprini with 
dimidiate form corresponding to Lenzites, \&c. In my opinion the explanation of this fact is not that such fruit-bodies have become extinct but that they never existed.

Massee in his "Revision of the Genus Coprinus" states that "the species of Coprinus differ from the remainder of the Agaricinere in one important biological feature-the deliquescence of the gills at maturity into a liquid which drops to the ground, carrying the mature spores along with it." This mode of sporedissemination he describes as "primitive and relatively imperfect," "as compared with the minute wind-borne spores of the remainder of the Agaricinea." 1 Massee takes this mode of spore-dissemination as important eridence that "in the genus Coprinus we have in reality the remnant of a primitive group from which have descended the entire group of Agaricinere having wind-borne spores." since my own investigations have now shown that the spores of the Coprini are wind-borne, it must be concluded that Massee's argument for the ancestral position of the Coprini is based on an unfortunate misconception of the ecology of Coprinus fruit-bodies. The arrangement for liberating spores into the air by neans of "deliquescence," instead of being primitive, appears to be the most highly specialised in the whole group of Agaricineæ. The relative antiquity of the genus Coprinus seems to me to be no easy matter to decide. Howerer, at present I fail to find any satisfactory evidence that the genus is to be regarded as closely related to the one from which the other groups of gilled Agarics have arisen. It seems more reasonable to regard it as a specialised oftshoot from a more generalised fimgus of the IIushroom type.

1 G. Massee, "A Revision of the Genus Coprinus," Amn. of Bot., vol. x. p. 129 ; also Text-Liook of F'unyi, London, 1906, p. 364. 


\section{CHAP'IER XX}

\section{THE DISPERSION OF THE SPORES AFIER LIJERATION FROM THE FRUIT-J3ODIES-FALCK'S THEORI}

WE have now gained some insight into the arrangements wherely spores are enabled to escape from hymenomycetons fruit-bodies. It still remains, however, to diseuss the dispersion of the spores in the onter air. Doubtless, in the narrow, blindly-ending tubes of the Polyporeat, and between the elosely-packed gills of the Agaricinese, the air is extremely still, so that the spores fall approximately vertically downwards in it, in the manner already discussed in Chapter XVII. If the air between the pilei and the ground were also quite still, the spores would continue falling in their vertical paths after emerging from the fruit-bodies, and would strike the ground immediately below the basidia from which they had been liberated. It is of interest to calculate the length of time that would be required for the spores to reach the gromnd in still air. The results of a few such ealculations, together with the data on which they are based, are given in the following Table :-

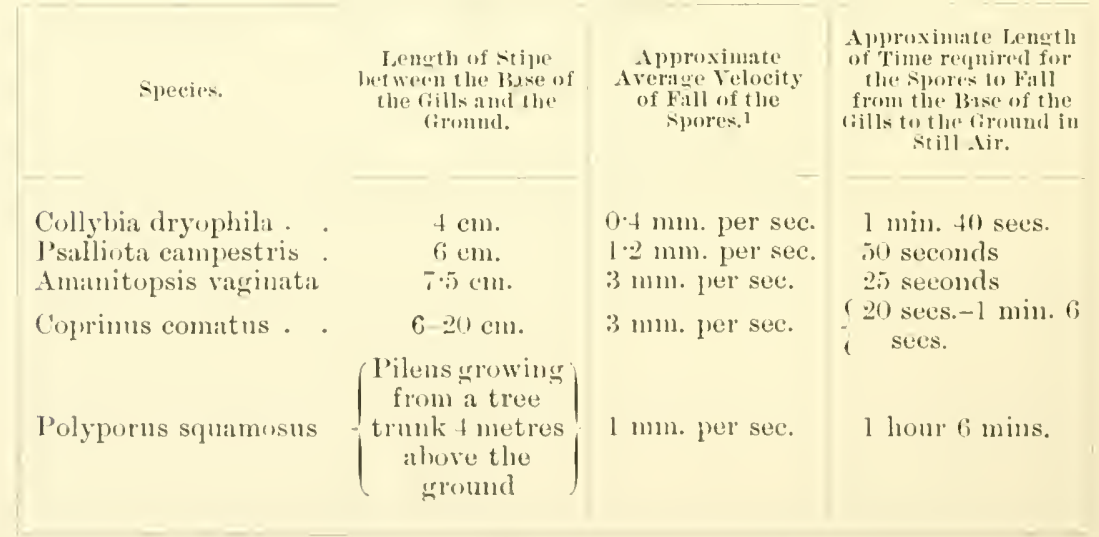

\footnotetext{
1 Estimated from the data griven in Chaps. XV. and XVI.
} 
It is clear, from the results just given and from our knowledge of the size of spores in Hymenomycetes generally, ${ }^{1}$ that for the fruit-bodies of many species about a minute would be required for the spores to fall from the gills to the ground. Even in the case of Amanitopsis vaginata, where the spores are unusually large in addition to being spherical, about half a minute would be necessary. For fruit-bodies of Polyporus, Polystictus, Fomes, Stereum, Corticium, ¿ce., growing on tree-trunks or dead branches some metres high, the ground would only be reached after the spores had been falling through the air for a period of time of the order of an hour.

It seems certain that, owing to the alternation of day and night and other meteorological causes, the air above the surface of the earth is never quite still. The average speed of the air in exposed situations is very considerable, amounting to miles an hour. In woods and meadows, \&c., where ground-fungi grow, the airmovements are probably never less than some feet per minute, and, as every one knows by experience, they are very frequently much greater. Even when the air seems extremely still, so that one cannot feel its motion and scarcely a leaf trembles on the tallest trees, it is astonishing how complex and active are the small convection eurrents and air-dritts that one may discover near the ground, in gardens and woods, by the cautions liberation of smoke or puff-ball dust. From what we know by experience of air-movements, and from the calculations of the time that would be required for spores to fall from their pilei to the ground in perfectly still air, it seems to me to be an obvious conclusion that the external air-currents, as a rule, are fully sufficient to carry off the falling spores from beneath the pilei and to scatter them broadcast. As a matter of fact in nature, unless a fruit-body is confined by dense grass, loose leaves, or other natural obstacles, one never finds any noticeable spore-deposit on the ground beneath a pileus. For fruit-bodies of Stropharia semiglobata, Anellaria separata, Coprinus comatus, or any other species growing in open pastures, \&c., it seems theoretically impossible that, if the wind is blowing appreciably, any of the spores should settle on the ground immediately beneath the pilei.

\footnotetext{
${ }^{1}$ Chap. XIV.
} 
One of the chicf functions of the stipe is undoubtedly to provide a space usually one or more inches high between the under surfice of the pileus and the substratum on which the fruit-body may grow. Owing to the very small rate of fall of the spores and the relatively very much greater average horizontal speed of air-eurrents near the ground, the space is amply sufficient, under normal conditions, to permit of the falling spores being carried awaly from the fruit-borly and deposited at a distance from it.

Richard Falck ${ }^{1}$ has put forward the thenry that the fruit-bodies

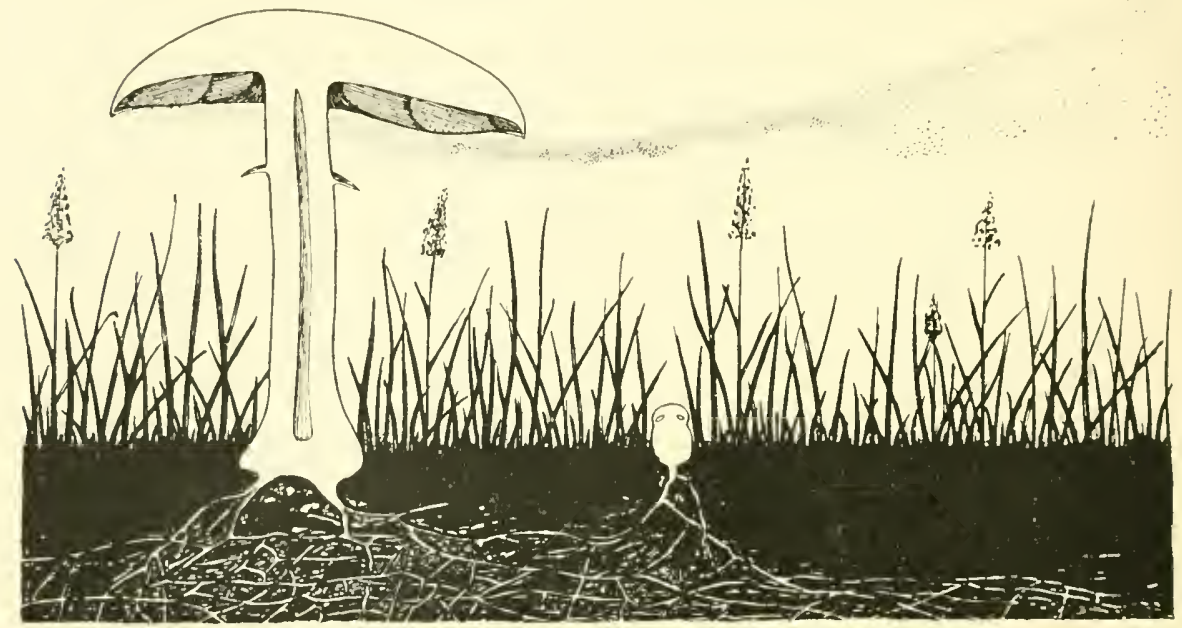

Fig. 7f.- Semirliagranmatic sketch of a section in a field illustrating the manmer in which the spores of the Horse II ushrom Psalliotu rrensis) are liberatert and dispersed. A slight laterat movement of the air is supposed to be carring the spore-clourl away from the underside of the pileus. Reduced to $\frac{1}{2}$.

are themselves specially adapted to produce air-currents for the purpose of scattering the spores. His theory is founded on the fict that fruit-bodies, when insulated, become distinctly warmer than the surrounding atmosphere. In one of his experinents, he found that the hymenial tubes of Polyporus squemosus, placed thickly together in a carefinly insulated chamber for ten hours, beeame $9 \cdot 6^{\circ} \mathrm{C}$. watrmer than similarly situated hymenial tules which had previonsly

1."1)ie Sporenverbreitung bei den Basidinnyceten mud der biologische Wert

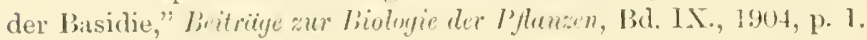


been killed by heating. Falck believes that "the fruit-bodies produce heat not to raise their own temperature but to warm the layers of air beneath the pilei." ${ }^{1}$ He considers that the heat thus given off creates convection currents in which the spores are borne away from the pilei. In support of this, Falck has described experiments in which spore-deposits werc obtained from pilei which had been suspended in closed glass vessels. He found that the spores were carried up and down in the glass vessels so that they settled upon ledges placed both above and below the pilei. Falck has followed out his idea still further. After showing that the presence of maggots leads to an appreciable increase in the temperature of insulated pilei, he came to the following theoretical conclusions. The pileus flesh of large Agarics has become specially thickened and laden with food substances for the purpose of feeding maggots. The maggots respire actively and thus produce heat, which is added to that resulting from the respiration of the pileus, and is made use of for increasing the convection currents which bear away the spores in the neighbourhood of the gills. We thus have a symbiotic relationship between hymenomycetous fruit-bodies and flies.

It must be admitted that Falck's theory is a very ingenious one. However, I am not sure to what extent we are justified in drawing conclusions from the laboratory experiments as to what actually happens in fields and woods. Proof has yet to be brought forward that in nature the pilei become sufficiently warmed to produce effective convection currents. If the ordinary air-currents in fields and woods are never less than a few feet per minute, and are usually much greater, it seems to me that they must be so active in carrying away the spores from the fruit-bodies that the convection currents arising from the very slightly warmed condition of the pilei can be only quite insignificant, and therefore ineffective, in comparison. From this consideration it seems that in nature the heat produced by a pileus must be generally useless and unnecessary for the purpose assigned to it by Falck.

When the wind is blowing, transpiration becomes active. Possibly the loss of heat from a fruit-body thereby occasioned, counterbalances the gain by respiration. Falck's theory would be placed on

$$
1 \text { Loc. cit., p. } 32 .
$$


ammeh firmer basis if it could be shown that out in the open the temperature of fruit-bodies becomes appreciably higher than that of the surrounding atmosphere, but this has not yet been lone. For Polymmes squamesus (Fig. 1) and other fruit-bodies growing on trees, where air-currents are never absent and the free space below the pilei is usually great, for small or thin fruit-bodies such as those of Mycena, Gralera, Schizophyllum, Corticium, Stereum, and Polystictus, and also quite generally for all fruit-bodies during weather which is at all windy, the unimportance of any very slight warming of the pilei seems to me to be obvious.

As a rule, in nature, it is impossible to see what happens to spores on leaving the pileus. Otherwise a direct test might quickly be applied to Falck's theory. However, in the ease of l'olyporus squumosus, as described in Chapter. VI., 1 have been able to see the spore-clouds leaving a large fruit-body growing on a log. The log was placed in a closed greenhonse, where the air was so quiet that one could not feel that it was moving. As the spores emerged from the hymenial tuhes, they were earried along the maderside of the pileus in one direction by a very slow air-current moving at the rate of a few feet per minute. The spore-clouds could be seen to drift laterally to a distance of 2 metres from the fruit-body. Whilst doing so, they were gradually broken up by small but very complex convection eurrents, the presence of which was only revealed by the spore-movements. As the spore-clond moved outwards from the edge of the pileus, it showed no tendency to pass upwards. In the course of several hours, nothing happened to suggest that the fruitbody was giving off so much heat that it produced convection currents of importance in scattering the spores. It seems to me that these observations are distinctly adverse to Falck's theory, for they not only show that, even when the air seems very still, quite slow air-currents due to external causes are of the greatest importance in carrying the spores from bencath a pileus, lnt also that the convection currents produced by a large pileus may be practically inappreriable when this is not insulated.

However, it might be argned that the fruit-body was a solitary one: that P'olyports squamosus frepuently produces from four to ten sporophores in a densely imbricated cluster: that the space between 
any two would become slightly warmed, and that, in eonsequenee, useful convection currents would be formed. However, since the fruit-bodies are developed at some height on trees ( $c f$. Fig. 1), any such convection currents would most probably always be swamped by more pronounced air-movements. If it be granted that there is no special adaptation for producing heat in the fruit-bodies of Polyporus squumosus, then the adaptation part of Falck's theory becomes much weakened, for it was with this species that one of the highest rises in temperature was obtained in the insulation experiments.

The maggots which so frequently are to be found in fruit-bodies, in most instances at least, seem to me to be in no way beneficent to the latter, and, in general, I am strongly inclined to look upon them simply as harmful parasites. It would need a special investigation to decide the matter. but it seems probable that of two fruit-bodies equal in size, but one of them free from maggots and the other badly infected, the former would produce and liberate the greater number of spores. Even if they both liberated the same number, we could still regard the maggots in the same light as some gall-insects, i.e. as parasites which, as a rule, do no very appreciable amount of harm, and for getting rid of which the plants concerned possess no mechanism. Sometimes the harm done is quite obrious. In a number of instances in the ficld, I have noticed fruit-bodies of Amunita rubescens, \&c., with the gills perforated and otherwise damaged by maggots long before the spores had all been shed. Occasionally, at an equally early period, the flesh of a pileus becomes so weakened by the inroads of these animals that it can no longer support the gills in the requisite vertieal planes.

Doubtless, the heat which an expanding, maggot-free pileus produces, like that arising in the rapidly opening capitula of Composite, is due to respiration accompanying other active metabolic changes. The gills in particular, whilst developing and setting free their millions of spores, have a large amount of work to do. There seems no reason to suppose that the fruit-bodies give rise to any more heat than is necessitated by the processes eoncemed in rapid growth. Probably puff-balls, which certainly do not use any heat which they develop for seattering their spores, would become warmed on insulit- 
tion in the same manner as the hymenonycetous fruit-bodies in Falck's experiments. The metabolism which leads to the production of a billion or more spores in a Ciiant Puff-ball in the course of a few days, must be very considerable. For the present, at least, I am not inclined to look upon the heat arising in the pilei as in any way surprising in amount or as being more than incidental in character.

Although Falck's theory seems to me to require some modification, and in any case to be of linited application, its promulgation has certainly raised an important question. The fruit-bodies of certain species of Boletus, Amanita, Paxillus, de., have broad pilei and comparatively short stipes: and they often come up, half concealed in grass or loose leaves, in hollows, dense woods, or other protected places. Here the air, immediately beneath the gills, on quiet days must be at its stillest. IVe require to know whether under such circumstanees, owing to physical or metabolic changes groing on in the fruit-bodies, convection currents arise from the latter capable of carrying the spores between the surrounding obstacles and lifting them to such height that they pass into more active air-currents in motion above the herbage or forest floor. This ought to be determined by direct observation in nature. Should such convection currents be discovered, it would then be necessiury to find out to what extent they were brought about by radiation, transpiration, or the giving off' of heat due to respiration. If the air surrounding a fruit-body were ever quite still, any conrection currents arising from the pileus, in order to raise the spores above the pileus, would require to have an average upward velocity of 1-6 $\mathrm{mm}$. per second according to the size of the spores.

Beam-of-light and other observations of my own have served to corroborate Falck's discovery, that exceedingly faint convection currents, such as one can never feel, are capable of transporting the spores of Hymenomycetes with astonishing ease. Even in large closed beakers it is exceedingly difficult to reduce the air to anything like real stillness. Simall convection currents can certainly be produced with a very small expenditure of energy. Whether sufficient can be given oft' by a large fruit-body to be of use under special circumstanees remains to be determined. If this should prove to be the case, we could draw the conclusion 
that millions and millions of spores, which otherwise might never be dispersed, are as a matter of fact spread far and wide over fields and woods.

If effective convection currents were given off by fruit-bodies, then, doubtless, they might be increased by the presence of maggots in the pileus and stipe. From this point of view the presence of these animals in the sporophores of Amanita muescens, \&c., might be of oceasional advantage; but it seems to me that, from the data at our disposal, we are not yet justified in assuming a symbiotic relationship between flies and Agaries.

We have now seen how easily the spores may be conveyed away from the fruit-bodies by air-eurrents. The wind, when travelling several miles an hour, must frequently carry the spores from a fruit-body for very long distanees. Owing, however, to their steady fall at the rate of $0.5-5 \mathrm{~mm}$. per second, sooner or later all spores must reach the earth. The larger the spores, the sooner will they settle. The big spores of many species of Coprinus will not be earried on the average so far as the smaller spores of the Mushroom or of Collybic dryoplita. With the ultimate fate of the spores after they have once settled we are not here concerned. 


\section{CHAP'IER XXI}

\section{THE DISPERSION OF SPORES BY ANLMALS-COPROPHLOCS HYMENOMICETES-SLUGS AND HYMENOMYCETES}

T'He fruit-bodies of the Hymenomyectes, as we have seen, exhibit many beatiful arrangements both in structure and function, which enable the spores to be liberated into the air beneath the hymenimm in such a manner that they may be carried away by the wind. A comparative study of fruit-body organouraphy in the nunerous and diverse species existing at the present day, permits us to conelude with some certainty that the fruit-bodies of the Hymenomycetes, at the beginning of their phylogenetic development, were anemophilous, and that they remained so ever since. Howerer, for certain of the coprophilous fungi, or possibly for most of them, mimal agency is made of secondary use in bringing the spores into a suitalle situation for germination and further development.

Coprophilous Hymenomycetes.-Certain species belonging to the genera Coprinus, Panieolus, Anellaria, and Galera are to be seen with remarkable frequency upon the dung of horses and cattle, and one may look for them in rain upon any other substrata. It seems clear that they have become specialised for a coprophilous habit of life. ${ }^{1}$ The infection of the fieces may take place in two ways: (1) By spores carried to them directly by the wind, and (2) by spores which are first dispersed by the wind, which then settle, and which are snbsequently swallowed with herbage by the animals concerned. That the first mode of infection is possible maly bu

1 Saccardo grives ind species included in 187 genera as being eoprophilons. To this large number the Hymenomyeetes contribute but few species as complared with the Aseomycetes and Playcomycetes. Many coprophilous fungi, so far as is known, are only found on dung. Species to the number of 708 are recorded as living on the dung of Herbivora, 4i) on that of (amnivora, and 4 on that of lieptilia. Saccardo, sylloge Fungorum, NII., Pitrs. I., 3, si3-99-2. Cited from IIassee and Salmon, Aun. of lim., vol. xv., 1901, 1p. 317, 322.2. 
deduced from the fact that in the laboratory sterilised horse dung can readily be infected with spores of various species of Coprinus: the mycelium produced gives rise to fruit-bodies in the course of a few weeks. In many cases at least, it is not necessary for the spores to have passed through the alimentary canal of one of the Herbivora in order to become capable of development. The second mode of infection, in which the ageney of the wind is supplemented by that of animals, has been earefully investigated by several observers. Thus Massee and Salmon, using antiseptie methods, extracted the fecal matter from the intestines of dead rabbits and found that, when it was protected from aerial infection, there developed upon it a considerable number of speeies of fungi, a long list of which are recorded in their "Researches on Coprophilous Fungi." ${ }^{\prime}$ However, these authors were not successful in obtaining any species of Hymenomycetes in this way; but from their observations it seems probable that the more frequent mode of infection of the dung of horses and eattle in nature is indirect. The spores are scattered broadcast over pastures by the wind: they are then swallowed with grass by animals; they pass uninjured through the alimentary canal, find their way into the freal matter as soon as it is formed, and germinate in it immediately after it has been deposited. By this means the spores eome to be intimately mixed throughout a frecal mass, so that its infection is much more thorough and takes place sooner than could be the ease with spores merely settling upon its outer surface. No doubt, of the two modes of infection the more highly specialised leads to a more rapid development of new fruit-bodies.

Coprophilous Hymenomycetes, such as many Coprini, are adapted to their environment in three special ways: firstly, in the capacity of the mycelium to use the materials contained in dung as food and to flourish when developing in fieces: secondly, in the spores being able to pass through the alimentary canal of herbivorous animals uninjured; and, thirdly, in the nature of the fruit-bodies. The food specialisation has advanced so far that a number of species of Coprinus, \&e., judging from their distribution

1 Massee and Salmon, Amm. of Bot., vol. xv., 1901 ; vol. xvi., 1902. 
in nature, are dependent on the existence of particular herbivorous vertebrates. It seems likely that the extinction of lare Herbivora in past geological agres has often brought about the extinction of some of their associated fungi. With regard to the fruit-bodies it may be pointed out that, as in Coprinus riveus, Panxolus phalanurum, Anellurin sepurate, and Guleru tenera (cf. Figrs. 25, p. 68, and 32, p. 80), they usually have more or less campanulate pilei situated on long and slender stipes. 'The latter, at least in many Coprini and probably in the other coprophilous genera, are at first heliotropic. This enables the compact young pilei to be pushed out into the open from beneath or between balls of horse dung, \&e., so that afterwards, when the stipes change their physiological properties and become negatively geotropic instead of heliotropic, the pilei are placed in such a position that they can expand and shed their spores into the air free from all olstacles. The length and relative slenderness of a stipe are well suited to enable that structure to thread its way outwards to the light by a process of growth, and afterwards to make a geotropic curvature by which the pileus can be brought into an advantageous position for shedling its spores.

Slugs and Hymenomycetes.-Many slugs find certain fruitbodies exceedingly palatalle and often devastate them in a wood to a surprising extent. One sometimes has difficulty in obtaining a single intact specimen of Russula emetica, R. ritrine, Amanit» muscuria, de., even where they occur in considerable numbers. The gills are particularly relished, but large pieces of the pileus Hesh are also frequently devoured.

Voglino ${ }^{1}$ has made an investigation upon the relations existing between slugs and Hymenomycetes, and has arrived at a very interesting conclusion. His chief observations were as follows. The digestive tracts of slugs collected in some pinewoods were found to contain germinating spores of the following species: Tricholoma hemile, Mycena allialina, Inocybe fastigiata, Lactarius deliciosus, and species of Russula. Slugs were fed with fruit-bodies of Russule and Lactarii, and subsequently numerous germinating

${ }^{1}$ P. Voglino, "Richerche intorno all" arione delle lumache e dei rospi nell" sviluppo di Agaricini," N'woro triomule Betanir", vol. 27, 1895, ]'1. 181-185. 
spores of the species used were found in the digestive tracts of the slugs and also in their fieces. When the fieces were placed in hanging drops, the germ-tubes developed into a branched mycelium. The spores of eertain Hymenomycetes refused to germinate in ordinary culture media, but germinated readily in the fluid obtained from the digestive tract of a slug. An enclosure was made around some ten specimens of Hebeloma fastibile which were growing in the open, and four starved slugs were introduced into it. In a few days the lamelle of all the fruit-bodies were completely devoured. One of the slugs when dissected was found to contain germinating spores of the fungus in its digestive tract. The enclosure was kept moist with sterilised water and maintained for about a year. At the end of this period it was observed that the specimens of Hebeloma fustibile were much more numerous in the enclosure than elsewhere in the neighbourhood. Toads which were collected in some pinewoods were found to contain germinating spores of species of Russula and Lactarius within their alimentary canals. Some toads which were fed with shugs were subsequently found to contain spores of Russula in an advanced state of germination. Voglino cane to the conclusion that the propagation of fleshy Agaries, especially of Russula and Laetarii, is in a large measure due to slugs and toads which provide conditions in their digestive tracts for spore germination.

Although it may be true that slugs help in the local dispersal of spores in a wood or field and provide conditions for their germination, these animals, owing to their slow rate of movement, could scarcely aet as agents in spreading fungus species from wood to wood when these are separated by considerable distances. That slugs find a fruit-body palatable is no proof that they are the agents for distributing the species to which it belongs. In this connection we may consider the case of Polyporus squamosus. Its fruit-bodies are much relished by shugs. I have known them, when young, so persistently visited and so voraciously eaten that they have been utterly ruined and have ceased development. Now in mature the trees on which the fungus occurs are usually a considerable distance apart, rarely less than several hundred yards and frequently much further. Moreover, the fruit-bodies, 
as a rule, are produeed at some height from the ground. For a slug, the infected trees are often several days' journey apart, and, even if a slug were to travel directly from one to another. spores swallowed on one tree would all be lost in the firces before the next had been reached. From a consideration of the distribution of the fungus and of the movements of slugs it seems impossible that these animals should materially help in spreading the species from tree to tree. A similar argument might be applied to Pleurotus ulmorius and many other species growing on trees, as well as to such fungi as grow on the ground and are characterised by the fruit-bodies developing sporadically at consuderable distances from one another. The Russulae, Amanite, \&c., exhibit all the usual arrangements in their fruit-bodies for liberating the spores into the air in such a manner that they may be carried off by the wind. In the absence of slugs, hundreds of millions of spores fall from the gills. We can scarcely suppose that spores thus carried off by the wind have no chance of reproducing the species. It scems probable, therefore, that the wind, even in the case of the Russula, is still by far the chief agent in sprearling the fungi from place to plice.

The conditions necessary for the germination of the spores of many of the higher fungi in nature are unknown. Voglino's observations suggest that small herbivorous animals provide these conditions much more often than has hitherto been supposed. It was recorded in Chapter V. that a single Mushroom (Paulliotu (ampestris), with a dianeter of $8 \mathrm{~cm}$., produced 1,800,000,000 spores. We are justified in supposing that a very large Agaric might produce $4,000,000,000$. If these were seattered miformly in nature there would be sufficient of them to provide one for every square inch in a square mile. This calculation may perhaps serve to indieate how widely dispersed the spores of one of the Hymenomyeetes may becone, and how frequently they must be prenent on grass, leaves, fruits, de. Herbivorous binds, toads, shugs, inseets. worms, fec. must very frequently devour spores with their fool. Perhaps then, whilst in general the wind is the chief agent in dispersing the spores of Hymenomycetes, in some species small herbivorous animals provide the conditions for their germination and the 
production of a mycelium. It seems not at all impossible, for instance, that the spores of a speeies of Russula or Laetarius might be earried several miles from one wood to another, and that after settling they might be eaten with other regetation by slugs: the spores might then germinate in the fieces of these animals, and the myceliun thus produced might make its way into the vegetable mould of the forest floor.

The fruit-bodies of eertain species of Hymenomycetes appear to be protected from destruction by slugs owing to the presence in their cells of nauseous or distasteful substances. In the summer of $190+$ I began to investigate the relations of slugs to fungi, but unfortunately, owing to my removal to Winnipeg, the work was interrupted, and I have not found opportunity up to the present to resume it. Such results as were obtained five years ago are embodied in the aceompanying Table. The observations on Omphalia, Hypholoma, and Cantharellus were kindly made for me by Miss J. S. Bayliss. Before each test the slugs were starved for about two days.

\section{Stugs and Hymenomyetes.}

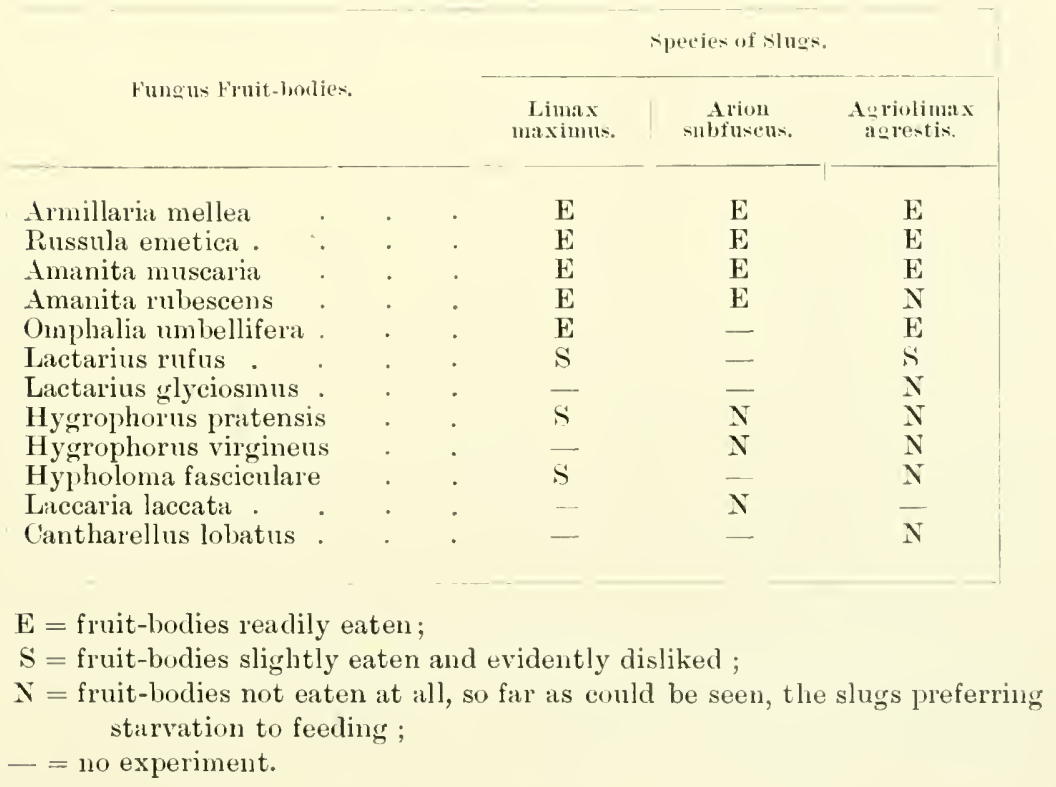


The results just given indicate that, whilst species of Armillaria, Russula, Amanita, and Omphalia are relished by the slugs tested, species of Lactarius, Hygrophorus, Laccaria, Hypholoma, and Cantharellus are disliked to a greater or less extent.

Lucturius rufus to our taste is exceedingly acrid, and its peculiar latex may well be the cause of its being but very slightly eaten by hungry slugs. In nature, among thousands of fruitbodies of this species, I have very rarely found one slug-eaten, and then very slightly. Once a specimen was noticed which, from the slime left all over the gills, had evidently been risited by a slug, but which had not been attacked; whereas fruitbodies of Russule citrinc close by had been seriously damaged. This seems to afford distinct evidence that the one species is chemically protected from slugs and that the other is not. Lacterius glyciosmus contains a peculiar aromatic substance, and it may be this which causes the fruit-bodies to be left uneaten by Agriolimux ugrestis.

The fruit-bodies of most species of Hygrophorus are shutinous or viscid and their gills are waxy. Possibly it is their physical nature which renders them distasteful to slugs. The exact causes which render these and other fruit-bodies, such as those of Hypholome fusciculure and Laccerie larcute, inedible, require further investigation.

Mere acridity of itself is not sufficient to cause a fungus to be rejected by slugs. Every one is agreed that the fruit-bodies of Russule metire are very acrid: yet all three species of slugs tester eat them with avidity.

Slugs can feed upon a number of fruit-bodies which are poisonous to man. Thus Amanita muscerie was eaten voriciously by all three of the slugs tested and without any ill effects to them. Amenitu plutloides is one of the most poisonous of fungi, and yet in nature one may often find shug-eaten fruitbodies of this species. It is evident that muscarine, phalline, and other toxines present in species of Amanita have no protective significance so far as sluggs are concerned. 


\section{PA R'T I I}

SOME OBSERVATIONS UPON THE IISCHARGE AND DIS-

PERSION OF THE SPORES OF ASCOMYCETES AND OF PILOBOLUS 



\section{CHAP'TER I}

THE DISPERSION OF SPORES BY THE WIND IN ASCOMYCETESPEFFING-THE PHYSICS OF THE ASCUS JET IN PEZIZA-THE FIXATION OF THE SPORES IN THE ASCCS OF PEZIZA REPANIMA -COMPARISON OF THE SIZES OF WIND-BORNE SPORES IN ASCOMYCETES AND HYMENOMYCETES-THE HELVELLACE E.

Not only in the Hymenomycetes, but also in many other fungi, beautiful adaptations are to be found by which the spores are suitably dispersed, but in most instances the mechanism involved still awaits a careful analysis from the point of view of physics.

In the majority of the Ascomycetes, the ascus is an explosive mechanism of considerable power, and it often shoots out its spores to a distance of one or several centimetres, thus causing them to become effectively separated from the sporocarp. It was pointed out in the first chapter of Part $I$. that the profound differences between Hymenomycetes and Asconycetes in the position occupied by the hymenial surfaces, and in the structure of the fruit-bodies, are correlated with the equally profound differences between basidia and asci as spore-discharging mechinisms.

The dispersal of ascospores after ejection from the ascus appears in many cases to be brought about either by the wind or by herbivorous animals. I regard it as a distinct matter of importance which of these two means of dispersal is employed, for each of them is associated with a particular type of ascus. As examples of Ascomycetes with wind-dispersal may be mentioned Gyromitra esculente, Morchelle gigas, Bulgarice polymorphe, and Pesizu aurentia, whilst Ascobolus immersus and Saccobolus may be regarded as representing those forms which are spread by herbivorous animals. It is probable that there are some species of Ascomycetes which have an intermediate type of spore-dispersal, corresponding to that associated with coprophilous Hymenonycetes, in which the spores are first scattered by the wind and subsequently 
become redispersed by herbivora. In these species it is to be expected that the structure of the aseus would be correlited with wind-dispersal.

The Dispersal of Spores by the Wind in some Ascomycetes.According to Falck, in Gyromitru exculenta-one of the Helvellaces - the spores, after being shot out of the ascus, become separated from one another and settle singly: and I have noticed a similar phenomenon in Bulgariu polymorpler (Wettst.). Doubtless, in both these species, the spores, which are no larger than those of many Hymenomyectes, are carried away from the fruitbodies by the wind.

Plowright ${ }^{2}$ watched the discharge of the spores of Horchelle gigas one evening with the aid of an oblique bean of sunlight. He observed that the head of each Morel was surrounded by a cloud of spores extending 3 or 4 inches around it. He states that "This cloud could only be seen in the oblique light against a dark background. When acted upon by a gentle current of air, such as would be produeed by gently waving the hand, it swayed to and fro without manifesting any tendency to become dispersed. The component sporidia were in constant motion, rising and falling and circling about, as if the law of gravity were a myth, existing only in the imagination of philosophers. When the cloud was quite blown away by a more powerful aircurrent, it in the course of a few seconds reformed. The contents of each ascus could be seen to be separately ejected in a minute jet consisting of a linited number of sporidia, which speedily became lost with the others forming the eloud." From this description it seems evident that the cloud of spores which forms above a fruit-body of a Morchellat is very similar to that which forms under the pileus of a Hymenonycete, such as a Mushroom or a Polyporus. In both clouds the spores are separated from onc another and fall so slowly through the air that they can readily be carried ofi by very slight air-currents.

${ }^{1}$ R. Falck, "Die Sporenverbreitmo bei den Basidiomyceten," Beitrige zur Biwl. der Pflunen, Bi. IX., 1904, p. 51.

${ }^{2}$ C. B. Plowright, "On Spure Diftusion in the larger Elvellacei," Grevillen, vol, ix., 1880-81, 1. 47. 
We shall now consider the phenomenon of the separation of the spores from one another, just after discharge from the ascus. That this actually occurs in some and probably in very many species seems to me to be conclusively proved by-(1) The definite observation by Falck ${ }^{1}$ that the spores of Gyromitre esculente settle singly, and a similar observation by myself upon Bulgarice polymorpha; (2) the just quoted description by Plowright of spore-discharge in Morchellu giges; and (3) some observations upon the discharge of individual asci of Peziza which have been made by my laboratory attendant, Mr. C. W. Lowe, and myself. Mr. Lowe has informed me that he watched the discharge of spores from a fruit-body of Pesiza curantia beneath an electric lamp with a lens. He states that each individual ascus jet appeared to break up at a distance of from 2 to 2.5 $\mathrm{cm}$. from the top of the fruit-body, and that in one instance on the breaking up of a jet, he was able to count six separated spores.

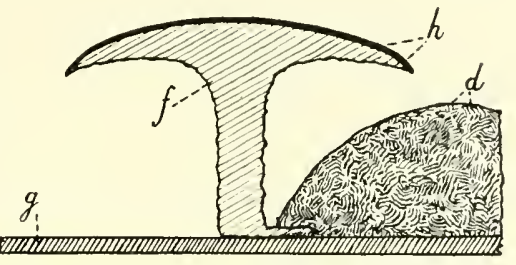

FI: 77.-The discharge of spores from Peziza repanda. $f$, section of a fruitbody covered above with the bymenium $h$ and supported by a stipe with a rooting base ; $l$, horse dung; $g$, glass base of the culture dish. Above the hymenium are shown several groups of eight spores as seen in a concentrated beam of light immediately after their discharge from the asci. Natural size.

With the help of my bean-of-light method I have fortunately been able to repeat and extend these observations.

A fruit-body of Pezize repanda (Fig. 77) came up upon horse dung in the laboratory. When ripe, it was placed upright in the middle of a covered glass jar, 6 inches high and 4 inches in diameter: and a strong beam of light was directed through the air immediately above the hymenium.2 I then observed that the asci discharged their contents into the air suceessively, at intervals of a few seconds. Although in the course of two or three hours I watched the discharge of several hundred asci, in no case was I able to detect an ascus jet taking its upward flight 
into the air. The discharged contents of each ascus always made their tirst appearance as eight spores which had already separated from one another, and which were filling very slowly downwards at a distance above the hymenimu of about 2-:3 $\mathrm{cm}$. (Fig. 7T). The sudden bursting into view of the eight glistening and falling particles against a black background forcibly reminder me of the surden illumination of the sky at night by a shower of brilliant points of light produced by an explosire rocket. 'The eight spores of each ascus, at the moment of their appearance in the beam of light. usually formed a more or less regular vertical series in which

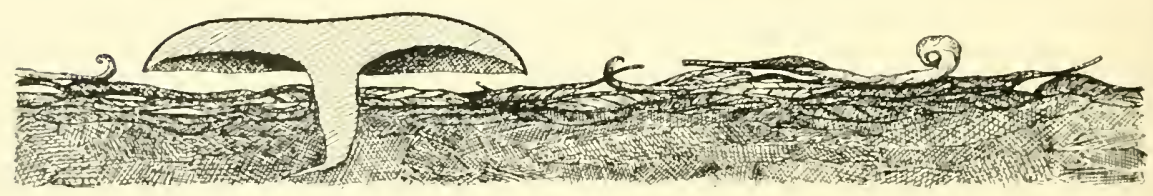

FI(. 78. - Semi diagrammatic sketch of a section throngh a fruit-body of $P_{r}=i z a$ repanda whilst discharging its spores. The spores are shot up to a height of $1-2 \cdot 5 \mathrm{~cm}$. above the hymenium and are then carried off by the wind. Natural size.

the highest spore was several millimetres from the lowest. It was observed that very slight air-currents were sufficient to carry the separaterl spores round and round in the air contained within the class jar. It can scarcely be doubted, therefore, that the spores of the Peziza are dispersed in nature by the wind in the sume manner as those of Hymenomycetes. It is interesting that the clout of spores produced by the Pezizil comes into being, not immediately above the hymenium, but at a distance of $2-: 3 \mathrm{~cm}$. above it. This enables horizontal air-currents which are almost universally found above the surface of the ground to earry away the spores before they have time to fall back on to the fruit-body from which they have been discharged (Fig. 78). 
Puffing.-The normal method of spore-discharge from Peziza repanda under natural conditions is probably a more or less successive discharge of ripe asci, the spore-discharge period lasting for some days. A similar gradual emptying of the asci has been observed in other Pezize, in Helvella, Morchella, Bulgaria, Exoascus, \&c. ${ }^{1}$ When a fruit-body of Pezisa repande was left undisturbed for some hours in a damp-chamber it ceased to liberate its spores. The beam of light showed that none of the asci were discharging their contents. However, when the glass plate covering the culture vessel was raised and the hymenium was rubbed with a match-stick or other rod, a considerable number of asci burst almost simultaneously and spore-discharge continued for at least an hour. According to De Bary, the simultaneous discharge of a large number of asci-the phenomenon known as "puffing"-may be caused in Pesica acetabulum, P. sclerotionem, and Helvellu erispa by shaking a fruitbody, or by suddenly allowing a fruit-body which has previously been kept in a damp-chamber to come into contact with dry air." He further found that the bursting of isolated ripe asci when lying in water can be brought about "by exposing them to the operation of agents like alcohol and glycerine, which withdraw their water." 3 He came to the conclusion that loss of water causes puffing "by altering the state of tension in each ascus either by lessening the expansion of the lateral walls and so increasing the pressure of the fluid contents on the place of dehiscence, or by lessening the power of the place of dehiscence to resist the pressure which remains unaltered." ${ }_{4}$ Massee ${ }^{5}$ has pointed out that this explanation is not entirely satisfactory, "as fungi will often puff, after lying in a room for some hours, if moved." In Pezizu repanda I have found that mere rubbing without change of atmospheric conditions was sufficient to cause some of the asci to burst. The simplest explanation of these two observations seems to be a mechanical one. One may suppose that at any one time the hymenium of a mature sporocarp contains a number of asei which have almost reached the critical

${ }^{1}$ De Bary, Comparutive Horphology and Biology of the Fungi, Mycetozou, and Bacteria, English translation, 188̄, p. 89.
2 Ibid., p. 90.
3 Ibid.
4 Ibiel.
${ }^{5}$ G. Massee, British Fungus Flora, 1895, vol. iv. p. 4. 
bursting stage of development, and that the rubbing or shaking simply eauses the premature bursting of a few such asei owing to their equilibrium having been mechanically disturbed. Aceording to this theory, the discharge of the asci may be likened to the premature bursting of the capsules of Impatiens, which one may bring about by slight alternate compression and relaxation with the fingers. However, it seems to me not unthinkable that the rubbing, shaking, or moving of a fruit-body may serve to stimulate the protoplasm in the asci in some way so that it reacts in such a manner as to cause the asci to explode.

I have tried the effeet of various chemical substances upon the discharge of ripe asci lying in water, and 1 have been unable to confirm De Bary's statement that bursting of the asei can be brought about by agents which withdraw water from them. Sections through the ripe hymenim of Pesize repende were cut and mounted in water on microscope slides in the usual manner. In order to test its effect upon the asei, a solution of a salt or other substance was then run under the cover-glass gratually. It was found that strong solutions of grlycerine, sodium chloride, potassim nitrate, and grape sugar did not cause explosions to occur. The sodium chloride, potassium nitrate, and grape sugar led to considerable contrietion in the rolume of the asci, so that it is evident that mere withdrawal of water from asei is not sufficient to eause them to explode. On the other hand, solutions of iodine, meremic chloride, silver nitrate, copper sulphate, sulphuric acid, acetic acid, and alcohol gave rise to very marked puthing. A very active discharge of spores took place as soon as the asei came weli into contaet with these substances. In a number of instanees practically all the living asci discharged their spores, and a heary spore-deposit collected a short distance in front of the ascus mouths. The seven substanees last named are all poisonous, whereas the four which do not eause putting are nonpoisonous. I was therefore tempted to draw the conchusion that poisonous substances cause putting, whereas non-poisonous ones do not. Howerer, further experiment showed that this rule does not hold miversally. Strong sodium hydrate poisons the asei without causing them to explode. When a solution of this substance was 
brought into eontact with the preparation, after a time the asci one by one eontracted suddenly without diseharge. Evidently their turgidity beeame lost owing to the death of the protoplasm lining the aseus wall. Sodium carbonate also did not cause aseus diseharge, although the asei died from its effeets. Up to the present, therefore, it seems that non-poisonous substanees and alkalies do not eause puffing, whereas poisonous substances, exeluding alkalies, do. Why alkalies should behave differently to other poisonous substances seems for the present inexplieable.

In one experiment an aseus was eaused to contraet considerably with potassium nitrate. It did not explode. It was then restored to its former size by plaeing it in water. When brought into contact with iodine dissolved in water, it immediately exploded without undergoing any preliminary measurable decrease in volume. This observation will serve to emphasise the differenee in aetion between a neutral salt which merely withdraws water from an aseus, and a non-alkaline poisonous substance whieh affects the protoplasm.

Asci which have contracted in volume owing to loss of water on treatment with a strong solution of a neutral salt, may be caused to explode when brought into eontatet with iodine. The explosions under these eonditions are naturally eomparatively weak, and the spores shot out from the asci travel but a very short distanee from the ascus mouth.

The experiments just recorded seem to me to suggest that the bursting of ripe and expanded asei is not brought about by an inerease in the pressure of the cell-sap upon the aseus lid, but rather by an alteration in the strength of attachment of the aseus lid to the rest of the aseus wall. We inay regard the protoplasm at the end of the ascus as speeially entrusted with the work of loosening the attachment of the ascus lid, as its final duty. By suitable stimulation of this guardian protoplasm, the attaehment may be indireetly loosened and thus an aseus explosion brought about. Possibly the necessary stimulus ean be given meehanieally, as when a sporoearp is eaused to puff by mere moving or shaking; possibly it may be given by a sudden withdrawal of water from the end of the ascus, as when a sporocarp is caused to puff by suddenly allowing it to corne 
in contact with dry air; lut it secms certain that it can be given by chemical means, as when an aseus is caused to explode when treated with silver nitrate, mercuric ehloride, alcohol, and eertain other poisonous substanees. Where there is a gradual emptying of ripe asci, as, according to De Bary, oceurs in Bulgaria, Exoascus, de., probably the activity of the guardian protoplasm is controlled by stimuli arising from internal derelopmental changes taking place in the asens as a whole.

At present there does not seem to be any evidence that putfing takes place under natural conditions, and it would therefore be fruitless to diseuss whether or not the phenomenon has any useful biological significance. It may be added that puffing, when observed in still air with the aid of a beam of light, is a beautiful exhibition of sporocarp activity. It may be likened to the grand finale of sky-rockets in a pyrotechnic display.

The Physics of the Ascus Jet in Peziza.-From ny obserrations upon the discharge of individual asci, it is clear that the spores contained within an aseus jet become separated from one another within a fraction of a second, between the time that they leare the ascus mouth and the time that they suddenly appear as eight separated particles in the bean of light. We shall now inquire into the nature of the forees which serve to detach the spores from one another during their ascent into the air.

The ascus wall contracts during the ejection of the ascus jet, so that the ascus volume becomes reduced to abont one-half (Fig. 79, E and F). The nature of the contraction affords a strong argument for the belief that the pressure exerted upon the asens contents is greatest at the beginning of the discharge, and that it diminishes continuously and rapidly during the discharge, so that it finally becomes zero when the discharge has been completed. The ascus jet on leaving the ascus mouth may be regarded as a more or less cylindrical column of fluid containing eight spores situated in a row. Owing to the nature of the ascus contraction, it seems almost certain that the front end of the ascus jet must be shot outwards with the greatest relocity and the rear end with the least. The whole jet after its emission 
will tend to become elongated. The first spore will have a
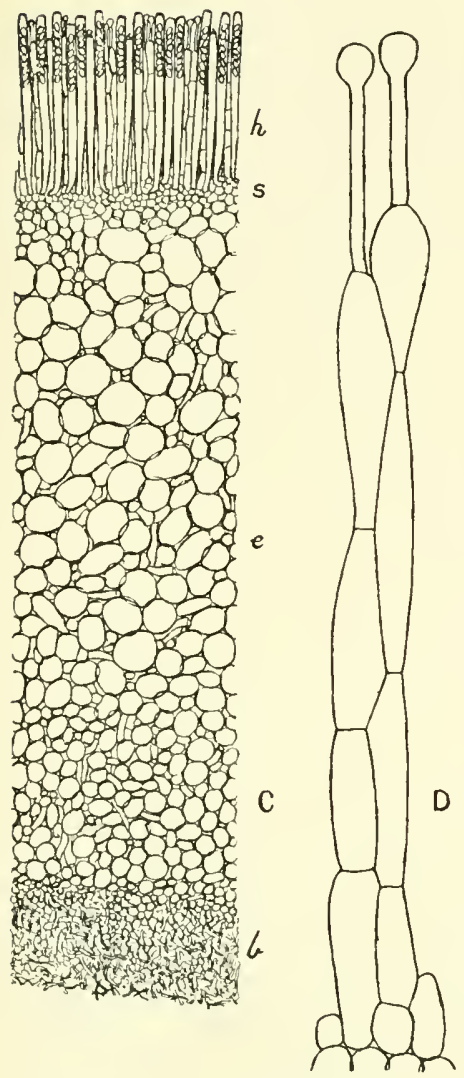
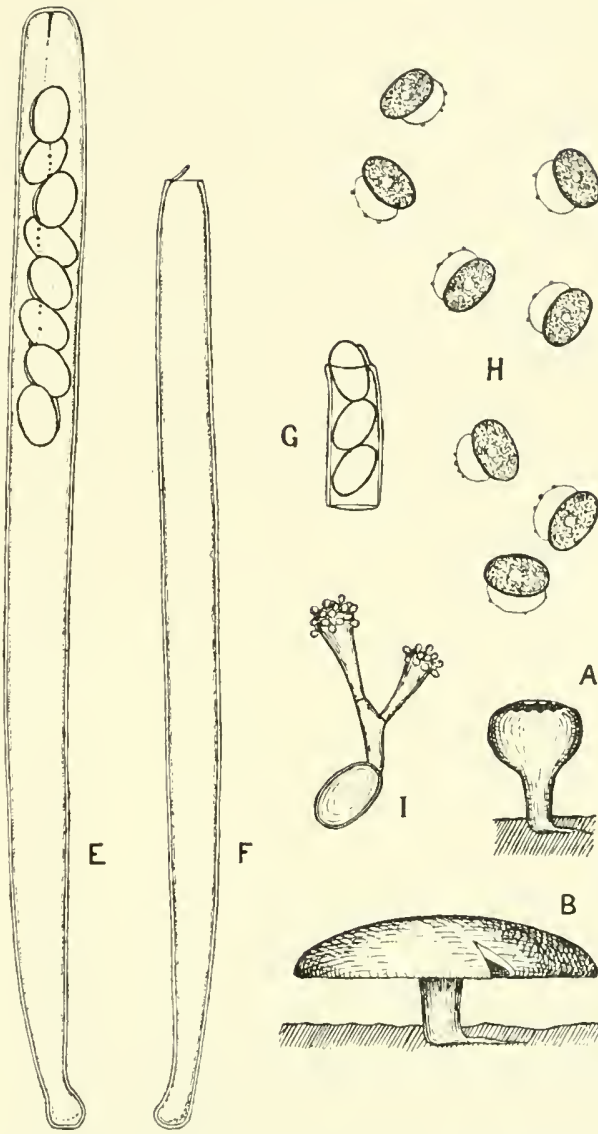

G

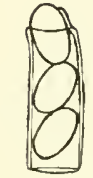

H

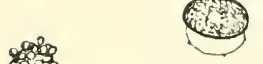

$A$
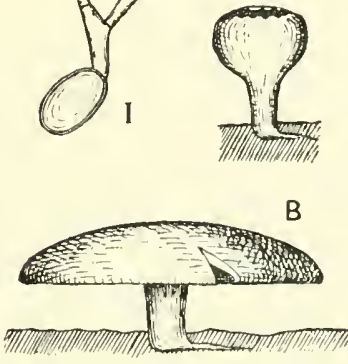

Fig. 79.-Pezisa repanda. A, a young unripe fruit-body. Natural size. B, an older expanded fruit-body which was discharging spores. Natural size. C, a vertical section through the disc of $\mathrm{B}$ showing the hymenium $h$, the subhymenium $s$, and the excipulum $e$ with an external brown layer $b$. Magnification, 40. D, two septate paraphyses with clavate terminal cells. E, a ripe ascus containing eight spores which are loosely attached to one another and are suspended in a subterminal position by a filament probably composed of protoplasm. F, a contracted ascus just after the spores have been discharged. G, the end of an ascus in which only partial spore-discharge had taken place. A spore was making its exit endwise through the ascus mouth. H, eight separated spores as seen near the mouth of an ascus just after discharge into a fluir medium. The unilateral gelatinous investments, shown within the aseus at $\mathrm{E}$, have now become very much swollen. I, a spore which after discharge had fallen back on to the hymenium and had then germinated. The germ-tube gave rise to two clavate conidiophores bearing minute conidia. D-I magnification, $: 317$.

higher velocity than the second, the second a higher one than 
the third, and so on. It seems to me very probable that it is the considerable differenees in the initial velocities given to the different spores upon their discharge which is the chief factor in separating the spores from one another during their upward flight into the air. There is, however, another factor which must be concerned with the breaking up of the ascus jet, namely, surface tension.

It has been found both by mathematies and experiment that the equilibrium of a free eylinder of any liquid, under the influence of surface tension only, becomes unstable as soon as the length exceeds $\pi$ times the diameter; and it is regarded as a necessary consequence of this that such a cylinder, if once realised, will spontaneously split into as many equal and equidistant spheres as $\pi$ tines the diameter is contained in the length. ${ }^{1}$

Thus if $n$ be the number of drops,

$l$ the length, and

d the diameter of the cylinder,

the law of segmentation is expressed by the formula

$$
n=\frac{l}{\pi d}
$$

From this formula we can calculate that, if the length of a cylindrical column of fluid is twenty-five times the diameter, the column will break up under the influence of surface tension into eight separate drops. It seems to be a simple inference from this that, if in a minute eylinder of this kind there were placed eight equidistant solid spheres with diameters equal to the diameter of the cylinder, then the eylinder would break up in such a manner that each spherieal body would become separated from its neighbours and enclosed within a film of fluid. The ascus jet inust be at first essentially a cylindrical liquid column containing solid oral nuelei at intervals. Probably the spores are ejected end-wise through the contractile ascus mouth so that they come to have their long axes in the same direction as the long axis of the jet. As the jet becomes elongated, owing to its

${ }^{1}$ A. M. Worthington, "On the Spontaneons Segmentation of a Liquid Annulus," Proc. of the lioy. Suc, vol. xxx., 1879-80, p. 49. 
parts, beginning with the front end, having been ejected from the ascus mouth with successively diminishing velocities, it will reach a stage when the relationship of its length to its diameter becomes such that surface tension must cause it to break up into eight separate parts. Each tiny column of fluid, which at first must conneet adjacent spores, will become unstable when its length exceeds three times its diameter, and upon slight further elongation it will snap into two in the middle. Since the eight spores ejected from an aseus, on their first appearance in the beam of light, usually form a more or less vertical series in which the highest spore is several millimetres above the lowest, it seems to me probable that the segmentation of the ascus jet takes place almost immediately after it has left the aseus mouth.

If the ascus is regarded as a mechanism for discharging a jet in such a manner that the jet elongates and becomes segmented by surface tension into eight separate parts, each part containing a spore, then the structure of the ascus becomes more intelligible. The long cylindrieal form of the aseus and the size of the spores are such that the spores must lie in a single row one behind the other. This arrangement filvours the production of a long jet in which the spores are situated in a row. The oval shape of the spores, and the fact that their long diameters are wider than the aseus mouth, must necessitate their being ejected through the ascus mouth end-wise (Fig. 79, G). Whilst the first half of a spore is passing through the contractile ascus mouth, the velocity of movement of the spore is probably slightly diminished; and whilst the last half is passing; the velocity is probably slightly inereased. This would lead to a separation of the spores in the jet at the very beginning of its formation. The advantage in an ascus containing a number of spores insteat of one is probably to be found in the fact that less energy would be required to shoot up several spores from one ascus at one time than would be required to shoot up the same number of spores if each were contained in a separate aseus. The production of exactly eight spores in each ascus rather than a few more or less may have been determined in the first place by convenience in nuclear 
division. The advantages accuing to a fungus from the separation of the spores of an ascus after they have been cast up into the air are: (1) The increase in the number of separate infecting particles which the fungus can produce, and (2) the splitting up of the mass of the ascus jet. The separrate parts of the asens jet must each fall considerably more slowly than the ascus jet would do if it remained undivided and contracted into a ball, for, according to Stokes' Law, the terminal velocity of fall of a mieroscopic sphere varies directly as the square of the radius. The smaller the rate of fall of a particle, the further can it be transported by the wind hefore settling. The separation of the ascus spores from one another is therefore farourable to their dispersal ly air-emrents.

It has been shown that the spores of Hymenomycetes, when falling in air unsaturated with water vapour, dry up within a few seconds after leaving the hymenimm, and that, in consequence, their rate of fall often becomes considerably reduced. In some instances it was found that the initial teminal velocity becomes reduced to one-half or one-third according to the degree of hunidity of the air. Doubtless, in Ascomycetes, the small film of liquid on the exterior of each separate spore, and also the spore itself, dry up in unsaturated air within a few seconds after the spore has been discharged. Evaporation, by decreasing the size of the filling particles, must indirectly decrease their rate of fall, and therefore in the end be advantageous for the dissemination of the spores by the wind.

The Fixation of the Spores in the Ascus of Pesize RepundreIn order to permit of the etticient ejection of the ascospores, it is necessary that they should be situated at the distal end of the ascus; for the asens is an apparatus which squirts out only about one-half of its contents-the half nearest the ascus mouth. Zopf has shown that in many cases the spores are retained in the expanded end of the ascus by a special appatratus of attachment: the uppermost spore in some Sordariea is attacherl to an inwardly directed process produced from the membrane at the ascus 
apex. ${ }^{1}$ De Bary ${ }^{2}$ in this connection said, "Similar apparatus may perhaps frequently be in use especially in the Pyrenomycetes. . . . In many cases, especially in the Diseomycetes, there is no such apparatus present, the spores being suspended in the fluid of the ascus. The spores must have nearly the same specific gravity as the fluid; if not, they would ehange their position as the ascus changes its inclination, which they do not do. Most, if not all, spores produced in asci sink in pure water; the fluid contents of the aseus must therefore be of greater specific gravity than pure water, since it holds in suspension bodies of greater specific gravity than water. If increase in the amount of the fluid contents causes the apical portion of the ascus to stretch more than the other parts, currents inust be set up in the fluid in the direction of the apex and continue as long as the expansion continues, and push the spores therefore permanently towards the apex. The arrangements of the spores may then be affected by special directions in the currents which we cannot at present determine, as well as by the conditions of space noticed above." This hypothesis of currents does not seem to me to be at all adequate to explain the position of the ascospores at the end of the ascus. There are varions objections of a physical charneter which may be made to it, but it does not appear necessary to discuss them. On the other hand, I shall show that in Periza repunde the position of the spores is attained by other than hydrostatic means.

In Peziza repande the eight spores occupy a subterminal position, so that there is a short space between the first spore and the ascus lid (Fig. 79, C and E). Schröter ${ }^{3}$ has figured an ascus of $P$. rependa with the first spore in contact with the lid. This arrangement may often be seen in dead asci but never in living ones. Each spore possesses a firm cell-wall, and in addition is coated on one side with a thin oval gelatinous investment (Fig. 79, E). These inrestments appear to serve the purpose of attaching the spores to one another so that they cannot slip

${ }^{1}$ Zopf, sitzsber. d. Berliner naturf. Freunde, Feb. 17, 1880. Cited from de Bary's Comparatice Morphology and Biology of the Fungi, de., English translation, 1887, p. 88.

${ }^{2}$ De Bary, loc. cit.

3 J. Schröter, "Pezizinere," in Die natürlichen Pfanzenfumilim, by Engler and Prantl, Teil 1., Abteil. 1, p. 183, printed 1894. 
apart. The group of eight spores is attached to the ascus lid by means of a fine, somewhat gramular filament which has the appearance of a protoplasmie bridle. A row of granules can be seen passing down the middle of the gelatinous cap of each spore, so that it seems probable that the filament is eontinued downwards from the topmost to the bottom-most spore (Fig. 79, E). It seems not minkely that the row of spores is fixed to the sides of the aseus by other protoplasmic bridles, but I lave not leen able to discover them. The fine terminal filament is very transparent, and it mal be on this account that it has hitherto been overlooked. It can be made more prominent by treatment with 1 per cent. corrosive sublinate. From the foregoing, it is clear that in P'ezisa irpunder the spores are not freely floating in the ascus sap as de Bary supposed was the case in Disconlyeetes generally, but are carefully anchored in position by one or more special protoplasmic tilaments. This being so, one can easily understand bow it is that the spores keep near the end of the aseus during the stretching period, and there is no need of the current hypothesis to explain the phenomenon. Lack of material has prevented me from investigating the extent to which protoplasmic bridles are used for anchoring the spores in the asei of Discomycetes generally, but it scems probable that this method of spore tixation will be fornd to be of very common oceurrence.

There can be no doubt that in Pesize repunde the eight spores in each aseus are attached together. They always appear to be in intimate contact with one another, but that they are really attached to one another may be shown in the following manner. A section through the hymenimm (Fig. 7.), C) is momnted in water. A strong solution of grape sugar or sodium chloride is then run under the cover-glass of the preparation, with the result that the turgor of the asci becomes reduced. When this has happened a solution of iodine is run under the cover-glass. The iodine on eoming in contact with the asci causes them to explode, but sinee the pressure of the ascus sap has been reduced, the explosions are eomparatively weak. Sometimes the spores are not all shot out of the aseus (Fig. 79, G), and in some cases they are only just ejected from the ascus mouth. When the latter has happened, one sometimes sees 
the ejected spores placed end to end, one behind the other, so as to form a continuous chain. It is highly improbable that a group of ejected spores should form such a chain if they were not really attached together.

When a section through the hymenium of Pesiza repanda is mounted in water, the asei are fully turgid. If such asci are caused to explode by bringing a solution of iodine into contact with them, the spores are discharged to a distance from the ascus mouths about equal to the length of the asci. When vigorously discharged in this manner, the eight spores are shot out so quickly that one ean see nothing of them as they pass through the fluid medium. The eight spores suddenly come into sight in front of the ascus which has discharged them. They are then not travelling horizontally but merely sinking in the fluid. On their first appearance they are all separated from one another in the manner represented in Fig. 79, H. The very transparent, unilateral, gelatinous cap on each spore then swells up considerably. doubtless owing to the absorption of water. Running down the middle of each cap is a row of granules, which are doubtless the same as those shown in Fig. 79, E, and therefore the remains of the suggested extension of the protoplasmic bridle over the spores.

The attachment of the eight spores of an ascus to one another in Pesize rejundu is not a firm one like that in Ascobolus immersus (cf. Figs. 81 and 82 ), but only a very loose one-just strong enough to hold the spores together before discharge, and therefore of use in aiding them to take up a favourable position in the ascus, but weak enough to be easily broken down at the moment when the ascus ejects its contents. In all probability, the snapping of the spore chain into eight parts is due to the different spores receiving different velocities during their ejection, and takes place as the aseus jet is elongating whilst leaving the ascus mouth.

One further point concerning the spores of Pezisa repanda may here be mentioned. When a fruit-body is confined in at small closed chamber, many of the spores, after being cast up into the air, fall back again on to the hymeninm. Under moist conditions such spores often germinate and produce conidia, as shown in Fig. 79, I. 
Comparison of the Sizes of Wind-borne Spores in Ascomycetes and Hymenomycetes. - The size of wind-borne spores, which is so important a factor in determining their rate of fall, is doubtless adapted to the spread of the spores by such aircurrents as ordinarily oceur above the surface of the ground. In this connection it is a distinctly interesting fact that although Ascomycetes produce and then liberate their spores into the air in a very different manner to that of Hymenomycetes, yet in both groups of fungi the order of magnitude of the wind-borne spores is the sante. Evidence supporting this statement is given in the following Table, where the sizes of the spores of a few Ascomycetes which make use of the wind for dissemination are compared with the sizes of the spores of a few well-known Hymenomycetes. In each series the spores are arranged according to the magnitude of their short diameters. This arrangement has been adopted because the rate of fill of spores, and therefore the ease with which they can be transported by aircurrents, is chiefly determined by the size of their short dianeters and not by that of their long diameters, since spores tend to fall with their long axes in a horizontal position. ${ }^{1}$ The unit of measurement is $1 \mu$. The sizes of the spores of the Ascomycetes are those given by Hassee.? The sizes of the spores of the Hymenomycetes were measured by myself and are taken from the Table in Part I., Chapter XIV.

Comparion of the sizes of Symier.

\begin{tabular}{|c|c|c|c|c|c|c|}
\hline \multicolumn{3}{|c|}{$A$ seonyectes. } & \multicolumn{4}{|c|}{ Hymenomyortes. } \\
\hline Species. & & $\begin{array}{l}\text { Short } \\
\text { Axis. }\end{array}$ & $\begin{array}{l}\text { Long } \\
\text { Axis. }\end{array}$ & Fipecies. & $\begin{array}{l}\text { Short } \\
\text { Axis. }\end{array}$ & $\begin{array}{l}\text { long } \\
\text { Ixis. }\end{array}$ \\
\hline & & & & (Polyporus syulmosus. & $5 \cdot 1$ & $1+\cdot 6$ \\
\hline Bulgraria polymorphiı & . & $5-6$ & $10-14$ & Psalliota campestris . & $5 \cdot 5$ & $7 \cdot 2$ \\
\hline & & & & Marasmins orearles. & $5 \cdot 6$ & $(9)$ \\
\hline Peziza amantia & . & $7-8$ & $15-16$ & I Coprinus comatus . & $7 \cdot 5$ & $12 \cdot 6$ \\
\hline Gyromitra esculenta & . & $9-11$ & $17-25$ & 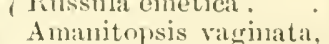 & $10 \cdot 2$ & $\begin{aligned} 58 \\
10 \cdot 2\end{aligned}$ \\
\hline & & & & fruit-body $\mathrm{I}$. & & \\
\hline Morchella grigas & . & $11-14$ & $21-24$ & $\begin{array}{l}\text { Amanitopsis vacinata, } \\
\text { fruit-buly lll. }\end{array}$ & $11 \cdot 7$ & $11 \div$ \\
\hline
\end{tabular}

1 Cf. the end of Chap. XV., Part I. 2 (A. Massue, Pritish Fungus Floru, vol. iv. 
The Helvellaceæ.-The Helvellacea are characterised by possessing long stipes which have exactly the same significance as in the Hymenomycetes. The hymenium becomes raised up above surrounding leaves and herbage, so that the spores, after being discharged from the asci, can readily be carried off by air-currents. A specimen of one of the largest species - Morchella crassipes - is illustrated in Fig. 80. It was 9 inches high and therefore rivalled in stature some of the largest of the Agaricinese.

The pileus of a Morchella is provided with anastomosing ribs or plates which enclose irregular polygonal pits. The hymenium covers the whole of the exterior of the pileus, so that it is evident that the plates have the same function as the gills of a Mushroom: they serve to increase the amount of the spore-bearing surface. However, if one compares the pilens of a Morchella with that of a Mushroom, one notices that the folding of the hymenium is vastly more compact in the latter than in the former. The reason for this is to be found in the fundanental difference between basidia and asci as spore-liberating mechanisms. The spores of a basidium are only shot

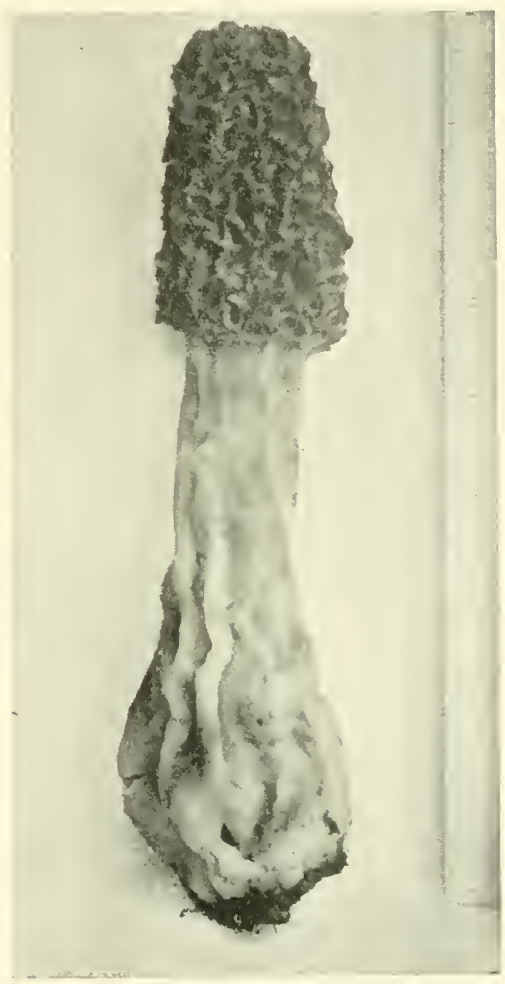

FIG. SO.-Fruit-borly of Morehella crassipes, an Ascomycete which resembles many Hymenomycetes in having its pileus supported on a long stipe. Photographed at Winnipeg by C. W. lowe. $\frac{2}{5}$ natural size.

outwards to a distance of about $0^{\cdot} \cdot \mathbf{m m}$., whereas those of an ascus are often propelled several centimetres. Hence adjacent gill surfaces can be placed very near together without interfering with the escape of the spores. On the other hand, the plates on a Morchella pileus must be a considerable distance apart or the asei would not have sufficient room for discharging their contents. 
It seems that, owing to their possessing basidia, the Hymenomycetes are better adipted to produce large fruit-hodies which liberate their spores into the air, than Ascomycetes. In large fruit-bodies the hymenium of Hymenomyeetes cim be much more folded than that of Ascomyeetes, and therefore can produce a much larger number of spores. It may be on this account that the Hymenonycetes have become the dominant fungi upon the regetable mould of fields and forests. 


\section{CHAP'TER II}

THE DISPERSAL OF THE SPORES OF ASCOMYCETES BY HERBTYOROCS ANIMALS ILLUSTRATED BY AN ACCOLNT OF ASCOBOLUS IMUERSUS-PILOBOLUS, EHPUSA MUSCA-LYCOPERDON-THE SOUND PRODLCED BI THE DISCHARGE OF SPORES, WTTH SPECIAL REFERENCE 'TO PILOBOLCS.

\section{The Dispersal of the Spores of Ascomycetes by Herbivorous} Animals, illustrated by an Account of Ascobolus immersus. Pilobolus, Empusu musce-Ascomycetes in which the spores after ejection from the asci are dispersed by herbivorous animals develop on fieces and have a coprophilous mode of existence. Of these the most striking examples are afforded by species of Ascobolus, e.g. A. immersus, and by Saccobolus. Their spores are arranged in the ascus more or less in two rows, and are held firmly together-in Ascobolus by their gelatinous coats (Fig. 81), and in Saccobolus by a special investing membrane. The object, so to speak, of sporedischarge in these fungi is to eject the spores from the ascus to as great a distance as possible, so that they may fall at once on to the surrounding grass. In feeding, herbivorous animals swallow the grass and spores together. The latter pass out in the excrement uninjured and ready to germinate. In their mode of spore-dispersal these Ascomycetes exactly resemble Pilobolus. The attachment of the eight spores to one another, so as to form an oval mass, prevents the ascus jet being broken up by surface tension and thus keeps the mass of the projectile constant. This enables the spores to be thrown to a greater distance from the frecal substratum than would otherwise be possible.

For the sake of comparison with the Hymenomycetes, a special investigation was made upon the spore-discharge of Ascobolus immersus, the asci and spores of which are of large size even for an Ascobolus. The fungus made its appearance on a horse-dung culture 
in the latioratory. 'The asei were found to be heliotropie, ${ }^{1}$ and they were camsed to point directly upwarts by enelosing the culture in at dark-chamber and reflecting light downwards upon it through a small top window. The spores, attached together in groups of eight,

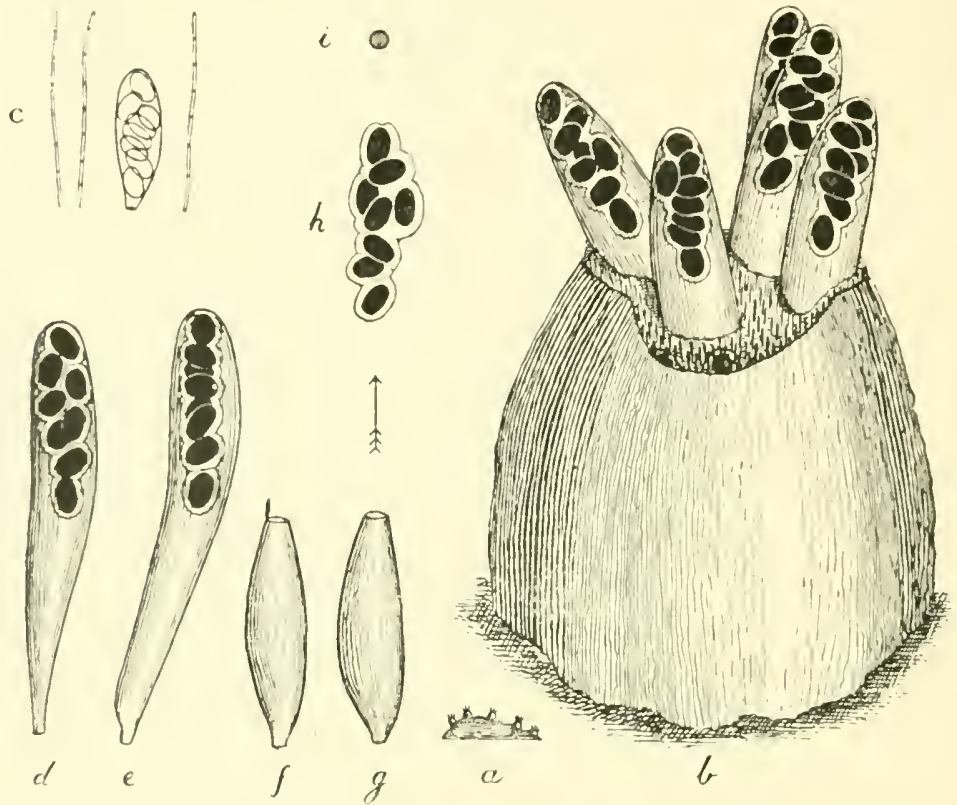

FIG. S1.-Ascrlolus immorsus. a, fire fruit-bodies, shown natural size, on a section of horse dung. $b$, fruit-boly with five asci projecting from the hymenium just before bursting. "Two asci belonging to the next yommer series are to be seen almost hidden among the paraphysus in the foreground. $c$ a young ascus and parmplyses. $d$ and $r$, two fully swollen asci isolated from the hymenium. $\dot{f}$ and $/$, burst asci which bave contracted to half lleir original length. In $f$ the lid of the ascus has opened as if attachorl by a hinge. y shows the result of an aseus explosion wateh und water with the microscope. 'The lid $i$ has been shot away along with the ascospore mass $h$. The eight ascospores are attached by their grelatinous envelopes. $b-i$ magnification, 70 .

were then discharged in a vertical direction, so that they struck and adhered to the underside of a horizontal glass plate pliced 2.j $\mathrm{cm}$. above the fruit-bodies. Further experiment showed that the maxinum height of projection was about $35 \mathrm{~cm}$. The eulture was then set in a large glass case which was exposed to the light at a haborat-

1 For the significance of heliotropism in asci, vide Chap. IV., pp, 74, 75. 
tory window. The floor of the case was covered with a sheet of white paper. After falling upon the latter, the ejected groups of spores could be distinguished with the naked eye as tiny dark specks. The maximum horizontal distanee to which any of them was shot was found to be about $30 \mathrm{~cm}$. In violence of sporedischarge possibly Aweobolus immersus is not exceeded by any other Ascomycete, although it is easily beaten by Pilobolus, which can squirt its sporangia to a distance of more than a metre. These performances seem truly titanic when compared with those of the Hymenonycetes, for the maximum horizontal distance of discharge of basidiospores was observed to be only $0.01-0.02 \mathrm{~cm} .^{1}$

A group of eight Ascobolus spores elinging together was estimated to have a volume about 2000 times greater than that of a single spore of Amanitopsis vaginatu. It is the large mass of the united ascospores which permits of the projectile receiving sufficient initial velocity to carry it a distance of many centimetres. In order to shoot out a tiny Amanitopsis spore to an equal distance, a relatively enormous initial velocity would require to be given to it. A parallel ease may be eited from everyday life. A good thrower can throw a cricket ball one hundred yards. With his strongest effort, howerer, he ean throw a small shot only a few feet. If he were determined to make the shot travel as far as the cricket ball he could succeed in doing so by putting it into a gun and driving it out with gunpowder. The very high initial velocity which it would then receive would be vastly greater than that imparted to the ericket ball, although the distance traversed by both objects would be the same. It is just as impossible for a man to throw a small shot a hundred yards as it would be for a Mushroom to shoot out a basidiospore to a distance of a single centimetre. In order to accomplish the latter feat, it would be necessary for the spore to be projected with an initial velocity of the order of 65 metres per second: ${ }^{2}$ On the other hand, the united eight spores from an aseus of the Ascobolus conld be shot a centimetre with an initial veloeity of only $0.2-0 \cdot 3$ metres per second.

1 Chap. XI., Method II.

2 Calculated by using the first equation in Chapter XVII. and taking the terminal velocity of a 11 ushroom spore as $0^{\cdot} 15 \mathrm{~cm}$. per second (vide Chapter XirI.). The spore was assumed to be spherical. 
The initial velocity which an ascospore group would need to have imparted to it in order to fall $30 \mathrm{~cm}$. from a fruit-body would be less than 10 metres per second.1

From the above discussion it seems that a ehief factor in securing a sufficiently large trajectory for the ascus contents of Ascobolus

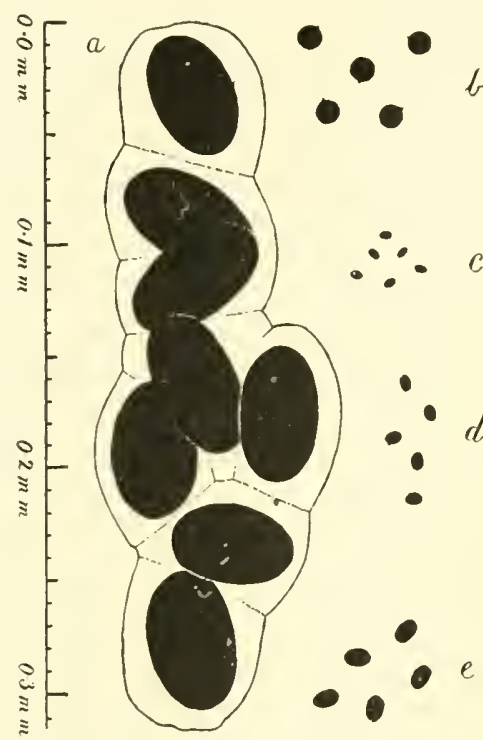

FIG. 82.-Comparative sizes of fungus projectiles. ", spore mass of Ascobolus immersus; $b$, spores of Amanitopsis vaginata; c, spores of Collylia dryophila; $d$, spores of Psalliota campestris;, , spores of coprinus comatus. All drawn to the scale given. immersus is the large mass of the projectile. The projectile owes its f size to four factors: (1) The unusually large size of the spores, (2) the thick gelatinous envelope round each spore, (3) the elinging of the spores together, and (4) the large mass of the discharged ascus sap. The spores, excluding their gelatinous investments, ineasure $35-45$ $\times 55-65 \mu$, and therefore are $50-100$ times greater in rolume than the wind-borne spores of Peziza aurantia. The grigantic size of the spores as compared with those of the Hymenomycetes will at once be realised by a glance at Fig. 82.

In Pilobolus, where the unopened sporangium is squirted off the sporangiophore, the projectile is relatively of great size. That it should be shot out farther than the contents of any ascus is, for the mechanical reasons already diseussed, not in the least surprising. Empuer musre, as is well known, can send its unicellular conidia to a distance of some centimetres. Here, however, the spores are not only very large but become eoated with a thick and sticky fluid discharged from the conidiophore. 'The large size of the projectile may be at once recognised from the accompanying photograph (Fig. 83).

${ }^{1}$ Here the terminal velocity was taken to be $30-50 \mathrm{~cm}$. per sezond (vide infru). The spore-group was assumed to be spherical. The calculations are only very rough approxinutions to actual values. 
The large mass of a group of eight ascospores, of the sporangium of Pilobolus, or of the conidium of Empusa musce, is unfavourable to the dispersion of these structures by the wind owing to the fact that it causes them to fall with comparative rapidity. Let us compare the terminal vertical velocity of an Ascobolus immersus ascospore group with that of a basidiospore of Amonitopsis

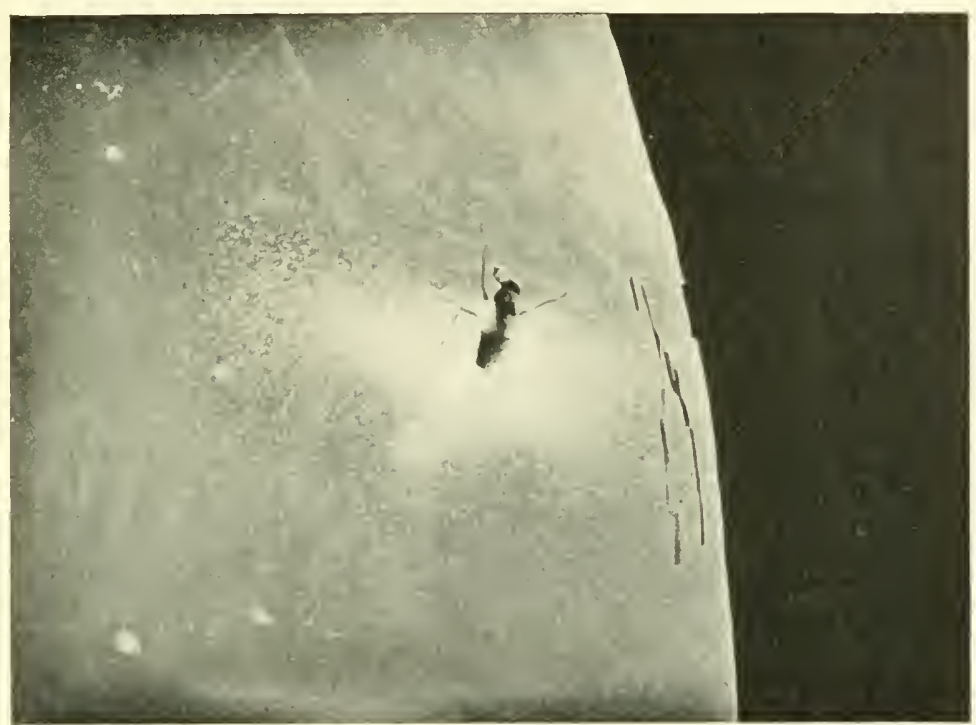

Ficr. 83.-Empusa musca. The house-fly has been killed by the fungus and is now fixed by its proboscis to a window-pane. The halo around the fly's body consists of discharged conidia, many of which have been shot to a distance of $2 \mathrm{~cm}$. and some to about $3 \mathrm{~cm}$. Photographed by C. W. Lowe. $\frac{3}{4}$ natural size.

vaginate. Assuming Stokes' Law and equal densities for the falling particles, it may be shown that

$$
\frac{\mathrm{V}}{\mathrm{V}_{1}}=\frac{a^{2}}{u_{1}^{2}}
$$

where $\quad \mathrm{V}=$ the terminal vertical velocity of the basidiospore,

$V_{1}=$ the terminal vertical velocity of the ascospore group,

$a=$ the radius of the basidiospore,

$u_{1}=$ the radius of a sphere with a volume equal to that of the ascospore group.

Since, from measurements made, we may take $V=0.5 \mathrm{~cm}$. per second, $a=0.0005 \mathrm{~cm}$., and $a_{1}=0.005 \mathrm{~cm}$., we may calculate that 
$V_{1}=50 \mathrm{~cm}$. per second. Since $\mathrm{V}$ is only $0.5 \mathrm{~cm}$. per second, the conclusion may be drawn that the ascospore group falls about one hundred times more rapidly than the basidiospore. Since for high velocities stokes' Law breaks down and the resistance of the air becomes proportional to a higher power of the velocity, the rate of fall of the ascospore group is in reality somewhat less than $50 \mathrm{~cm}$. per second. Its actual value, however, must still be enormous compared with that for the velocity of fall of a basidiospore. The latter was observed to be only about $0.5 \mathrm{~cm}$. per second.

Since the terminal vertical velocity of an ascospore group of the Ascobolus has been calculated to be of the order of $50 \mathrm{~cm}$. per second, we can easily understand why it is that a thick spore-deposit often collects within a short radius of the fruit-bodies. Ordinary convection currents, such as occur in dwelling-rooms, or slight movements of the air in the open, can be of little use in scattering the ejected ascus contents, although dispersion may be effected by winds of moderate strength. On the other hand, basidiospores, owing to their tiny size, fall very much more slowly than the ascospore groups, and in consequence are splendidly adapted for transport through the air. Even very slight convection currents, such as oceur almost universally near the earth's surface, are able to carry them about and render the position where they come to settle a matter of the greatest uncertainty.

The fruit-bodies of Ascobolus immersus exhibit a number of special adaptations to a coprophilous mode of existence which enable them to liberate their spores from the sides of horse-dung balls, fe., with success. These adaptations may be summarised as follows: (1) The protrusion of the ripe asci, just before discharge, to some distance beyond the surfice of the hymenium: (2) the diurnal periodicity in the ripening and discharge of successive series of asci: (3) the heliotropic reaction of the asci whilst beconing protuberant: and (t) the great violence of spore-discharge. The protrusion of the ripe asci far beyond the hymenial surface permits of the asci making positive heliotropic curvatures. Such reactions to light would be impossible if the asci were entirely embedied in the hymenium like those of Pezize. The periodicity in the 


\section{ADAPTATIONS IN ASCOBOLUS}

ripening of the asci is of such a kind that each morning a few asci go through their final phases of stretching and discharge their spores almost simultaneously about midday or in the early afternoon. After one series of asci has exploded, another immediately begins to develop which will discharge its spores on the following day. Owing to this periodic development of successive series of asci, the asei always come to maturity in daylight, i.e. they always go through their tinal stretching at a time when their direction of growth can be controlled by heliotropic stimuli. The positive heliotropism of the asci causes these structures-the fungus gunsto become directed toward well-lighted positions and therefore in general toward open spaces. When the spore-masses are shot outwards, they thus come to have a good chance of avoiding obstacles in their flight through the air. The orientation of the asci must prevent a very large number of spores from being wasted by being shot against adjacent dung balls, \&e. We thus see that the protrusion of the ripe asci, their periodic development, and their heliotropism are intimately correlated with one another. The great violence of spore-discharge is associated with the unusually large size of the asci and of the spores. The clinging of the spores together during discharge and the large mass of the projectile, as we have already seen, are significant in that they enable the spores to be shot to a greater distance from the horse-dung balls than would otherwise be possible. The aseospores are thrown to such a distance that they fall on the surrounding herbage, where they can be devoured by herbivorous animals and thus find their way into fieces.

Lycoperdon.-In Gastromycetes the modes of spore-dispersion are of various kinds. Sphrerobolus stellatus has a wonderful catapult mechanism for casting a sac containing spores a distance of several inches. In the Phalloidei, ${ }^{1}$ the fruit-bodies are specialised for attracting flies by means of form, colour, scent, and sweet juices. In the Tuberacer, the hypogean Truffles, \&c., are eagerly sought for by certain quadrupeds and other animals. The main facts in these instances are now well known and recognised. However, a few remarks may be

\footnotetext{
1 'T. W. Fulton, loc. cit.
} 
added on Puff-balls. In the genus Lycoperdon, ${ }^{1}$ the fruit-bodies develop an enormous number of spores, and at maturity constitute sacs full of a dry powder mixed with capillitium threads. The peridiun breaks away above so that each Puffball comes to have a more or less circular opening at the top. The arrangement is such that the spores leave a fruit-body only when the wind is blowing at a firvourable speed for their dispersion. When the air is quiet, the spores lie safe and motionless within the protecting peridium. As soon, however, as the wind becomes violent, it sweeps in gusts into the Puff-ball from above, gradually disengages the spores from the capillitium threads, and bears them forth to long distances. A more effective mode of spore-dispersion can scarcely be inagined. In connection with l'uff-ball spores an interesting physical problem awaits solution. We are still ignorant why it is that the spores of Hymenomycetes never form a mass of loose dust, whereas this regularly occurs with those of a Lycoperion. The adhesiveness or non-adhesiveness of spore cell-walls must be recognised as a matter of importance in connection with sporedispersion.

The Sound produced by the Discharge of Spores, with Special Reference to Pilobolus.-Although many Agarics which have come under my notice shed spores at the rate of about a million a ininute, I have never been able to detect the least sound caused by spore-discharge. So far as maided human ears are concerned, it seems likely that spore-emission by Hymenomycetes must for ever be a quite silent process. On the other haud, the discharge of spores by certain Asconycetes appears to be distinctly audible. Thus de Bary was able to hear " a very perceptible hissing sound produced ly strong specimens of Pezizu acetubulume and Helectlu "rovere."

Pilobolus, as is well known, exceers all Asconycetes in the violence with which it ejects its projectiles. C'oemans records that the sporangia can be projecterl to a height of over

1 Tide Chap. V. p. Sfi.

? De Bary, comparative Worphology und Physiology of the Fungi, de., English

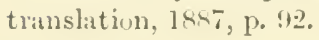


3 feet, ${ }^{1}$ and Grove found that on one occasion the maximum horizontal distance of discharge was 4 feet 10 inches. ${ }^{2}$ The largest of all the Piloboli is P. longipes, the stipe of which is usually '2-3 $\mathrm{cm}$. long, whilst the diameters of the sporangium and subsporangial swelling are $0.5 \mathrm{~mm}$. and $1 \mathrm{~mm}$. respectively. When I placed the sporangiophores of this species so that they inclined obliquely upwards at an angle of about $45^{\circ}$, sereral sporangia were shot more than 5 feet in a horizontal direction, and one to a distance of 6 feet 2 inches. Grove noticed that, when a sporangium strikes one in the face, one can distinctly feel the blow, like that of a small drop of rain, ${ }^{3}$ and he called attention to the fact that each discharge is accompanied "by a faint but distinctly audible "puff," like the sound of a minute pop-gun." 4 From personal experience with a number of Pilobolus cultures, I am able to confirm Grove's statements both as to feeling the blows of the sporangia and also as to hearing the sound of the explosions. Some horse-dung cultures of Pilobolu Kleinii were carefully watched during the mid-day hours on several successive days. At first I mistook very slight sounds produced involuntarily from my collar and mouth for sounds proceeding from the fungus. However, when these sources of error had been eliminated, I found that it was still possible to detect some, although perhaps not all, of the discharges. On listening very intently in a quiet roow, two sounds were to be heard: firstly, a little click as a sporangium left its sporangiophore, and secondly, a more metallic sound, whenever a sporangium struck the grass side of the crystallising dish which contained the culture. So far as I am aware, the sound of the projectiles, made on striking obstacles, has not hitherto been noticed. Its audibility can be very much increased by a method devised by Mr. F. Wakefield, who was assisting me in the laboratory. One makes use of a drum consisting of a glass funnel, 3 or 4 inches in diameter, across the mouth of which a sheet of thin tissue

1 Coemans, Monogrephic du Genre Pilobolus, 1860, p. 39; quoted from Grove's monograph, p. 15.

2 W. B. Grove, Monogreph of the Pilobolidx, Birmingham; reprinted from the Miellenel Naturelist, 1884, vol. vii. p. 219.
${ }^{3}$ Lor. cit., p. 16.
+ Loc. cit., p. 15. 
paper has been pasted. If one holds such a drum a little wily above the Pilobolus culture, one can readily hear the bang each time a sporangium hits the tissue paper. I found that Mr. Wakefield conld detect the sound made on the drum at a distance of 21 feet. 


\title{
GENERAL SUMMARY
}

\author{
The following is a summary of the more important results obtained \\ cluring the incestigations
}

\section{PAR'T I}

CHapter I.-The spores of the Hymenomycetes are very adhesive when freshly liberated. In consequence of this, special arrangements are necessary for their liberation from the surfaces of gills and hymenial tubes, ic. Successful liberation can take place only when the hymenium is so situated that it occupies a vertical position or looks downwards at a greater or less angle.

Paraphyses are useful as spacial agents. They prevent the adhesive spores of adjacent basidia from coming into contact during development and discharge. The functions of cystidia are for the most part still quite unknown.

Occasionally certain species of Coprinus give rise to fruit-bodies which are normal in size and form, but are either partially or completely sterile. The basidia fail to produce spores. Fruit-body sterility of this kind was observed in Coprinus fimetarius, var. cinereus, and also in an ephemeral, coprophilous species, which has been called C. plicatiloides.

Fruit-bodies are frequently visited by Springtails (Collembola), Nites (Arachnida), and Fungus Gnats (Mycetophilidæ). Their relations with these animals stand in need of a detailed investigation.

Direct sunlight injuriously affects the vitality of the dry spores of Srhirophyllum commune and of Derlatea unicolor. Possibly the colouring matters deposited in the walls of the spores of Coprini and of other Hymenomycetes may serve a useful purpose by screening off certain of the sun's rays from the living protoplasm.

C'HAPTER II.-The disposal of the hymenium beneath a fruit-body on gills, on spines, or in tubes, dre, instead of on a flat surface, is an economical arrangement which permits of a great increase in the number of spores which a fruit-body of a given size may produce. Species of the genus Fomes appear to be the most highly specialised in this respect. The specific increase in the extent of the hymenium due to the presence of gills and tubes was measured in a few cases. In the Mushroom it was 
found to be 20 ; in Fomes vegyetus 148 for one year, aml 500 for three; whilst in a large and old specimen of Fomes igniasius it proved to be nearly 1000 .

The crowding of the gills and the reduction in diameter of the tubes in certain fruit-bolies (e.\% those of the Yushroom and of Fomes ignirrius), after allowing for a small margin of safety, appear to have reacherl their limits consistent with the violent horizontal dischurge of the spores from the basidia.

Chrpter III.-The fruit-bodies of most species of Hymenomycetes are very rigid. This rigility is of considerable importance in keeping the axes of the tubes of Polyporea, the planes of the gills of Agaricinest, trc., in vertical positions. Slight swaying movements canse loss of spores. In a Mushroom it was calculated that, when two arljacent gills are tilted from their vertical planes to an angle gleater than the ritical angle of abont $2^{\circ} 30^{\prime}$, some of the spores are mable to escape from the interlamellar spaces. With a tilt of about $5^{\circ}$, half the spores are lost; and with a tilt of about $9^{\circ} 30^{\prime}$, four-fifths of them. The rigillity of stipes in many species is secured by hollow cylindrical form and by mequal tensions in the layers of cells.

CHAPTER IV.-The growth movements of a fruit-body cam be regarded as so many adjustments of a delicate machine made with the object of placing the hymenium in the best possible position for liberating the spores. A Inshroom and the ephemeral, coprophilous Coprini exhibit four snch adjustments, aml Polyporus squmosus five. The nature of the adjustments is correlated with the general structure of the fruit-bodies and with the orientation of the substratum.

The amount of eccentricity of the pileus of Polyporus srgamosus is controlled by a morphogenic stimulus of gravity.

The stipes of certain ephemeral Coprini, just hefore the pilei expand, are extremely sensitive to the stimulus of gravity. When a stipe had been changed from the vertical to the horizontal position, a distinct upward curvature was noticed after a stimulation of 1.5 minntes. Another stipe, similarly displaced, gave a distinct macroseopic reaction to the stimulus of gravity after 3 minutes' stimulation, and tumed through a complete right angle, so as to regain a vertical position, in 17.5 minutes. The last $80^{\circ}$ were turned through with a greater angular velocity than that of the minute-hand of a clock. 'This angular velocity is far greater than that known for any. Planerogam, or indeed any other plant organ when stimulated by gravity.

Chapter V.-In perfectly still air, the spores liberated from a pileus placed above a horizontal sheet of paper fall vertically downwards and 
produce a spore print consisting of radiating lines corresponding to the interlamellar spaces. Extremely minute convection currents give a horizontal drift to the falling spores and cause the spore-rleposit to become cloudy.

The number of spores liberated by large fruit-bodies amounts to thousands of millions. A specimen of Psalliote campestiv with a diameter of $8 \mathrm{~cm}$. was found to produce 1,800,000,000 spores, one of Cominus comatus 5,000,000,000, and one of Polyporus squamosus 11,000,000,000. The rate of elimination of the spores or young plants by death can be shown to be enormous. The most prolific kind of fish is not so prolific as a Mushroom plant. It was estimated that a large fruit-body $(40 \times 28 \times 20 \mathrm{~cm}$. $)$ of Lycoperdon bacista, Linn., the Giant Puff-ball, contained 7,000,000,000,000 spores, or as many as would be liberated by 4000 Nushrooms, each having a diameter of $8 \mathrm{~cm}$.

CHApter VI.-With the unaided eyes by daylight, clouds of spores were observed to be given off continuously for thirteen days from the undersicle of a large fruit-body of Polyporus squamosus. It was found that each hymenial tube was liberating spores from every part of its hymenium. The visible discharge of spores appeared to be unaffected by light conditions or by changes in the hygroscopic state of the atmosphere. The formation of irregular clouds, wreaths, and curls of spores is not due to intermittent spore-emission, but is brouglit about by air-currents sweeping beneath the fruit-body.

Chapter VII.-Spores falling from any fruit-body suspended in a suitable glass chamber, e.g. a closerl beaker, can be seen in clouds or individually without magnification by using a concentrated beam of light. Much use was made of this discovery in the research.

The beam-of-light method can be used to make a very simple and effective laboratory demonstration of the discharge of spores from Mushrooms, \&c. It may be carrier out with great convenience at any time by using as material the mature xerophytic fruit-bodies of Lenzites betulina, Schizophyllum commune, Polystictus versicolor, \&c. These can be kept dry in bottles for months or years. After wet cotton-wool has been placed above them they quickly revive, and they begin to shed their spores within six hours. The emission of the spores continues for days.

CHAPter VIII.-Spore-discharge from any fruit-body under normal conditions is continuous. The period of spore-discharge in some species lasts for a few hour's, in others days, and in yet other's for weeks. With the beam-of-light methor a fruit-boly of Schicophyllum commune and also one of Polystictus iersicolor were both observed to shed a continuous stream of spores for sixteen days. A specimen of Lenzites letulina shed spores for 
ten days. These fruit-borlies, doubtless, had already shed spores for some time before they were gathered.

After the number of spores produced had been estimated and the length of the spore-fall period had been observel, it was calculated that large fruit-bodies of Psalliota campestitis, Coprimus comatus, Polyporus squamosus, ic., shed about a million spores a minute for two or more days.

Cnapren IX.- The fruit-bodies of corky or leathery consistency growing on sticks and logs are xerophytic. They can be dried up without any loss of vitality. (on access to moisture they revive in a few hours and resume the function of discharging spores. The retention of vitality after desiccation in some species is continued for years. The spores liberated from revived fruit-bodies are capable of germination. Typical genera constituting a xerophytic hymenomycetous log-flora are: Lenzites, Polystictus, Stereum, dc.

The fruit-bodies of Schirophyllum commune prossess special adaptations for a xerophytic morle of existence. The gills are partially or completely divided down their median planes into two vertical plates. Whilst desication is proceeding, the two plates of each of the longer and deeper gills bend apart and spread themselves over the shorter and shallower gills. When desiccation is complete, the whole of the hymenium is hidden from external view and the fruit-body is covered both above and below with a layer of hairs. The closing up of the fruit-bodies at the beginning of a period of drought serves to protect the hymenium from external enemies. A fruit-body can retain its vitality in the dried and closed-up condition for two or more years. When allowed to absorb free water through the top of the pileus, it revives in a few hours. The two plates of each pair return to their original vertical positions, and again become closely apposed. The liberation of spores is then recommenced, and may last for some days.

Cinapter X.-The fruit-body in some species can only be developed so as to produce a pileus when subjected to the morphogenic stimulus of light. When a hymenium has once been produced it sheds its spores independently of light conditions and of the direction of gravitational attraction.

So long as a fruit-body itself contains sufficient water, spore-discharge appears to continue without heing affected by the hygroseopic state of the atmosphere.

Some of the xerophytic fruit-bodies growing on $\operatorname{logs}$, fe., continue to shed their spores at the freezing-point of water. The range of temperature permitting spore-discharge in the case of Lenates betulina was found to be approximately $0^{\circ}-30^{\circ} \mathrm{C}$.

When a fruit-brdy is placed in hylrogen or carbon dioxide, the liberation of spores quickly ceases. The presence of oxygen in the surrounding atmosphere appears to be essential for the continnance of spore-discharge. 
In pure oxygen fruit-bodies shed their spores for several hours at the same rate as in air.

When a fruit-body is subjected to the vapour of ether or chloroform, spore-discharge ceases almost instantaneously, but can be resumed when the anæsthetic has been removed. A fruit-body of Lensites betulina recovered its spore-liberating function after this had been inbibited by ether vapour for a week.

Chapter XI.-The four spores on each basidium are discharged successively. They leave the sterigmata within a few seconds or minutes of one another:

Each spore is shot out violently from its sterigma to a distance of about $\frac{1}{10} \mathrm{~mm}$.

Chapter XII.-The propelling force during spore-discharge seems to be provicled by the pressure of the cell-sap of the basidium upon the cellwall, and possibly by a similar pressure in the spore. On the discharge of a spore, the sterigma breaks across but does not open. Spore-discharge in the Hymenomycetes appears to resemble that in Empusa Grylli, and may be said to be brought about by a jerking process, which may be contrasted with the squirting process of Empusa musra and the Ascomycetes.

Chapter XIII.-The specific gravity of spores can be determined approximately by using heavy fluids containel in a counting apparatus, the chamber of which is $0.1 \mathrm{~mm}$. deep. The specific gravity of spores of Amanitopsis vaginata was found to be nearly that of water, namely, $1 \cdot 02$, whilst that of the much heavier Coprinus plicatilis spores proved to be approximately $1 \cdot 21$.

Chapter XIV. - The size of spores can be measured with accuracy and rapidity by using a Poynting Plate Micrometer. The apparatus has been described.

The average size of the spores of a fruit-body may differ considerably in different fruit-bodies of the same species. This fact may well account for' the waut of agreement of spore measurements as given by different mycologists.

Chapter XV.-The rate of fall of spores in still air was determined for the first time. A small piece of a fruit-body was placed in a verticallydisposed compressor cell. The falling spores were observed with a horizontal microscope and their rate of fall accurately recorded upon a revolving drum.

The first direct test of the applicability of Stokes' Law to the fall of microscopic spheres in air has been carried out by determining the size, 
specifie gravity, and terminal velocity of the spherical spores of Amanitopsis calinata. The rate of fall of the spores was fouml to be about 46 per cent. greater than was expecterl. While, therefore, the observer speed has proved to be of the same order of magniturle as the calculated, Stokes' Law has not been confirmed in detail. To fully satisfactory reason for the discrepancy between theory and observation has so far been fonnd.

C'napters XV. Axu XVI.-The rite of fall of hymenomycetous spores ranges from 0.3 to $6.0 \mathrm{~mm}$. per second. It varies with the size of the spores, their specific gravity, and the progress of desiceation. The relatively very small spores of Collylia dryophila in very dry air was found to fall at an averige rite of $0: 37 \mathrm{~mm}$. per second, whilst the relatively very large spores of Amanitopsis refinata in a saturated chamber attained a speed of $6.08 \mathrm{~mm}$. per second. The spores of the Mushroom (Psalliota campestris), shortly after they have left the pileus, fall at a speed of approximately $1 \mathrm{~mm}$. per second.

CHAPTER XVI.-The spores fall most ripidly between gills, down tubes, fre, immedrately after liberation from the sterigmata. After emerging from the fruit-bodies, they dry up within about one minute. The liminntion of volume causes a considerable reduction in the rate of fall.

Chapter XVII. - The importanee of violent spore-discharge lies in the fact that thereby the very adhesive spores are prevented from touching one another or any part of the hymenium whilst eseaping from the fruit-body. Each spore is shot out more or less horizontally into the spaces between the gills, in hymenial tubes, \&c. The horizontal motion is very rapilly brought to an end owing to the resistance of the air. In consequence of this, and also of the attraction of gravitation, the spore describes a slarp curve and then falls vertically downwards.

The path of the spore between the gills, in tubes, de., has been called the sporabola, and is remarkable in that it appears to make a sudden bend approximately through a right angle. When for any spore the terminal vertical velocity and the maximum horizontal distance of discharge have been determined, its sporabola becomes amenable to a satisfactory mathematical treatment. It was observed that the spores of Amanitopsis varinata are shot outwards from the gills in a horizontal direction to a maximal distance of $0.2 \mathrm{~mm}$. It was calculited that they complete this movement in approximately $+0,0$ second, and leave the sterigmata with an initial horizontal velocity of "pproximately $40 \mathrm{~cm}$. per second. The steady, terminal, verticil veloeity of about $0.5 \mathrm{~cm}$. per second is attained by the time a spore has fallen a listance equal to its own diameter, i.e. about $10 \mu$.

Chapter XVIII- At the moment of discharge, or within a few seconds 
afterwards, the majority of spores of the Mushroom, sc., become electrically charged. The charges are relatively of different strengths, and either positive or negative. A few spores appear to be unelectrified. No biological significance has been ascribel to these facts.

Chapter XIX.-In the Agaricines there are two distinct spore-proulucing and spore-liberating types of fruit-body-the Coprinus comatus type and the Ilushroom type. These differ from one another in several structural and developmental details.

In the Coprini "deliquescence" is a process of autodigestion which renders important mechanical assistance in the process of spore-discharge. It was more especially studied in the case of Coprimus comatus. The spores on each gill ripen and are discharged in succession from below upwards. Autodigestion leads to the removal of those parts of the gills which have already shed their spores and thus permits of the continued opening out of the pileus. By this means the necessary spaces for the violent discharge of the spores from the basirlia are provided. The spores, after describing sporabolas, fall vertically downwards between the gills. On emerging fiom the pileus they are scattered by the winds. "Deliquescence" is in no way comnecterl with the visits of insects to the fruit-hodies.

The genus Coprinus may be regarted as a specialised offshoot from a more generalised fungus of the Mushroom type. There appears to be no satisfactory evirlence in support of Massee's view that "in the genus Coprinus we have in reality the remnant of a primitive group from which have descended the entire group of Agaricineie."

Cirapter XX.-One of the chief functions of the stipe is to provide a space usually one or more inches high between the under surface of the pileus and the substratum on which the fruit-boly may grow. Owing to the very small rate of fall of the spores and the relatively rery much greater average horizontal speed of air-currents near the ground, the space is amply sufficient under normal conditions to permit of the falling spores being carried away from the fruit-boly and deposited at a distance from it.

Falck's theory, that the heat produced in pilei by respiration and in consequence of the presence of maggots is of importance in creating convection currents which scatter the spores, has been discussed. If partially true, it is of limited application, and further investigations are necessary in order to decicle its value.

Chapter XXI. Coprophilons Ilymenomycetes have fruit-borlies adapted to their peculiar habitat both in form and in reactions to external stimuli. 
Slugs are probably of but minor importince in dispersing the spores of Hymenom ycetes.

Shugs do not find the fruit-hodies of all Agaricina equally palatable, but prefer to starve rather than eat those of certain species.

\section{P'AR'T II}

Cinapteli 1.-The spores of some Discomycetes (Peziza, Bugaria, Gyromitra, dco) are scattered ly the wind, whilst other's (Asobolus immersu, Saccobolus, drc.) are dispersed by herbivorous animals. Each mode of spore-dispersion is correlated with special adaptations in the asci.

The spores of Pexiza repanda are shot up into the air to a height of 2-:3 cm. The eight spores from an ascus separate from one another almost immediately after leaving the ascus mouth, ancl are then carried off by the wind. The fact that the ascus jet breaks up on leaving the ascus was observed by means of the beam-of-light methorl.

Puffing is probably not due (as de Bary supposed) to the mere withdrawal of water from asci. Sohutions of grape sugar, glycerine, sodium clloride, and potassium nitrate, which merely withdraw water from the ripe asci of Pesiar repranda, lo not cause their explosion. On the other band, solutions of many poisonous substances, e.y. iodine, mercuric chloride, silver nitrate, copper sulphate, sulphuric acid, acetic acid, and alcohol, give rise to marked puffing. Two alkalies-sodim hydrate and sodium carbonate-kill the asci without causing them to discharge their contents. It seems probable that puffing is caused by a stimulus given to the protoplasm in contact with the ascus lic.

The physics of the ascus jet in Periac repanda has been discussed. It seems probable that the separation of the eight spores of an ascus during their upwarl flight into the air is due to considerable differences in the initial velocities given to the individual spores upon their discharge. Surface tension probably plays but a minor part in breaking up the ascus jet. When the ascus is regarderl as an apparatus for squirting out a jet in such a mamer that the jet immediately breaks up into eight parts so that each part contains a spore, its structure becomes more intelligible.

The eight spores in an ascus of Periza repanda are loosely attached together, and the row of spores is anchored to the ascus licl by a special protoplasmic brille. De Bary's hypothesis of currents is muecessiry in accounting for the means by which the spores are caused to take up their characteristic positions in the ascus.

The wind-borne spores of Ascomycetes and of Hymenomycetes are of the same order of magnitude with respect to their short dimeters, and are therefore equally well adapted to be dispersed by ordinary air movements. 
The Hymenomycetes, owing to the possession of basidia, are better organised for the production of large fruit-bodies which discharge their spores into the air than Ascomycetes. This is due to the fact that, without interfering with the escape of the spores, a hymenium containing basidia can be nore compactly folded than one containing asci. The present dominance of large-fruited Hymenomycetes over largefruited Ascomycetes in forests and fields may be indirectly due to the fundamental difference between basilia and asci as spore-rlischarging mechanisms.

CHAPTEn II.-Ascololus immersus is specially adapted to a coprophilous mode of existence. The special adaptations of its fruit-bodies are : (1) The protrusion of the ripe asci beyond the general surface of the hymenium, (2) the diurnal periodicity in the ripening of successive groups of asci, (3) the positive heliotropism of the asci, (4) the considerable distance to which the spores are ejected (sometimes $30 \mathrm{~cm}$.) -with which is associated (5) the large size of the asci and spores, and (6) the clinging of the eight spores together whilst describing their trajectory through the air. The adaptations are such as to permit of the asci discharging their contents so that these may be shot outwards clear of immediate obstacles, such as dung balls, \&c., and fall on the surrounding grass where they may be swallowed by herbivorous animals.

The projectiles of Ascololus immersus, Empusa, and Pilobolus are much larger than those of the Hymenomycetes. The distance to which they are ejected is proportional to their size.

The clinging together of the eight spores in the ascus of Ascobolus immersus involves an increase in the mass of the projectile, and thereby enables the spores to be shot to a greater distance than that to which they would be shot if they separated from one another inmerliately after leaving the ascus mouth.

When sporangiophores of Pilololus longipes are inclined upwards at an angle of about 45 , the sporangia are often thrown to a horizontal distance of 5 feet. The maximum horizontal distance of ejection observed was 6 feet 2 inches.

Grove's observation that the sound of the discharge of the sporangia from the sporangiophores is autible, las been confirmed. Another sound can be detected when the sporangia strike against a glass vessel or a piece of paper. The impingement of sporangia upon a tissue paper drum could be distinctly heard at a distance of 21 feet.

Attempts to detect a sound proceeding from fruit-bodies of the MLushroom and Polyporus squamosus, when discharging about a million spores a minute, failed. Probably for unaided human ears, the liberation of the spores of Hymenomycetes will for ever remain a quite silent process. 


\section{EXPLANATION OF PLA'TES I.-V}

\section{PLATE I}

FIti. 1.-Coprinus comatus. Vertical section through a large fruit-body showing the thin flesh, the vertically-placed gills, darkening from below upwards, and the hollow stipe. $m$, marginal band cosered with cystidia. Natural size.

FIG. 2.-Psalliote cumpestris. Section throngh a ripe fruit-body at maturity to be contrasted with that of Coprinus comatus in Fig. 1. Its flesh is thick, and the gills are nearly horizontally ontstretched. Specimen obtained from a field. Natural size.

Fı. 3.-Section through the hymenium of Polyporus squamosus, constructed from sketches made with a camera lucida. ", a basidium with unripe spores; $b$, a basidium with ripe spores; $c$, a basidium with two of its spores already discharged; $d$, a basidium which has discharged all four spores. Paraphyses separate the hasidia. Magnification, 625 .

Fig. 4.-Psalliote campestris. Vertical and transverse section through three gills. The hymenial surfaces are almost vertical. The arrows indicate the sporaholas or paths described by spores after violent discharge from the sterigmata. Each spore is shot outwards horizontally to a distance of $0 \cdot 1-0 \cdot 2 \mathrm{~mm}$., and after making a sharp turn falls vertically downwards in the space between the gills. Magnification, 25.

Fig. 5.-Coprime comatus. 'Transverse section through some of the gills whilst the spores are ripening. $s$, s, spaces letween the gills lined by the hymenium; $e$, inner swollen edges of wills covered with cystidia; $f$, pilens flesh. Magnification, 8 .

\section{PLATE II}

Figs. all of Coprinus comatus.

Fig. 6. - Vertical section through a young fruit-body shortly after it had appeared above the ground. $s$, level of soil. Natural size.

Fig. 7.- Vertical section through an older fruit-hody shortly before the gills separate from the stipe. $x$, level of soil. Natural size.

FIG. 8. - Vertical section throngh a frnit-body after antodigestion has begun. The rills are becoming liquefied from below upwards. The dotted lines show the shape and position of the gills at the moment antodigestion began. s, lower edgre of gill where spore-discharge and subsequently autodigestion first become active; $"$, oblique edge of gill where spore-discharge and antodigestion are taking place; $m$, marginal band on gill edge eovered with eystidia. Natural size.

F16. 9.-Vertical section through a fruit-body which las become helmetshaped. By antodigestion the gills lave now become redneed to about one-third their original length. ", edge of gill where spore-liberation and antodigestion 
are still in progress. $m$, marginal band on gill edge covered with cystidia. Natural size.

FIG. 10.- Vertical section through a fruit-body when antodigestion is nearly completed. The remains of the gills have now become horizontally ontstretched. Liquid drops may be seen at $d$ in such a position that they do not interfere with the liberation of the spores into the air. $a$, edge of gill where spore-liberation and antodigestion are still in progress. $m$, marginal band on gill edge covered with cystidia. Natmal size.

FIG. 11.-Fruit-body in the last stage when spore-liberation has ceased. The gills have now entirely disappeared. The central part of the pileus flesh still crowns the stipe. Natural size.

FIG. 12.-Semi-diagrammatic drawing of part of a gill surface in the region of autodigestion. There are five zones rumning parallel to the oblique gill edges: (1) $a-a^{\prime}$, zone of basidia with ripe spores. (2) $b-b^{\prime}$, zone of basidia discharging spores into an interlamellar space. The spores are shot off their sterimata successively, so that in this zone some basidia have three spores left upon them, some two, and some one, whilst some have lost them all. (3) $c-c^{\prime}$, zone of basidia which have discharged all their spores. (4) $d-d^{\prime}$, zone of autodigestion. The basidia and paraphyses are becoming indistinct and gradually liquefied. (5) $\ell-\ell^{\prime}$, the dark liquid film on the gill edge containing the products of autodigestion. Magnification, 320 .

\section{PLITE III}

Figs. $13-17$ all of Coprinus comatus.

FIG. 13.--Surface view of part of one side of the inner swollen edge of a gill before autodigestion has begun. $m$, marginal band covered with cystidia, $c$; $h$, hymenium containing basidia with ripe spores. Magnification, 120.

FIG. 14.-Transverse section through the inner swollen edges of three gills before autodigestion has begun. The swollen edges contain large air-spaces, $a$ a, and are covered by cystidia, $c$. The spaces $s s$ between the gills are lined by the hymeninm. The basidia each bear four spores; but of these, for the sake of elearness, two only are shown. Magnification, 120.

Frg. 15. - Surface view of a piece of gill, $0.01 \mathrm{~mm}$. by $0.02 \mathrm{~mm}$, in the regrion of ripe spores close to the zone of spore-discharge. Each basidium bear's four black spores, and is separated from its neighbours by paraphyses. Magnification, 320.

FIr. 16.-Section through the hymenium in the region of spore-discharge. The two uppermost basidia each bear four ripe spores; the middle basidium has discharged two spores, the next below that three spores, and the lowest basidium of all four spores. Two sporabolic paths, one with the horizontal distance $0.1 \mathrm{~mm}$. long and the other with it $0.15 \mathrm{~mm}$. long, are also shown. Magnification, 320 .

Fig. 17.-Diagram showing the paths of spores during discharge from the gills. A, transverse section cut horizontally through three gills. The dark, free edges are covered by liquid films produced by antodigestion. The arrows show the direction in which the spores are discharged from the zones of spore-discharge, and also the distance to which they travel horizontally. B shows a piece of one of the gills seen from the side. The arrows indicate by their positions and directions the vertical paths of the spores after leaving the zone of spore-discharge. 
C shows the appearance of the three gills when looked at edgewise from the stipe. The arrows indicate the sporibolas or paths taken by the spores when escaping from the gills.

\section{Figs. 18-20 all of Coprinus micaccus.}

Fig. 18. - Young fruit-body from which spore-liberation has begun. Natural size.

Ficr. 19.-Vertical section through a young fruit-body before spore-liberation has begun. The gills are turning brown and ripening their spores from below upwards. Natural size.

FIt. 20.- $a, b, c$, and $d$. Successive stages rnring the autodigestion of the gills. Drawn from four different fruit-bodies. Natural size.

\section{PLATE IV}

Figs. 21-24 all of Coprinus comatus.

FrG. 21.-Characteristic group of fruit-bodies growing in a field. Owing to excessive crowding, parts of the free margin of the pileus of two individuals have stuck to younger fruit-bodies. Magnification about 6 .

FIt. 22.--Specimens placed in a row and photographed to show the rarious stages of development. The gradual opening out of the pileus and the curling up of its free margin during antodigestion, and also the lengthening of the stipe, may be traced from right to left. Magnification about 7 .

FIG. 23.-Underside of a fruit-body liberating spores. Autodigestion is taking place where the gills look black and are evidently separated by free spaces. Spores are being discharged into the air from hymenial zones just above and parallel to the wet gill edges. The inner and higher parts of the gills, where autodigestion is not yet taking place, are still united at their edges by the large white cystidia. Natural size.

FIG. 24.-Photograph of a helmet-shaped fruit-body in a field. A marked feature is the ontwardly folded remains of the gills at the free margin of the pileus. A drop of "ink" hangs from the pilens opposite the stipe. The dark liquid drop is in such a position that it does not interfere with the discharge of the spores into the air. Magrnification about $\frac{1}{2}$.

FIG. 25.-View of the underside of a mature pileus of Psalliota campestris grown on a Mushroom bed. The gills are horizontally outstretched and free froni each other throughout their length. Spores are liberated from all the interlamellar spaces and from every part of them simultaneously. Natural size.

FIG. 26.-The Poynting Plate Hicrometer and a microscope for using it. The glass plate, $p$, can be pushed into the slot $s l$. The stand, st, has a vertical alm, $a$, with a scale, sc. The plate, $p$, is attached to the lorizontal rod, $r$, which can be rotated by means of the lever, $l$, which terminates in a small framework carrying a piece of glass on which is etched a line parallel to the lever. For further description see the text.

Fig. 27.-Polyporus squamosus. Spore-deposit made in about twenty-four hours from the hymenial tubes of a piece of the pileus. Each tube has produced its own heap of spores. Natural size.

FIG. 28.-Polyiorus squemosus. Spore-deposit made in about twenty-four 


\title{
EXPLANATION OF PLATES
}

hours from a rertical section of the pileus. Each half-tube has liberated spores throughout the whole length of its hymenium-bearing surface. Natural size.

FIG. 29.-Measurement of the rate of fall of spores. The observer is looking through the horizontal microscope at a field focussed below the gills of a piece of pileus contained in a vertically-placed compressor cell held in a clip. The cell is illuminated by cliffuse daylight reflected from a glas. roof to the eye by means of a mirror. On the table to the right is placed a drum driven by electricity. The chrononeter at the back is used for making time-records. The small battery on the right of the drum is connected with the fountain pen which touches the drum paper as the latter revolves, and also with the tapping-key upon the knob of which the observer has his first finger. As a spore passes the three eye-piece lines in the field of riew, the observer makes three successive taps upon the tapping-key. The fountain pen in response makes three deviations from its normal course on the paper. Each spore record is afterwards measured on the drum by means of a steel tape.

Fig. 30.-Amenitopsis tugincete. A fruit-body photographed in a wood. Maqnification about $\frac{1}{2}$.

\section{PLATE T}

\author{
Figs. all of Polyporus squamosus.
}

FIGs. 31. 32, 33, and 34,--Snccessive stages in the development of two fruitbodies grown on a log in the light. Natural size.

FIt;. :31.-One day old. A stromatous knob half hidden in a rift of the log has developed four conical processes.

FIG. 32.-Two days old. The four conical processes have become flattened at their ends in preparation for the development of pilei.

FIG. 33.-Three and a half days old. Two of the conical processes have ceased to grow ; the other two have become converted into young fruit-bodies. These have obliquely-placed stipes, and their pilei, which at first were symmetrically developed, already show distinct signs of eccentricity. The growth of the stipes has raised the pilei so that their upper surfaces have now come to lie in a horizontal plane.

FIG. 34.- Nearly five clays old. The eccentricity of the pilei and their growth in a horizontal plane have become very marked. The posterior sides of the pilei are in contact and have now ceased to derelop. The stipes have attained their maximum size.

When seven days old the fruit-bodies were fully extended and shedding spores abundantly, although the hymenial tubes had not yet reached their maximum length. The left-hand pileus had become $11 \mathrm{~cm}$. wide from the posterior to the anterior edge, and the right-hand one $9 \mathrm{~cm}$. wide. When looked at from above, both pilei appeared very eccentric and resembled the pileus shown in Fig. 4 in the text (p. 28). The last stage is shown in Fig. 34 in the text (p. 84).

Fig. 35.- Young fruit-body about three days old. It has developed from the only conical process produced by the stromatous knob. The pileus is very centric. Natural size.

FIG. 36.-Stromatous knob giving rise to a number of conical processes in the dark. Natural size. 
FIG. 37.-Conical processes dereloping on a stromatous knob in the dark. Natural size.

FIG. 38.-Branched stag's-horn-like fruit-body produced from a conical process. It was grown in the dark until it had nearly attained its full size. It was then feebly illuminated with daylight. Whilst previously it had been quite sterile, it reacted to the stimulus of light by developing on its underside three white patches of hymenial tubes. $\frac{1}{4}$ natural size.

FIG. 39.-Part of the stag's-horn-like fruit-body just described shown in natural size. The hymenial tubes look downwards.

Fig. 40.- 'lwo trumpet-sliaped fruit-bodies developel from branches of a stag's-horn-like structure grown in the dark. The two pilei began their development unexpectedly. Since stag's-horn-like structures usually remain quite sterile in the dark ( $f f$. Fin. 20 in the text, p. 58), the development of these two pilei was probably initiated by the light which was allowed to enter the dark-room each day for the purposes of observation. About $\frac{1}{3}$ natural size. The scale shows 3 inclies.

FIG. 41.-Some fruit-bodies were found growing on a log in the open. When they were exceedingly rudimentary (at a stage slightly in advance of that shown in Fig. 32), the log was taken into the dark-room and so placed that the fruitbodies were directed downwards obliquely at an angle of about $45^{\circ}$ from the vertical $(c f$. Fig. $42, f)$. The stipes on continuing development curved upwards through an angle of more than $100^{\circ}$ until the planes of the young pilei had been brought into a horizontal position as here shown in the figure. This experiment proves that fruit-bodies can take up normal positions in regard to the substratum and assume fairly normal shapes in the absence of light. About $\frac{1}{2}$ natural size.

Fif. 42.-Thin sections taken throngh the median planes of rarious fruitbodies all photographed together. The white strips of paper show the positions of the wood surfaces upon which the fruit-hodies grew:-

$a$, very eccentric pileus-commonly found in nature;

$b$, less eccentric pileus-less commonly found in nature ;

$c$, nemly centric pileus grown on the top of a stump ( $f$. text-figures $1, p .8$, and 22, p. 61)-rarely found in nature;

$d$ and e, sections through the two trumpet-shaped fruit-bodies shown and described in Fig. 40. They were grown in the dark in the laboratory;

$f$, fruit-body started in light and then allowed to complete growth in darkness (cf. Fir. 41). The negative greotropic curvature of the stipe is marked, but the diageotropism of the pileus is not so pronounced as when development takes place in the light;

y, very young trumpet-shaped fruit-body developing on a branch of a starg'shorn-like structure after this had been exposed to light for an hour. 


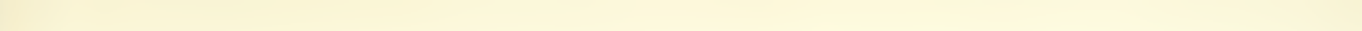





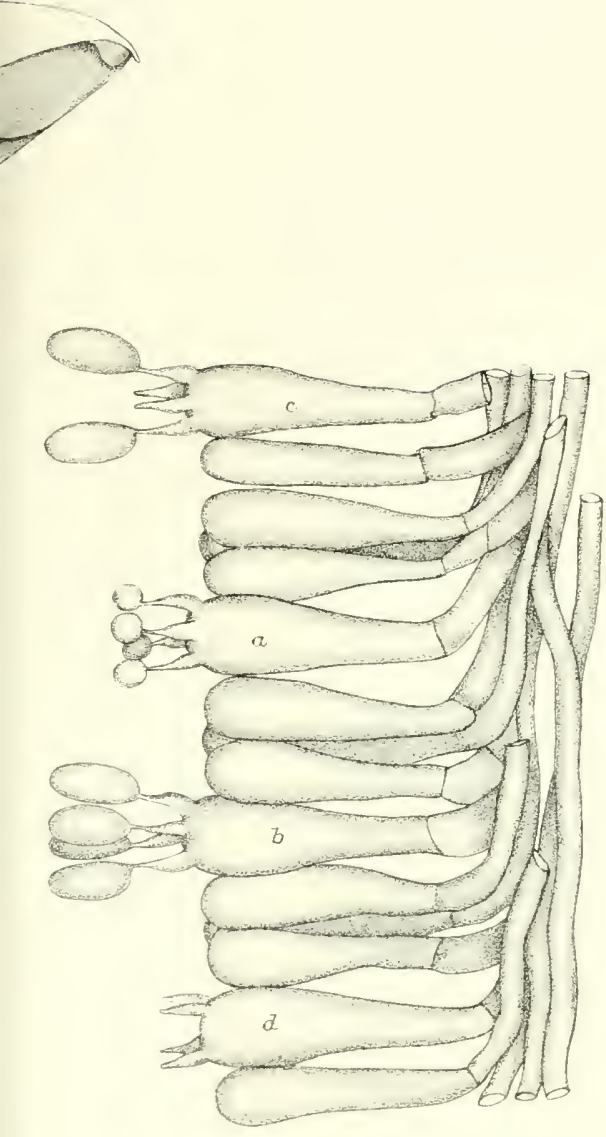

3.

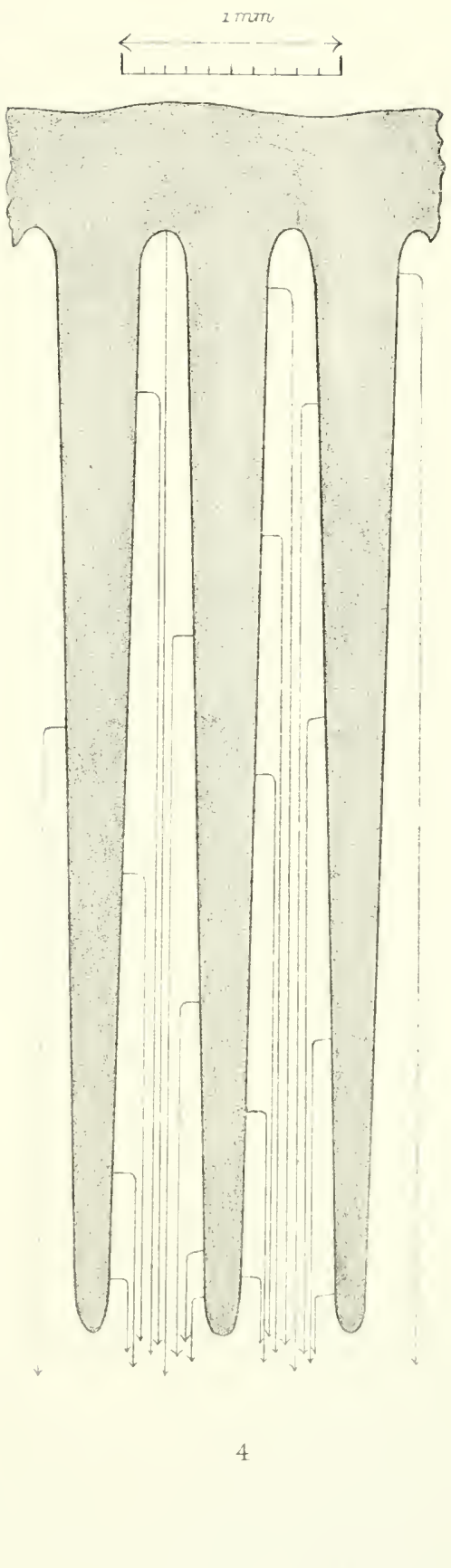

*izth sc et im 




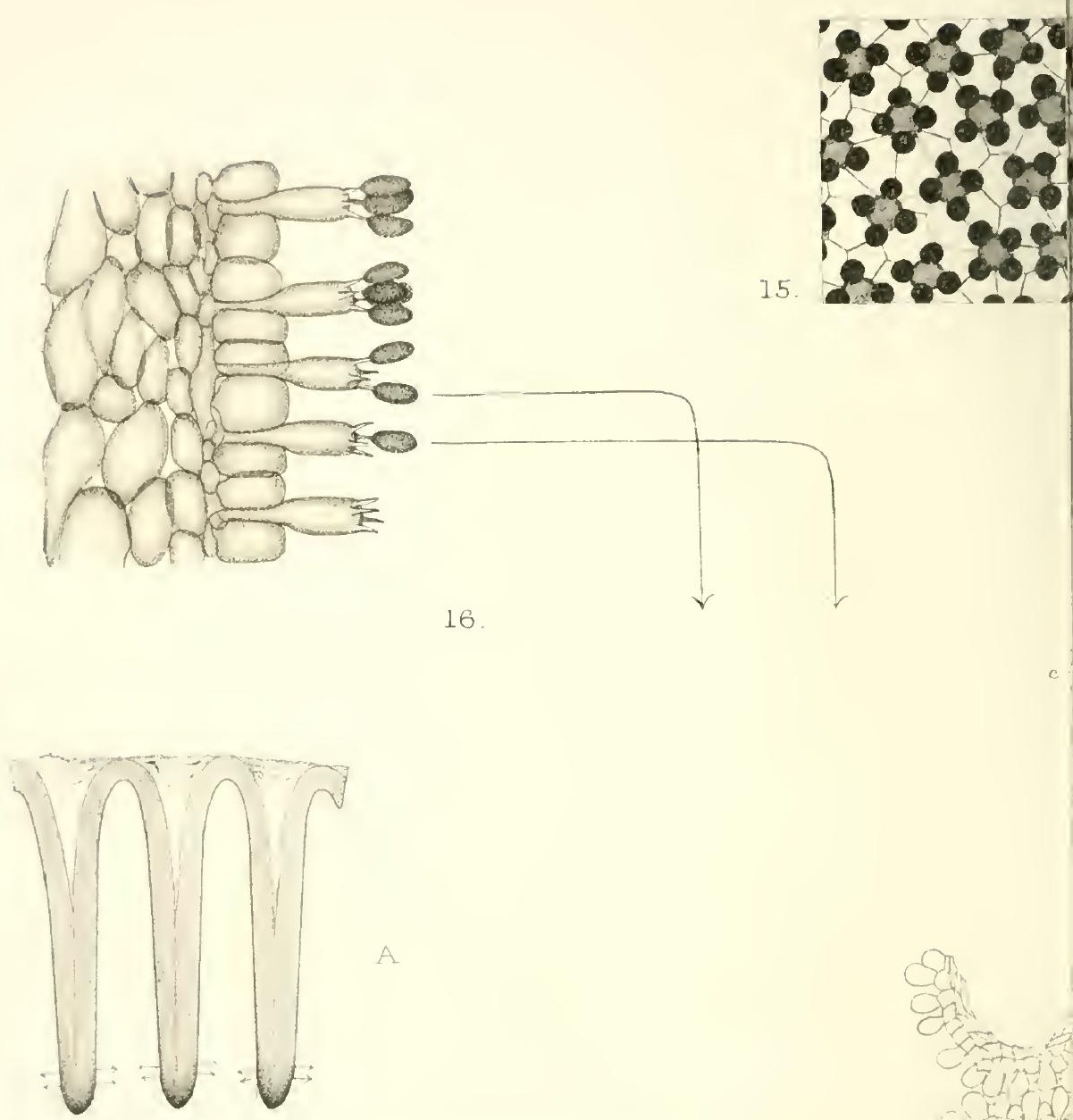

16.
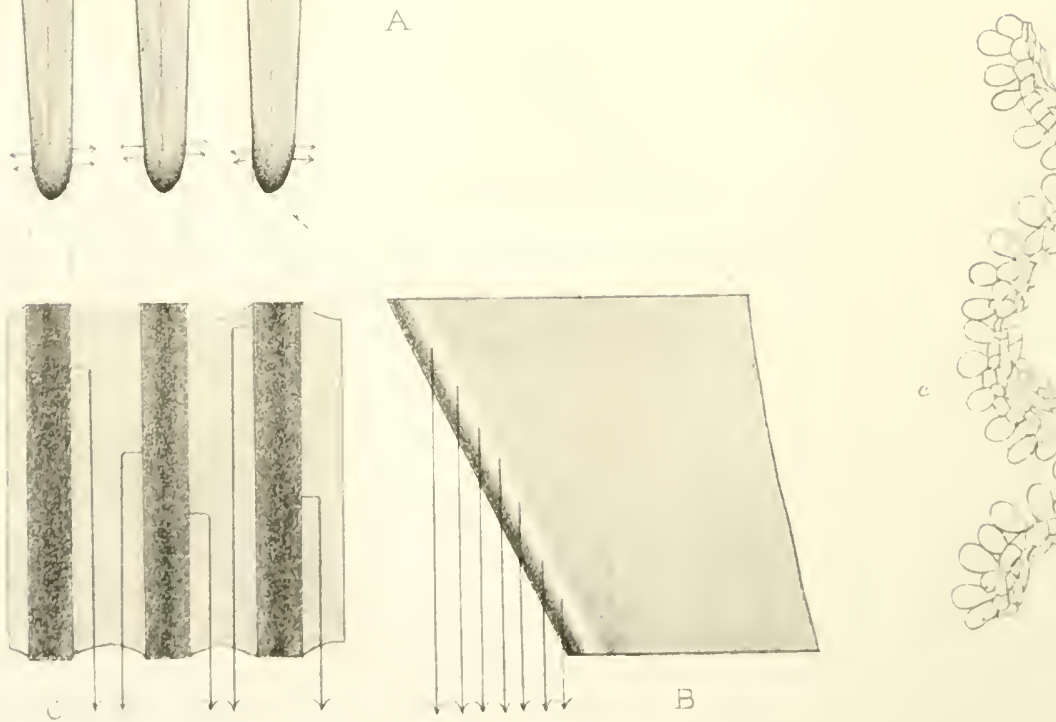

17. 


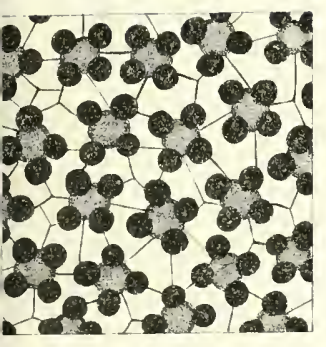

h

gououo: $\rightarrow 0000 \div \because$ Thoro: zo o o o i: $300000 \%:$ G20000 : $700000 \%$ a $0000 \div \because \div$
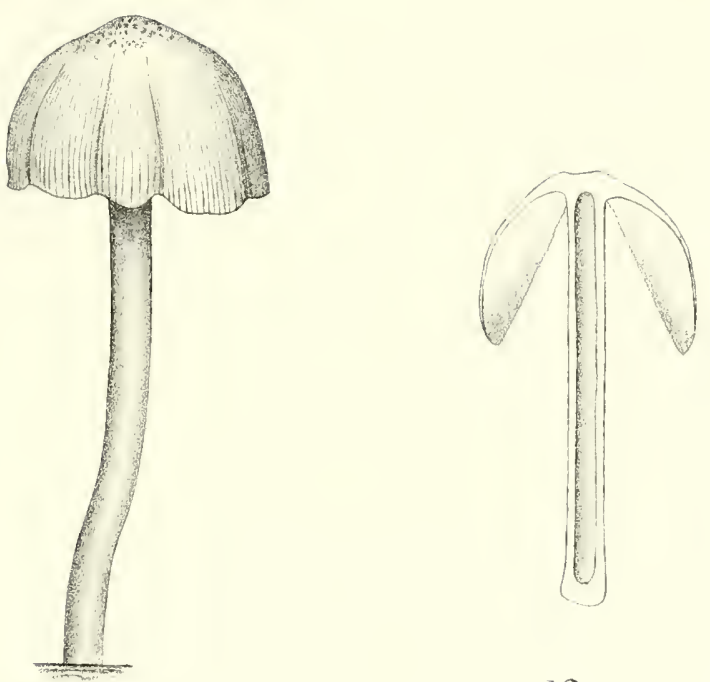

19

18
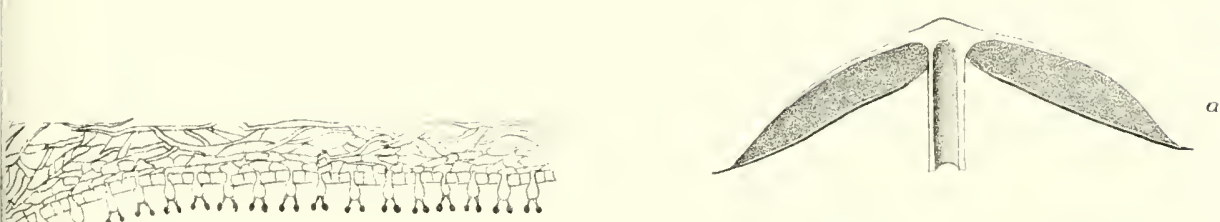

;:

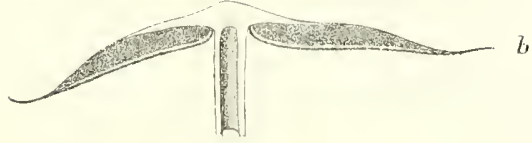

है

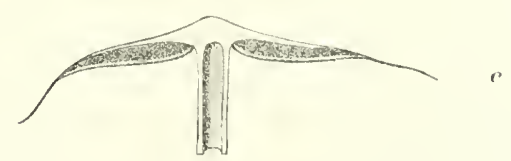

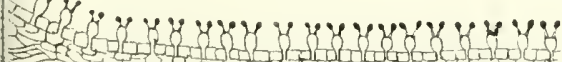

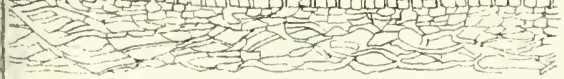

14

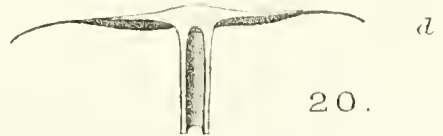




\section{-}






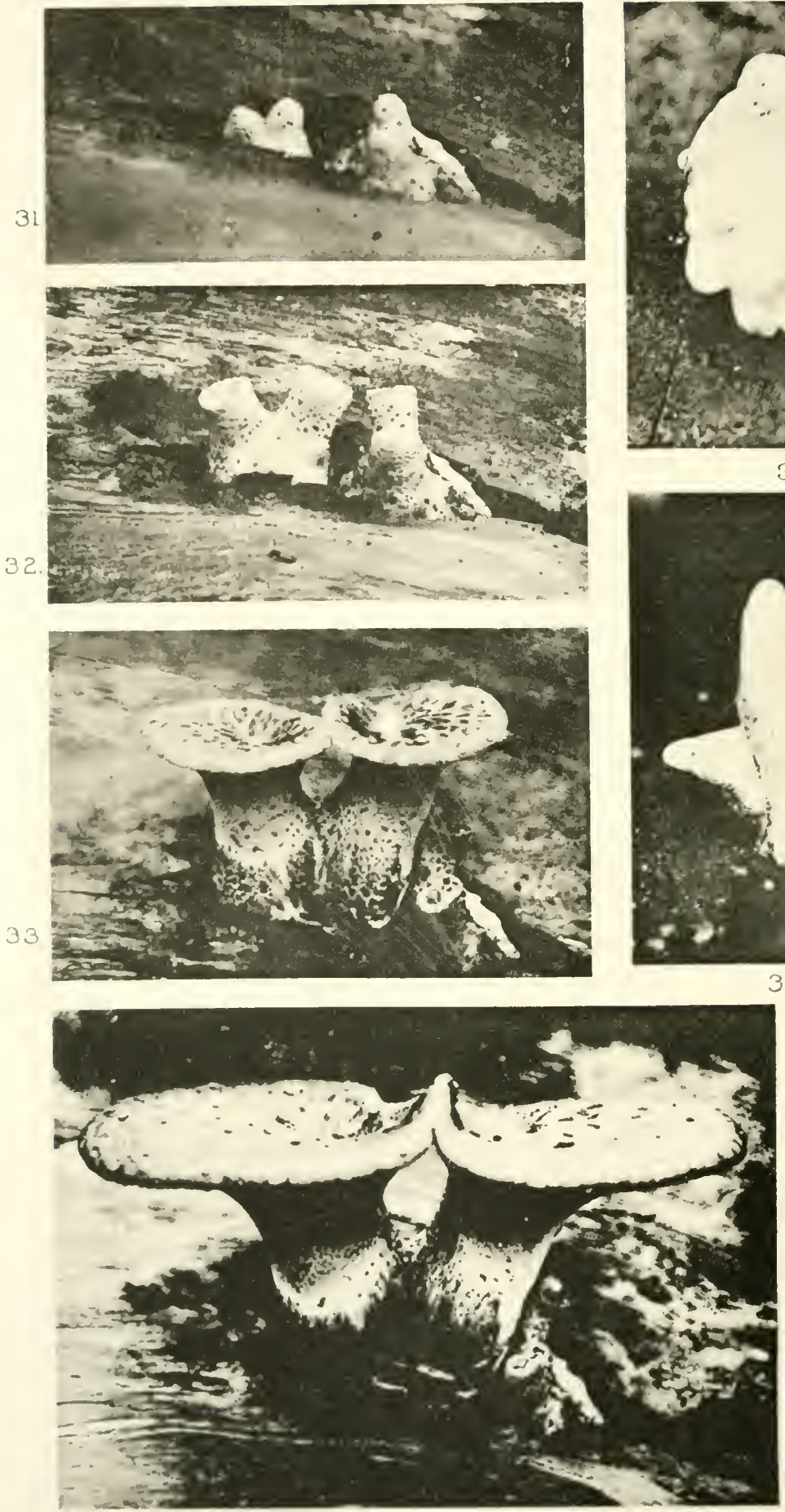

34

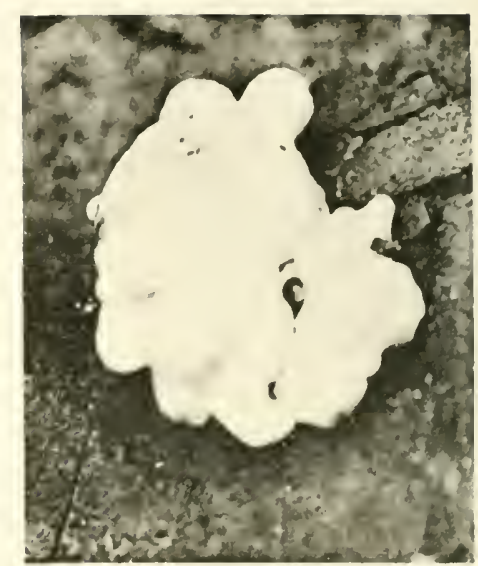

36

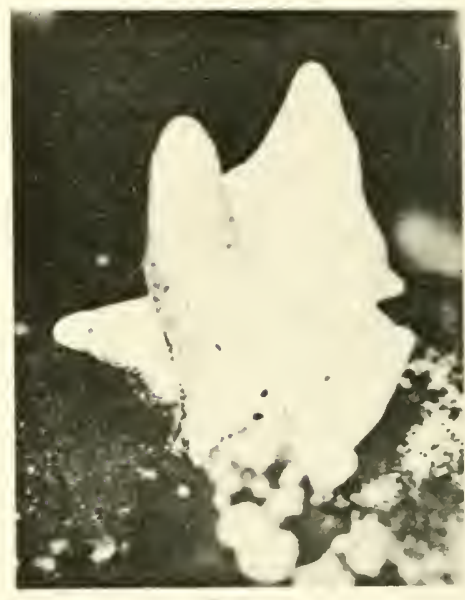

3'7

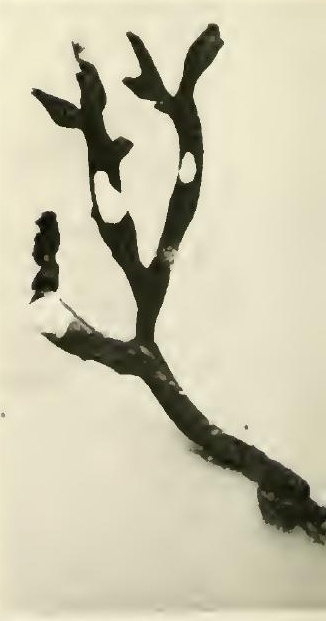

38 
PI V.
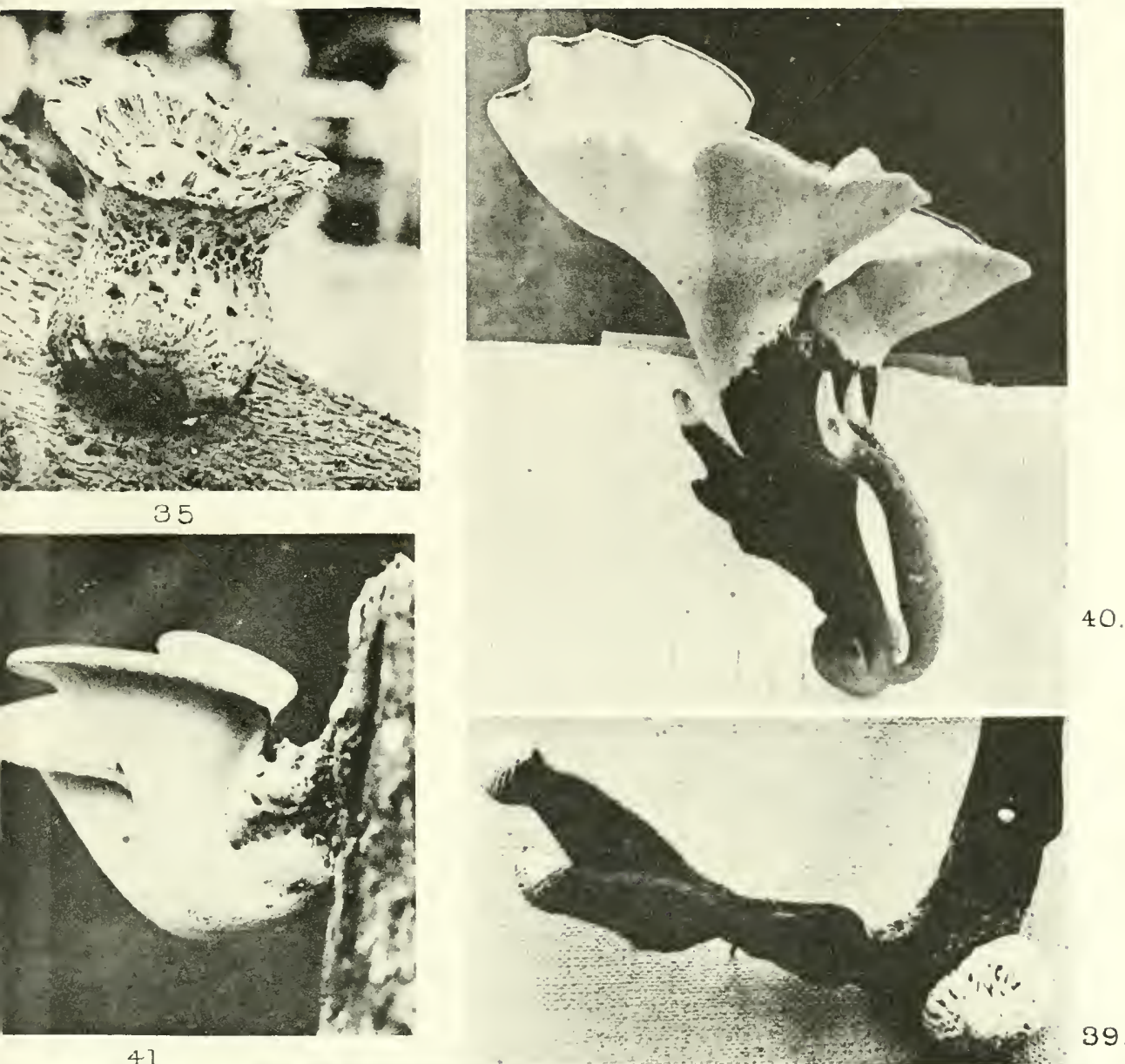

41.

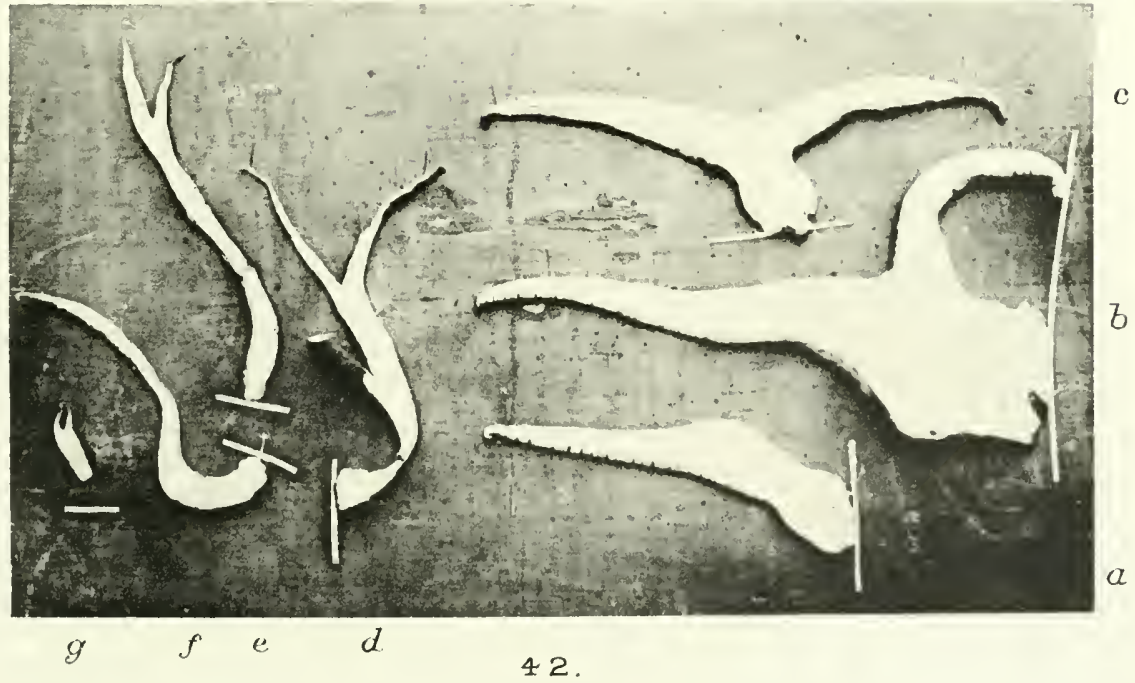





\section{GENERAL INDEX}

ACArixem, 46

Acetic acid, causes discharge of asci, 238

Adhesiveness of spores, 6, 79, 133, 258

Adjustments of fruit-bodies, 47-78

A garicines, declination of gill surfaces, 134

fall of spores between gills, 216

fixed position of gills, 39

geotropism, $7 \%$

eccentricity, 50

position of hymenium, 21 , 27

arrangement of gills, 34-36

specificincrease of hymenial surfaces, 30-33

stipes, 42

xerophytic species, 111

Ayuring nebularis, effect of chloroform, 129

Ayuricus radicatus, eystidia, 18

Air movements, speed, 217

, $\quad, \quad$ and spore dispersal, 222

A'leohol, causes discharge of asci, 237238

Alkalies, effect on asci, 239

Allen, Grant, 13

Amanita, dispersion of spores, 222

" gill-chamber, 45

$"$ and desiccation, 106

", violent discharge of spores, $1: 37$

Amanita muscaria, and slugs, 226, 229 230

spore-discharge, 134 , 212 velum partiale, 46

Amanita phalloides, and slugs, 230

Amunitu rubescens, hymenium, 30, 31

$\begin{array}{cc}, \quad, \quad & \text { and maggots, } 221, \\ 223 & \text { rate of fall of spores, } \\ 175 & \quad \text { and slugs, } 229 \\ , \quad & \text { size of spores, } 162\end{array}$

Amanitopsis, violent projection of spores, 137

Amanitopsis vaginata, distance of sporeprojection, 142 effect of humidity on spore - discharge, 122 fall of spores to ground, 216

improbability of observing spore. projection, 140 rate of fall of spores, 166-175, 255

size of spores, 162 , $163,248,253$

specific gravity of spores, 154-157 sporabola of, 185 and Stokes' Law, 166-173, 178

structure of gills, 165

variation in size of spores, 158

violent projection of spores, 141142

Ancesthetics, effect on spore-discharge, 129-132

Anellaria, habitat, $22 t$

, violent projection of spores, 1.37

Anellaria sepurute, adaptations, 226

, , fruit-body, 80

" $"$ geotropism, 76

, $\quad$, spore-deposits, 81

," $\quad$ spore-dispersion, 217

Anthracophyllum, systematic position, 13

Arachnida, 20

Armillaria, violent discharge of spores, 137

Amillaria mellea, colour of rhizomorpha subterramea, 14 
Armilleria mellue, esowding of frnitborlies, $7-78$

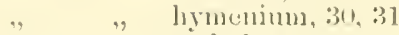

" aind slugs, 2-2!)

Ascobolus, discharee of spores, 150-151

Ascrüulus immersus, aclaptations, $256-$ $25 \%$

dispersal of spures, $2: 33,251-25.7$

Asconycetes and Hymenomycetes, 12 ,

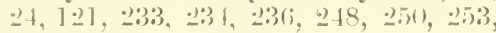
2.54

Ascospores, distance of ejection, 2:35, $2: 30$

drvine, 241

$\because$ fall, 236

., nmmber in an : $\quad$ sens, 243

.. seen in a bean of lingl, $23: 3 ;$

Asens, contraction of wall, 240

.. dischirge uncler water, 247

of Diseomvectes, $2.2-24$

.. fixation of spores, $244-247$

, heliotropism, 7.1-75, 2.7.2, 2.57

" jet of, $2: 35,240-244$

.. lid of, 2399

, putting, 2:3-2 -240

.. structure, 241,252

A.surgilles glaners, smulight and spores, 2t;

Atkinson, (:. F., on coprinus comatus, $196 ;$

, . . ontwo-sporerl basidia. 15

Antudicrestion, in (')prini, 20) signiticance of, 205

BAnLum, G., on the motion of a spliere, 190-19]

Basidia, and asei, 22-24, 249-250

., non-revelopment of, 15-17

, jusition of, 134

., relations with stipe, 42

"structure and derelopment, (j-1)

,. successive diseliarge of spores, ] $14-146$

two-s]ored, 15

besistioluolus runurum, discharge of s]rores, 151

Buyliss, Miss .J. S., on l'olystictus vmatcolor, 11:2, 11:3 on shugs and Hyonenomyectes, $22 ! 3$
Beam-of-light methor, $3,4,94-101$ " applied to ("ip)i-
nus comatus, 20.3
Beam-of-light method applied to Morchrllir !igyes, 2:31

a]plied thl'rnizll reprenula, 235

Becquerel, 1'., on dry seeds, 10.), 110

bermard, N., on nuclear fusions, 1:2

IBillen, R. H., on origin of cystidia, Is

13lackman, V. 11., on nuclei in Eredine:e, 11

13oletns, dispersion of spores, ․․․․

,. and desiceation, $106 ;$

, raclial form, 11:

" stipe, 11

,. violent projection of spores, 136

Boletws hartius, size of spores, 162

" $\quad$ rate of fall of spores, 175

,, violent projection of spores, 136 ;

bolotus chrysontron, violent projection of spores, 136

boletus fellews, rate of fall of spores, 175176

,, "violent projection of spores, 1:36

Bentustures, violent projection of spores, 136

linletus scaluer, violent projection of spores, $136 ;$

Bolotus subtomentosus, violent projection of sjores, 136

Bower, F. (), on spores of a fern, 88

Brefeld, O., on cystidia, 18

, oll ejaculation of spores, 4 , 1:) $4,1.48$

on sexulaty 10

Bulgaria, grachal empitying of asci, 237 , 240

limlguria polymonthe, dispersion of spores, 23:32:3.)

,$\quad$, size of slores, 248

Buller, A. H. R., un Lemtinus lepidens, 31,47

$$
\text { , } \quad \text { " (1) Polyporus sipua- }
$$$$
\text { mostss, } 5(;, 2) \cdot 2
$$

Caxtmarians, violent projection of spores, 137

Carbon dioxicle, elliet on fruit-bodies, $1: 3$

Cattle, dispersion of sjores by, $224-226$

(hloroform and spore-dischitige, I:9, $1: 31-1: 3: 2$

C'hristman, A. H., on nnclei in Rusts, 11

('lavarie:, position of hymenimm, 24, 2-

('vematus, on Pilubolus, 258-259 
Collembola, 20

Collybia, desiccation, 105

violent projection of spores, 137

Collybia dryophila, and convection currents, 97-98

desiceation, 107, 108, 111

fall of spores in a eompressor cell, 168

fall of spores to ground, 216

rate of fall of spores, $175,180-181$

settling of spores, 223

size of spores, 161 , 162

Collybir velutipes, erowding of fruitbodies, 77

Colon of spores, 12-15

origin of cystidia, 18

Compressor cell, use of, 167

Comidiobolus utriculosus, discharge of spores, 151

Convection eurrents, and spores, 98100,256

$$
\text { , , } \quad \text { and spore-depo- }
$$

Cooke, M. C., on cysticlia, 17

sits, 80-82

Copper sulphate, causes discharge of asei, 238

Coprinus, adaptations, 226 ;

, adjustments of gills, 67

, characters of genus, 209

,$\quad$ colour of spores, $14,15,97$

, a coprophilous crenus, 224

,, evolution, 214-215

,, creotrolism, 53

, heliotropism, 75, 76

,, hymenium, 7

, desiccation, 106

, and gravity, 50

,, not cross-fertilised, 11

, nuclei, 11

, oceasional sterility, 15-17

,, settling of spores, 223

, spores of a basidium succes-

sively projected, 145

spore-deposit, 99-100

stipe, 41

systematic position, 13

,, type of fruit-boly, 196-215

,$\quad$ violent spore-projection, 142 143,145

Coprinus atramentarius, colour of sporedeposit, 14

, , , eystidia, 18
Coprinus atramentarins, liberation of spores, 208209

Coprinus comatus, biology, 196-208

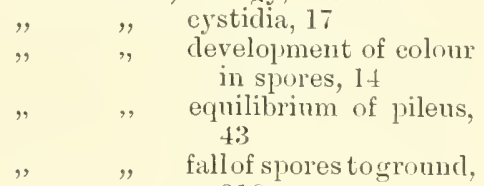
216

," $\quad$, $\quad$ hill edges, 7

" $\quad$ "

, , lengthening of stipe, 45

,$\quad$, number of spores, 82
,$\quad$ rate of emission of spores, 83,86

rate of fall of spores, 175

size of spores, 162,248

spore-clispersion, 206

spore-fall period, 104

stipe, 41

successive projection of spores from a basidium, 150

$\begin{array}{ll}, \quad & \text { survival of spores, } 87 \\ , \quad & \quad \text { swaying of fruit- }\end{array}$ bodies, 41

$, \quad, \quad$ tensious in stipe, 42

" ." turgidity of basidia, 10

", velum purtiale, 46

" " violent projection of spores, 142-143, 145

Coprinus fimetarius, spore-deposit, 208

,$\quad$, occasional sterility, 16

Coprinus yigusporus, large spores of, 161

Coumus micucens, erowding of fruitbodies, 77

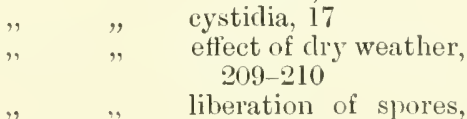
208-210

, , spore-deposit, 208

" $\quad$ ", successive projection of spores from a basidium, 146

, , violent spore-projection, 142-1 43

Coprinus nivens, adaptations, 226

, , adjustments of fruitbodies, 67-69

Coprinus plicutilis, adjustments of fruitbodies, 65-67 
Coprinus plicatilis and convection currents, 97-98

effect of dry wenther. $209-210$

". $\quad$ ". $\quad$ not cleliquescent, 209 215

rate of fall of spores, 175

rlythm in clevelopment, 75

size of spores, 161 , 162

specific sravity of spores, $154-157$

spore-fall period, 104

successive projection of spores from a basictium, 146

violent sprore-projection, 142-143, 145

Cojminus plicutilides, adjustments of fruit-bodies, 69 75

",$\quad$ occasional sterility, 16

Cuminus maliatus, rhythm in development, 75

Coprinus stercorurius, spore-projection, 4 , $134,136,148$

Coprinus strquilimes, vitality of mycelium, 112

Coprophilous Ascomycetes, 233, 251, 256-257

Coprophilous Hymenomycetes, 224-226

Corda, on eysticlia, 17, 18

Corticium, dispersion of spores, 220 fall of spores to ground, 217 ". a xerophytic senus, 10.

Corticinim lizer, vitality, 111

Craterelhs, position of hymenium, 24

'rutmellus comucopioides, stipe, 44,45

Crepidotus, vitality, 111

Cyphella, position of hymenium, 24

Cysticlia, of 'oprimes comatus, 198, 199, 200

$"$ significance, $\bar{\tau}, 17-20$

$"$ and spore-emission, 19

Ihaduliue confiatgosin, number of spores, $84-85$

desiecation and ritality; 111

Dovdulen yuercinu, desiccation and ritalit $y, 111$

Jardule unirolor, germination of spores, 106

recorery after desiccation, 110, 111
Drdulec mincolor, spore-discharge at $00^{\circ} \mathrm{C} ., 124-125$

$$
\begin{aligned}
& \text { ". spore-fall period, } 103 \\
& \text {." . violent projection of }
\end{aligned}
$$

Dingeard, on nuclei, io

De Bary, on cystidia, 18, 19

" on fixation of spores in asci, 245

" on putting, $237-238,240$

" on sound produced by sporedischarge, 258

Deliquescence, nature of, 200

$$
\text { , significance, } 205
$$

Desiccation of fruit-bodies, 38, 105-119

Dew and spore-fall, 102

Discomycetes and Hymenonycetes, 2224

Dispersion of spores, by herbivomus animals, 224226

$$
\begin{aligned}
& \text {, . . by slugs, 226- } \\
& 228 \\
& \text { by wind, 216- } \\
& 223
\end{aligned}
$$

Drought, may intermult spore discharge, 102

, and xerophytic frnit-bodies, $110-111$

Dry air, effect on small Coprini, 69, 209210

Dugrgar, B. M., on roprinus comutus, 208

Dust particles, 95

Eccestricity, of Lentinus lepideus, 49, 50

" of Polyporns squemosur, 60-6:2

use of, 49

Electric charges on spores, 192-195

Elving, on sunlight and slores, 2-26j

Eimure Grylli, discharge of spores, 151

Eimpusa Husce, discharge of spores, $150-151$

Entoloma, violent projection of sprores, 137

Entomophthorinee, spore-discharge. 151

Ether, effect on spore-discharge, 129131

Evolution, of Coprini, 215

$$
\begin{array}{ll}
" & \text { of fruit-bodies, } 27 \\
" & \text { of } 1 \text { yymenomycetes, } 22-4 \\
, & \text { of spore colour, 13-14 }
\end{array}
$$

Exoascus, emptying of asci, 237,240

Exobasidiinere, lymenimu, $:-7$

External conditions and spore-discharge, $90-91,120-132$ 
FALCK, R., his theory of spore-dispersion, $218-223$

on abnormal fruit-bodies, 21

on anesthetics and sporedischarge, $1 \geq 9$

on Coprinus sterquilinus, 112 on dispersion of spores in

Basidionycetes, 4

on movement of spores by convection currents, 22.2 on spore-cleposits, 98-100

on spore-dispersal in Gryromitre esculenta, 234

Ferguson, Miss M. C., on sunlight and spores, 25

Ferns, psendapogamous, 12 spores, 88

Fish, number of eggs, $87-88$

Flesh of the pilens, function of, $42-45$

Flies, and Hymenomycetes, $19-20$, 219

Fomes, fall of spores to ground, 217

" specialised fruit-bodies, 37-38

Fomes igniarius, effects of frost and desiccation, 38

,,$\quad$ specific increase of hymenial surface, 33

, violent projection of spores, 136

width of hymenial tubes, 38

Fomes vegtus, specific increase of hymenial surface, $32-33$

, , riolent projection of spores, 136

width of hymenial tubes, 38

Fraser, Miss H. C. I., on nuclear fusions, 12

Freeman, E. M., on insects and Coprini, 206

Frost, effect of, 38, 112, 113, 126

Fruit-bodies, abnormal, $48,54,63,64$

$" \quad$ acridity of some, $2: 30$

" annual and perennial, 37

", coprophilous, $224-226$,

" $250-257$

desiccation, 105-1 19

" developnent in Polyporus

squamosus, 57-65

" development in Lentinus lepicleus, 48,49

effect of tilting, 38

evolution, 211

individual variability, 163

poisonous, eaten by slugs, 230
Fruit-bodies, rhythm in development, 74,75

" rigidity, 39

" rudmentary, $77-7 \mathrm{~S}$

,. some protected from slugs, 229-230

, tests for vitality, 105-I06

Fulton, F. W., on the eggs of fish, 87

Fulton, T. W., on clispersion of spores by insects, 206, 25\%

Galera, dispersion of spores, 220

$" \quad$ habitat, 225

, stipe, 41,42

, violent discharge of spores, 137

Galere tenera, adaptations, 226

$$
\text { , rate of fall of spores, } 175
$$

," size of spores, 162

Gases and spore-discharge, 127

Geotropic swinging, 65-66, 72-74

Geotropism, of Anellaria separate, 76

,$\quad$ of Coprinus niveus, 68-699

, of Coprinus plieutitis, 65-66

," of Copminus plicatiloides, 70 74

" of Lentinus lepideus, 48-49

, of Polyporus squemosus, 59 65

" of Psalliota campestris, $50-$ 5.)

Germination of spores, $11,25,26,106$, $227-228$

Gill-chamber, significance of, $45-46$

Gills, autodigestion in Coprinus comatus. 200

," not geotropic in Coprinus, 67-68

, reactions to gravity, 49-53

", separation of $7,34-35,199$

, and slugs, 226

" splitting in Coprinus, 67

Gleoporus conchoides, growth after desiccation, 106 desiccation, 111

Glycerine, effect on asci, 237, 238

Gomphidius, colour of spores, 14 systematic position, 13

Gomphidius viscosus, eystidia, 18

Grape sugar, effect on asci, 238

Gravity, and spore-discharge, 122

, morphogenic stimulus of, $4 y-$ 50,62

responses in Agaricinese, 77

Grove, W. B., on Pilololus, 259

" on sterility of strophuriu simiglobata, 26

Gyromitru eseulentu, disper'sal of spores, $233-235$

size of spores, 248 
H.M.MER, or I'lurotus ostrutus, 89

Heat, eflect on spore-discharge, 123127

produced by funiri, Falck's theory, 219-22:3

Ifeluleme frestibile, and sings. 22.27

Heliotropism, absent in the Mushroom, j.j

ahsent in Polupuress steucmosus, 5!)

of asci, 252,$250 ;-257$

of Coprini, 75

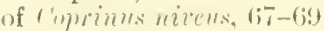
of Cinminus plicutiloides, (is) 70

of Lentinus lequilens, th

Helvellat, gradual emptyine of asci, 237

Hrieclle rrisym. cause of putting. 237

sound of spore-discharge, 258

Helvellicese, fruit-bodies, 249

spore-discharue, 234

Hennings, P., on Hymenomyeetes, 1213

on Hypochnacese, 14

Herbirorons animals, dispersion of spores by, 2-24-226, 233, 251-25.

Hirnola auricula-juda, spore - discharce, 5

Hotliman, H., on Polylurus destructur, 89

", on eysticlia, 17

Horses, dispersion of spores by, 224$2-26,233,-251-257$

Horse Mushroom, fall of spores, 94 spore-cloud, 218

Humuri" rutiluns, muclei, 12

Humidity, eflect on ('nprini, 2(1:)

, effect on falling spores, 179$18: 3$

eflect on spore-liheration, 91, $12 \cdot 2-1: 22$

Hybrids, possibility of, 1르

Hydne:e, position of hymenimm. 27 ., xerophytie species, 111

Hyrlüum repundum, abnormal frnit budies, 61

Hrolrogen, effect oll fruit-bodies, 1:129

Hygropluorus, systematic position, 1:3 violent projection of spores, 1:37

Hentroulmores virgimens and sluss, 22:)

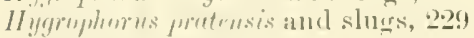

Hyoroseopic endition of air and spene. discharese, 1220-1:3

Hymenial tubes, geotropism, 5!)

$$
\text { " " sridiail development, }
$$

Hymenial tnles, width, $37,3 \mathrm{~s}$

Hymenium, nature of, 6-?

\begin{tabular}{|c|c|}
\hline , & displitcement of, -21 \\
\hline , & extcut, $: 2-: 3: 3$ \\
\hline ", & of Heliellace:e, 24 !) \\
\hline & likenerl to a hattery, Is! \\
\hline , & $\begin{array}{l}\text { position, 21, 24, } 134 \\
\text { melei, } 9-10\end{array}$ \\
\hline
\end{tabular}

Hymenochiete, cystidia, 18

Hymenomycetes, compared with iscomycotes, $23: 3,234,236,245.250$, $25: 3,2.54$

Hypholoma, violent projection of spores, 1:37

Hupholome fuscionlure and sluses. 2.24-20.30

Hypholome perphtrim, muclei, 11

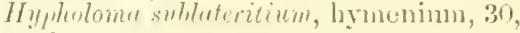
31

Hypochnace: colomr of sp mes, 14

LARXOGAMY, 10-12

LACCARI, violent projection of spores, $1: 3$

laceruriu luerutu and slugs, $2.29-230$

Lactarius, and shuss, -26-20?

" cystidia, is

, volent projection of spores, $1: 37$

Lurturius deliciusts, and slues, 2-2r;

$$
\text { , , }, \quad \text { origin of eysticliat, } 18
$$

Lacturius glyciosmens and slues, $2-2 y_{-}-230$

Luctarius ivfus and sluss, $229-230$

lamrent on sumlight and spores, 26

Lentinns, systematic josition, 13

l. mtinus lepiders, adjustments of fruitbodies, $47-50,53$, $5.5,54$ cflect of ligrht on spore-clisehatre, $1: 0$

Ienzites, continnity of spore-fall. $1: 0$

, demonstration of spore-fall, 101

, effect of inverting fruitbodies, 21

". spore-fall period, 10:-111;

, spore stream, 96

". a xerophytic «enus, 10s

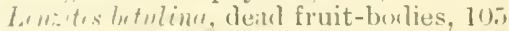
eflect of loss of water, 12:3

eflect of etlrer in spore-clischarere, $1: 31$ desicention, 10!9-110, 111 and frost, 126-127

spore-rliseluarere and temperature, 12t$1: 6$ 
Len:ites hetulinu, spore-fall period, 103, 104

Len:ites sapiaria, desiccation, 111

Lepiote procere. fruit-body mechanics, 43,44

Lepiota ruchodes, fruit-body mechanies, 43,44

Lencospora, descent of, 12

Light, and rhythmic development, it

, eftect on Lentinus lipidens, 48

" eflect on Polyporus sifuamosus, 59, $62,63,65$

effect on spores, 24-26

, effect on spore-discharge, 120122

, non-effect on MIshroom, 55

Lowe, C. W., on l'exirce auruntia, 235

", $\quad$ and Folyporus squemosus, 90

Lycoperdun, spore-dispersion, 257-258

Lycoperdon boristr, number of spores, 85,86

Lycopodium powder and Stokes' Law, $177-178$

MagGots, harm done by, 2:21

heat produced by, 219

Magnus, W., on the Mushroom, 5t

Marasmius, desiccation, 105-106

, systematic position, 13

,$\quad$ riolent projection of spores, 137

Murusmius oreules, desiceation, 106-108, 111

distance of sporeprojection, 142 effect of yases on spore - discharge, $127-129$

rate of fall of spores, 175

size of spores, 162 , $2+8$

successive discharge of spores from a basidium, 150

violent projection of spores, 142

Marusmius peronatus, ettect of desiccation, 107,111

Maroin of safety, 34, 35, 38, il

Massee, G., on Coprinus plicutilis, 209

, , on cystidia, 18-19

", ", on mechanical sheaths, $4: 3$

", , on the mechanism of sporedischarcre, 149

.,$\quad$, on the position of the hymenimm, 24
Massee, G., on putting, -238

" , on size of spores of Ascomycetes, 244

" , on spores of riprinus gimuspoitus, 161

, , on the systematic position of Coprinus, 13, 215

Massee and Salmon on copiophilous fungi. 22.24, ․․․․

Melanosporie, descent. 12 colour of spores, 15

Mercuric ehloricle, causes discharce of asci, 238

Merulius, contains xerophytic species, 109

Merulius corium, desiccation, 109, 111

, , spore-fall period, $10 \%$

Mernlius luerimuns, abnomal fruitbodies, 21

Micrometer, Poynting's Plate, 15s-160

Mites, 20

M'Keehan and 'teleny on stokes' formula, 177

Morchella, sradual emptying of asci, 237

Morchellu cressipies, fruit-body, 249

Morelelle griges, dispersal of spores, 233235

Morphogenic stimulus of sravity, 49 , 50,62

Mucor, heliotropism, 75

Muscarine, 230

Mushroom, arrangement of grils, $34-36$ basidia, 7-9

" colour of spores in beam of light, 97

contrasted with c'omminus conutus, $210-215$

(lisplaced crill, 21

, effect of tilting crills, 39-40

" electric charres on spores, 192-195

grill-chamber', 46

"

, aud luw temperatures, 1.27

.. not heliotropic, 76

mass of a spore, 253

" optical illusion in sporedischarge, 140

radial form, 113

" rate of enission of smol" \pm , 8.2, 86

ruclimentary fruit-bodies, 77

series of gills, 35

settling of spores, 2.23

spores carried by convection currents, 95

stipe, 11 
Mushroom, sugrested experiment with, 12

, type of fruit-looly, 210-215

.. violent projection of spores, $142-145$

(For further referenees virle Psalliotu

Mutations, 1 1 , 15 (ceimpentris)

Mrcelium, desiccation, 1 1 1-1 12

.. nuclei, 10-12

,. possibility of cross-fertilisation in, $11-12$

Iycena, dispersion of spores, 220

., creotropism, 53

. stipe, 41,42

.. violent projection of spores, 137

Hycene ullieline and slugs, 2.26

Myene cpijtreygue, stipe, 42

Mreetophilidie, 19-20

Sphrodiun Filia-nas, number of spores, ss

Nichols, Miss S. P., on nuclei, 11

Nolanea, violent projection of spores; 137

Noluneu puscua, imperfection of sills. 189

Nowakowski on Empusu Criplli, loj

Nuclei, in asci, 243

. of Hymenomycetes, 9-12

()hrospor E, descent of, 12

Olive, E. II., on nuclear fusions in Pusts, 11

(Im)halia tibula, gills not seotropic, 76

Omplutici umbellifere and sluss, 2.29

Optical illusion in spore-discharge, 13s140

()xy-n, eftect on fruit-bodies, 128-129

PAx.eults, habitat, 224

violent projection of spores, 137

Punaulus pholanurum, adaptations, 2.26 , fruit-lody, 76

gills, 9

Parapliyses, of topinus comuctus, 198 ,$\quad$ function, 7

" nuclei, I0

Parasol Fungi, mechanies, 43-44

Paxillus, dispersion of spores, 2222

I'uxillus ineolutus, and small animals, 20 rate of $f_{i 1} l l$ of spores, 175

, size of spures, 162

Peniophora, cystictia, 18

Periza, sradual emptying of asei, 237 , position of liymenimm, 2.2-24
Periza, sepuration of spores, 235

l'sice rectuhulum, canse of putting in, 237

,,$\quad$ somind of spore-discharge, 258

I'rime ununtiu, dispersal of spores, 233

, , size of spores, 245

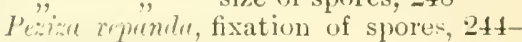
247

production of coniclia,

, $\quad$, pufting, 237-240

. $\quad$., separation of spores, $23 \mathrm{~J}$

, $\quad$, size of spores, 254

." ., spores dispersed by wind, 236

spore-discluarge observed with a beam of light, 235

, $\quad$ structure of fruit-body, 241

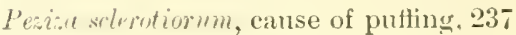

Pfetter, II., on eftect of oxygen, 129

Phalline and slngs, 230

Phallinex, spore-dispersion, 206-207. 257

Phallus imputicus, spore-dispersion, 2017

Plilebia, a xeroplyytic genus, 109

Phlebia pileata, desiccation, 111

Phlebia sonata, desiccation, 111

Plryeomyces, heliotropism, 75

Pileus, eccentricity, 49, 50, 60-62

" non-derelopment, 48, 49, 57-5s

Pilens flesh, heat developed in, 219

" . variations in thickness, $211-213$

Pilobolus, discharge of sporangia, 150. 25s-260

, heliotropism, 75

mode of spore-dispersal, 151

,. mass of sporanginm, 255

Piluholus Lilinii, somd produced hy, 259

Pilobolus longives, distance of sporanginm projection, 259

Plemotus ustrictus, eccentrieity, 50

, , grrowing un Beech, 2.2. 23

respouses to irravity, 77

system of gills, 36

visible spore-cloucls, 89

Plemotus nlmarius, spore-fill period, 104

and sluers, 22s

l'uteus cervinus, rate of fall of spores, 175

size of spores, 162 
Plowright, C. B., on spore-dispersal in Morchella gigus, $\mathbf{2 3 4}$

Poisonous fruit-bodies eaten by slugs, 230

Puisonous substances and puffing, 238

Polyporere, fall of spores in hymenial tubes, 216

fixed position of hymenial tubes, 39

hymenial surface, 31

position of hymenimm, 21, 27

principles in arrangement of hymenial tubes, $36-37$ xerophytic species, 109, 111

Polyporus, effect of inverting fruitbody, 21

,. fall of spores to ground, 217

, violent projection of spores, 136

Polyporus cameus, desiccation, 111

Polyports conchifer, desiccation, 111

Pulyporus destructor, visible spore-clouds, 89

Polyporus floceopus, mechanical sheath, 43

Polypmos lirsutus, violent projection of spores, 136

Polyporus lepiteus, mechanical sheath, 43 Polyporus pisochapani, mechanical sheath, 43

Polyporus rigens, growth after desiccation, 106

desiccation, 111

Polyporus rugosus, mechanical sheath, 43

Polyporus schueinitiit, visible sporeclouds, 89

Polyporus squamosus, abnormal fruitbodies, 58, 63, 64

adjustments of fruit - bodies, 56-65

basidia, 7

dispersion of spores, 220

distance of sporeprojection, 142 , $146-147$

earlier work on, 4-5

eccentricity, 50 , 60-62

effect of humidity on spore - discharge, 122

effect of light on s pore - dis. charge, 120
Polyporus stuanosus, electric charges on spores, 195

fall of spores to sround, 216

fruit-bodies on Elm, 8

heat dereloped by hymenial tubes, 218 $2 \cdot 21$

humidity and rate of fall of spores, 180 183

length of sporefall period, 102, 103, 104

macroseopic observations on fall of spores, 89-93

number of spores, 83-84

openings of hymenial tubes, 32

position of spores in falling, 177

rate of emission of spores, 86

rate of fall of spores, 175

responses gravity, 77

rudimentary fruit-bodies, 77

separation of spores from sterigmata, $\mathbf{1}+9$

size of spores, 162,248

specific increase in hymenial surface, $31-32$

sporabola of, 185189

spore - deposits, 84,92

and slugs, 227228

successive discharge of spores from a basidium, 146

survival of spores, \$7

unimportance of heat developed in pileus, 2:20 
P'olytorns squmosus, violent projectim of spores, $135-142,146$ 147

visits of Collembola, 20

wirlth of tubes, 38

P'ulyporus curius, abnormal fruit-bodies, rit

Polystictus, continuity of spore-fall,

$$
1: 20
$$

demonstration of sporefall, 101

, dispersion of spores, 220

. effect of inverting fruitborly, 21

, fall of spores to wroumd,217

" spore-fall period, 102

,. $\quad$ spore stream, 96

., violent projection of spores, $1: 36$

a xerophytic genus, 109

Polystictur hirsutur, desiecation, 111

. $\quad$ effect of tilting fruithody, 38

srowth after desiccation, 106

spore-discharge at 0 C., 124-125

spore-fall period, 103

l'mlystictus pergumenus, lesiceation, 111

I'ulystirtus rersicolor, desiceation of fruitbody, 109, 111

desiccation of $1 \mathrm{my}$ celium, 111, 112

dischitrge of spores in a beam of lisht, 97

eflect of drying on spore-discharge, 123

spore-discharge at (1) C., 121-125

spore-fall period, 103,104

violent projection of spores, 136;

P'uria veporurie, abnormal fruit-bodies, 21

Porphyrosirore, descent of, 12

Potassium nitrate, effect on asci, 238239

Poyntiug, J. H., on evaporation plessure, 173

plate microneter of, $15 x-160$

Projection of spores, distance of, 142 , 147
Projoction of spores, evidence of, 133$1+77$

I'sulliota, effect of inverting fruitbody, 2l

grill-clistmber, 45

"desiccution, 106 ;

" stipe, 42

,, violent projection of spores, 137

I'salliote arrensis, spore-cloud, 214

,$\quad$ fall of spores in :
beam of light, 94

I'sulliotre cumpestris, arljustments of fruitbodies, 50 - j) 6

distance of spore1rojection, 142

effect of hmmidity on spore - discharche, 122

etfect of light (1) spores, 25

fall of spores to ground, 216

humidity and rate of fall of spores, $180-183$

non - response to morplogenic stimulus of gravity; 50

number of spores, S2

rate of fall of spores, 175

size of spores, 162 , $1633,-248$

specific rravity of spoles. $154-157$

specific inclease in hymenial surface, $30,31,33$

sporabola of, 185, 189

survival of spores, $S i$

$\begin{array}{ll}, & \text { " system of wills, } 36 \\ , & \text {., two-spored bisirlial, }\end{array}$

, 15

",$\quad$ vitality of splawn, 112

(For further references vide Mushroomi)

Psathyrella, (geotropism, 53

Psilucybe, violent projection of spores, $1: 37$

I'silurybe forniserii, ettect of oxygen, $125-129$

Puff-balls, lieat produeed ly, 2:21$22: 2$

, , number of spores, $85-86$ 
Puff-balls, spore-dispersion, 258

Pufting of Discomycetes, 237-240

RAIN, absorption of, 113 and spore-fall, 102

Rate of fall of spores, 164-178

Respiration, 2.2.2

Rhodosporce, descent of, 12

Rhythmic development, of A scoboli, 257 , ,,$\quad$ of Coprini, 74-

Rubland, Wr, on nuclei, 9

$$
75
$$

Russula, eystidia, 18

$$
\begin{aligned}
& , \quad \text { stipe, } 41,42 \\
& \text {, } \quad \text { and slugs, } 226-229 \\
& \text { violent projection of spores, } \\
& \quad 137
\end{aligned}
$$

Russule citrina, and slugs, 226, 230 specific increase in hy-

Russulu emeticu, acridity, 230 menial surface, 30,31

$$
\begin{array}{lll}
\text {, } & \text {, } & \text { rate of fall of spores, } 175 \\
\text {, } & \text {, } & \text { size of spores, } 162,248 \\
\text {, } & \text {,. } & \text { and slugs, } 226,229 \\
\text {,, } & \text {,, } & \text { stipe, } 42
\end{array}
$$

SACCARDo, P.A., on coprophilous fungi, $2 \cdot 24$

Saccobolus, mode of spore-disposal, 233, 251

Schizophyllum, continuity of spore-fall, 120

dispersion of spores, 220 spore stream, 96 a mique genus, 113

a xerophytic genus, I09

schicopülyllum commune, biology, 113129

effect of sunlight on spores, 2526

germination of spores, 106

de siceation, 109-110, 111 recovery after f ree $z$ ing, $126-127$

spore - fall period, 103

spore - discharge at low temperatures, 124125

Schröter on asci of T'exis repanda, 245
Sexuality of Hymenomycetes, 10-12

Silver nitrate discharges asci, $2: 38$

Size of spores, 158-163, 254

Slugs, and cystidia, 18

," dispersal of spores by, 226-229

,. and xeropliytes, 112

Smith, Worthington, on Goprinus rectivetus, 75

$$
\text { , , , on cystidia, }
$$
$17,18,19$

Smut-ball, number of spores, 85

Sodium carbonate, effect on asci, 239

Solinm chloride, effect on asci, 238

Sodium hydrate, effect on asci, $23 \mathrm{~s}$

Sordarixe, heliotropisn:, 75

Sordariese, fixation of spores, 244

Sound produced by spore-discharge, $258-260$

Specific cravity of spores, 153-157

specific increase in hymenial surfaces, 28-33

Sporabola, nature of, 184-191

correction of, 5

Sporangiophores, heliotropism, 75

Spore-dissemination in Coprini, Massee's view, 215

Spores, action of convection currents

on, $98-100,256$
arlhesiveness, $6,79,133,258$

" adjustments of fruit-bodies for

" atiberation of, $47-78$

attachment in asci, $245-247$

colour, 1 - -15

comparative sizes, 254

diminution of velocity of fall, 180-18:3

dispersion by herbivorous animals, $224-226,233,251-$ $25 \%$

dispersion by slugs, $226-228$

lispersion by toads, 227

dispersion by wind, 216-223, 233

distance of projection, 142 , $252-253,255,259$

drying of, 182-183, 244

and eccentric pilei, 49

effect of curvature, 183

effect of humidity on rate of fall, 179-183

ejected endwise from asci, 242, $24: 3$

electric charges on, 192-19.;

" fall in a beam of liglit, 94101

fixation in asci, 244-247

germination of, $11,25,26,106$, $22 \div-228$ 
Spores, mass. 251, 253, 254

, melei, II

, 1 mmber, \&2-8!

" patl between gills, dc., 184189

, position in falliner, 176-177

, pusition on lassicium, 6

, rate of emission of, $4,2,3,8.7$ 86. 201 ;

rite of fall. $255-256$

". separation after leaving ascus, $235,243,-244$

settling of, 2.23

size, $155-163$

somnd produced by discharge of. $255-260$

speeitie wravity, 153-157

streams of, 96

sucessire projection from a basidimm, 144-146;

time of fall from hymenium to gromud, 216

walls of, 14

" wind-borme,

, wind-bor

Spore-deposits, 79-84,9s-100

$$
\begin{gathered}
, \quad \text { of coprinus cometus, } 203, \\
206,208
\end{gathered}
$$

spore-discharge, in Hirncolu ariculujud $x, 5$

, , mechanism of, 148 $15 \%$

Spore-fall, eontimuity of, 120

, , period, $92,102-104,206$

Springtails visit fruit-bodies, 20

stereum, dispersion of spores, 220

., eftect of inverting fruitbodies, 21

fall of spores to ground, 217

spore-fall period, 102

spore-stream, 96

, il xerophytic cremus, 109

stereum biculor, desiceation, 111

Stereum hirsutum, desiccation, 111

" $\quad$ spore-fall period, 103

Stereum purpurenm, desiccation, 111

, , reeovery of frozen fruit-bodies, 126 127

,,$\quad$ spore-fall period,

Sterigma, neck of, 6,9 111:3

sterility, occasional, of fruit-hodies, 15-

$$
\begin{aligned}
& 17,26 \\
& \text { of J'olypurus syurmosus, 57- } \\
& 5 y \\
& \text { of Lintinus trinilens, ts } \\
& \text { ", of stropherine semiglobutir, } 26
\end{aligned}
$$

Stipe, alnnormal, in Mnsluoom, 54

"barren, 48

" elongation in Coprinas somatus, 214

, functions, 39-45, 218

, tensions, $42,4: 3$

Stokes' Law, first direct test of, 3, 164 $174,17-178$

Stropharia, stipe, 41

,, violent projection of spores, 137

Siropharia semigloluta, spore-dispersion, 217

$$
\begin{array}{lll}
, & \text {, } & \text { sterility, } 26 \\
\text { visits of Collem- } & \text { bola, } 20
\end{array}
$$

Sulstratum, efteet on fruit-loodies, 55

Sulphuric aeid discharges asci, $23 \mathrm{~S}$

Surface tension, ettect on aseus jot, 242

Thelephorfas, hymenimm, 27 xeroplytic species, 111

Theobald on Fungus Gruts, 20

Thomson, J. J., on the electronic charge, 164,165

Tilletiu curies, number of spores, 85

Toads and Hymenomycetes, 227

'Transpiration, effeet of, 24, 210, 219, 222

Tremellinere, hymenimm, 27 spore-discharge, 5

Tricholome humile and slugs, 226

Tricholoma personatum, hymenimm, 30, 31 system of gills, 35

Trogia, a xeroplytic genus, 109

Trorjue crispa, desiccation, 111

'Truttles, spore-dispersion, 257

Tuberacede, spore-dispersion, 257

Types, different, in Acrarieinex, 210-21

Carrella Fungi, mechanics of, 43, 44

Uredine:t, nuclei, 11-12

Ustilugo carbo, sunlight and spores, 26

Velum puriale, use of, 46;

Toglino, P., on dispersal of spores by slugs and touds, $2026-227$

Von Schrenk, H., on Polyporus schewinitzii, s9

WAKEFIELD, F. W, on spore-discharge in Pilobolus, 259 
Weather, effect on small Coprini, 209 Wilson, C. T. R., cloud method of, 165

Wind and spore-dispersal, of Ascomycetes, $23 ; 3-236$

of Coprini, 206

of Hymenonycetes, $216-2203$
Worthington, A. M., on surface tension, 242

Xerophytic fruit-bodies, spore-fall period, 102-103

Xerophytic fungus flora, 109-113

Xerotus, systematic position of, 13

Zelexy, J., and MrKeehan, on Stokes' formula, 177

Zopf, on fixation of ascospores, 2-44

THE END

Printed by Ballantyxe, Haxson \& Co.

Edinburgh \& London 



QK601.B849 v.1

gen

on fungi 
